


\section{A plant's inheritance}

Soil legacy effects of crops and wild relatives in relation to plant functional traits

Janna Marlinde Barel 


\section{Thesis committee}

\section{Promotors}

Prof. Dr G.B. de Deyn

Personal chair at the Soil Biology \& Biological Soil Quality Group

Wageningen University \& Research

Prof. Dr T.W. Kuyper

Personal chair at the Soil Biology \& Biological Soil Quality Group

Wageningen University \& Research

\section{Co-promotor}

Prof. Dr W. de Boer

Special Professor Microbial Soil Ecology

Wageningen University \& Research

\section{Other members}

Prof. Dr L. Mommer, Wageningen University \& Research

Dr R. Milla, Universidad Rey Juan Carlos, Mostoles-Madrid, Spain

Dr G.F. Veen, Netherlands Institute of Ecology (NIOO-KNAW), Wageningen

Prof. Dr E. Lammerts van Bueren, Wageningen University \& Research

This research was conducted under the auspices of the C.T. de Wit Graduate School for Production Ecology and Resource Conservation (PE\&RC). 


\title{
A plant's inheritance
}

\section{Soil legacy effects of crops and wild relatives in relation to plant functional traits}

\author{
Janna Marlinde Barel
}

Thesis

submitted in fulfilment of the requirements for the degree of doctor at Wageningen University

by the authority of the Rector Magnificus,

Prof. Dr A.P.J. Mol,

in the presence of the

Thesis Committee appointed by the Academic Board

to be defended in public

on Thursday 30 August 2018

at 11 p.m. in the Aula. 
Janna Marlinde Barel

A plant's inheritance: soil legacy effects of crops and wild relatives in relation to plant functional traits,

184 pages

PhD thesis, Wageningen University, Wageningen, the Netherlands (2018)

With references, with summaries in English and Dutch

ISBN: 978-94-6343-471-3

DOI: $10.18174 / 455078$ 
To my parents,

whose legacy inspires my life 


\section{Abstract}

During their lives plants build-up a legacy for subsequent plants to inherit. The soil that supports plant growth is simultaneously conditioned by the growing plant and carriesover lasting imprints of the previous plant to influence growth of next plants. The microbial soil community and litter decomposition are two essential aspects of plant-soil legacies, as decomposition, mineralisation and microbial community composition and functioning have profound effects on subsequent plant growth by providing nutrients or by causing diseases. Characteristics of a plant may be predictive of its inheritance. Functional plant traits reflect a plant's growth strategy and response to selection forces in the environment. During crop domestication plant characteristics have been artificially selected for, with potential unwanted side-effects as some characteristics might have been altered unintentionally. Since productivity in agriculture relies on the interactions between plant and soil, it is a necessity to study the relationship between plant traits, decomposition, microbial community composition and the possible effects on future plant growth.

This thesis presents results from several experiments studying how plants influence the soil, through decomposition of plant residues, the soil microbial community assemblage, and its possible consequence for subsequent plant growth. In a crop rotation experiment plant-soil feedback effects have been studied at field scale, with legacy effects of winter cover crops as the primary focus. Influences of plant traits on litter decomposition and microbial community were studied both in a field context and under controlled greenhouse conditions. By comparing the legacy effects of crops with close-relatives from natural grasslands the effects of domestication on litter decomposition and rhizosphere microbial community composition were explored.

In the field experiment, it was observed that mixtures of cover crops can perform better than the sum of their parts when the plants in the mixture complemented each other during their growth. Productivity and quality of cover crops was found to promote growth of subsequent main crops, in part through stimulation of soil fungal biomass and feedback effects of decomposing litter. In the greenhouse, growing plants were observed to suppress decomposition of root and shoot litter to varying extent depending on which plant was present and on the quality of the decomposing litter. The results also indicate that domestication has affected plant functional traits in a variety of ways, rather than having predictable effects across a range of crops. Plant functional traits are a useful approach to study legacy effects, as they predict decomposability of plant residues and partially explain the microbial community composition in the rhizosphere. Significance of plant traits as predictors varied with environmental conditions, thus interpretation of the results should be related to its context. This thesis contributes to the understanding of plant-soil interactions, with emphasis on differences and similarities of agricultural and natural ecosystems. 


\section{Table of Contents}

CHAPTER 1 General Introduction

CHAPTER 2 Legacy effects of diversity in space and time driven

by winter cover crop biomass and nitrogen concentration

CHAPTER 3 Winter cover crop legacy effects on litter decomposition act through litter quality and changes in microbial community

CHAPTER 4 Plant presence reduces root and shoot litter 77 decomposition of crops and wild relatives: a trait's perspective

CHAPTER 5 Assessing the influence of soil origin and root traits 99 on the rhizosphere microbiome of crops and their wild relatives

Literature References

Summary

Samenvatting

Acknowledgement

About the Author

Affiliation of co-authors

Education Statement 


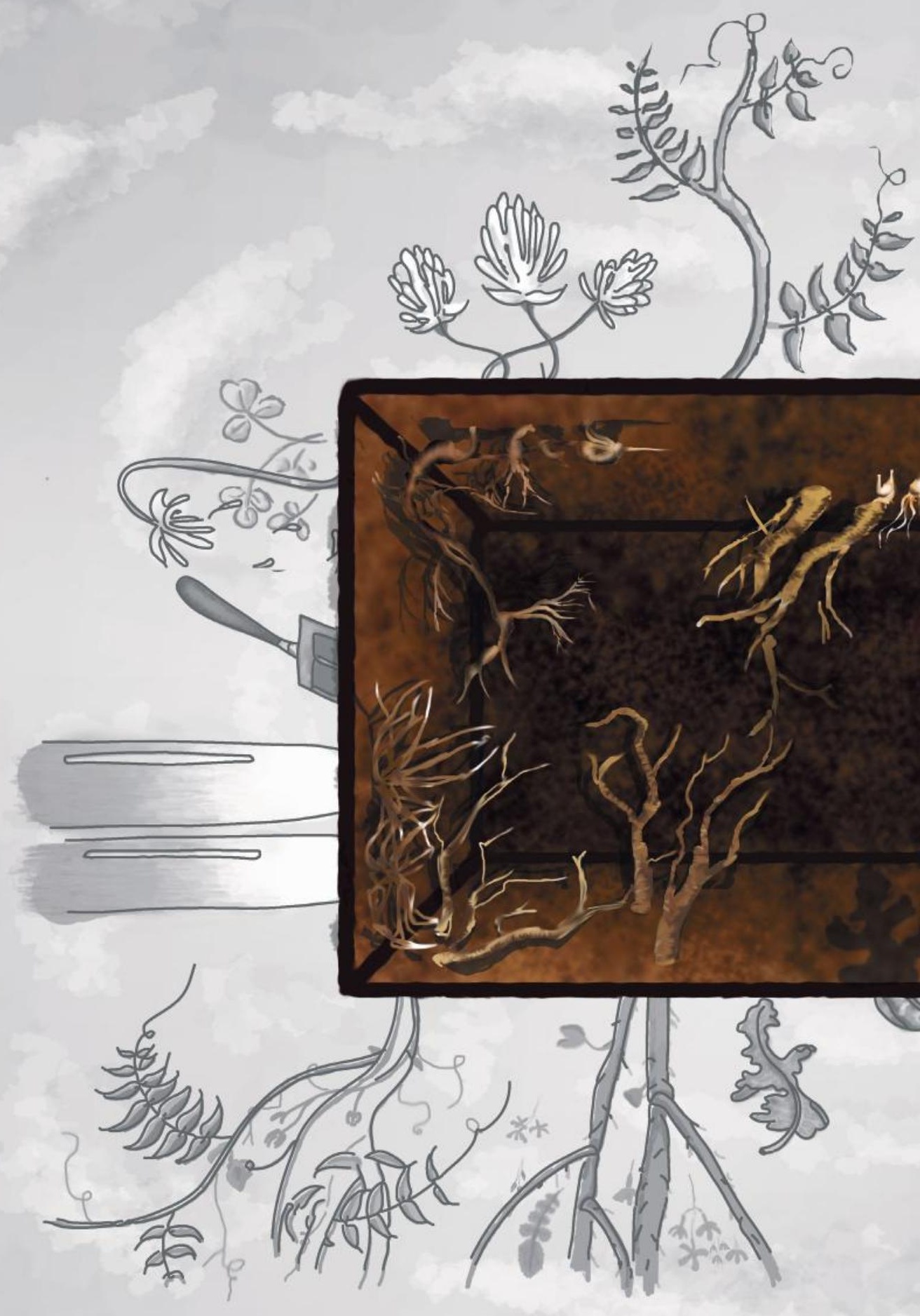




\section{Chapter 1}

General Introduction

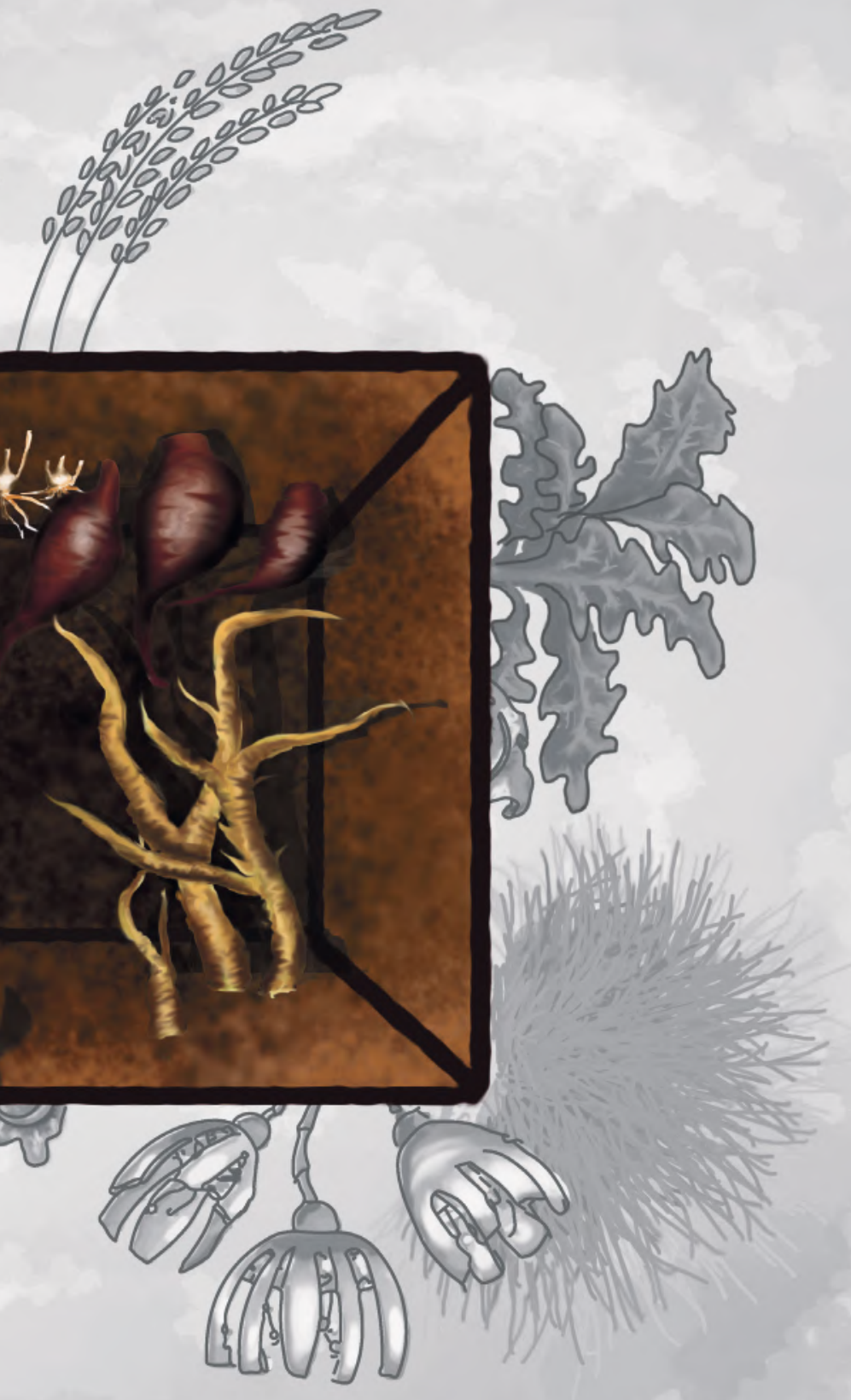




\subsection{The ecological wealth of a plant's inheritance}

Natural and agro-ecosystems share a fundamental basis to their functioning: plants are the primary producers in the system and plant productivity depends on the environmental conditions. Despite their sessile lifestyle, a plant's interactions with the environment are versatile and have profound and lasting effects on ecosystem functioning (Wardle et al. 2004a). By rooting in the soil for support and acquisition of resources, plants connect aboveand belowground ecosystems. The growth of a plant can result in a lasting imprint on the soil, also referred to as soil legacy (see Box 1 for definition of terms marked in italics), soil carry-over effects, or soil memory (Bartelt-Ryser et al. 2005; van der Putten et al. 2013). The change in soil conditions can be of a chemical, physical or biological nature (Ehrenfeld, Ravit \& Elgersma 2005). Plant-induced changes of soil conditions can influence soil functioning and create feedback loops that affect subsequent plant growth, also known as plant-soil feedback (PSF) (Ehrenfeld, Ravit \& Elgersma 2005; van der Putten et al. 2013; van der Putten et al. 2016). What is more, plant legacy effects can explain vegetation dynamics, such as plant invasion, succession, plant productivity and diversity (van der Putten et al. 2013; van der Putten et al. 2016).

A plant's biological soil legacy includes the legacy of direct interactions with plant mutualists, which can facilitate plant uptake of nutrients, and pathogens and pests (or antagonists) which can negatively affect subsequent plant growth (van der Putten et al. 2016), like an inheritance of beneficial and detrimental soil biota associated with the plant which previously occupied the soil. Additionally, plants indirectly influence subsequent growth by influencing nutrient availability through decomposition and mineralisation rates. Plant litters are the organic input for soil organic carbon $(\mathrm{C})$ and nitrogen $(\mathrm{N})$ cycling. Additionally, plants influence the decomposition process via the composition of the saprotrophic soil community that performs the decomposition (van der Putten et al. 2016). The net-effect of plant legacies is the combination of processes, which influence subsequent plant growth simultaneously

Despite the scientific recognition that plants can have plant species-specific legacy effects which influence ecosystem responses to environmental change and management practices, it is unclear what the drivers and underlying mechanisms of plant legacy effects are. The need to understand and predict how plants shape their biotic soil legacy motivated the research presented in this thesis. Here, I review current literature, outline the research questions and formulate the research hypotheses of this thesis.

\subsection{Plant legacy effects on the soil community}

Plant and soil biota are inextricably linked, as plants fuel the soil food web (Wardle et al. 2004a). Soil organisms that directly interact with plants, including mutualists, pathogens, 
and herbivores, can mediate PSFs (Kulmatiski et al. 2008; van der Putten et al. 2013; van der Putten et al. 2016). Using soil inocula, Bever (1994) demonstrated that PSF are mediated by soil biota and suggested that root pathogens are likely agents to cause negative feedbacks. Alternatively, mutualistic interactions between plants and, for example, arbuscular mycorrhizal fungi can mediate positive feedbacks (Cortois et al. 2016). If plants can condition the soil community in a plant species-specific manner, and if the composition and functioning of the soil community are fundamental for soil functioning and derived processes, it is pivotal to understand how the soil community is shaped by plants.

Many direct interactions between plants and soil biota take place in the rhizosphere, the layer of soil surrounding and under the influence of the root (Hartmann, Rothballer \& Schmid 2008). The term 'rhizosphere' was first named by Lorentz Hiltner in 1904, who hypothesised that soil organisms are attracted by rhizodeposits, including unwanted uninvited guests, suggested that these effects can be plant species-specific (Hartmann, Rothballer \& Schmid 2008). Rhizodeposits, which consist of exudates, sloughed-off cells and mucilage, and provide C-rich substrates to the rhizosphere community, primarily consisting of bacteria, fungi and archaea (Buée et al. 2009; Raaijmakers et al. 2009). Moreover, through pathways such as attracting the enemy of the enemy, plant-soil interactions can lead to build-up of disease suppressiveness (Berendsen, Pieterse \& Bakker 2012). Root exudates vary between plant species (Jones 1998; van der Krift et al. 2001b; Jones, Hodge \& Kuzyakov 2004). However, the extend of plant-species specific influence on the rhizosphere community, as mediated by root exudates, remains unclear. This may, in part, be attributes to the difficulty in collecting root exudates in situ and the variability in composition and amount of exudation that occurs. Therefore, it would be desirable to find other plant characteristics that are more easily quantified which can be indicative for the changes plant species will create in soil, both during plant life but also during its afterlife through a plant's legacy.

\subsection{Plant legacy effects on litter decomposition}

Decomposition of plant litter is the onset for C- and N-cycling in soil and is thought to be controlled by abiotic environmental conditions, litter quality and the decomposer community (Swift, Heal \& Anderson 1978; Cornwell et al. 2008; Bradford et al. 2016). Depending on litter quality, $\mathrm{N}$ from litter can be immobilised or mineralised, thus plant legacy effects on litter decomposition can indirectly influence subsequent plant growth (Parton et al. 2007; De Deyn, Cornelissen \& Bardgett 2008; García-Palacios et al. 2013; Hobbie 2015).

Litter chemical characteristics determine litter quality and exert control over decomposition rates. Litters with labile $\mathrm{C}$ compounds and high $\mathrm{N}$ concentrations generally have high turnover rates, whereas recalcitrant $\mathrm{C}$ compounds like lignin, and low litter nutrient 
concentrations have been related to low litter decomposition rates (Cornwell et al. 2008; Freschet et al. 2013). To date, most decomposition studies have focussed on turn-over of aboveground plant material despite the fact that belowground plant input can be substantial (Freschet et al. 2013; Roumet et al. 2016; Jackson et al. 2017): roots account for $33 \%$ annual biomass input in natural grasslands (Freschet et al. 2013). In agricultural systems aboveground biomass is harvested, thus root biomass forms the predominant biomass input of $\mathrm{C}$ and nutrients by crops. Although comparisons of root to shoot decomposition suggest lower decomposition rates and similar controls for roots as for shoots (Vivanco \& Austin 2006; Birouste et al. 2012; Freschet et al. 2013), this is debated in other studies (Hobbie et al. 2010; Hobbie 2015).

Additional controls of litter decomposition are the abiotic and biotic soil properties. On large spatial scales, soil temperature and moisture control litter breakdown (Swift, Heal \& Anderson 1978; Prescott 2010), although recent studies suggest these controlling effects are mediated by microbial action (Bradford et al. 2016; Bradford et al. 2017). Soil N availability can limit breakdown of lignin (Berg \& Meentemeyer 2002), and promote decomposition of cellulose (Hu \& van Bruggen 1997). Studies on decomposer communities demonstrated that these can be functionally dissimilar (Strickland et al. 2009a; Strickland et al. 2009b). Decomposer communities adapt to the quality of the dominant litter (Freschet, Aerts \& Cornelissen 2012a; Austin et al. 2014), resulting in faster decomposition of home-litter than of away litter, also known as home-field advantage. Thus, plants may influence decomposition not only by the input of their litter and its quality but also through their legacy effects on biotic and abiotic soil properties. Further insight on the controls of plant legacy effects on decomposition will contribute to the understanding and subsequent management of $\mathrm{C}$ - and $\mathrm{N}$-cycling in the soil.

Besides the plant legacy effects, decomposition can also be influenced by the presence of growing plants. The influence of plant presence on decomposition has mainly been studied for turn-over of soil organic matter, a process known as rhizosphere priming (Kuzyakov 2002; Huo, Luo \& Cheng 2017), but the influence of growing plants on fresh-litter decomposition and mineralisation have also been observed (Cheng \& Coleman 1990; Bek 1994; van der Krift et al. 2001a; van der Krift, Kuikman \& Berendse 2002). Most priming effects reported in literature are positive (Huo, Luo \& Cheng 2017), as exudates of an active plant can facilitate the breakdown of more recalcitrant litters. The priming effect of a plant can vary between litter species and depends on the identity of the plant species (van der Krift et al. 2001a; van der Krift, Kuikman \& Berendse 2002). This raises the question: does the direction and magnitude of the priming effect depend on the quality of the litter and/or on the properties of the growing plant? 


\subsection{Plant functional trait ecology}

Plant ecology comprises the study of the interaction between plants and their environment. Plant species are studied in how they respond to environmental pressures and how plants, in turn, affect ecosystem processes. Species responses to and effects on the environment have been related to plant functional characteristics (Lavorel \& Garnier 2002; de Bello et al. 2010). Because of morphological and physiological trade-offs (resources can only be invested once), plants have developed strategies to cope with environmental pressures. For example, plant species from nutrient-rich habitats often display acquisitive strategies, with fast growth, high nutrient uptake rates and with tissues with high turnover rates. On the other hand, plant species growing under nutrient-poor conditions display more conservative strategies: slow-growth, resource investment in recalcitrant tissues of high density and a long lifespan (Wright et al. 2004). This interspecific variation of resource use strategies in plants along a gradient of acquisitive to conservative strategies is also referred to leaf-economic spectrum (LES) (Diaz et al. 2004; Wright et al. 2004), yet is primarily based on aboveground plant traits. However, it has been suggested that plants coordinate their trait values across above- and belowground plant organs (Freschet et al. 2010), i.e. generally plants with high $\mathrm{N}$ concentrations in leaves also have high $\mathrm{N}$ concentrations in root and stem tissue. As a result, decomposability of leaves, stems and roots were found to be coordinated in plants worldwide across the main natural ecosystem types (Freschet et al. 2013). Furthermore, in an extensive study across three biomes root functional traits were related to root respiration and decomposition rates, therewith supporting the existence of a root-economic spectrum (RES) which is comparable to those of leaves (Roumet et al. 2016).

A functional-trait approach allows the study of ecological interactions without a priori assigning species to functional groups according to their assumed effects (Lavorel \& Garnier 2002). In theory it would also allow for generalisation of interactions and processes beyond the specific effects of the species included in the experiment. Trait-based approaches are widely used to study effects of organisms on ecosystem processes in different ecosystems (de Bello et al. 2010), with standardised protocols developed for plant traits (PérezHarguindeguy et al. 2013) and recently also for terrestrial invertebrates (Moretti et al. 2017). Moreover, a trait-based approach has been recommended for the study of plant-soil interactions and plant legacy effects (Bardgett, Mommer \& De Vries 2014; Kardol et al. 2015; Bardgett 2017), as well as agro-ecosystem functioning to inform sustainable management practices (Martin \& Isaac 2015; Wood et al. 2015; Lammerts van Bueren \& Struik 2017).

\subsection{Learning from natural and agro-ecosystems}

Most of the aforementioned studies consider plants, plant traits and their legacy effects in natural systems. However, it is conceivable that also in agro-ecosystems these ecological 
principles can be applied despite the fact that in those systems human intervention creates specific conditions for plant growth (Philippot et al. 2013; Milla et al. 2015; Pérez-Jaramillo, Mendes \& Raaijmakers 2016; Mariotte et al. 2018). Not only are soil nutrient levels managed but also the plant traits themselves have undergone selection by humans for desirable traits such as fast growth and high yields (García-Palacios et al. 2013; Tribouillois et al. 2015; Milla \& Matesanz 2017; Roucou et al. 2018). This, on the one hand provides an extension to the trait and environmental spectra and on the other hand enables to test mechanisms underlying plant legacy effects in a relative simple yet highly relevant setting, as agroecosystems tend to be simplified in comparison to natural systems (García-Palacios et al. 2013; Tribouillois et al. 2015; Mariotte et al. 2018). The relevance is two-fold as first, beneficial plant legacy effects may enable the development of more sustainable agriculture and second, many mechanistic studies on PSF or plant legacy effects have been performed in highly controlled settings which raises questions about their relevance for the 'real world' (Faucon, Houben \& Lambers 2017; Mariotte et al. 2018). For example, in PSF research in natural ecosystems this problem is recognised by several authors, who call for testing of PSF mechanisms under realistic field conditions (Kulmatiski et al. 2008; van der Putten et al. 2016). Because plant legacy effects are variable, and feedback effects are a combination of processes acting in concert, the relative importance of these underlying processes need to be tested at field scale. The simplicity of sequential crop cultivation provides an ideal model system for testing plant legacy effects under realistic field-conditions.

\subsubsection{Legacy effects under field conditions}

Sequential cultivation of crops in crop rotations is an old practice, stemming from the mediaeval times (van der Putten et al. 2013). The classic three-field cropping system, i.e. legume-grain-fallow rotation, was inspired by the notion that legumes improve soil fertility, and recurrent cropping of the same plant species builds up disease and depletes soil nutrients. Conventional agriculture is rediscovering the benefits of rotation schemes (Dias, Dukes \& Antunes 2014; Finney, White \& Kaye 2016; Finney \& Kaye 2017). Moreover, the application of cover crops in addition to cultivation of main crops is promoted in agriculture policies as a means to improve soil quality (Dijksma 2014; FAO 2017). Nevertheless, to date the design of crop rotations is primarily based on experience, and solid scientific evidence for the underlying mechanisms of the workings of rotations is scarce (Dias, Dukes \& Antunes 2014). Testing plant legacy effects in crop rotations allows to quantify the relative importance of plant mediated changes in soil biology, nutrient availability for subsequent plant growth and explores the extent of legacy effects if diversity of plants is increased over time and in space.

In natural ecosystems most plants are neighboured by several other species. Plants growing in mixtures can complement each other in the uptake of resources which enables increased 
plant community productivity and build-up of soil C- and N stocks, as well as reduced pathogen pressure (De Deyn et al. 2009; Schnitzer et al. 2011; Cong et al. 2014; Iverson et al. 2014). Conversely, in agro-ecosystems crops are often grown in monocultures, however these systems offer an intermediate stage towards the complexity of natural plant- and soil biodiversity as plant diversity in time is or can be easily integrated in the system (Mariotte et al. 2018). The cultivation of a sequence of crops allows to test plant legacy effects of diversity over time, raising the question: do the legacy effects of a first plant affect the growth of a third plant, or are they overcome by the growth of a second plant? Moreover, the agricultural practice of cover crops also allows for testing legacy effects of plant species mixtures (diversity in space) in comparison to monocultures as these types of crops do not require farmers to harvest species separately.

\subsubsection{Side effects of artificial crop selection}

In natural ecosystems plants have adapted to the environment, whereas in agro-ecosystems the farmer intends to modify or adapt the environment to facilitate plant growth and crops are selected to make use of generous growing conditions. However, the level of intensive adaptation of the agro-ecosystem environment has resulted in side-effects, such as reduced belowground resource allocation and reduced herbivore and pathogen defences (Milla et al. 2015; Pérez-Jaramillo, Mendes \& Raaijmakers 2016; Milla \& Matesanz 2017). Therefore, a comparison of plant-soil interactions in agriculture and natural systems is advocated (Philippot et al. 2013; Mariotte et al. 2018), because it offers opportunities to strengthen sustainable agriculture based on insights from natural mechanisms of resource use efficiency, disease suppression and pest control.

In agro-ecosystems, plant-soil interactions are under anthropogenic selection that differs from selection pressures in natural ecosystems. For example, frequent soil disturbances (tillage, sowing, harvesting) and altered resources (fertilisation, irrigation) are not conducive for slow-growing plants or plants that heavily depend on mutualistic symbionts for their nutrient acquisition. Rather these conditions would select for plants with a so called ruderal strategy which grow and reproduce fast (Hodgson et al. 1999; Tribouillois et al. 2015). Moreover, in agro-ecosystems plants and environment are engineered towards high productivity: selection of crops, reduction of competition through weeding, herbicide and pesticide application. In line with PES theory, such selection would result in plants with more resource-acquisitive traits. Indeed, several studies focussing on functional traits of crops support this expectation (García-Palacios et al. 2013; Milla \& Matesanz 2017; Roucou et al. 2018) although other studies find more variable effects of domestication (Milla et al. 2014). Most research has focussed on aboveground productivity and plant traits. It is unclear whether artificial selection for crop productivity has also led to belowground acquisitive traits. Not only is agriculture an ideal model system to test plant legacy effects 
under realistic conditions, there is also a need for fundamental understanding of plant-soil interactions in the context of environmental selection. By comparing crops with wild relatives, the relationships between plant functional traits and litter decomposition and soil community can be studied along a gradient in trait values.

\subsection{This thesis}

The research objective of this thesis is three-fold: i) to study how plants influence the soil, indirectly through decomposition of plant residues, and directly through soil microbial community assembly, and its possible consequence for subsequent plant growth. Specifically, I test ii) whether functional plant traits provide a means of predicting plant legacy effects, and iii) how soil legacies of crops differ from those of wild relatives.

\subsubsection{Practical approach}

The plant's influence on the soil environment is the central study objective of this thesis. Choices on the experimental design were made based on this objective and in second place to approach agricultural practice. The results of this research thus address fundamental processes in plant-soil ecology with high relevance for agriculture.

Since the feedback effects of plant legacies in soil are composed of a myriad of processes acting in concert, studying plant legacies was done across scales, across levels of control and by including a number of plant species. Field experiments allow to test net effects under realistic conditions but for practical reasons allow for a limited number of species that can be tested simultaneously for their legacy effects. Therefore, corresponding greenhouse experiments were set up in order to zoom in on the processes underlying the observed net effects in the field experiment and to allow for the inclusion of a wider range of plant species.

The plant species used in this study were selected to represent different plant families and functional groups (grasses, legumes, forbs) with different functional traits, in order to facilitate testing whether plant legacies can be explained by these traits. Across the plant families both crops and related (preferably congeneric) wild species were selected. The selected crop species had to be suitable for field cultivation under the temperate maritime climatic conditions in The Netherlands. Furthermore, root-crops (e.g. carrot or potato) were excluded, as their cultivation and harvest practice would imply heavy soil disturbance as a confounding factor in the experiments. Crops were selected to be native to western Europe in order to avoid differential co-evolution between plant and soil microbes among the plant pairs. The resulting pairs consisted of crops occurring in the Dutch national "Recommended list of varieties" of arable crops (issued by CSAR: www.rassenlijst.info). 
The wild species were selected as being closely related to the selected crop species and naturally occurring in nutrient-rich grasslands in temperate climate (Table 1.1). Four of the plant pairs are congeneric, including $\mathrm{N}_{2}$-fixing legumes Trifolium and Vicia, arbuscular mycorrhizal forbs Cichorium and non-mycorrhizal forbs Raphanus (Harley \& Harley 1987). Pairs of grasses did consist of closely related species: Festuca and Lolium (Soreng, Davis \& Voionmaa 2007), and Avena and Arrhenatherum (Winterfeld, Döring \& Röser 2009).

T a b l e 1.1 Overview of crops and "wild relatives", i.e. closely related natural-grassland plant species, used in the experiment assigned to one of six (near-) congeneric plant pairs.

\begin{tabular}{|c|c|c|c|c|}
\hline & Pair & Family & Plant species & Common name \\
\hline \multirow{6}{*}{$\begin{array}{l}\text { के } \\
\text { ठี } \\
\text { Un }\end{array}$} & 1 & Poaceae & Avena sativa L. var. Dominik ${ }^{1}$ & Oat \\
\hline & 2 & Poaceae & Lolium perenne L. var. Mathilde ${ }^{1}$ & Perennial ryegrass \\
\hline & 3 & Fabaceae & Trifolium repens L. var. Alice ${ }^{1}$ & White clover \\
\hline & 4 & Fabaceae & Vicia sativa L. var. Ebena ${ }^{1}$ & Common vetch \\
\hline & 5 & Brassicaceae & Raphanus sativus (L.) Domin var. Terranova ${ }^{2}$ & Fodder radish \\
\hline & 6 & Asteraceae & Cichorium endivia L. var. Nummer vijf2 ${ }^{3}$ & Endive \\
\hline \multirow{6}{*}{$\begin{array}{l}\stackrel{\infty}{0} \\
\stackrel{0}{\frac{\pi}{0}} \\
\frac{0}{0} \\
\frac{0}{3}\end{array}$} & 1 & Poaceae & Arrhenatherum elatius (L.) J. \& C. Presl ${ }^{4}$ & False oat-grass \\
\hline & 2 & Poaceae & Festuca rubra L. ${ }^{4}$ & Red fescue \\
\hline & 3 & Fabaceae & Trifolium pratense L. 5 & (Wild) red clover \\
\hline & 4 & Fabaceae & Vicia cracca L. ${ }^{4}$ & Tufted vetch \\
\hline & 5 & Brassicaceae & Raphanus raphanistrum L. ${ }^{5}$ & Wild radish \\
\hline & 6 & Asteraceae & Cichorium intybus L. ${ }^{5}$ & Common chicory \\
\hline
\end{tabular}

\subsubsection{Chapter outline}

In chapters 2-5, I provide a sequence of studies in which I investigated plant-soil legacies in increasing detail (Fig. 1.1). First, PSF effects are studied in their applied context in a realistic field setting: a crop rotation. Next, I studied the decomposition pathway in the same field experiment as a hypothesised mechanism for the observed feedback effects. Subsequently, I present the greenhouse experiment in which I compare decomposition of crop litters with litters from closely-related wild plants. Finally, I zoom in on the direct feedback pathway by investigating the relationship between plant functional traits and the composition of the rhizosphere microbial communities across four different soils, for both crops and wild relatives. 


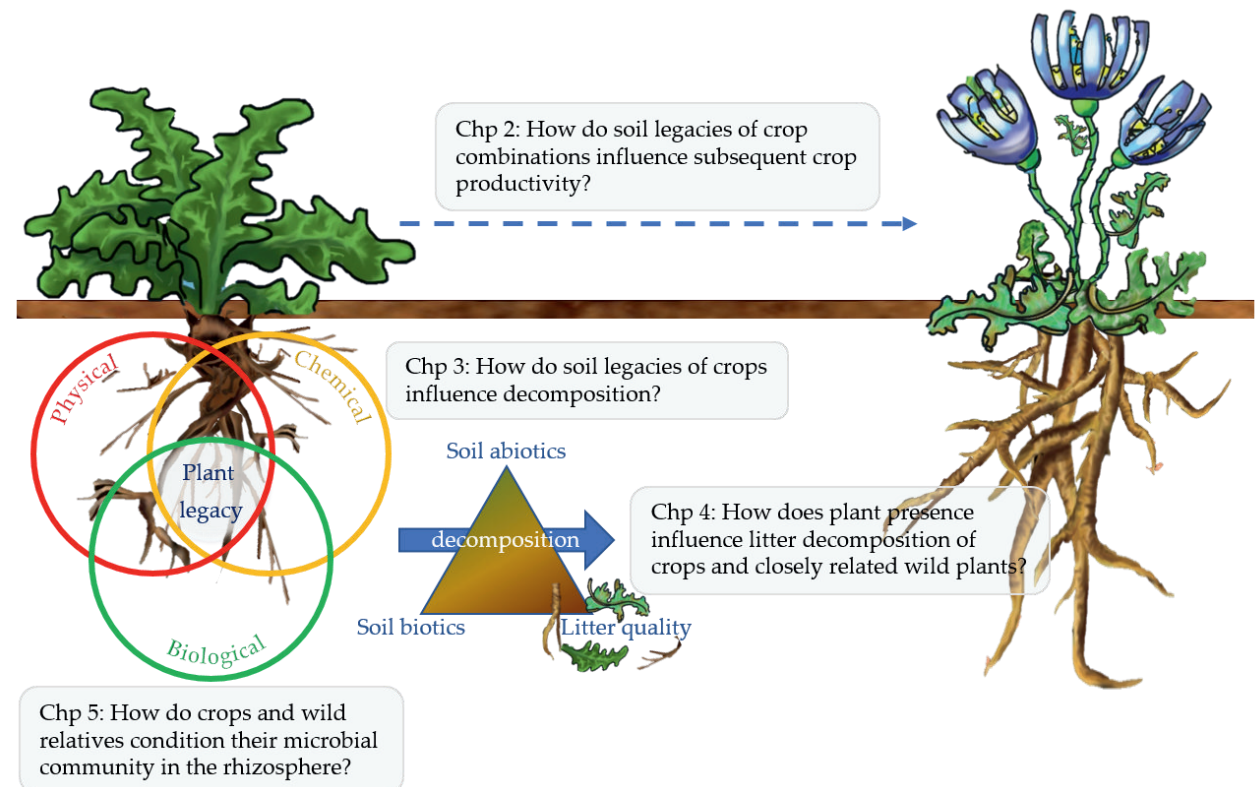

F ig u re 1.1 Schematic overview of research questions addressed in the indicated chapters (Chp) of this thesis.

In chapter 2, I studied how crop diversity in space (cover crop mixtures) and time (crop rotation) influences subsequent crop growth, in a field experiment. Crops were hypothesised to leave a species-specific soil legacy, which influences the growth of subsequent crops in the rotation. By comparing winter cover crops grown in monocultures with cover crop mixtures, the effects of spatial diversity were tested on both performance of the winter cover crops, their soil legacy and subsequent crop growth. Productivity and $\mathrm{N}$-concentration of the preceding crop were hypothesised drivers of soil legacy and feedback effects on subsequent crop growth.

Chapter 3 focusses on the indirect feedback pathway. Here, my aim was to study how cover crop legacy effects on litter quality, soil abiotic and biotic conditions are interlinked as drivers of decomposition, and to understand how a crop rotation design influences these drivers. The PES was assumed to explain variation in litter quality and intrinsic decomposability of winter cover crop litters: $\mathrm{N}$ concentration of the litters were expected to be positively related to litter decomposition rates, and $C$ and lignin concentrations negatively. In line with chapter 2 , the winter cover crop treatments were hypothesised to influence soil abiotic and biotic conditions species-specifically. Standard substrates were used to disentangle the influence of changes in the soil environment (soil legacy) and presence of decomposing crop residues (litter legacy) on the decomposition of added substrates. Therein, I tested whether the legacy effects of winter cover crops on 
decomposition were specific for the quality of the decomposing substrate: crop litters were expected to decompose faster in the home-plots than in control plots (e.g. home-field advantage), and recalcitrant litters were expected to benefit most from home-plot incubation.

The decomposition process is studied in more detail in chapter 4 . In the previous two chapters, I focussed on the legacy of crop cultivation and breakdown of aboveground plant parts. In chapter 4, I tested whether decomposability of root and shoot litters of the same plant species are comparable, as a consequence of trait coordination. In line with PES theory, decomposition of both litter types was hypothesised to be related to litter quality: litters with a high $\mathrm{N}$ concentration, but low $\mathrm{C}$ and lignin concentration were expected to decompose fastest. Secondly, litter decomposition rates were tested in absence and presence of growing plants, such that I could test whether plant presence has a positive priming effect on litter decomposition similar to priming effects found on soil organic matter. Moreover, differences between species of present plants were also tested for. Priming effects were related to litter traits, to test if the magnitude of priming effects can be explained by litter quality. The experiment included both crops and closely-related wild plant species, thereby testing whether litter traits and (their relation to) decomposition rates differ between the two ecosystem types.

Whereas, the previous two chapters focus on the indirect feedback pathways, I studied the direct plant-soil interactions in chapter 5 . The conditioning of rhizosphere microbial communities associated with roots of crops and wild relatives was investigated and tested whether functional root traits can explain the plant species differences in rhizosphere microbiomes. What is more, the six crop-wild plant pairs were grown on sandy soils of four different origins. Therewith, the extend of a plant's influence on the rhizosphere community was tested relative to the influence of the local soil microbial species pool.

Finally, I close this thesis by reflecting on my research objectives in chapter 6 . The General Discussion points out lessons learned by comparing plant-soil interaction of crops and wild relatives, discusses the conclusions of the previous chapters and their implications for plant-soil ecology as well as for agro-ecology. 
B ox 1.1 Definition of terms

Functional group: group of organisms that share functional characteristics as a consequence of similar responses to environmental pressures and have comparable effects on ecosystem processes (de Bello et al. 2010; Harrington et al. 2010).

Functional trait: characteristic of an organism with an evidential link to its functioning. Functional traits are the manifestation of physiological trade-offs in response to environmental conditions. An organism's responses to environmental pressures are measured as response traits, whereas effect traits are indicative of an organism's influence on ecosystem processes (Lavorel et al. 1997; Lavorel \& Garnier 2002; de Bello et al. 2010; Harrington et al. 2010).

Home-field advantage (HFA): accelerated decomposition of litter in its home environment, due to adaptation of local microbial community to that litter (Ayres et al. 2009; Austin et al. 2014).

Plant economic spectrum (PES): Interspecific variation of resource use strategies in plants along a gradient of acquisitive/fast-growing to conservative/slow-growing strategies, based on physiological trade-offs for plants in response to environmental disturbances, which are reflected in functional traits across plant organs (Reich 2014). Economic spectrum theory was originally based on leaf traits, known as leaf economic spectrum (LES) (Wright et al. 2004).

Plant legacy: Imprint or effect of plant growth on the plants environment, which lasts beyond the lifetime of the plant. Plant legacy can be biological, chemical or physical in nature (see Fig. 1.1) and can feedback to growth of subsequent plants (Ehrenfeld, Ravit \& Elgersma 2005; van der Putten et al. 2013; van der Putten et al. 2016). Changes in soil conditions are also referred to as soil legacy. Plant legacy effects mediated by its litter is referred to as litter legacy.

Plant-Soil Feedback (PSF): Influence of a plant on the growth of a subsequent plant that succeeds the first, as mediated by changes in soil conditions (Ehrenfeld, Ravit \& Elgersma 2005; van der Putten et al. 2013; van der Putten et al. 2016).

Priming effect: originally defined by Bingeman, Varner and Martin (1953) as the increase of soil organic matter decomposition after addition of organic material, decrease of decomposition is referred to as negative priming effect. In this thesis, I quantified priming effect as the change in litter decomposition rate in presence of a plant, compared to plant absence, which can be positive (decomposition rate increase) or negative (decrease).

Rhizodeposition: process of combined root development and secretion activity, which result in release of rhizodeposits and include actively secreted exudates (including acids, sugars, polysaccharides and ectoenzymes), mucilage produced by root cap cells, sloughed-off cells and dead cells and debris (Hartmann et al. 2009; Bulgarelli et al. 2013).

Rhizosphere: plant root and surrounding soil (Hartmann et al. 2009). Soil in immediate vicinity of and adherent to roots is, here, referred to as rhizosphere soil

Trait coordination: co-variation of trait values in organs of the same plant. 


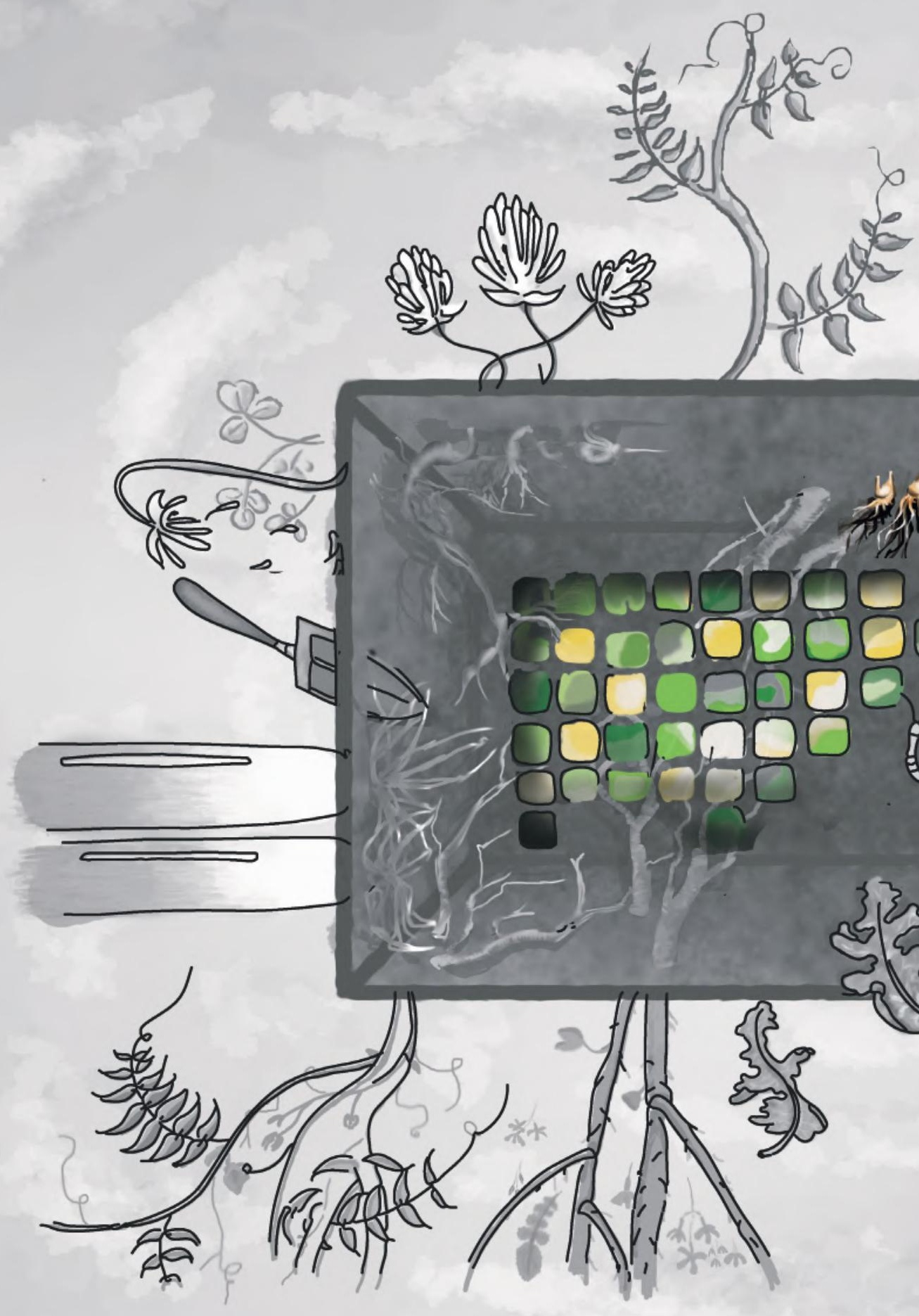




\subsection{Abstract}

Plant diversity can increase nitrogen cycling and decrease soil-borne pests, which are feedback mechanisms influencing subsequent plant growth. The relative strength of these mechanisms is unclear, as is the influence of preceding plant quantity and quality. Here, we studied how plant diversity in space and time influences subsequent crop growth.

During two years, we rotated two main crops (Avena sativa, Cichorium endivia) with four winter cover crop (WCC) species in monocultures and mixtures. We hypothesised that, relative to monocultures, WCC mixtures promote WCC biomass (quantity) and nitrogen concentration (quality), soil mineral nitrogen, soil organic matter, and reduce plant-feeding nematode abundance. Additionally, we predicted that preceding crops modified WCC legacies. By structural equation modelling (SEM), we tested the relative importance of WCC shoot biomass and nitrogen concentration on succeeding crop productivity directly and indirectly via nitrogen cycling and root-feeding nematode abundance.

WCC shoot biomass, soil properties and succeeding Avena productivity were affected by first-season cropping, whereas subsequent Cichorium only responded to the WCC treatments. WCC mixtures' productivity and nitrogen concentration showed over- and under-yielding, depending on mixture composition. Soil nitrogen and nematode abundance did not display WCC mixture effects. Soil organic matter was lower than expected after Raphanus sativus + Vicia sativa mixture. Subsequent Avena productivity depended upon mixture composition, whereas final Cichorium productivity was unresponsive to WCC mixtures. SEM indicated that WCC legacy effects on subsequent Avena $\left(\mathrm{R}^{2}=0.52\right)$ and Cichorium $\left(\mathrm{R}^{2}=0.59\right)$ productivity were driven by WCC biomass and nitrogen concentration, although not by the quantified soil properties.

Through understanding plant-soil feedback, legacy effects of plant species and species mixtures can be employed for sustainable management of agro-ecosystems. Biomass and nitrogen concentration of plants returned to the soil stimulate subsequent plant productivity. Winter cover crop quantity and quality are both manipulable with mixtures. The specificity of spatial and temporal diversity effects warrants consideration of plant species choice in mixtures and rotations for optimal employment of beneficial legacy effects. 


\subsection{Introduction}

Studies on plant diversity in space (diversity experiments) and time (plant-soil feedback) are mostly executed in natural ecosystems. Agro-ecology could greatly benefit from this knowledge as an ecological basis for sustainable management (Dias, Dukes \& Antunes 2014; Wood et al. 2015). Although soil-mediated influences of preceding on succeeding plants is an established phenomenon (Tilman 2001; van der Putten et al. 2016), how and to what extent legacy effects of diversity influence subsequent-plant growth is unresolved. Biodiversity experiments showed that niche differentiation allows mixtures to be more productive than the average of their component monocultures (Loreau \& Hector 2001; Tilman 2001). Additionally, mixtures promote the build-up of soil C- and N-stocks (De Deyn et al. 2009; Cong et al. 2014), and reduce pest pressure (Schnitzer et al. 2011; Iverson et al. 2014), forming potential feed- backs to subsequent-plant growth.

Plant-soil feedback (PSF) is the phenomenon in which preceding-plant conditioning of the soil forms a legacy influencing subsequent-plant growth (Bever 1994; Ehrenfeld, Ravit \& Elgersma 2005). Legacies can be understood mechanistically through specific feedbackpathways between plants and soil properties such as nutrient cycling, plant mutualists and enemies (Wardle et al. 2004a; van der Putten et al. 2016). Soil legacies are not restricted to the next generation of plants but can persist for over a year (Bartelt-Ryser et al. 2005; Campiglia et al. 2014). Indirect PSF between plant species separated in time finds its application in agriculture (Bever, Westover \& Antonovics 1997), forming the cornerstone of crop rotation. Indeed, crop rotation is recommended because it disrupts the build-up of specialist herbivores and pathogens (Snapp et al. 2005; Dias, Dukes \& Antunes 2014). However, to what extent previous-plant growth affects the feedback between current and subsequent crops has not been quantified. Yet, such tests are needed to design optimal crop sequences.

Crop rotation increases diversity in time. Through increased quantity and quality of plant residues (Dias, Dukes \& Antunes 2014; Tiemann et al. 2015), farmers can employ positive PSFs without losing the summer season by growing winter cover crops (Snapp et al. 2005). Deep or dense-rooting and productive cover crops can improve nutrient retention (ThorupKristensen, Magid \& Jensen 2003), whereas leguminous cover crops can fix atmospheric nitrogen. Although growing plants stimulate plant-feeding nematodes, careful selection of cover crop species can reduce specific nematode species (Thoden, Korthals \& Termorshuizen 2011; Fourie et al. 2016), and reduce yield losses in subsequent crops (Singh, Hodda \& Ash 2013). Traditionally both nutrient cycling and pathogen suppression feedback pathways have been studied in isolation. Mechanistic underpinning of how these PSF pathways act in concert can improve crop rotation guidelines.

Including cover crop mixtures into rotations combines beneficial spatial and temporal diversity effects. Finney and Kaye (2017) confirmed the diversity- ecosystem functioning 
relationship in agriculture. Next-crop productivity is positively correlated with cover crop biomass and nitrogen concentration (Finney, White \& Kaye 2016). Plant-feeding nematode densities decreased with increasing plant diversity in natural grasslands (Cortois et al. 2017). Moreover, mixing cover crops could suppress nematode numbers as host plants are harder to find (Mitchell, Tilman \& Groth 2002; Iverson et al. 2014). How cover crop mixture legacies act on nitrogen cycling and pest management simultaneously, however, remains unaddressed.

Understanding legacies of plant diversity in space and time is essential for successful application of winter cover crop mixtures. We therefore studied soil-mediated legacies of winter cover crop (WCC) mixtures compared to monocultures on succeeding-crop productivity. We tested (1) if WCC mixtures increase WCC productivity and nitrogen concentration, soil organic matter content, soil mineral nitrogen and subsequent-plant productivity, and if plant-feeding nematode abundance differentially increases under WCC monoculture and mixtures in comparison to winter fallow. For the latter, we predicted neutral to negative mixture effects on plant-feeding nematode abundance. Additionally, we tested (2) for differential influence of two previous main crops (Avena sativa and Cichorium endivia) on these WCC legacies. Lastly, through structural equation modelling we quantified (3) the relative importance of WCC quantity and quality on next-crop productivity through mediation of soil properties. In this 2-year field study, we demonstrate that WCC biomass and shoot nitrogen concentration increase subsequent-crop productivity and that these properties can be promoted by mixing functionally complementary plant species, without trading-off with increased root-feeding nematode abundance. This makes winter cover crop mixtures, a promising avenue for sustainable agro-ecosystem management. 


\subsection{Materials and methods}

\subsubsection{Study site and experimental design}

Legacy effects of winter cover crop (WCC) mixtures and monocultures and the previous main-crop history on the productivity of Avena sativa L. and Cichorium endivia L. (henceforth generic names are used) were tested in a factorial rotation experiment consisting of three phases (Fig. 1). The experiment was carried out on sandy soil (91\% sand, pH 5.8, $1.31 \mathrm{~g}$ total $\mathrm{N} \mathrm{kg-1,} 284 \mathrm{mg}$ total $\mathrm{P} \mathrm{kg}-1$ of which $7.2 \mathrm{mg}$ plant available $\mathrm{P} \mathrm{kg}-1$, and 93.8 mg K kg-1; Nergena, Wageningen, The Netherlands, 5159'41.9"N 5³9'17.5"E).

In summer 2014, Avena and Cichorium were grown as preceding main crops $\left(\mathrm{S}^{\prime} 14\right)$ followed by autumn cultivation of WCCs (W'14): 4 monocultures (Lolium perenne L., Trifolium repens L., Raphanus sativus L., and Vicia sativa L.), 2 mixtures (Lolium+Trifolium (henceforth L+T); Raphanus+Vicia $(\mathrm{R}+\mathrm{V})$ ) and fallow as control. Lastly, Avena and Cichorium were cultivated as subsequent main crops ( $\left.S^{\prime} 15\right)$. The rotation treatments were replicated five times following a randomised block design of 120 plots of $3 \times 3 \mathrm{~m}$ (Fig. 1c). Each plot consisted of two experimental units (1.5x3 m). Monocultures and fallow were applied on full $3 \times 3 \mathrm{~m}$ plots (one of two experimental units was randomly selected for sampling). Mixtures were grown on one of the experimental units $(1.5 \times 3 \mathrm{~m})$ per plot. Plots were separated by grass strips (Phleum pratense L., $1.5 \mathrm{~m}$ width).

\subsubsection{Plant and soil treatments}

All plant material was obtained from commercial suppliers in The Netherlands and chemically untreated. Avena (var. Dominik), Phleum (var. Grindstad), Lolium (var. Mathilda) and Vicia (var. Ebena) seeds were purchased from Agrifirm (Apeldoorn, NL). Organically reared Cichorium seedlings were obtained from Jongerius (Houten, NL). Trifolium (var. Alice) was provided by Barenbrug (Nijmegen, NL), and Raphanus (var. Terranova) by Joorden's Zaadhandel (Kessel, NL).

To homogenise the field cultivation history prior to the experiment Phacelia tanacetifolia Benth. (var. Angelia) (June-Aug 2013) was grown, mown and residues left on the field (Fig. 1b). In March 2014, the field was ploughed (25 cm depth). All plots were fertilised in both spring 2014 and 2015, following general practice. End of March 2014 all plots received: 82 kg N ha-1, $249 \mathrm{~kg} \mathrm{~K} \mathrm{ha}^{-1}, 168 \mathrm{~kg} \mathrm{~S} \mathrm{ha}^{-1}, 84 \mathrm{~kg} \mathrm{Ca} \mathrm{ha}^{-1}$. Early May another $28 \mathrm{~kg} \mathrm{~N} \mathrm{ha}^{-1}$ and 4.2 kg Ca ha-1 was given. In March 2015, $41 \mathrm{~kg} \mathrm{~N} \mathrm{ha}^{-1}, 203 \mathrm{~kg} \mathrm{~K} \mathrm{ha}^{-1}, 137 \mathrm{~kg} \mathrm{~S} \mathrm{ha}^{-1}, 6.4 \mathrm{~kg} \mathrm{Ca} \mathrm{ha-}$ ${ }^{1}$ were applied, and additionally $14 \mathrm{~kg} \mathrm{~N} \mathrm{ha}^{-1}$ and $3 \mathrm{~kg} \mathrm{Ca} \mathrm{ha}{ }^{-1}$ in May. In 2015, the N fertilisation was halved compared to 2014 to facilitate observation of WCC effects on nitrogen-cycling without potential overruling effects of high levels of fertiliser application. No P was added to the soil as this was amply available. 
(a)

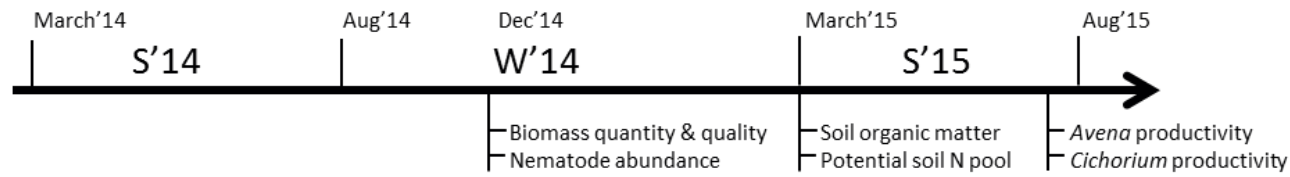

(b)

\begin{tabular}{|c|c|c|c|c|}
\hline$S^{\prime} 13$ & $S^{\prime} 14$ & \multicolumn{2}{|l|}{$W^{\prime} 14$} & $S^{\prime} 15$ \\
\hline \multirow{25}{*}{ 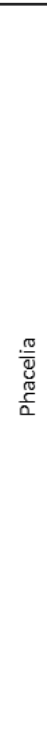 } & \multirow{12}{*}{ 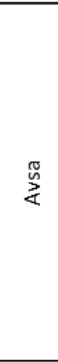 } & \multirow{2}{*}{\multicolumn{2}{|c|}{ Fallow }} & Cien \\
\hline & & & & Avsa \\
\hline & & \multirow{2}{*}{\multicolumn{2}{|c|}{ Lope }} & Cien \\
\hline & & & & Avsa \\
\hline & & \multirow{2}{*}{\multicolumn{2}{|c|}{ Trre }} & Cien \\
\hline & & & & Avsa \\
\hline & & \multirow{2}{*}{\multicolumn{2}{|c|}{ Rasa }} & Cien \\
\hline & & & & Avsa \\
\hline & & \multirow{2}{*}{\multicolumn{2}{|c|}{ Visa }} & Cien \\
\hline & & & & Avsa \\
\hline & & & & Cien \\
\hline & & $\mathrm{R}+\mathrm{V}^{*}$ & $\mathrm{~L}+\mathrm{T}^{*}$ & Avsa \\
\hline & & & & \\
\hline & & Fallo & & Cien \\
\hline & & Fallon & & Avsa \\
\hline & & Ione & & Cien \\
\hline & & Lope & & Avsa \\
\hline & & & & Cien \\
\hline & ๘ & Irre & & Avsa \\
\hline & $\frac{0}{0}$ & & & Cien \\
\hline & & Rasa & & Avsa \\
\hline & & & & $\begin{array}{l}\text { Cien } \\
\end{array}$ \\
\hline & & Visa & & Avsa \\
\hline & & D. & T* & Cien \\
\hline & & $\mathrm{R}+\mathrm{V}^{*}$ & {$\left[+T^{*}\right.$} & Avsa \\
\hline
\end{tabular}

* mixtures grown on one experimental unit (c)

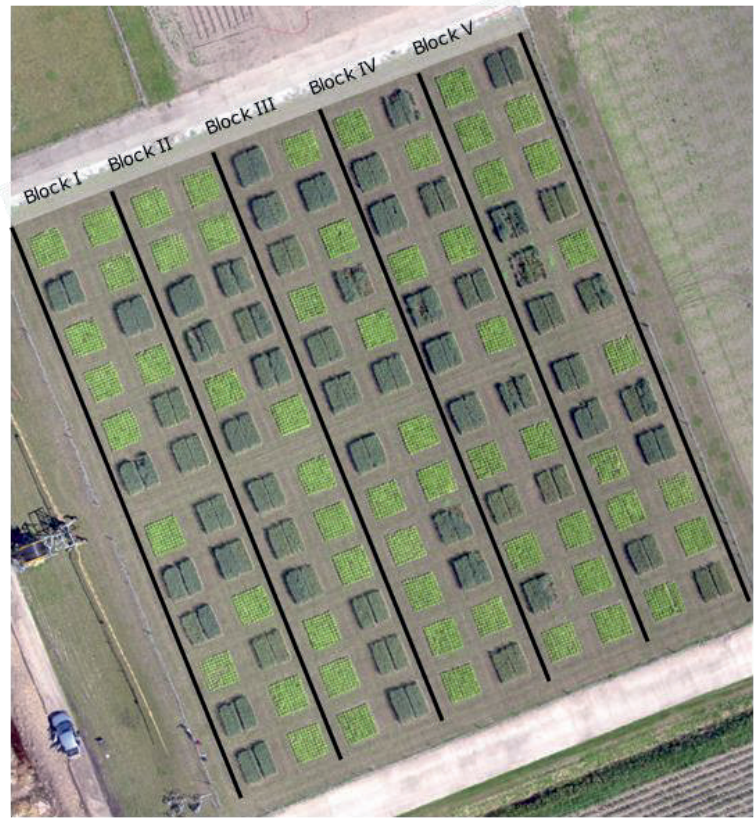

Figure 2.1 Experimental set-up. (a) Timeline field experiment in three phases: summer 2014 (S'14), winter 2014/15 (W'14), summer 2015 (S'15), indicating when measurements were taken. (b) Rotation design ( $n=5)$ : Phacelia was grown in summer 2013 (S'13) prior to cultivating main crops Avena sativa (Avsa) and Cichorium endivia (Cien), followed by winter cover crop monocultures Lolium perenne (Lope), Trifolium repens (Trre), Raphanus sativus (Rasa), Vicia sativa (Visa) and mixtures Lolium+Trifolium (L+T) and Raphanus+Vicia (R+V), with fallow as control. Subsequently, Avena and Cichorium were grown. (c) Aerial photograph during S'15, showing 60 Avena (dark) and 60 Cichorium (light) plots of two experimental units $(1.5 \times 3 \mathrm{~m})$ in five randomized blocks (by J Suomalainen).

\section{Main crop cultivation (S'14 \& S'15)}

Avena and Cichorium cultivation was similar in 2014 and 2015. End March, Avena was sown (193.5 $\mathrm{kg} \mathrm{ha}^{-1} ; 12.5 \mathrm{~cm}$ row spacing, 3-5 cm depth). Early May, all plots were treated with herbicide to suppress dicot weeds (Damine $5002 \mathrm{~L} \mathrm{ha}^{-1}$, mcpa $5001 \mathrm{~L} \mathrm{ha}^{-1}$, Starane $2001 \mathrm{~L}$ ha${ }^{1}$ ), and four-week-old Cichorium seedlings were planted (interplant distance $30 \times 30 \mathrm{~cm}$ ). Hereafter, all Cichorium plots were manually weeded. All plots were irrigated according to 
general agricultural practice. Cichorium was grown until mid-July and Avena was harvested late-July. Shoots were harvested, and stubble left on the field.

Winter Cover Crop cultivation (W'14)

All plots were hoed prior to WCCs sowing on August $25^{\text {th }}(12.5 \mathrm{~cm}$ row spacing, 2-3 cm depth, Lolium $25 \mathrm{~kg} \mathrm{ha}^{-1}$, Trifolium $10 \mathrm{~kg} \mathrm{ha}^{-1}$, Raphanus $30 \mathrm{~kg} \mathrm{ha}^{-1}$, Vicia $125 \mathrm{~kg} \mathrm{ha}^{-1}$ ). Mixtures were composed of 50/50 proportions of the monoculture seeding densities. Mid-September, plots were manually weeded and additionally $10 \mathrm{~kg} \mathrm{ha}^{-1}$ Trifolium was hand-sown to ensure establishment ( $5 \mathrm{~kg} \mathrm{ha}^{-1}$ for L+T). Weeding was repeated early October. WCCs were mown mid-February and the residue incorporated into the soil by milling (10 $\mathrm{cm}$ depth), twice with a one-week interval.

\subsubsection{Measurements}

Winter cover crop biomass and nitrogen concentration

WCC shoot and root biomass were determined mid-December 2014, at time of first frost. Shoots were cut $(25 \times 25 \mathrm{~cm})$ in the centre of each experimental unit. Root biomass was determined from soil cores (8 cm diameter, 0-30 cm depth) taken in the centre of each sampling square. Roots were gently rinsed with tap water. Samples were dried at $70^{\circ} \mathrm{C}$ for 72 hrs and weighed. Shoots were ground with a Retsch MM 2000 ball grinder (Retsch Benelux VERDER NV, Aartselaar, Belgium). N concentration of shoots from blocks 1, 3 and 5, was measured with a CHN analyser (LECO Corporation, St Joseph, Michigan, USA).

\section{Plant-feeding nematodes}

Nematodes samples were taken mid-December 2014. Per plot, 12 cores (6 per experimental unit) were taken with an auger $(2.5 \mathrm{~cm}$ diameter, $20 \mathrm{~cm}$ depth) and mixed. Samples were stored at $4^{\circ} \mathrm{C}$ until processing within two weeks. Nematodes were extracted from $100 \mathrm{~g}$ fresh soil following Oostenbrink (1960). The elutriator suspension was washed over four stacked sieves (mesh $45 \mu \mathrm{m}$ ), then poured over double cotton filters on a coarse sieve on a shallow tray with $90 \mathrm{ml}$ tap water. After $24 \mathrm{~h}$, the filtrate was collected and filled up to 100 $\mathrm{ml}$. Total number of nematodes was counted in a $9 \mathrm{ml}$ subsample from the $100 \mathrm{ml}$ suspension. Next, nematode suspensions were concentrated into $2 \mathrm{ml}$ and subsequently fixed by adding $4 \mathrm{ml}$ hot and $4 \mathrm{ml}$ cold formalin (concentration of $4 \%$ ). Nematodes were identified microscopically by applying $0.15 \mathrm{ml}$ formalin-suspension on microscope slides. In each sample, 150 individuals were assigned to feeding groups (Yeates et al. 1993). 


\section{Soil organic matter and mineral nitrogen}

Soil abiotic properties were quantified on April $7^{\text {th }}$ 2015. Mixed soil samples were collected per experimental unit, by taking three cores (diameter $2.5 \mathrm{~cm}$, depth 0-30 cm). Samples were stored one week at $4^{\circ} \mathrm{C}$ and sieved over $2 \mathrm{~mm}$. Soil organic matter (SOM) content was determined as loss on ignition $\left(550^{\circ} \mathrm{C}\right.$ for 4 hours). Potential soil nitrogen pool was defined as total mineral $\mathrm{N}\left(\mathrm{NO}_{3}{ }^{-}\right.$and $\mathrm{NH}_{4}{ }^{+}$) after incubation (3 weeks, $20^{\circ} \mathrm{C}, 60 \%$ water holding capacity) (see Appendix S1). Mineral $\mathrm{N}$ was measured on dried soil $\left(40^{\circ} \mathrm{C}\right)$, using $\mathrm{KCl}$ extraction (Keeney \& Nelson 1982).

\section{Productivity of main crops in 2015}

Cichorium was harvested $6^{\text {th }}$ of July. Average dry weight per plant was determined by harvesting three plants per experimental unit. Samples were taken equally spaced, omitting the outer rows. Plants were cut at soil surface and stored at $4^{\circ} \mathrm{C}$ until processing within four days. Avena was harvested $24^{\text {th }}$ of July, by cutting $25 \times 25 \mathrm{~cm}$ area (containing 2 rows) $6 \mathrm{~cm}$ above soil surface in the centre of the experimental unit. Samples were dried at $70^{\circ} \mathrm{C}$.

\subsubsection{Data analysis}

Statistical analyses were performed with $\mathrm{R}$ statistical software version 3.2.1 (R Core Team 2015) using the below-mentioned packages.

\section{Winter cover crop performance}

Differences between WCC treatments effects on crop biomass (quantity) and nitrogen concentration (quality) were tested using linear mixed effects models (nlme package (Pinheiro et al. 2016)), with cropping history as a covariate. For model selection and optimisation we followed the protocol outlined in Zuur et al. (2010). In brief, full models included WCC treatments ( $\left.W^{\prime} 14\right)$, previous cropping history $\left(S^{\prime} 14\right)$ and their interaction $\left(\mathrm{W}^{\prime} 14^{*} \mathrm{~S}^{\prime} 14\right)$ with block as a random factor. To account for heteroscedasticity, we selected variance structures best capturing the difference in variance between the strata. Models were further optimised by backwards removal of non-significant interactions and main effects. The goodness of fit of the simplified model and the original model were compared through the likelihood-ratio test. Parameters of the final models were estimated with restricted maximum likelihood (REML). Normality and homogeneity of residual variances of each model were verified with resp. Kolmogorov-Smirnov and Levene's test. Differences between treatments were evaluated post-hoc with Tukey's test. 
We tested whether soil properties of the WCC treatments differed from fallow by a linear mixed model with fallow as baseline and block as random factor. We quantified the WCC effect on soil properties by expressing the response of the soil parameters ( $\mathrm{Y}$ ) per treatment (i) relative to the fallow (f) according to equation 1 (Brinkman et al. 2010). Treatment-control comparisons were made pairwise, within the same previous cropping history (j) and block (b).

relative $W C C_{i, j, b}=\operatorname{Ln}\left(\frac{Y_{i, j, b}}{Y_{f, j, b}}\right)$

Next, the relative WCC effect on soil parameters and previous cropping effect thereupon were tested with a linear mixed effects model as described above.

\section{Plant-soil feedback effects}

Subsequent Avena and Cichorium productivity on former WCC plots was compared to the productivity on former fallow plots. In addition, the feedback-effects of WCC on the productivity of both main crops and the influence of previous cropping thereupon was quantified with equation 1 and tested with a linear mixed effects model.

\section{Mixture effects}

WCC mixtures effects were tested separately for WCC biomass and nitrogen concentration, as well as for soil properties (SOM, potential $\mathrm{N}$ pool, nematode abundance) and productivity of subsequent Avena and Cichorium. Per response variable, the expected value $\left(Y_{\mathrm{E}}\right)$ was calculated as the average of the observed component monocultures values. The mixture effect was quantified as the natural logarithm of the ratio of the observed response to the mixture treatment $\left(\mathrm{Y}_{\mathrm{O}}\right)$ and the expected value $\left(\mathrm{Y}_{\mathrm{E}}\right)$ (equation 2) within block (b).

mixture effect ${ }_{b}=\operatorname{Ln}\left(\frac{Y_{O, b}}{Y_{E, b}}\right)($ eq 2)

Mixture effects were considered significant if they deviate from zero based on two-sided student t-test $(\alpha=0.05)$. Positive mixture effects on productivity were considered as overyielding. Mixtures would overyield transgressively when productivity exceeded the most productive component monoculture (Schmid et al. 2008). 
Testing relative importance of plant-soil feedback pathways

The extent to which the legacies of WCC mixtures were mediated by soil properties and affect biomass production of subsequent plants was evaluated by structural equation modelling (SEM), using packages Lavaan (Rosseel 2012) and MVN (Korkmaz, Goksuluk \& Zararsiz 2014).

The degree of model fit given the data was tested in a multigroup model grouped per subsequent main crop (Avena or Cichorium), in which we constrained the paths between WCC shoot biomass and nitrogen concentration, and soil properties SOM, potential soil nitrogen pool and plant-feeding nematode abundance, as well as the pathway between SOM and potential N pool to be equal across both groups (see Appendix S2). Data on fallow were excluded. The degree of fit was measured with maximum likelihood chi-squared statistics (multivariate normal distribution of endogenous variables was verified). We verified the model outcome with methods for small sample size by Bollen-Stine bootstrapping and Monte-Carlo $\chi^{2}$ simulations (Shipley 2016). 


\subsection{Results}

\subsubsection{Winter cover crop performance}

WCC shoot biomass varied by WCC treatment ( $\left.\mathrm{W}^{\prime} 14: \mathrm{F}_{5,104}=82.78, \mathrm{P}<0.001\right)$, previous main crop ( $\left.S^{\prime} 14: F_{1,104}=10.37, P=0.0017\right)$ and displayed an interaction effect $\left(S^{\prime} 14{ }^{*} W^{\prime} 14: F_{5}, 104=2.35\right.$, $\mathrm{P}=0.0457)$. The WCC treatments that included Raphanus were three-fold more productive than Lolium and Trifolium monocultures and mixture (Fig. 2.2a). Lolium was more productive on former Cichorium plots than on former Avena plots. Other WCC species were unaffected by previous cropping. The Lolium+Trifolium $(\mathrm{L}+\mathrm{T})$ mixture was as productive as expected based on monoculture biomass (Fig. 2a), whereas the Raphanus+Vicia $(\mathrm{R}+\mathrm{V})$ mixture overyielded on both former Avena ( $\left.\mathrm{t}_{9}=3.18, \mathrm{P}=0.011\right)$ and Cichorium soil $\left(\mathrm{t}_{9}=5.29\right.$, $\mathrm{P}<0.001)$.
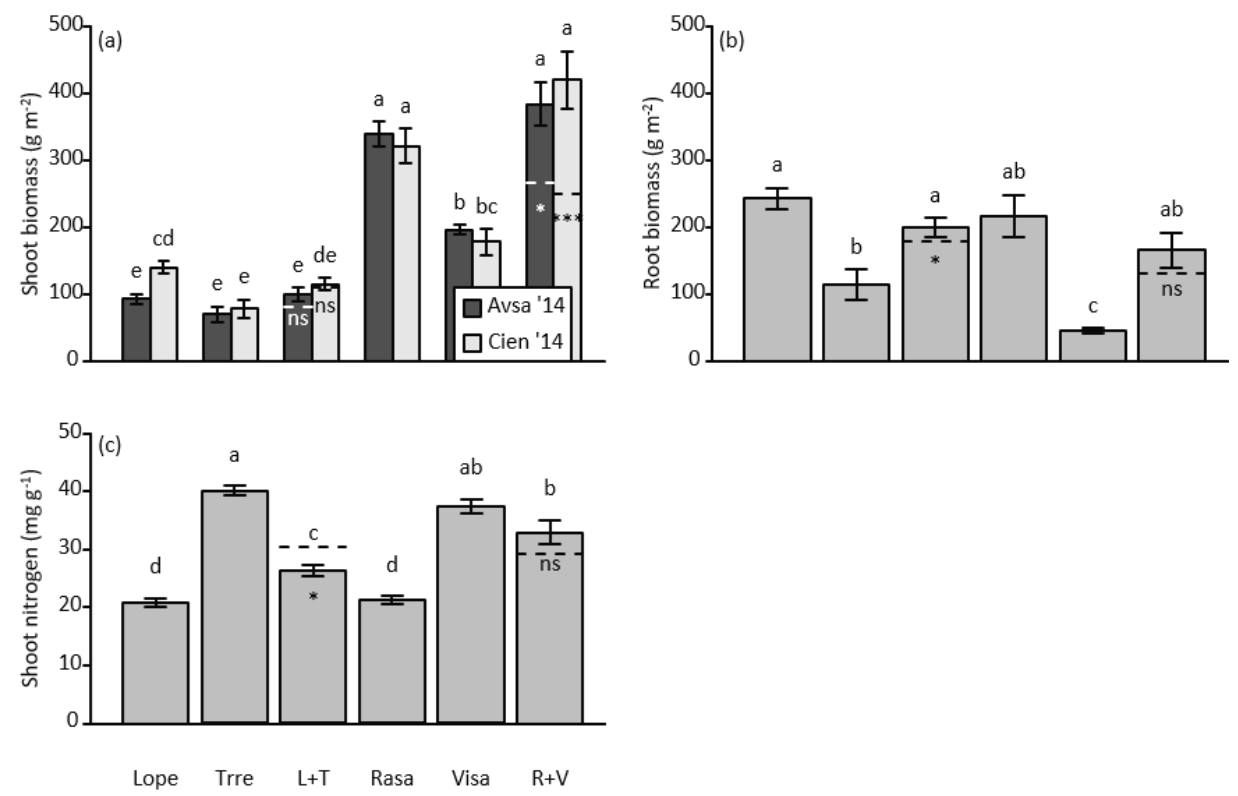

Figure 2.2 Winter cover crop (WCC) biomass of shoot (a), root (b) and shoot nitrogen concentration (c). For abbreviations see Fig. 2.1. Shoot biomass (a) is specified per previous main crop Avena (Avsa '14) or Cichorium (Cien '14). Dashed lines specify expected mixture response based on component monoculture performance, ${ }^{*}$ specifies a significant deviation from expected response based on two-sided t-test $(\mathrm{P}<0.05),{ }^{* * *}(\mathrm{P}<0.001)$, ns $(\mathrm{P}>0.05)$. For (a) $\mathrm{n}=10$, (b) $n=20$, (c) $n=12$ except Lope $(\mathrm{n}=11)$. Error bars $\pm 1 \mathrm{SE}$, letters indicate significant differences based on Tukey post-hoc test. Note: Shoot biomass (a) of Lolium differed per preceding main crop, as indicated by different letters.

Standing root biomass differed significantly between WCC treatments ( $W^{\prime} 14: F_{5,110}=57.35$, $\mathrm{P}<0.001$, Fig. 2.2b), while previous main crop effect on root biomass was non-significant. 
Treatments with Lolium and Raphanus had the highest root biomass, whereas the legume treatments, specifically Vicia monoculture, had low root biomass. The L+T mixture had a significantly larger root biomass than expected ( $\left.\mathrm{t}_{19}=2.30, \mathrm{P}=0.033\right)$, whereas $\mathrm{R}+\mathrm{V}$ mixture root biomass did not significantly deviate from the expectation (Fig. 2.2b).

Shoot nitrogen concentration differed between WCC treatments $\left(F_{5,63}=95.98, P<0.0001\right.$, Fig. 2.2c) and was unaffected by previous main crop. Nitrogen concentration in legume shoots was twice as high as in Lolium and Raphanus. The $L+T$ mixture showed a lower shoot nitrogen concentration than expected $\left(\mathrm{t}_{10}=-3.58, \mathrm{P}=0.005\right.$, Fig. $\left.2.2 \mathrm{c}\right)$, whereas the nitrogen concentration of $\mathrm{R}+\mathrm{V}$ mixture did not differ from expectation.

T a b l e 2.1 Means and standard error of soil properties and productivity of succeeding plants per winter cover crop treatment ( $\left.W^{\prime} 14\right)$ and previous cropping history $\left(S^{\prime} 14\right)$ : soil organic matter (SOM), potential soil nitrogen pool and plant-feeding nematodes abundance per soil dry weight $(\mathrm{dw})$, and dry biomass (Bm) of Avena (Avsa '15) and Cichorium (Cien '15). For abbreviation see Fig.2.1. Significant differences (two-sided $t$-test $P<0.05$ ) between expected and observed mixture responses are underlined and the direction indicated $((+)$ positive, $(-)$ negative). Bold values indicate a significant difference $(\mathrm{P}<0.05)$ of $\mathrm{W}^{\prime} 14$ treatments relative to fallow in a linear mixed model.

\begin{tabular}{|c|c|c|c|c|c|}
\hline & $\begin{array}{l}\text { SOM } \\
(\%)\end{array}$ & $\begin{array}{l}\text { Potential } \mathbf{N} \\
\text { pool } \\
\left(\mathrm{mg} \mathrm{kg}^{-1} \mathrm{dw}\right)\end{array}$ & $\begin{array}{l}\text { Nematodes } \\
\left(\# 100 \mathrm{~g}^{-1} \mathrm{dw}\right)\end{array}$ & $\begin{array}{l}\text { Bm Avsa '15 } \\
\left(\mathrm{g} \mathrm{m}^{-2}\right)\end{array}$ & $\begin{array}{l}\text { Bm Cien '15 } \\
\left(\mathrm{g} \text { plant }^{-1}\right)\end{array}$ \\
\hline \multicolumn{6}{|l|}{$W^{\prime} 14$} \\
\hline Fallow & $4.75(0.06)$ & $20.58(0.93)$ & 707 (63) & 999.66 (26.59) & $34.37(1.23)$ \\
\hline Lope & $4.53(0.06)$ & $21.54(1.00)$ & $822(69)$ & $836.53(43.29)$ & $33.86(0.90)$ \\
\hline Trre & $4.79(0.06)$ & $26.79(1.46)$ & $620(72)$ & $1295.74(44.17)$ & $41.03(0.90)$ \\
\hline $\mathrm{L}+\mathrm{T}$ & $4.65(0.05)$ & $25.04(1.50)$ & $788(47)$ & $\underline{836.42(53.98)(-)}$ & $38.99(1.01)$ \\
\hline Rasa & $4.82(0.06)$ & $29.77(1.19)$ & $992(91)$ & $941.94(85.32)$ & $43.22(0.91)$ \\
\hline Visa & $4.75(0.07)$ & $24.69(1.24)$ & $1385(132)$ & $1292.18(44.83)$ & $40.55(0.68)$ \\
\hline $\mathrm{R}+\mathrm{V}$ & $\underline{4.65(0.06)(-)}$ & $28.69(1.22)$ & $1295(123)$ & $\underline{1477.39(75.94)(+)}$ & $41.32(1.13)$ \\
\hline \multicolumn{6}{|l|}{$S^{\prime} 14$} \\
\hline Avsa14 & $4.73(0.03)$ & $25.34(0.73)$ & 1059 (63) & 1016.89 (42.98) & $39.53(0.62)$ \\
\hline Cien14 & $4.68(0.04)$ & $25.26(0.77)$ & $830(47)$ & $1177.35(36.20)$ & $38.57(0.66)$ \\
\hline
\end{tabular}

\subsubsection{Legacy effects on soil properties}

Most WCC treatments left soil organic matter (SOM) content unaltered compared to fallow, except for a reduction by former Lolium monocultures ( $\mathrm{t}_{129}=-3.38, \mathrm{P}=0.0009$, Table 2.1). Mixtures effects varied with composition; SOM levels in former $\mathrm{L}+\mathrm{T}$ plots were as expected, but $\mathrm{SOM}$ in $\mathrm{R}+\mathrm{V}$ plots was lower than expected $\left(\mathrm{t}_{19}=-2.50, \mathrm{P}=0.022\right.$, Table 1$)$. The relative 
effect sizes of WCCs on SOM were small but significantly different between WCC treatments $\left(\mathrm{F}_{5,109}=2.83, \mathrm{P}=0.019\right.$, Fig. 2.3a) and lower on plots with legacies of Avena than of

Cichorium ( $\mathrm{F}_{1,109}=6.95, \mathrm{P}=0.01$, Fig. 2.3b).

\section{Winter cover crop legacy}
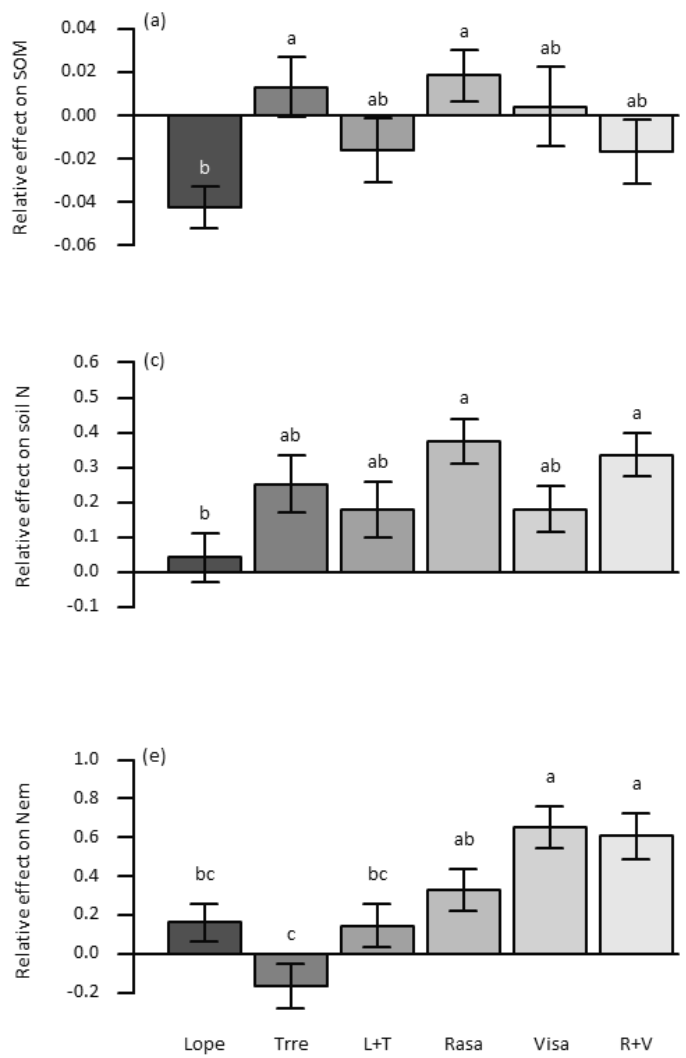

Previous cropping history
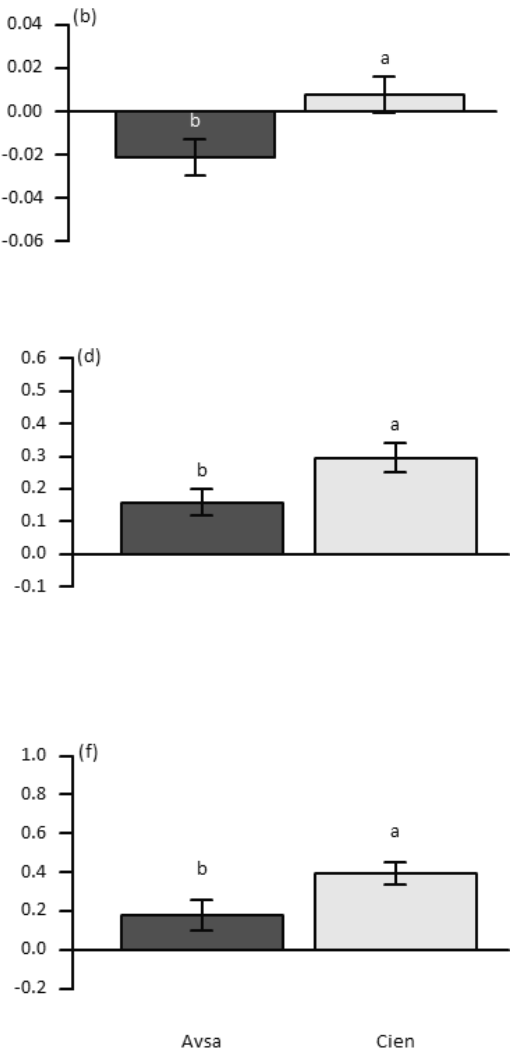

Fig u re 2.3 The effect of winter cover crops (WCCs) relative to fallow on four soil properties: soil organic matter content (SOM, (a) \& (b)), potential mineral nitrogen (soil N, (c) \& (d)), abundance of plant-feeding nematodes (Nem, (e) \& (f)) specified per WCC treatment (left panels) and aggregated per previous cropping history (right panels). Positive effects indicate values in WCC treatments are higher than in fallow. For (a), (c) and (e) n=20, for (b), (d) and (f) $n=60$. For abbreviations see legend Fig.1. Error bars \pm 1 SE. Letters indicate significant differences $(\mathrm{P}<0.05)$, based on Tukey post-hoc test. Note: y-axes are scaled differently.

The potential soil nitrogen pool was increased by all WCC treatments except Lolium monoculture (Table 2.1), with highest values in Raphanus and R+V plots. WCC mixture effects were non-significant. Relative WCC effects on the potential N pool were different 
between WCC treatments ( $\mathrm{W}^{\prime} 14$ : $\mathrm{F}_{5,109}=3.33, \mathrm{P}=0.008$, Fig. 2.3c), and more positive on former Cichorium plots than on Avena plots ( $\mathrm{S}^{\prime} 14: \mathrm{F}_{1,109}=6.38$, $\mathrm{P}=0.013$, Fig. 2.3d).

The abundance of plant-feeding nematodes showed large differences between WCC treatments $\left(\mathrm{F}_{5,109}=9.03, \mathrm{P}<0.0001\right.$, Fig. 2.3e). Compared to fallow, plant-feeding nematode abundances were almost doubled in plots with Vicia and R+V. Raphanus also significantly increased nematode abundances. No mixture effects were observed (Table 1, Fig. 2.3e). Previous cropping history influenced the relative WCC effect significantly $\left(F_{1,109}=6.38\right.$, $\mathrm{P}=0.013)$, with nematode abundance being higher on former Cichorium plots than Avena plots (Fig. 2.3f).

\subsubsection{Legacy effects on subsequent-crop growth}

Relative to fallow, WCC treatments resulted in contrasting feedback effects on both Avena $\left(\mathrm{F}_{5,49}=15.68, \mathrm{P}<0.001\right.$, Fig. 2.4a) and Cichorium biomass ( $\mathrm{F}_{5,50}=3.90, \mathrm{P}=0.005$, Fig. 2.4c). Mixtures of WCCs influenced Avena productivity differently than Cichorium (Table 1). Avena productivity on former $\mathrm{L}+\mathrm{T}$ plots was lower than expected ( $\left.\mathrm{t}_{9}=-2.63, \mathrm{P}=0.027\right)$, while $\mathrm{R}+\mathrm{V}$ mixtures led to higher Avena biomass than expected ( $\left.\mathrm{t}_{9}=2.59, \mathrm{P}=0.029\right)$. WCC mixtures effects on Cichorium productivity were non-significant. More specifically, Avena grown on former Trifolium ( $\mathrm{t}_{59}=4.04, \mathrm{P}<0.001$, Table 1$)$, Vicia $\left(\mathrm{t}_{59}=4.15, \mathrm{P}<0.001\right)$ and $R+V\left(\mathrm{t}_{59}=4.20\right.$, $\mathrm{P}<0.001)$ plots resulted in higher Avena biomass compared to the fallow treatment, whereas Lolium reduced it ( $\left.\mathrm{t}_{59}=-2.37, \mathrm{P}=0.02\right)$. Overall, Cichorium biomass increased by most WCC treatments (except Lolium) compared to fallow. Previous main crops influenced the WCC legacy effects on Avena $\left(\mathrm{F}_{1,49}=43.58, \mathrm{P}<0.001\right.$, Fig. 2.4b), with more positive feedback on former Cichorium than on former Avena plots, whereas the identity of the preceding main crop did not influence the WCC feedback effects on succeeding Cichorium. 

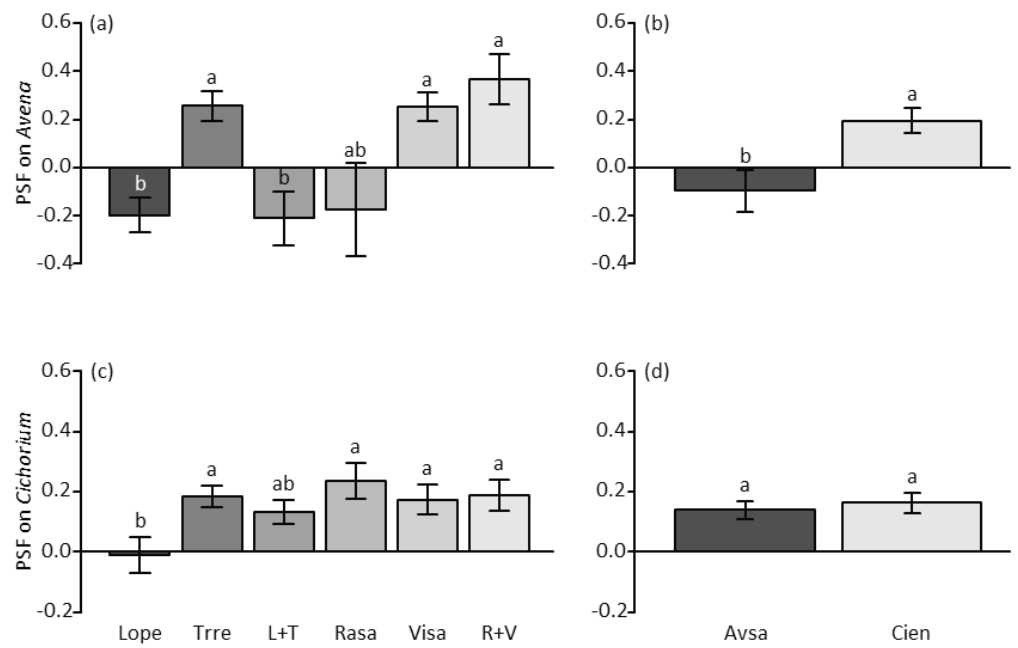

F i g u r e 2 .4 The effect of winter cover crops (WCCs) relative to fallow on four soil properties: soil organic matter content (SOM, (a) \& (b)), potential mineral nitrogen (soil N, (c) \& (d)), abundance of plant-feeding nematodes (Nem, (e) \& (f)) specified per WCC treatment (left panels) and aggregated per previous cropping history (right panels). Positive effects indicate values in WCC treatments are higher than in fallow. For (a), (c) and (e) n=20, for (b), (d) and (f) n=60. For abbreviations see legend Fig.1. Error bars \pm 1 SE. Letters indicate significant differences $(\mathrm{P}<0.05)$, based on Tukey post-hoc test. Note: y-axes are scaled differently.

\subsubsection{Relative strength of plant-soil feedback pathways}

Our SEM model including both indirect and direct effects of WCC aboveground biomass (quantity) and nitrogen concentration (quality) on subsequent-plant productivity was consistent with our data $\left(\chi^{2}=13.01, \mathrm{df}=14, \mathrm{P}=0.526\right.$, Fig. 2.5). Biomass of succeeding Avena and Cichorium was positively related to WCC quantity and quality. Avena biomass was more strongly influenced by quality than quantity, while for Cichorium productivity quantity was a stronger driver than quality (Fig. 2.5). Moreover, Cichorium biomass was most influenced by SOM, whereas this was not a significant factor for Avena. WCC biomass positively affected the potential $\mathrm{N}$ pool and plant-feeding nematode abundance. However, biomass did not influence SOM content. Neither did WCC shoot nitrogen concentration influence the potential $\mathrm{N}$ pool, nor nematode abundance. SOM did positively influence the potential $\mathrm{N}$ pool. Although there was a strong positive effect of WCC biomass and N concentration on the biomass of both main crops, these effects did not operate via the quantified soil parameters. 
(a)

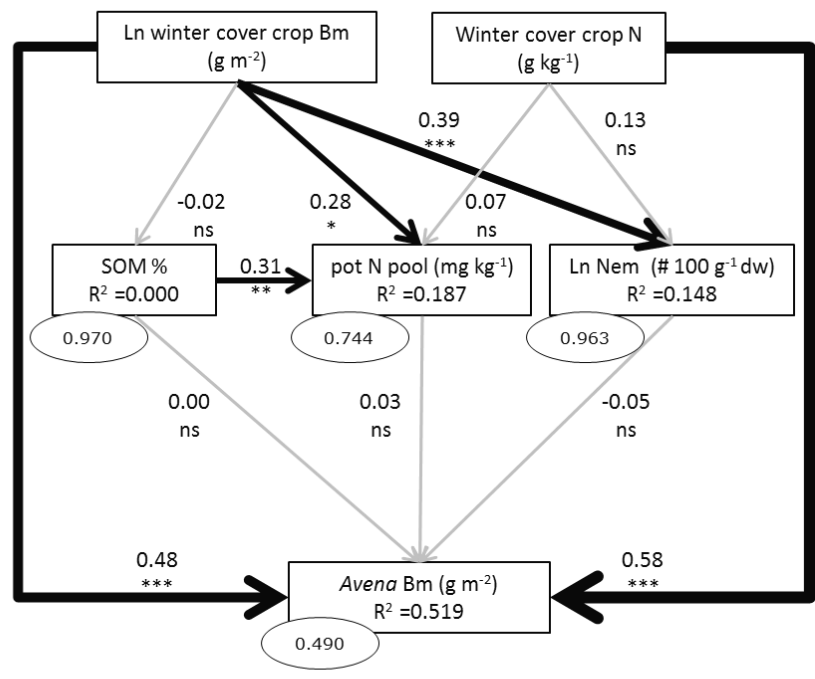

(b)

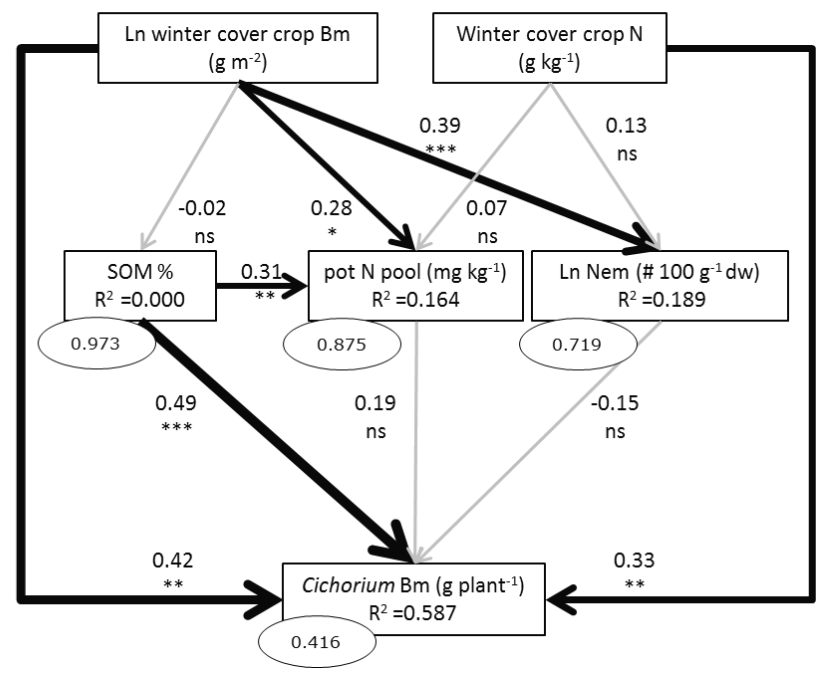

F i g u r e 2.5 Multigroup structural equation model explaining soil-mediated effects of winter cover crops on productivity of Avena ((a), n=36) and Cichorium ((b), n=35) (ML) $\chi^{2}=13.01, \mathrm{df}=14$, $\mathrm{P}=0.526$. Biomass quantity ( $\mathrm{Ln}$ winter cover crop Bm) and quality (winter cover crop $\mathrm{N}$ ) were tested to influence subsequent-plant productivity (Avena or Cichorium $\mathrm{Bm}$ ) directly or indirectly via soil organic matter (SOM), potential nitrogen availability (pot N pool) and plant-feeding nematode abundance (Nem). Black lines are significant: ${ }^{*} \mathrm{P}<0.05$, ${ }^{* *} \mathrm{P}<0.01,{ }^{* * *} \mathrm{P}<0.001$, grey lines are nonsignificant. Numbers near arrows are standardized path coefficients. Encircled numbers are standardised residual variances. $\mathrm{R}^{2}$ is given for each endogenous variable. 


\subsection{Discussion}

Significance of temporal and spatial diversity in agro-ecological management is increasingly recognised by scientists and policy makers (FAO 2017; Finney \& Kaye 2017). Including cover crops and their mixtures in rotation is promoted (Dijksma 2014; FAO 2017), although the scientific basis to decide which crops to include is lagging behind (Dias, Dukes \& Antunes 2014). We discuss our results in the light of biodiversity-ecosystem functioning (BEF) theory to assess WCC diversity effects in space, and place the role of crop diversity in time in the context of indirect PSF.

\subsubsection{Winter cover crop performance}

We hypothesised our WCC mixtures to overyield. Indeed, we found positive mixture effects for shoot biomass of Raphanus+Vicia (R+V) and root biomass of Lolium+Trifolium $(\mathrm{L}+\mathrm{T})$. Legumes fix nitrogen, improving nitrogen availability to neighbouring plants (Thorup-Kristensen, Magid \& Jensen 2003). Nyfeler et al. (2009) demonstrated aboveground overyielding in grass-clover mixtures. However, we did not observe aboveground overyielding of our $\mathrm{L}+\mathrm{T}$ mixture. Interspecific competition is a possible explanation as Trifolium is cold sensitive (Brandsæter et al. 2008) leading to reduced competitive ability when grown with Lolium in late summer/autumn (Nesheim \& Boller 1991). Lolium domination is reflected in the overyielding of $\mathrm{L}+\mathrm{T}$ root biomass, which was similar to Lolium root biomass. In contrast, $\mathrm{R}+\mathrm{V}$ mixture showed aboveground overyielding as was also observed by Möller and Reents (2009), indicating decreased competition for $\mathrm{N}$ in the mixture.

We expected increased levels of mixture shoot $\mathrm{N}$ due to complementarity by legumes. The neutral mixture effect on $\mathrm{R}+\mathrm{V}$ shoot $\mathrm{N}$ suggests improved nitrogen-use efficiency rather than a quality increase. In contrast, the nitrogen concentration in L+T shoots showed a negative mixture effect, probably because the species with the lowest nitrogen concentration was most abundant (own observations).

Ideally, WCC mixtures increase nitrogen input into the soil through increased biomass and/or plant nitrogen content. Positive mixture effects (overyielding) are desirable mixture properties (Schmid et al. 2008). Since the choice of species in a mixture is key to its performance, studying the behaviour of species in mixtures under winter growing conditions is needed to validate BEF principles in utilising WCC mixtures. 


\subsubsection{Winter cover crop legacy effects on soil properties}

As predicted, most WCCs increased the potential soil $\mathrm{N}$ pool relative to winter fallow. However, the hypothesised mixture effects were not observed. Previous field experiments showed that WCC species differ in productivity and N concentration and consequently in their nitrogen supply to following crops (Campiglia et al. 2014; Finney, White \& Kaye 2016). The potential $\mathrm{N}$ pool in our SEM was, indeed, driven by WCC shoot biomass. However, the proposed causal pathway between WCC shoot N concentration and potential N pool was non-significant, indicating that the $\mathrm{N}$ pools are steered by plant productivity rather than plant quality. Orwin et al. (2010) found that highly productive plants often produce easily decomposable litter compared to less productive plants, making it likely that highly productive WCCs promote soil nitrogen through high inputs of easily mineralisable plant residues.

Increased plant diversity in both time and space increases SOM (f.e. Dias, Dukes \& Antunes 2014; Tiemann et al. 2015). Here, the observed relative effects of WCC treatments were small and, except for a reduction by Lolium, did not differ from fallow. Moreover, the causal pathway between WCC shoot biomass and SOM in our SEM was non-significant. The L+T mixture did not influence SOM differently than its monocultures, whereas the $\mathrm{R}+\mathrm{V}$ treatment displayed a negative mixture effect. Build-up of SOM requires carbon inputs exceeding its turn-over. The incorporation of residues into the SOM-pool takes time, whereas there is a continuous break-down of old SOM. The presence of growing plants and the addition of fresh organic matter could prime the break-down of old SOM (Kuzyakov 2010), and the effect-size can depend on the residing organic matter quality (Saar et al. 2016). Understanding carbon and nutrient dynamics of WCC residues in rotation through decomposition studies would be crucial for available $\mathrm{N}$ synchronisation with crop requirements.

Plant-feeding nematode abundances were expected to increase in WCC plots compared to fallow. Raphanus, Vicia and R+V mixture increased nematode abundances in comparison to fallow. Our SEM estimated that WCC shoot biomass stimulated nematode abundances, whereas WCC shoot N did not. Increased plant productivity could lead to increased feeding area for herbivorous nematodes (Thoden, Korthals \& Termorshuizen 2011). Also, increase of bottom-up resource quantity (Chen et al. 2016) or quality (Cortois et al. 2017) can stimulate nematode herbivory. Additionally, mixtures were expected to dilute the abundance of nematode host plants, resulting in neutral to negative mixture effects. Our increased root productivity of L+T mixtures had neutral effects on nematode abundances. These results are in line with Cortois et al. (2017) who show a decrease of plant-feeding nematode density per unit of root biomass in plant species rich communities. Although, plant productivity generally stimulates nematode abundance, diversifying the biomass composition is a potential bio-control for nematode increases. 


\subsubsection{WCC legacy effect on Avena and Cichorium}

The legacy effects of WCCs on subsequent Avena and Cichorium represent indirect (or interspecific) feedback effects (Bever, Westover \& Antonovics 1997). All WCC treatments except Lolium monoculture promoted Cichorium productivity, whilst Avena productivity increased only after legume treatments (Trifolium, Vicia and R+V). Preceding Lolium reduced Avena productivity. We expected that WCC mixtures generate non-additive effects on Avena and Cichorium productivity via changes in mineral $\mathrm{N}$ availability and plant-feeding nematode abundances. We found significant mixture effects on Avena biomass in that L+T suppressed, and $\mathrm{R}+\mathrm{V}$ promoted Avena biomass beyond the expectation. Cichorium biomass did not show WCC mixture effects.

Avena and Cichorium display differential feedback responses because of species identity and associated management. Plants exhibit different feedback effects depending on their functional traits (Kulmatiski et al. 2008; Cortois et al. 2016). Our crops likely profited differently from WCCs, since Avena and Cichorium have different growing seasons. The differential responses are exemplified in our SEM by varying relative pathway strengths. Avena biomass was most influenced by WCC shoot N. Whereas Cichorium biomass was principally driven by SOM, representing the importance of soil structure related processes (Carter 2002). These results emphasise the specificity of plants responding to their environment and the need to tailor crop management.

Our SEM supports the findings of Finney, White and Kaye (2016) that both WCC biomass quantity and quality promote subsequent-crop productivity, indicating the relevance of nutrient-cycling for positive PSF effects. Despite the significant pathways from WCC biomass to soil nitrogen and plant-feeding nematode abundance, those soil properties did not capture the hypothesised PSF mechanisms. To build a sound scientific foundation of crop rotation principles, the components of soil-mediated WCC legacies that promote subsequent growth of specific crops are yet to be identified. Taking the growth requirements of subsequent crops as starting point, future studies should make efforts to disentangle nutrient cycling processes from direct biotic influences (pathogens, mutualists, decomposers) that underlie the WCC biomass quantity and quality pathways.

\subsubsection{Legacy effects of previous main cropping}

Despite the increasing PSF literature, most studies are limited to legacy effects of preceding plants to directly succeeding plants wherein persistence of plant legacies remains unclear (Kardol et al. 2013). The positive indirect feedback effects on subsequent Avena growing on former Cichorium plots illustrate that preceding-crop legacies can persist for at least one year, which agrees with other studies (Bartelt-Ryser et al. 2005; Campiglia et al. 2014). Previous studies show reduced plant-productivity on soils previously occupied by closely 
related species (Kulmatiski et al. 2008). Particularly grasses show strong negative feedback effects on soil conditioned by (near-) congeneric species (Kulmatiski et al. 2008; Cortois et al. 2016). Indeed, Lolium shoot biomass was lower on previous Avena than Cichorium plots. Lolium significantly reduced subsequent Avena productivity. These observations strengthen the general rotation recommendations of avoiding successive cultivation of closely related crops. Therefore, persistence of legacies should be considered when employing legacy effects for sustainable management.

\subsubsection{Synthesis}

Disentangling the relative strength of plant-soil feedback mechanisms is vital for management of (agro-) ecosystems (Kardol et al. 2013; Dias, Dukes \& Antunes 2014; van der Putten et al. 2016). Here, we showed that plant diversity effects can influence subsequent-plant growth in agro-ecosystems. The effects of plant-soil interactions are species combination specific and warrant consideration of previous plant growth. Both biomass quantity and quality are key drivers of soil legacies on subsequent-plant productivity, and research should undertake efforts to disentangle nutrient cycling processes from direct biotic influences. Understanding these underlying pathways is essential to sustainably manage ecosystem functioning through spatial and temporal dynamics of plant mixture effects. Well-chosen winter cover crop species mixtures are a promising agricultural practice to promote biological and chemical soil quality.

\subsection{Acknowledgements}

We thank G. Korthals for advice, J. Paul, D. Piwcewicz, I. García González, H. Martens and Unifarm for practical assistance, Joordens Zaadhandel and Barenbrug for provision of seeds, and J. Suomalainen for the aerial photograph. We are grateful for the constructive comments of three anonymous reviewers. This work was supported by NWO-ALW VIDI to G.B.D.D. (grant nr 864.11.003).

\subsection{Data Accessibility}

Data supporting the results of this manuscript is archived in Dryad Digital Repository: http://dx.doi.org/10.5061/dryad.sp21b (Barel et al. 2017). 
Appendix S1. Soil mineral nitrogen and potential nitrogen mineralisation

Ta b le S1.1 Means and standard error of soil mineral N $\left(\mathrm{NO}_{3}+\mathrm{NH}_{4}\right)$ and potential $\mathrm{N}$ mineralisation per winter cover crop treatment (W'14) and previous cropping history ( $\left.\mathrm{S}^{\prime} 14\right)$. For abbreviation see Fig. 2.1 in main text. Bold values indicate a significant difference $(\mathrm{P}<0.05)$ of winter cover crop treatments relative to fallow in a linear mixed model. No mixture effects were observed

\begin{tabular}{l|l|l}
\hline \hline & $\begin{array}{l}\text { Mineral N } \\
\left(\mathrm{mg} \mathrm{kg}^{-1} \mathrm{soil} \mathrm{dw}\right)\end{array}$ & $\begin{array}{l}\text { Potential N } \\
\text { mineralisation } \\
\left(\mathrm{mg} \mathrm{kg}^{-1} \mathrm{soil} \mathrm{dw} \mathrm{day}{ }^{-1}\right)\end{array}$ \\
\hline $\begin{array}{l}\text { W'14 } \\
\text { Fallow }\end{array}$ & $12.46(0.75)$ & $0.39(0.020)$ \\
Lope & $12.87(0.74)$ & $0.41(0.023)$ \\
Trre & $\mathbf{1 5 . 9 8 ( 0 . 8 8 )}$ & $\mathbf{0 . 5 1 ( 0 . 0 3 6 )}$ \\
L+T & $\mathbf{1 5 . 2 9 ( 1 . 0 8 )}$ & $\mathbf{0 . 4 6 ( 0 . 0 2 9 )}$ \\
Rasa & $\mathbf{1 7 . 7 2 ( 0 . 9 7 )}$ & $\mathbf{0 . 5 5 ( 0 . 0 2 6 )}$ \\
Visa & $14.98(0.95)$ & $\mathbf{0 . 4 6 ( 0 . 0 2 3 )}$ \\
R+V & $\mathbf{1 7 . 7 6 ( 1 . 1 5 )}$ & $\mathbf{0 . 5 2 ( 0 . 0 2 9 )}$ \\
S'14 & $15.40(0.54)$ & $0.47(0.015)$ \\
Avsa14 & $15.15(0.55)$ & $0.47(0.016)$ \\
Cien14 & & \\
\hline \hline
\end{tabular}


winter cover crop legacy
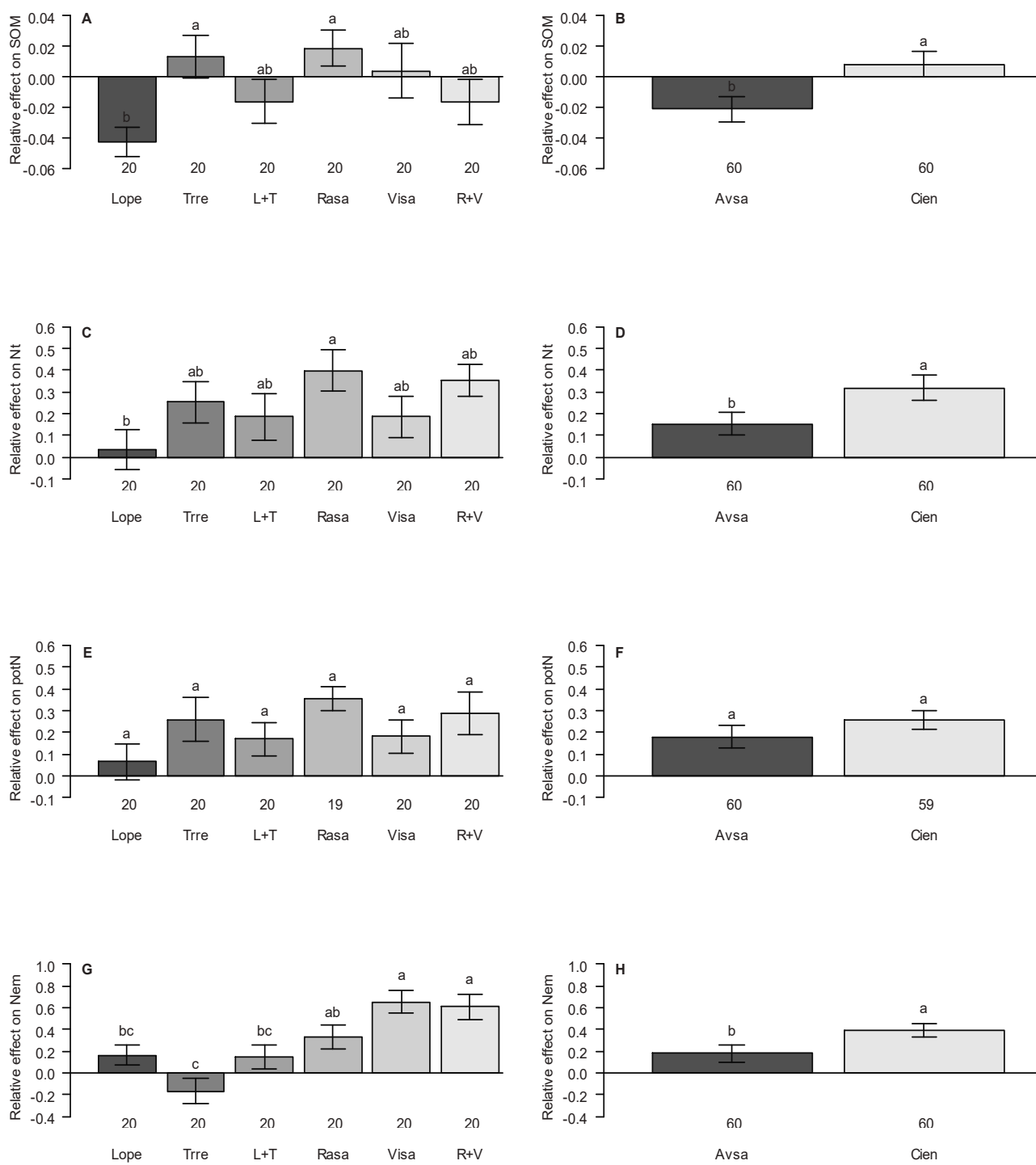

F i g u re S1.2 The relative effect of winter cover crops (WCC) compared to fallow on four soil properties: A\&B: soil organic matter content $(\mathrm{SOM}), \mathrm{C} \& \mathrm{D}$ : available mineral nitrogen $(\mathrm{Nt}), \mathrm{E} \& \mathrm{~F}$ : potential nitrogen mineralisation (potN), G\&H: abundance of plant parasitic nematodes (Nem) specified per winter cover crop treatment (left panels) and aggregated per previous main crop history (right panels). Positive effects indicate that values in WCC treatments are higher than in fallow. Numbers under bars denote number of replica's. Note: y-axes are scaled differently for readability. For abbreviations see legend Fig.1 in main text. Bars are means \pm 1 SE. Letters indicate significant differences $(\mathrm{P}<0.05)$, based on Tukey post-hoc test. 


\section{Appendix S2. Detailed description of Structural Equation modelling}

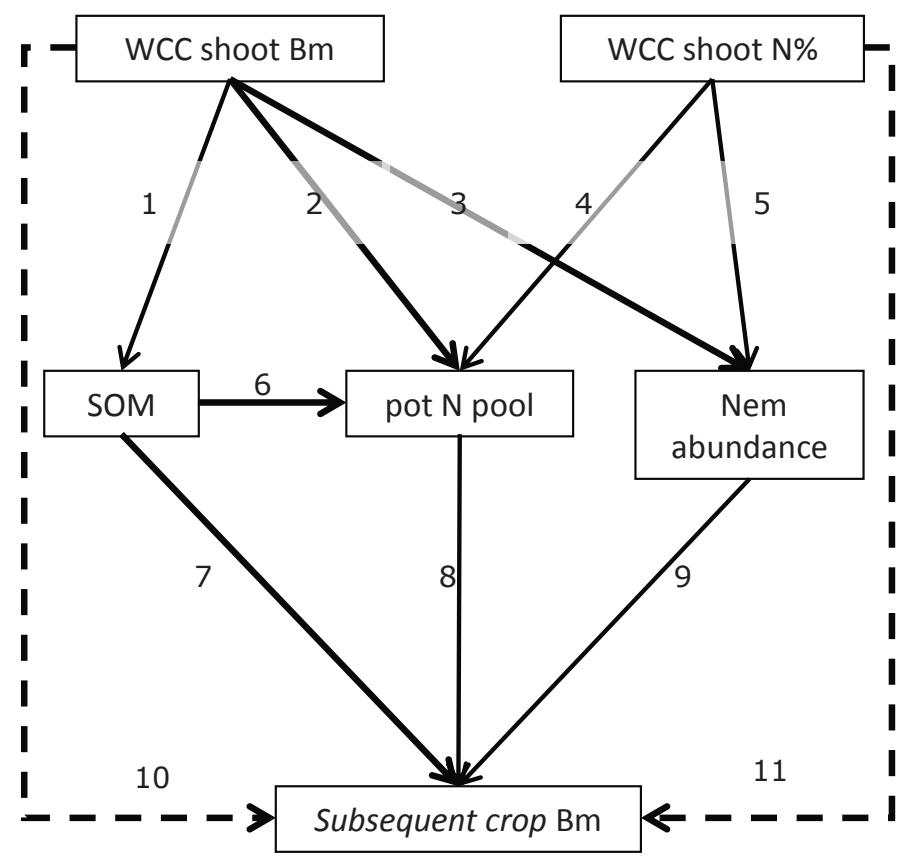

F i gu re S 2.1 Initial SEM model as described by arrows 1-9. Alternative model testing included arrows 10 and 11. All relationships were hypothesized to be positive except for arrow 9 . Abbreviations stand for: $\mathrm{WCC}=$ winter cover crop; $\mathrm{Bm}=$ biomass dry weight; $\mathrm{N} \%=$ nitrogen concentration; $\mathrm{SOM}$ = soil organic matter content; pot $\mathrm{N}$ pool = potential nitrogen pool; $\mathrm{Nem}=$ plant feeding nematode abundance.

\section{Detailed model description}

To test the relative strength of the different pathways that lead to cover crop legacies, we initially posited that winter cover crop (WCC) shoot biomass $\left(\mathrm{g} \mathrm{dw} \mathrm{m}^{-2}\right)$ affects soil organic matter (\%), and that WCC shoot biomass and nitrogen concentration $\left(\mathrm{g} \mathrm{kg}^{-1}\right)$ affect the potential soil nitrogen pool $\left(\mathrm{mg} \mathrm{kg}^{-1}\right)$ and the abundance of plant feeding nematodes. Soil organic matter influences the potential soil $\mathrm{N}$ pool. Next, soil organic matter (\%), the potential soil nitrogen pool $\left(\mathrm{mg} \mathrm{kg}^{-1}\right)$ and the abundance of plant feeding nematodes affect the aboveground biomass production of subsequently grown main crops Avena $\left(\mathrm{g} \mathrm{m}^{-2}\right)$ and Cichorium (g plant ${ }^{-1}$ ) (Fig.S2.1). Furthermore, we hypothesize that the effects of the soil variables on subsequent plant biomass (Fig.S2.1, arrows 7-9) might vary between subsequent crops while the effects of WCC shoot biomass and nitrogen concentration on 
the soil parameters (Fig.S2.1 arrows 1-6) are independent from the identity of the following crop (Avena and Cichorium). Additionally, we assumed the WCC biomass and nitrogen concentration to be independent. Prior to analysis we Ln transformed winter cover crop biomass, and plant feeding nematode abundance. Data on winter fallow treatment were excluded for the analysis.

The degree of fit of the model given the data was tested in a multigroup model grouped per next main crop (Avena and Cichorium) and was measured with the maximum likelihood chi-squared statistic (multivariate normal distribution of endogenous variables was verified). Arrows 1-6 (Fig.S2.1) were constrained to be the same for both groups. The test statistic follows a chi-squared distribution with the degrees of freedom depending on the number of free parameters in the model. A P-value $>0.05$ indicates that the model is consistent with the data and therefore could be a causal explanation of the data.

Our initial model (Fig.S2.1 arrows 1-9) appeared not to be consistent with the data $\left(\chi^{2}=46.74\right.$, $\mathrm{df}=18, \mathrm{P}<0.001$ ). Therefore, we made two modifications to the original model and presumed that winter cover crop biomass and nitrogen concentration had a direct effect on final crop biomass (Avena and Cichorium, Fig.S2.1 arrows $10 \& 11$ ). These paths represent unmeasured soil-mediated effects. We verified the outcome of the model with methods for small sample size by Bollen-Stine bootstrapping and Monte-Carlo $\chi^{2}$ simulations as recommended in Shipley (2016).

Structural equation modelling was conducted using R packages Lavaan (Rosseel 2012) and MVN (Korkmaz, Goksuluk \& Zararsiz 2014). 

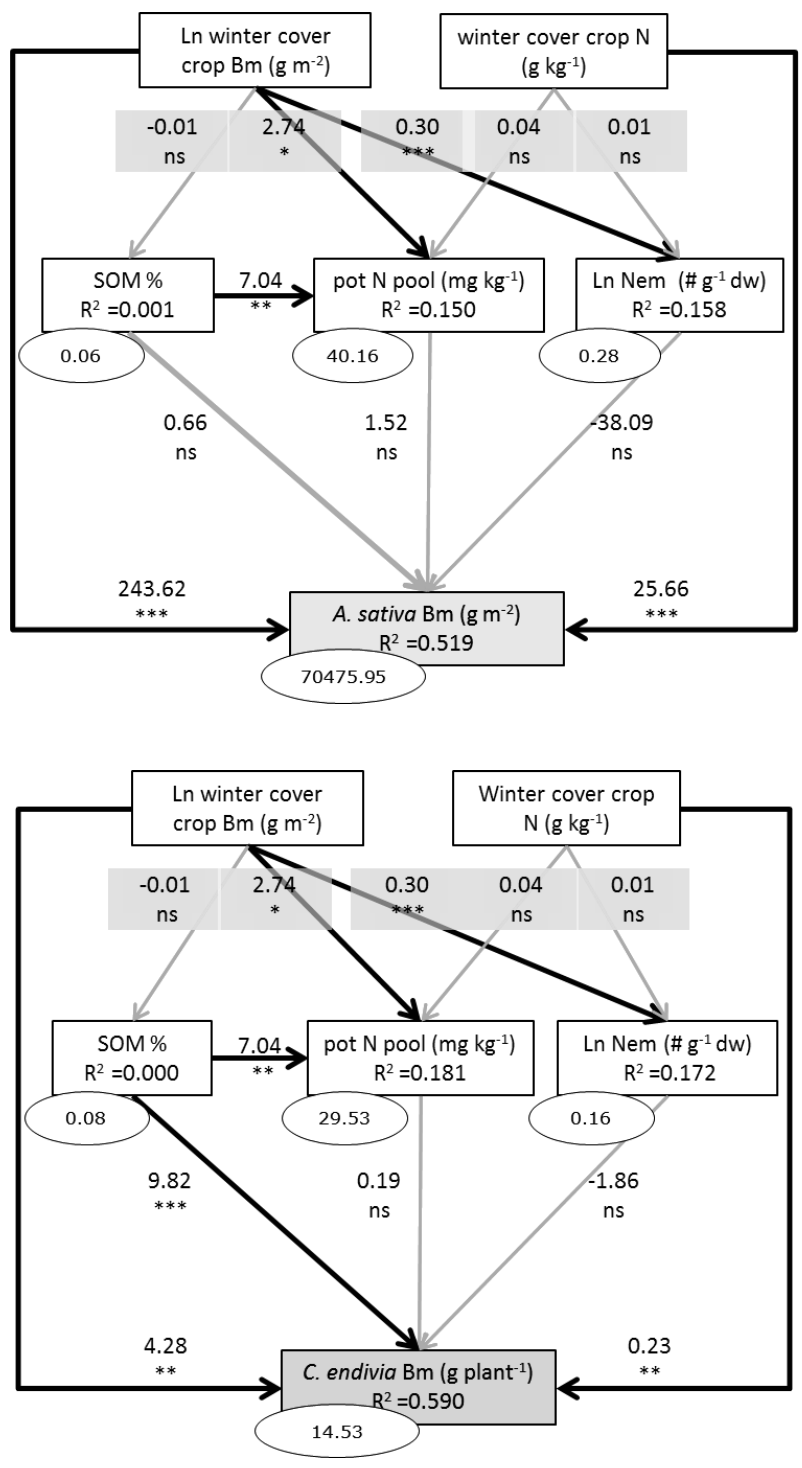

Figure S 2.2 Results of unstandardised multigroup structural equation model for explaining soil-mediated effects of winter cover crops on biomass production of Avena (upper panel, $\mathrm{n}=36$ ) and Cichorium (lower panel, $\mathrm{n}=35$ ) $(\mathrm{ML}) \chi^{2}=13.89, \mathrm{df}=14, \mathrm{P}=0.458$. Biomass quantity (Ln winter cover crop $\mathrm{Bm}$ ) and quality (winter cover crop N) were tested to influence subsequent plant productivity (Avena or Cichorium $\mathrm{Bm}$ ) directly or indirectly via soil organic matter (SOM), potential nitrogen availability (pot N pool) and plant-feeding nematode abundance (Nem). Black lines are significant: ${ }^{*} \mathrm{P}<0.05,{ }^{* *}$ $\mathrm{P}<0.01$, ${ }^{* * *} \mathrm{P}<0.001$, grey lines are non-significant. Numbers near arrows are the unstandardized path coefficients. Encircled numbers at the endogenous variables are the unstandardised residual variance. $R^{2}$ is given for each endogenous variable. 


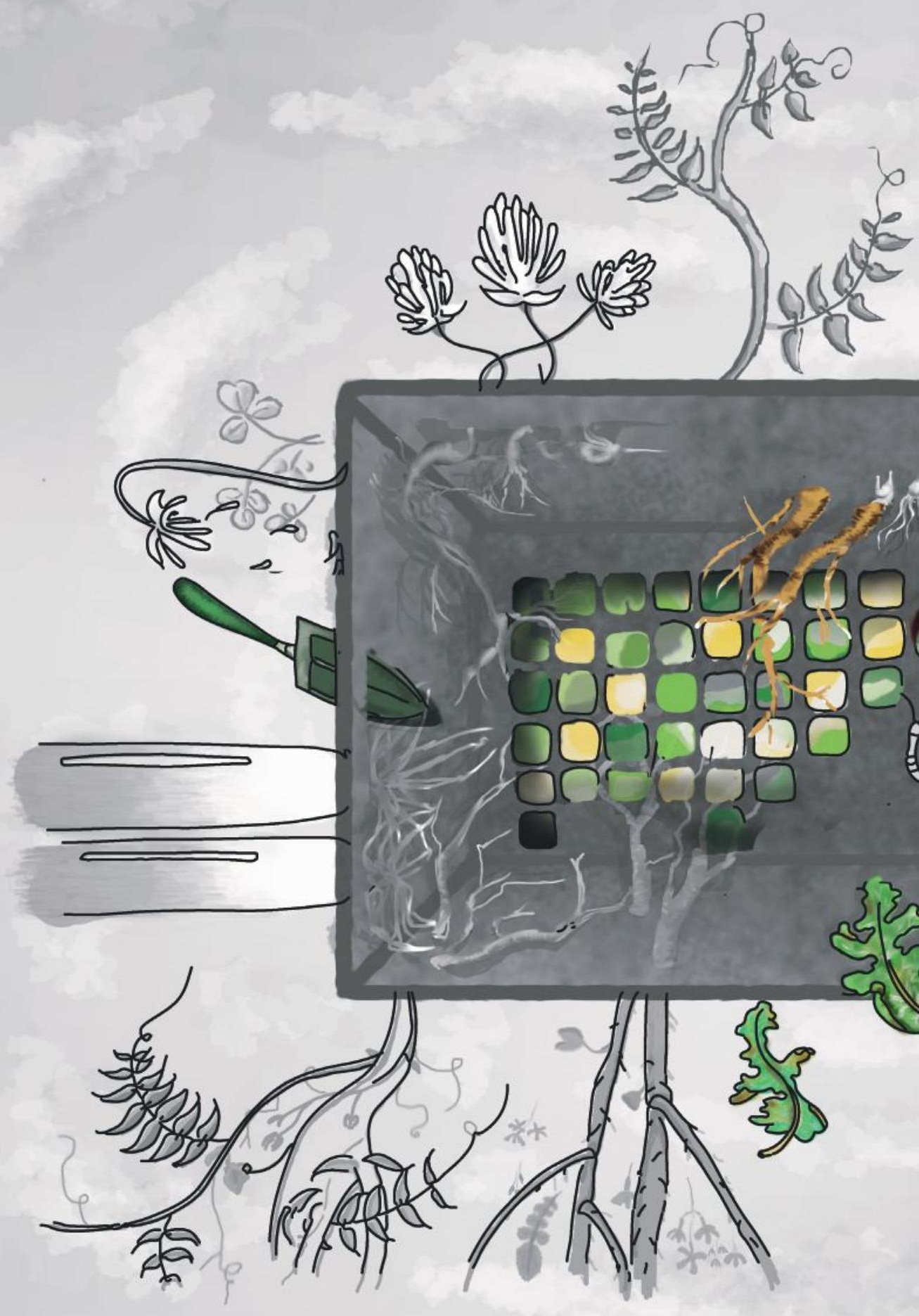




\subsection{Abstract}

In agriculture, winter cover crop (WCC) residues are incorporated into the soil to improve soil quality, as gradual litter decomposition can improve fertility. Decomposition rate is determined by litter quality, local soil abiotic and biotic properties. However, how these factors are interlinked and influenced by cropping history is unclear.

We grew WCC monocultures and mixtures in rotation with main crops Avena sativa and Cichorium endivia and tested how crop rotation influences WCC litter quality, abiotic and biotic soil conditions, and litter decomposition rates. To disentangle WCC litter quality effects from WCC soil legacy effects on decomposition, we tested how rotation history influences decomposition of standard substrates and explored the underlying mechanisms.

In a common environment (e.g. winter fallow plots), WCC decomposition rate constants $(k)$ correlated negatively with litter $\mathrm{C}$, lignin and, surprisingly, $\mathrm{N}$ content, due to strong positive correlations among these traits. Plots with a history of fast-decomposing WCCs exhibited faster decomposition of their own litters as well as of the standard substrates filter paper and rooibos tea, as compared to winter fallow plots.

WCC treatments differentially affected soil microbial biomass, as well as soil organic matter and mineral nitrogen content. WCC-induced soil changes affected decomposition rates. Depending on the main crop rotation treatment, legacy effects were attributed to biomass input of WCCs and their litter quality or changes in microbial biomass.

These results demonstrate that decomposition in cropping systems is influenced directly through crop residues, as well as through crop-induced changes in soil biotic properties. Rotation history influences decomposition, wherein productive winter cover crops with low lignin content decompose fast and stimulate the turn-over of both own and newly added residues via their knock-on effect on the soil microbial community. Thus, winter cover crops have promise for sustainable carbon- and nutrient-cycling management through litter feedbacks. 


\subsection{Introduction}

Decomposition of fresh organic matter initiates the cycling of newly added nitrogen $(\mathrm{N})$ and carbon $(\mathrm{C})$ in soils, which is fundamental to soil fertility. Litter quality, environmental conditions, decomposer biomass and community composition are major drivers of litter decomposition (Swift, Heal \& Anderson 1978; Cornwell et al. 2008; Bradford et al. 2016). Plants, in turn, shape several of these controlling factors, namely litter quality, abiotic soil properties and decomposer community composition (Hobbie 2015; Veen et al. 2015; van der Putten et al. 2016). However, our understanding of how plant legacies affect decomposition rates remains limited, despite benefits of such understanding to sustainable management of agroecosystems.

In agro-ecosystems, cover crop cultivation improves soil quality through incorporation of crop residues (Dias, Dukes \& Antunes 2014). N-fixing legumes are grown as green manures, whereas grasses and deep-rooting Brassicaceae can catch mineral $\mathrm{N}$ vulnerable to leaching (Thorup-Kristensen, Magid \& Jensen 2003). Subsequent crop productivity is stimulated by both quantity and quality of winter cover crops, presumably via decomposition and mineralisation (Barel et al. 2018). Decomposition rates and associated nutrient release from plant litter relate to litter traits as decomposition is impeded by recalcitrant compounds such as lignin and stimulated by high N concentrations (Cornwell et al. 2008; Freschet, Aerts \& Cornelissen 2012b). Depending on litter quality, organic $N$ can be mineralised or immobilised, thus changing mineral $\mathrm{N}$ availability for subsequent plant growth and ecosystem functioning via litter legacy effects (Parton et al. 2007; Hobbie 2015).

Locally, decomposer community activity is regulated by a range of factors (Bradford et al. 2016). For example, mineral N can limit break-down of lignin by soil microbes in later stages of decomposition (Berg \& Meentemeyer 2002), while $N$ availability stimulates decomposition of cellulose (Hu \& van Bruggen 1997). Mineral N availability, in turn, is influenced by plant growth history through nitrogen uptake and release, or through alterations of soil organic matter content and pH (Duval et al. 2016; Vanzolini et al. 2017; Barel et al. 2018). Clearly plant legacies may affect abiotic soil conditions, thus influencing decomposition. Yet, these legacy effects are poorly understood.

Since saprotrophic microbes are the actors of decomposition, their abundance and functioning determine decomposition rates, on top of or in interaction with inherent litter quality (Strickland et al. 2009b; Wickings et al. 2012). For example, soil microbial communities with high fungal to bacterial (F:B) ratios break-down recalcitrant litter faster than communities with a low F:B (van der Wal et al. 2013). Microbial communities can respond rapidly to the crops they are exposed to, as microbial biomass was found to increase and F:B ratio to decrease with increasing temporal crop diversity in crop rotations (Tiemann et al. 2015). Moreover, gram-positive bacteria and microbial activity increased with inclusion of cover crops into rotations (Chavarría et al. 2016; Brennan \& Acosta- 
Martinez 2017). Thus, winter cover crops (WCC) could provide a means of managing decomposition processes in soil, directly through crop residue inputs as well as indirectly through changes in abiotic and biotic soil conditions. But it remains to be tested to what extent WCCs affect the decomposition process during the following cropping season.

Plant legacy effects on decomposition processes may be general in nature, or litter quality specific as has been shown in numerous studies in natural ecosystems. Repeated litter inputs can result in functional specialisation of the local decomposer community, which decomposes home-litters faster than foreign litters: the so-called home-field advantage (HFA) (Ayres et al. 2009; Keiser et al. 2011; Austin et al. 2014). Such litter affinity can also occur with introduced litters of similar quality as the home-litter, wherein affinity decreases with increasing quality-contrast between the home and introduced litters (Freschet, Aerts \& Cornelissen 2012a). Generally, recalcitrant litters benefit most from home-decomposer specialisation (Wallenstein et al. 2013). Agro-ecosystems, however, are typically subjected to high nutrient inputs, high quality litters and frequent disturbance, possibly weakening local decomposer specialisation. Nevertheless, HFA was observed for locally produced cattle-manure (Rashid et al. 2013), and in potato cultivation (Brolsma et al. 2015). Thus, the question arises whether WCCs develop specific legacies, altering decomposition of own residues and newly added amendments. Alternatively, WCCs may increase the soils general ability to decompose organic matter regardless of its quality, by inducing a favourable soil environment. For example, legume presence in grassland systems can increase decomposition of contrasting substrates cellulose and wood (Scherer-Lorenzen 2008). Closing the knowledge gap of plant legacy effects on drivers of decomposition in crop rotation would be an important contribution to soil fertility management.

In this study, we aimed to understand how crop rotation design influences decomposition of WCC litters through litter traits and via legacy effects on soil abiotic and biotic properties. First, we tested (1) how crop rotation shaped WCC litter legacies. We predicted (1a) that high litter quality (high litter $\mathrm{N}$ - and low $\mathrm{C}$ - and lignin content) results in fast decomposition in a common environment. Also, we predicted (1b) that different crop rotations result in distinct soil abiotic conditions (soil organic matter, mineral $\mathrm{N}$, potential mineralisation, $\mathrm{pH}$ ), microbial biomass and community composition. Secondly, we tested (2) underlying mechanisms of litter legacy effects on decomposition. By comparing WCC litter decomposition in own-plots with decomposition of four standard substrates we tested (2a) whether the WCC legacy effects on decomposition were litter quality specific or general. Lastly, we tested $(2 b)$ the importance of WCC residue quantity and quality, soil abiotic and biotic conditions as drivers of WCC litter legacy effects. 


\subsection{Materials and Methods}

\subsubsection{Experimental design}

Winter cover crop (WCC) legacy on litter decomposition was tested in a field experiment on arable sandy soil at the field facilities of Wageningen University (Wageningen, The Netherlands, 51 $59^{\prime} 41.9^{\prime \prime} \mathrm{N} 5^{\circ} 39^{\prime} 17.5^{\prime \prime E}$ ). A full description of the experimental design is given in Barel et al. (2018). Briefly, the set-up was as follows (see also Fig. S1 in Supporting Information).

In spring 2014, monocultures of Avena sativa L. and Cichorium endivia L. were grown on $3 \mathrm{x}$ $3 \mathrm{~m}$ plots and harvested in July. Six WCC treatments and fallow (as control) were established in August 2014. WCC treatments included monocultures of Lolium perenne L., Trifolium repens L., Vicia sativa L., Raphanus sativus L. (hereafter, referred to by their generic names) and mixtures (50:50 seeding density): Lolium+Trifolium ( $\mathrm{L}+\mathrm{T})$, Raphanus+Vicia $(\mathrm{R}+\mathrm{V})$. In February 2015, WCCs were incorporated into the soil $(0-10 \mathrm{~cm})$ by rotary tilling. Fallow plots were treated similarly. In spring 2015, Avena and Cichorium were factorially cultivated as monocultures. This complete randomised block design included 28 rotations $(2 \times 7 \times 2$ treatments) replicated in five blocks. WCC legacy effects on soil abiotic and biotic properties and on in situ litter decomposition was studied during the third growing season (April-June 2015).

\subsubsection{Winter cover crop litter quality, litterbag preparation and incubation}

In the second week of December 2014, WCC litters were collected as fresh plant material cut at soil surface from a $25 \times 25 \mathrm{~cm}$ area, dried $\left(70^{\circ} \mathrm{C}\right)$ and weighed as shoot biomass $(\mathrm{g} \mathrm{dw}$ $\mathrm{m}^{-2}$ ) (presented in Barel et al. (2018)). At time of collection Vicia plants were partially senesced. Litter $\mathrm{C}, \mathrm{N}$ and lignin content were determined using standard protocols (as described in Barel et al. (2018) and Supporting Information).

WCC litterbags were prepared for incubation in own- and fallow-plots (2x120 litterbags, incl five replications). Litterbags measured $5 \times 5 \mathrm{~cm}$ of polyester fabric ( $0.02 \mathrm{~mm}$ mesh-size). WCC litterbags contained $1 \mathrm{~g}$ dried litter cut to $1 \mathrm{~cm}$ length; Trifolium litterbags contained $0.75 \mathrm{~g}$ and were replicated three times due to limited litter availability. Additionally, four contrasting standard substrates were incubated in all plots $(4 \times 140$ litterbags, incl five replications) namely: filter paper (Whatman GmbH, Dassel, Germany, ref. no.: 10311 645), bamboo satay-sticks (Vanka-Kawat, Den Haag, The Netherlands, article nr: 87601) as simple lignin poor vs lignin rich substrates, green tea and rooibos tea (Lipton EAN:8722700055525 resp. EAN: 8722700188438) as complex substrates with different decomposition rates, (Keuskamp et al. 2013). Green tea and rooibos tea were prepared according to Keuskamp et al. (2013). Filter paper and bamboo sticks were cut to $2 \mathrm{~cm}$ and used to fill another series of unused emptied teabags (mesh size $0.25 \mathrm{~mm}$ ) with $2 \mathrm{~g}$. 
All litterbags were buried vertically at $8 \mathrm{~cm}$ depth, $20 \mathrm{~cm}$ apart, in early April and were retrieved after 63 days, stored at $4^{\circ} \mathrm{C}$ for maximally one week until cleaning. Litterbags were gently rinsed to remove adherent soil and roots, dried at $70^{\circ} \mathrm{C}$ and remaining litter was weighed after removal of ingrown roots.

\subsubsection{Soil abiotic and microbiological properties}

Abiotic soil properties and microbial community composition were assessed in bulk soil samples taken at time of litterbag burial. Per plot, three auger cores (2.5 cm diameter, 0-30 $\mathrm{cm}$ ) were taken for one composite sample (140 samples in total). Samples were stored $\left(4^{\circ} \mathrm{C}\right.$, $<1$ week), sieved ( $2 \mathrm{~mm}$ ) and split for the following analyses.

Soil organic matter $(\mathrm{SOM})$, soil mineral nitrogen $\left(\mathrm{NO}_{3}+\mathrm{NH}_{4}\right)$ and potential $\mathrm{N}$ mineralisation were quantified as described in Barel et al. (2018) (see also Supplements). Soil pH was measured in a 1:5 (w/v) suspension of dry soil in $1 \mathrm{M} \mathrm{KCl}$. Soil volumetric moisture content and temperature were recorded by TMS-3 dataloggers (TOMST, Prague, Czech Republic), placed in fallow plots (see Supplements).

Microbial community composition was assessed by phospholipid fatty acid (PLFA) analysis of $3 g$ of sieved freeze-dried soil per plot, as described in Hedlund (2002). Twentyseven PLFAs were detected and quantified (Tab. S3), of which i15:00, a15:00, i16:00, i17:00 and a17:00 were classified as gram positive bacteria, cy17:00, 18:1 $\omega 7$ and cy19:00 as gram negative bacteria, and 15:00, 16:1 $\omega 9,16: 1 \omega 7 \mathrm{c}$ and 17:00 as general bacterial markers (Frostegård \& Bååth 1996), and 18:2 $\omega 6$ was used as indicator of saprotrophic fungal biomass (Hedlund 2002). Fungal and bacterial markers were used to calculate fungal to bacterial biomass ratio (F:B) (Frostegård \& Bååth 1996). Fungal biomass was also estimated by ergosterol biomass, according to Båăth (2001) and de Ridder-Duine et al. (2006) with minor protocol modifications (see Supplements).

\subsubsection{Data analysis}

Data were analysed with R statistical software version 3.3.1 (R Core Team 2016) using the below-mentioned packages.

For all litters and substrates exponential mass loss was assumed. Decomposition rate $k$ (day$\left.{ }^{1}\right)$ was calculated according to Olson (1963): the fraction remaining mass ( $f_{\text {rem }}$ ) was modelled as a function of incubation duration ( $t$ (days)):

$f_{\text {rem }}=e^{-k t}$

Differences in litter quality between WCC species and their preceding main crops (Hypothesis 1a) were tested with separate mixed effects models for response variables litter N-, C- and lignin concentration (nlme package (Pinheiro et al. 2016)), following the protocol by Zuur et al. (2010). Full models included main effects and interaction between WCC 
species and preceding main crop treatment (WCC*S14). Block was included as a random factor. Appropriate variance structures were selected to account for heteroscedasticity between strata. Normality and homogeneity of residual variances were verified with respectively Levene's and Kolmogorov-Smirnov test. WCC decomposition rates were likewise tested for WCC species (WCC), preceding (S14) and current (S15) main crop treatment differences and incubation location (own-fallow) following the same protocol. Dependence among litter traits was tested with Pearson's correlation coefficient. Hereafter, WCC decomposition rate $k$ in fallow plots was regressed against each trait separately to estimate the variance explained by each trait. The relationship between WCC decomposition and litter quality was tested in a full regression model by forward-selecting the traits explaining most additional variance. Block and variance structures were no significant additions to this model. Homogeneity and normality of variances were confirmed.

Changes in abiotic and biotic soil properties in response to rotation treatments $(\mathrm{H} 1 \mathrm{~b})$ were tested following the outlined mixed effects protocol (full model: WCC*S14). As abiotic soil properties, we considered SOM, mineral $\mathrm{N}$, potential $\mathrm{N}$ mineralisation and $\mathrm{pH}$ as response variables. Biotic soil properties included bacterial and fungal biomass, F:B and ergosterol concentration. Treatment effects of rotation on the PLFA profiles were investigated with principle component analysis (PCA, after verifying axis length) and PERMANOVA (10 5 permutations), with backward-selection of the significant factors starting from an additive model (S14+WCC), with strata defined by blocks (vegan package (Oksanen et al. 2016)). The influence of abiotic soil properties on the microbial community composition was likewise tested with PERMANOVA (full model: SOM+mineral $\mathrm{N}+$ potential $\mathrm{N}$ mineralisation $+\mathrm{pH}$ ).

Decomposition rates of the four standard substrates were tested for effects of preceding main crop, WCC and current main crop (H2a), with mixed effects modelling (full model: S14*WCC*S15). WCC legacy effects on the decomposition rates of the standard substrates and of WCC litters were tested by comparing the decomposition rate of the substrate or litter in a plot with a specific WCC history (h) relative to its decomposition rates in the fallow plot (f) of that same block (b) and same main crop (mc):

Relative WCC legacy effect ${ }_{h, b, m c}=\operatorname{Ln} \frac{k_{h, b, m c}}{k_{f, b, m c}}$

Differences between relative WCC legacy effects on litter and standard-substrate decomposition were tested with a mixed linear model including litter type as main factor, with block, preceding- and current main cropping as random factors. Finally, with multiple linear regression, we tested how decomposition rates of filter paper and rooibos were influenced by the decomposition drivers $(\mathrm{H} 2 \mathrm{~b})$ : directly through WCC residue turn-over rates (WCC $k$ in fallow) and WCC residue input (shoot biomass), or indirectly through soil abiotic ( $\mathrm{SOM}$, mineral $\mathrm{N}$, potential $\mathrm{N}$ mineralisation, $\mathrm{pH}$ ), microbial biomass and composition (bacterial and fungal biomass, F:B, ergosterol and coordinates 
PCA axis one and two). Filter paper decomposition rates in former Avena or Cichorium plots were considered separately as was rooibos tea decomposition for current main crop. Filter paper $k$ in former Avena plots was Ln transformed. Decomposition rate constants were regressed with each explanatory variable separately, with block as random factor. Final regression models for filter paper and rooibos tea decomposition were selected by forwardselecting significant explanatory variables in order of $\mathrm{R}^{2}$ marginal ranking (Johnson 2014). 


\subsection{Results}

\subsubsection{WCC litter traits}

WCC litters differed significantly in $\mathrm{N}\left(\mathrm{F}_{5.62}=88.01, \mathrm{P}<0.0001\right), \mathrm{C}\left(\mathrm{F}_{5.62}=107.60, \mathrm{P}<0.0001\right)$ and lignin ( $\left.\mathrm{F}_{5.62}=11.69, \mathrm{P}<0.0001\right)$ concentration (Fig. 3.1a-c, Table S1). Litter $\mathrm{N}$ ranged from 20 $\mathrm{mg} \mathrm{g}^{-1}$ in Lolium and Raphanus litters to $39 \mathrm{mg} \mathrm{g}^{-1}$ in the legumes litters. Raphanus litter contained least (22 $\left.\mathrm{mg} \mathrm{g}^{-1}\right)$ and Vicia litter contained most lignin (80 $\left.\mathrm{mg} \mathrm{g}^{-1}\right)$. Carbon content displayed a similar ranking (Fig. 3.1b), with lowest levels for Raphanus (404 $\mathrm{mg} \mathrm{g}^{-1}$ ) and highest for Vicia litters (453 $\mathrm{mg} \mathrm{g}^{-1}$ ). Litter traits were significantly positively correlated with each other, including a positive correlation between $\mathrm{N}$ and $\mathrm{C}(r=0.35)$, and lignin $(r=0.39)$ (Table S2).
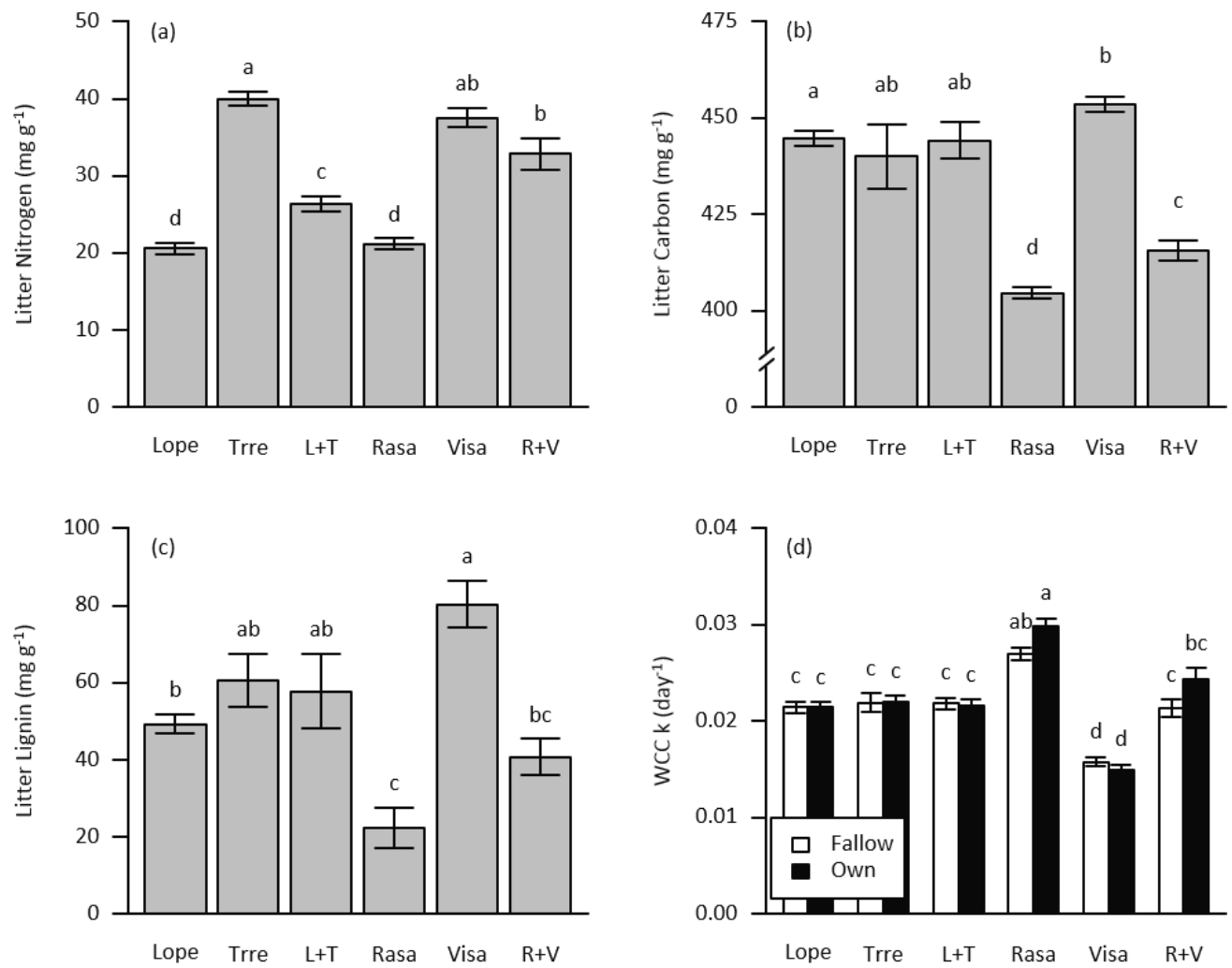

F i g u re 3.1 Winter cover crop litter traits a) nitrogen, b) carbon, c) lignin concentration and mean decomposition rates $(\mathrm{d})$ in fallow (white bars) or own plots (black bars), $\pm \mathrm{SE}$. Lope $=$ Lolium perenne, Trre $=$ Trifolium repens, $\mathrm{L}+\mathrm{T}=$ Lolium + Trifolium mixture, $\mathrm{Rasa}=$ Raphanus sativus, Visa=Vicia sativa, $\mathrm{R}+\mathrm{V}=$ Raphanus + Vicia mixture. Different letters indicate significant $(\alpha \leq 0.05)$ difference based on Tukey post-hoc. $\mathrm{N}=70$ (a-c), in (d) N=221. 
Ta b le 3.1 Winter cover crop (WCC) litter decomposition rate (k). Mean \pm standard error (SE) given by location (Fallow or Own plots), preceding main crop (S14) or current main crop (S15) treatment. Model statistics given for linear mixed effects model including block as random factor and varIdent variance structure on WCC. Bold values: $\mathrm{P}<0.05$, $(\mathrm{N}=221)$.

\begin{tabular}{|c|c|c|c|c|}
\hline \multirow[b]{2}{*}{ WCC } & \multicolumn{2}{|c|}{$\begin{array}{c}\text { WCC in Fallow } \\
k\left(\text { day }^{-1}\right)\end{array}$} & \multicolumn{2}{|c|}{$\begin{array}{c}\text { WCC in Own } \\
k\left(\text { day }^{-1}\right)\end{array}$} \\
\hline & Mean & SE & Mean & SE \\
\hline Lolium & 0.0215 & 0.0006 & 0.0215 & 0.0005 \\
\hline Trifolium & 0.0219 & 0.0010 & 0.0220 & 0.0006 \\
\hline Lolium+Trifolium & 0.0218 & 0.0006 & 0.0217 & 0.0006 \\
\hline Raphanus & 0.0270 & 0.0007 & 0.0299 & 0.0008 \\
\hline Vicia & 0.0158 & 0.0005 & 0.0150 & 0.0006 \\
\hline Raphanus+Vicia & 0.0213 & 0.0009 & 0.0244 & 0.0011 \\
\hline \multicolumn{5}{|l|}{ Incubation in S14 } \\
\hline Avena & 0.0221 & 0.0006 & 0.0228 & 0.0007 \\
\hline Cichorium & 0.0210 & 0.0006 & 0.0223 & 0.0007 \\
\hline \multicolumn{5}{|l|}{ Incubation in S15 } \\
\hline Avena & 0.0203 & 0.0006 & 0.0209 & 0.0007 \\
\hline \multirow[t]{2}{*}{ Cichorium } & 0.0227 & 0.0006 & 0.0241 & 0.0007 \\
\hline & $\mathrm{df}$ & $\mathrm{F}$ & $\mathrm{P}$ & \\
\hline Intercept & 1,203 & 9879.28 & $<0.0001$ & \\
\hline WCC & 5,203 & 109.79 & $<0.0001$ & \\
\hline S14 & 1,203 & 5.62 & 0.0187 & \\
\hline S15 & 1,203 & 46.59 & $<0.0001$ & \\
\hline Location & 1,203 & 0.75 & 0.3876 & \\
\hline Location*WCC & 5,203 & 3.18 & 0.0087 & \\
\hline
\end{tabular}

Ta b le 3.2 Model specification, regressing WCC decomposition rate $k \sim$ Nitrogen+Carbon+Lignin, including sum of squares (SS). Bold values: $\mathrm{P}<0.05$, $\mathrm{R}^{2}$ adjusted $=0.4112, \mathrm{~N}=70$.

\begin{tabular}{|c|c|c|c|c|c|}
\hline & SS & Estimate & SE & t-value & $\mathrm{P}$ \\
\hline (Intercept) & & 0.0518 & 0.0095 & 5.454 & $<0.0001$ \\
\hline Nitrogen & 0.00042 & -0.00019 & 0.000056 & -3.483 & 0.0009 \\
\hline Carbon & 0.00016 & $-5.2 \mathrm{E}-05$ & 0.000023 & -2.233 & 0.0289 \\
\hline Lignin & 0.00006 & $-4.2 \mathrm{E}-05$ & 0.000019 & -2.187 & 0.0323 \\
\hline
\end{tabular}




\subsubsection{WCC decomposition rate}

WCC decomposition rates differed significantly between WCC treatments (Table 3.1). In fallow plots Raphanus litter decomposed fastest, whereas Vicia decomposed slowest. The $k$ values were also influenced by the preceding (S14) and current main crops (S15). Litters incubated in former Avena plots decomposed faster than in plots with a Cichorium legacy. Current Avena and Cichorium cropping had opposite effects: Avena presence reduced decomposition compared to Cichorium presence. We observed a significant interaction between litter identity and location (own vs fallow). Contrary to our expectations, decomposition of fast decomposing litters (Raphanus, Raphanus+Vicia) tended to be elevated in own versus fallow plots (Fig. 3.1d, Table 3.1), although not significantly. To explore how litter quality influenced decomposition rates, WCC $k$ in fallow plots was regressed against litter traits (Table 3.2), therein $\mathrm{N}$ concentration explained more variation than $C$ and lignin ( $N: R^{2}=0.28$; lignin: $R^{2}=0.25 ; C: R^{2}=0.23$ ). Overall, WCC decomposition was best explained by a model including all three traits, in which all slopes were negative.

T a b l e 3.3 Soil abiotic properties. Mean \pm SE given by winter cover crop (WCC) or preceding main crop (S14) treatment. Bold values: $\mathrm{P}<0.05$. Different letters indicate significant $(\alpha \leq 0.05)$ difference based on Tukey post-hoc, $\mathrm{N}=139$. Lolium+Trifolium ( $\mathrm{L}+\mathrm{T})$, Raphanus+Vicia $(\mathrm{R}+\mathrm{V})$

\begin{tabular}{|c|c|c|c|c|c|c|c|c|}
\hline \multirow[b]{2}{*}{ WCC } & \multicolumn{2}{|c|}{$\begin{array}{c}\text { Mineral N } \\
\left(\mathrm{mg} \mathrm{kg}^{-1} \mathrm{dw}\right)\end{array}$} & \multicolumn{2}{|c|}{$\begin{array}{c}\text { Potential } \mathbf{N} \\
\text { mineralisation } \\
\left(\mu \mathrm{g} \mathrm{kg}^{-1} \mathrm{dw} \text { day }^{-1}\right)\end{array}$} & \multicolumn{2}{|c|}{ SOM } & \multicolumn{2}{|c|}{$\mathrm{pH}$} \\
\hline & Mean & SE & Mean & SE & Mean & SE & Mean & SE \\
\hline Fallow & $12.5^{\mathrm{b}}$ & 0.8 & $386.7^{c}$ & 19.9 & $4.75^{a}$ & 0.06 & 5.70 & 0.03 \\
\hline Lolium & $12.9^{\mathrm{b}}$ & 0.7 & $412.9^{\mathrm{bc}}$ & 22.9 & $4.53^{\mathrm{b}}$ & 0.06 & 5.73 & 0.03 \\
\hline Trifolium & $16.0^{\mathrm{ab}}$ & 0.9 & $514.7^{\mathrm{ab}}$ & 35.8 & $4.79 a$ & 0.06 & 5.72 & 0.03 \\
\hline$L+T$ & $15.3^{\mathrm{ab}}$ & 1.1 & $464.2^{\mathrm{abc}}$ & 29.0 & $4.65^{\mathrm{ab}}$ & 0.06 & 5.73 & 0.03 \\
\hline Raphanus & $17.7^{a}$ & 1.0 & $554.5^{\mathrm{a}}$ & 26.8 & $4.85^{\mathrm{a}}$ & 0.06 & 5.75 & 0.03 \\
\hline Vicia & $15.0^{\mathrm{ab}}$ & 0.9 & $462.5^{\mathrm{abc}}$ & 23.9 & $4.75^{\mathrm{a}}$ & 0.07 & 5.66 & 0.03 \\
\hline \multirow[t]{3}{*}{$R+V$} & $17.8^{\mathrm{a}}$ & 1.1 & $520.4^{\mathrm{ab}}$ & 29.1 & $4.65^{\mathrm{ab}}$ & 0.06 & 5.72 & 0.03 \\
\hline & $\mathrm{F}_{6,127}$ & 4.88 & $\mathrm{~F}_{6,127}$ & 5.02 & $\mathrm{~F}_{6,127}$ & 5.07 & $\mathrm{~F}_{6,127}$ & 1.91 \\
\hline & $\mathbf{P}$ & 0.0002 & $\mathbf{P}$ & 0.0001 & $\mathbf{P}$ & 0.0001 & P & 0.084 \\
\hline
\end{tabular}

\begin{tabular}{l|rr|rr|rr|rr} 
S14 & & & & & & & & \\
\hline Avena & 15.4 & 0.5 & 473.2 & 15.4 & 4.73 & 0.03 & $5.75^{\mathrm{a}}$ & 0.02 \\
Cichorium & 15.2 & 0.6 & 473.0 & 16.2 & 4.69 & 0.04 & $5.69^{\mathrm{b}}$ & 0.02 \\
& $\mathrm{~F}_{1,127}$ & 0.09 & $\mathrm{~F}_{1,127}$ & 0.003 & $\mathrm{~F}_{1,127}$ & 1.46 & $\mathrm{~F}_{1,127}$ & 19.84 \\
& $\mathrm{P}$ & 0.759 & $\mathrm{P}$ & 0.960 & $\mathrm{P}$ & 0.229 & $\mathbf{P}$ & $<0.0001$
\end{tabular}




\subsubsection{Legacy effects on soil abiotic and biotic properties}

WCC treatments significantly affected the abiotic soil conditions at the start of the in situ litter incubation (Table 3.3). Available mineral $\mathrm{N}$ and potential $\mathrm{N}$ mineralisation were highest after Raphanus, and lowest after fallow and Lolium treatments. SOM content decreased after Lolium. Moreover, soil $\mathrm{pH}$ displayed small yet significant differences between preceding main crops, with average soil $\mathrm{pH}$ of 5.75 on former Avena and 5.68 on former Cichorium plots.

The principal component analysis of the PLFA abundances resulted in the first axis explaining most variation (91.7\%) and the second axis only 3.7\% (Fig. 3.2). A few PLFA markers were very abundant (Table S3) whereof unspecified marker 16:00 and general bacterial marker 16:1 $\omega 7 \mathrm{c}$ strongly associated with the first axis. PLFA markers for Grampositive bacteria were found in the lower part of the PCA, of which markers i15:00 and a15:00 had a high abundance. Markers for Gram-negative bacteria associated positively with the second axis, of which 18:1 $\omega 7$ was found in high abundance.

Ta b le 3.4 Soil microbial biomass based on PLFA and Ergosterol, and specification of final mixed effects model. Mean \pm SE given by winter cover crop treatment (WCC) or preceding main crop (S14). Bold values: $\mathrm{P}<0.05$. Different letters indicate significant $(\alpha \leq 0.05)$ difference based on Tukey post-hoc, $\mathrm{N}=137$.

\begin{tabular}{l|rr|rr|rr|rr}
\hline \hline & \multicolumn{2}{|c|}{$\begin{array}{c}\text { Bacterial PLFA } \\
(\mathrm{nmol} \mathrm{g-1})\end{array}$} & \multicolumn{2}{|c|}{$\begin{array}{c}\text { Fungal PLFA } \\
(\mathrm{nmol} \mathrm{g-1})\end{array}$} & \multicolumn{2}{c|}{ F:B } & \multicolumn{2}{c}{$\begin{array}{c}\text { Ergosterol } \\
\left(\mathrm{mg} \mathrm{kg}^{-1}\right)\end{array}$} \\
WCC & Mean & SE & & Mean & SE & Mean & \multicolumn{1}{c}{ SE } & \multicolumn{2}{c}{ Mean } & SE \\
\hline Fallow & $18.0^{\mathrm{b}}$ & 1.2 & $0.68^{\mathrm{b}}$ & 0.05 & $0.038^{\mathrm{a}}$ & 0.001 & $0.44^{\mathrm{bc}}$ & 0.02 \\
Lolium & $17.9^{\mathrm{ab}}$ & 0.7 & $0.68^{\mathrm{ab}}$ & 0.03 & $0.038^{\mathrm{a}}$ & 0.001 & $0.43^{\mathrm{c}}$ & 0.03 \\
Trifolium & $18.6^{\mathrm{ab}}$ & 0.8 & $0.79^{\mathrm{ab}}$ & 0.05 & $0.042^{\mathrm{a}}$ & 0.001 & $0.50^{\mathrm{abc}}$ & 0.04 \\
Lolium+Trifolium & $18.1^{\mathrm{ab}}$ & 0.8 & $0.69^{\mathrm{ab}}$ & 0.05 & $0.037^{\mathrm{a}}$ & 0.002 & $0.48^{\mathrm{abc}}$ & 0.03 \\
Raphanus & $19.5^{\mathrm{ab}}$ & 0.9 & $0.75^{\mathrm{ab}}$ & 0.04 & $0.038^{\mathrm{a}}$ & 0.001 & $0.56^{\mathrm{a}}$ & 0.03 \\
Vicia & $20.6^{\mathrm{a}}$ & 0.8 & $0.84^{\mathrm{a}}$ & 0.04 & $0.040^{\mathrm{a}}$ & 0.001 & $0.51^{\mathrm{abc}}$ & 0.02 \\
Raphanus+Vicia & $19.0^{\mathrm{ab}}$ & 1.0 & $0.76^{\mathrm{ab}}$ & 0.05 & $0.040^{\mathrm{a}}$ & 0.002 & $0.55^{\mathrm{ab}}$ & 0.03 \\
& & & & & & & & \\
& $\mathrm{~F}_{6,126}$ & 2.20 & $\mathrm{~F}_{6,125}$ & 2.67 & $\mathrm{~F}_{6,125}$ & 2.23 & $\mathrm{~F}_{6,126}$ & 3.27 \\
& $\mathbf{P}$ & $\mathbf{0 . 0 4 7 3}$ & $\mathbf{P}$ & $\mathbf{0 . 0 1 7 9}$ & $\mathbf{P}$ & $\mathbf{0 . 0 4 4 3}$ & $\mathbf{P}$ & $\mathbf{0 . 0 0 5}$
\end{tabular}

\begin{tabular}{l|rr|rr|rr|rr} 
S14 & & & & & & & \\
\hline Avena & 19.4 & 0.5 & $0.78^{\mathrm{a}}$ & 0.02 & $0.040^{\mathrm{a}}$ & 0.001 & 0.51 & 0.02 \\
Cichorium & 18.3 & 0.5 & $0.70^{\mathrm{b}}$ & 0.02 & $0.038^{\mathrm{b}}$ & 0.001 & 0.48 & 0.02 \\
& & & & & & & & \\
& - & - & $\mathrm{F}_{1,125}$ & 7.59 & $\mathrm{~F}_{1,125}$ & 9.338 & $\mathbf{-}$ & - \\
& - & - & $\mathbf{P}$ & $\mathbf{0 . 0 0 6 7}$ & $\mathbf{P}$ & $\mathbf{0 . 0 0 2 7}$ & $\mathbf{-}$ & -
\end{tabular}

\begin{tabular}{|c|c|c|c|}
\hline Fixed factors & WCC & WCC+S14 & WCC+S14 \\
\hline Random structure & Block & Block & Block \\
\hline Variance structure & VarIdent on S14 & VarIdent on S14 & VarIdent on WCC \\
\hline
\end{tabular}

WCC

Block 


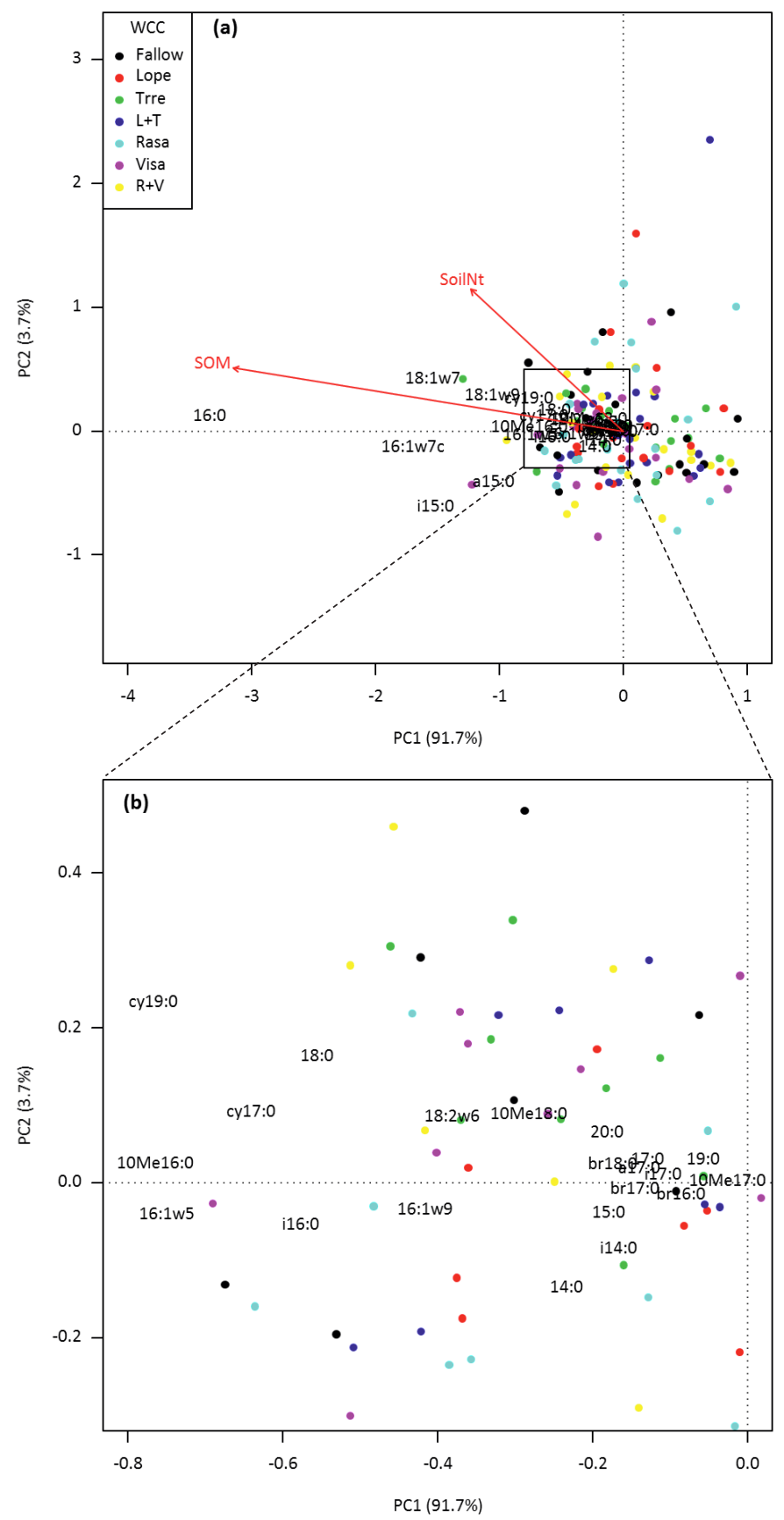

Fi g u re 3.2 Principle component analysis of PLFAs in winter cover crop (WCC) plots with unconstrained fit of significant abiotic soil properties (red arrows: soil organic matter (SOM), mineral N (SoilNt)) (a). Square indicates area displayed enlarged in (b). For WCC abbreviations see Fig. 3.1 For PLFA classification see Table S3. 
WCC treatments and preceding main crop identity significantly affected microbial biomass (Table 3.4), although fungal PLFA marker and ergosterol were low overall. Bacterial and fungal PLFAs were more abundant after Vicia than after winter fallow treatments. Preceding Avena increased fungal biomass and fungal:bacterial ratios (F:B), compared to preceding Cichorium cropping. The WCC on F:B ratios tested significantly, although the post-hoc test did not show significant differences. In line with the PLFA results, ergosterol quantities differed between WCC treatments, although not between preceding crops (Table 3.5). The ergosterol concentrations were highest after Raphanus and lowest after fallow and Lolium treatments.

Contrastingly, microbial community composition did not differ between WCC treatments, and was only marginally affected by preceding main crop treatment (PERMANOVA, WCC: $\mathrm{F}_{6,129}=1.33 \mathrm{P}=0.117 ; \mathrm{S}_{14} \mathrm{~F}_{1,129}=2.64 \mathrm{P}=0.0617$, not shown). Variation in microbial community composition related significantly to soil abiotic properties (Fig. 2a): SOM explained 8.6\% (PERMANOVA $\left.\mathrm{F}_{1,133}=13.03, \mathrm{P}<0.0001\right)$ and soil mineral $\mathrm{N} 4.0 \%\left(\mathrm{~F}_{1,133}=6.03 ; \mathrm{P}=0.015\right)$ of the variation; potential $\mathrm{N}$ mineralisation and soil $\mathrm{pH}$ were not significant factors.

\subsubsection{Decomposition of standard substrates}

Standard substrates decomposition rates varied widely (Table 3.5) though not exceeding WCC decomposition rates; average $k\left(\right.$ day $\left.^{-1}\right)$ ranked as: filter paper $(0.018)>$ green tea $(0.015)$ $>$ rooibos tea $(0.005)>$ bamboo (0.0008). Decomposition rates of all standard substrates were affected by rotation design, with most pronounced effects for filter paper and rooibos tea. Both substrates decomposed fastest in Raphanus and Raphanus+Vicia plots and slowest in former fallow plots. Green tea responses were opposite, with lowest rates in Raphanus, and $R+V$. Bamboo decomposition rates varied little and responded to the current crop. Furthermore, preceding Avena cultivation resulted in significantly decreased decomposition rates of filter paper compared to preceding Cichorium cultivation. Whereas the other substrates were influenced by current main crop presence, with reduced rates in presence of Avena compared to Cichorium cropping (Table 3.5).

\subsubsection{WCC legacy effects on decomposition}

We tested whether WCC legacy effects were specific for substrate quality by comparing decomposition rates of WCC litter and standard substrate incubated in plots with a WCC history to incubation in fallow plots. The relative effect of Raphanus and Raphanus+Vicia legacies varied significantly between the substrates and own litters (Fig. 3.3b \& f). In Raphanus plots, filter paper decomposed significantly faster than in fallow plots $\left(\mathrm{t}_{93}=4.74\right.$, $\mathrm{P}<0.0001$ ). Also, bamboo, rooibos and own Raphanus litter tended to decompose faster in former Raphanus than fallow plots, although this effect was not significant. Green tea 
responded barely to WCC legacies. Comparable results were found for Raphanus+Vicia plots; significantly faster decomposition of filter paper incubated in $R+V$ compared to fallow plots ( $\mathrm{t}_{94}=4.08, \mathrm{P}=0.0001$ ). Relative legacy effects for own litters was never larger than those for standard substrates.

Table 3.5 Standard substrates decomposition rate $(k)$. Model specifications $k$ of standard substrates across all plots. Mean \pm SE given by winter cover crop treatment (WCC), preceding (S14) or current main crop (S15). Final linear mixed effect model includes specified explanatory variables, with block as random, for green tea a variance structure varIdent (WCC), for Bamboo varComb (WCC+S14). Bold values: $\mathrm{P}<0.05$. L+T: Lolium+Trifolium; R+V: Raphanus + Vicia. S14*WCC*S15 was not significant in any of the models

\begin{tabular}{|c|c|c|c|c|c|c|c|c|}
\hline \multirow[b]{2}{*}{ WCC } & \multicolumn{2}{|c|}{$\begin{array}{l}\text { Filter paper } \\
k\left(\text { day }^{-1}\right)\end{array}$} & \multicolumn{2}{|l|}{$\begin{array}{l}\text { Bamboo } \\
k\left(\text { day }^{-1}\right)\end{array}$} & \multicolumn{2}{|c|}{$\begin{array}{l}\text { Green tea } \\
k\left(\text { day }^{-1}\right)\end{array}$} & \multicolumn{2}{|c|}{$\begin{array}{l}\text { Rooibos tea } \\
k\left(\text { day }^{-1}\right)\end{array}$} \\
\hline & Mean & SE & Mean & SE & Mean & SE & Mean & SE \\
\hline Fallow & $0.0106^{\mathrm{b}}$ & 0.0023 & 0.00079 & 0.00002 & $0.0162^{1}$ & 0.0004 & $0.0050^{c}$ & 0.0001 \\
\hline Lolium & $0.0147^{\mathrm{ab}}$ & 0.0032 & 0.00077 & 0.00002 & $0.0152^{1}$ & 0.0004 & $0.0051^{\mathrm{c}}$ & 0.0002 \\
\hline Trifolium & $0.0190^{\mathrm{ab}}$ & 0.0034 & 0.00086 & 0.00003 & $0.0160^{1}$ & 0.0006 & $0.0055^{c}$ & 0.0002 \\
\hline$L+T$ & $0.0149^{a b}$ & 0.0030 & 0.00077 & 0.00002 & $0.0155^{1}$ & 0.0003 & $0.0053^{c}$ & 0.0001 \\
\hline Raphanus & $0.0255^{\mathrm{a}}$ & 0.0030 & 0.00092 & 0.00005 & $0.0151^{1}$ & 0.0006 & $0.0063^{\mathrm{a}}$ & 0.0002 \\
\hline Vicia & $0.0188^{\mathrm{ab}}$ & 0.0039 & 0.00078 & 0.00002 & $0.0158^{1}$ & 0.0005 & $0.0054^{\mathrm{bc}}$ & 0.0003 \\
\hline$R+V$ & $0.0226^{\mathrm{a}}$ & 0.0028 & 0.00079 & 0.00002 & $0.0143^{1}$ & 0.0002 & $0.0062^{a}$ & 0.0002 \\
\hline \multicolumn{9}{|l|}{ S14 } \\
\hline Avena & $0.0132^{\mathrm{b}}$ & 0.0016 & 0.00083 & 0.00002 & 0.0155 & 0.0003 & $0.0055^{1}$ & 0.0001 \\
\hline Cichorium & $0.0188^{a}$ & 0.0017 & 0.00079 & 0.00001 & 0.0154 & 0.0003 & $0.0057^{1}$ & 0.0001 \\
\hline \multicolumn{9}{|l|}{ S15 } \\
\hline Avena & 0.0174 & 0.0017 & $0.00077^{b}$ & 0.00002 & $0.0146^{1}$ & 0.0002 & $0.0051^{1}$ & 0.0001 \\
\hline Cichorium & 0.0188 & 0.0018 & $0.00085^{\mathrm{a}}$ & 0.00002 & $0.0163^{1}$ & 0.0002 & $0.0061^{1}$ & 0.0001 \\
\hline \multicolumn{9}{|c|}{ Model specification } \\
\hline S14 & $\begin{array}{l}\mathrm{F}_{1,126} \\
\mathrm{P}\end{array}$ & $\begin{array}{l}20.59 \\
<0.000 \\
1\end{array}$ & - & - & - & - & $\begin{array}{l}\mathrm{F}_{1,125} \\
\mathrm{P}\end{array}$ & $\begin{array}{l}1.78 \\
0.1848\end{array}$ \\
\hline WCC & $\begin{array}{l}\mathrm{F}_{6,126} \\
\mathrm{P}\end{array}$ & $\begin{array}{l}3.20 \\
0.0058\end{array}$ & - & - & $\begin{array}{l}F_{6,121} \\
P\end{array}$ & $\begin{array}{l}4.11 \\
0.0009\end{array}$ & $\begin{array}{l}\mathrm{F}_{6,125} \\
\mathrm{P}\end{array}$ & $\begin{array}{l}9.17 \\
<0.0001\end{array}$ \\
\hline S15 & - & - & $\begin{array}{l}\mathrm{F}_{1,131} \\
\mathrm{P}\end{array}$ & $\begin{array}{l}35.83 \\
<0.0001\end{array}$ & $\begin{array}{l}\mathrm{F}_{1,121} \\
\mathrm{P}\end{array}$ & $\begin{array}{l}27.57 \\
<0.0001\end{array}$ & $\begin{array}{l}\mathrm{F}_{1,125} \\
\mathrm{P}\end{array}$ & $\begin{array}{l}66.69 \\
<0.0001\end{array}$ \\
\hline S14*WCC & - & - & - & - & - & - & - & - \\
\hline $\mathrm{S} 14^{*} \mathrm{~S} 15$ & - & - & - & - & - & - & $\begin{array}{l}\mathrm{F}_{1,125} \\
\mathrm{P}\end{array}$ & $\begin{array}{l}4.97 \\
0.0276\end{array}$ \\
\hline WCC*S15 & - & - & - & - & $\begin{array}{l}\mathrm{F}_{6,121} \\
\mathrm{P}\end{array}$ & $\begin{array}{l}2.28 \\
0.0403\end{array}$ & - & - \\
\hline $\mathrm{N}$ & 138 & & 137 & & 139 & & 139 & \\
\hline
\end{tabular}

1) For Green tea and Rooibos tea see Fig. S2 for pairwise comparisons of significant interaction terms. 

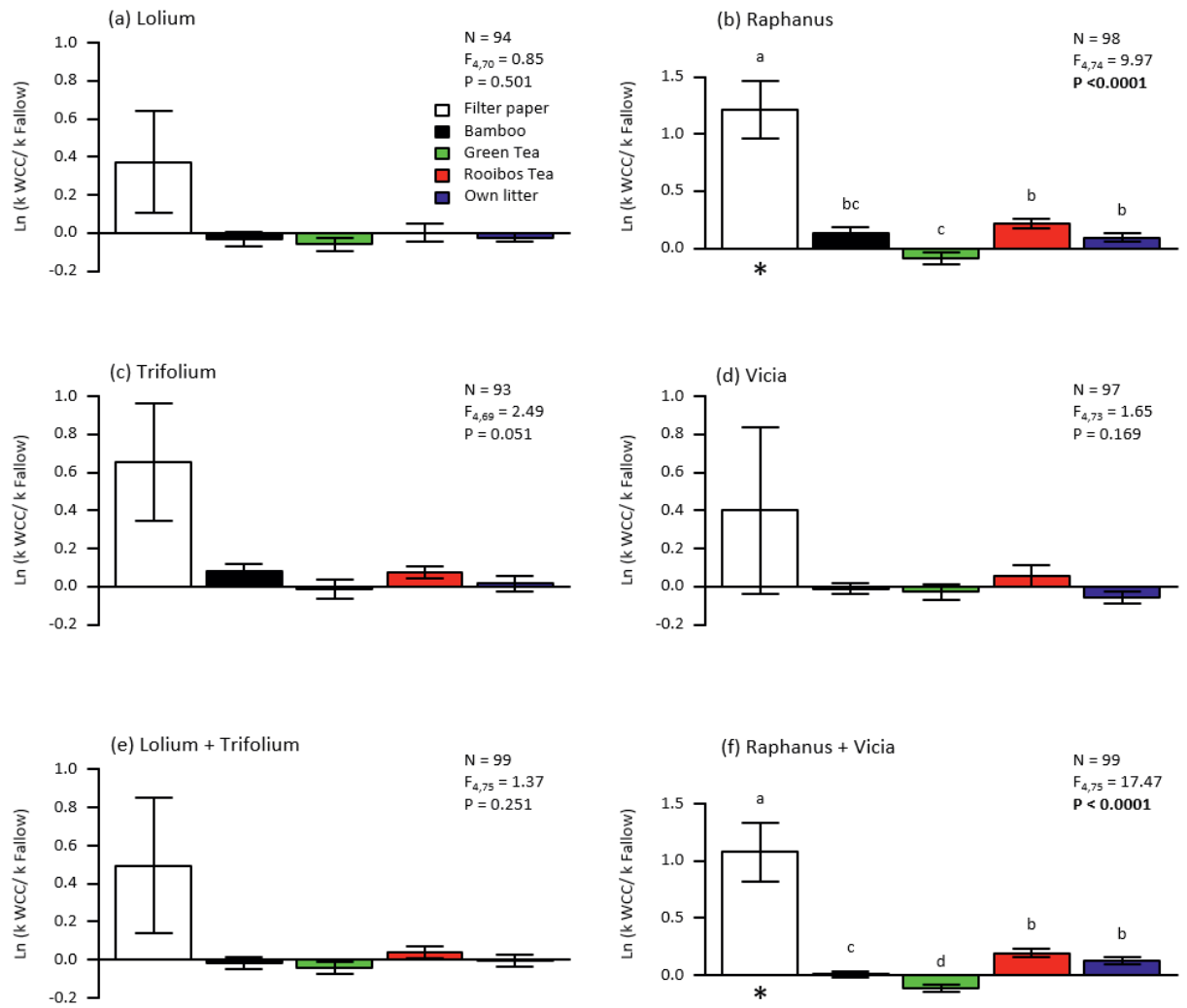

Figure 3.3 WCC legacy effect on decomposition rates of standard substrates and own litter incubated in indicated WCC plot compared to incubation in winter fallow plots. Positive values indicate higher decomposition rate $(k)$ in WCC field than in fallow, and vice versa. Note, $\mathrm{y}$-axis scaled differently for readability. Mean relative effects \pm SE. Different letters indicate significant difference between litters based on Tukey post-hoc test. * Indicates significant difference from zero.

To pinpoint the underlying mechanisms, we tested how decomposition drivers (abiotic and biotic soil properties and WCC residue characteristics) influenced decomposition rates of filter paper and rooibos tea across all plots with a WCC legacy (fallow plots excluded), as filter paper and rooibos tea displayed most pronounced WCC legacy effects. Effects of preceding main cropping treatments on filter paper decomposition and current main cropping on rooibos decomposition were considered separately. Filter paper decomposition incubated in former Avena plots was significantly influenced by WCC residue characteristics (Table 3.6). Both WCC biomass and litter turn-over (i.e. $k$ in winter fallow plots) promoted filter paper decomposition. Paper incubated in former Cichorium plots was influenced by fungal biomass. Furthermore, rooibos decomposition in current Avena plots was stimulated by WCC biomass, whereas decomposition in presence of 
Cichorium was promoted by the combined effect of WCC biomass and ergosterol concentrations. Filter paper nor rooibos decomposition rates were related to any of the abiotic soil properties.

T a b l e 3.6 Final multiple linear mixed regression models for decomposition rates $(k)$ of filter paper and rooibos tea as function of decomposition drivers.

\begin{tabular}{lllllll}
\hline \hline Paper & slope & SE & df & F & P & $\mathrm{R}^{2}$ marginal \\
\hline Avena '14* & & & & & & \\
$\quad$ WCC biomass & 0.0022 & 0.001 & 1,49 & 8.34 & $\mathbf{0 . 0 0 5 7}$ & 0.210 \\
$\quad$ WCC kfallow & 75.433 & 28.005 & 1,49 & 7.26 & $\mathbf{0 . 0 0 9 7}$ & \\
Cichorium '14 & & & & & & \\
$\quad$ Fungal Bm & -0.136 & 0.063 & 1,46 & 12.19 & $\mathbf{0 . 0 0 1 1}$ & 0.326 \\
$\quad$ Ergosterol & 0.031 & 0.013 & 1,46 & 8.01 & $\mathbf{0 . 0 0 6 9}$ & \\
F:B & 3.397 & 1.165 & 1,46 & 3.92 & 0.0538 & \\
PC1 & -0.053 & 0.023 & 1,46 & 5.49 & 0.235 & \\
& & & & & & \\
Rooibos & slope & SE & df & F & P & $\mathrm{R}^{2}$ marginal \\
\hline Avena '15 & & & & & & \\
$\quad$ WCC biomass & $2.06^{*} 10^{-6}$ & $0.67^{*} 10^{-6}$ & 1,53 & 9.577 & $\mathbf{0 . 0 0 3 1}$ & 0.142 \\
Cichorium '15 & & & & & & \\
$\quad$ WCC biomass & $2.58^{*} 10^{-6}$ & $0.92^{*} 10^{-6}$ & 1,50 & 11.8211 & $\mathbf{0 . 0 0 1 2}$ & 0.229 \\
$\quad$ Ergosterol & 0.00181 & 0.000815 & 1,50 & 4.9325 & $\mathbf{0 . 0 3 0 9}$ & \\
\hline \hline
\end{tabular}

* NOTE, $k$ for paper incubated in former Avena plots were ln transformed. 


\subsection{Discussion}

Litter decomposition is influenced by litter quality and soil biotic and abiotic conditions (Cornwell et al. 2008; Austin et al. 2014; Bradford et al. 2016). Answering the question how sequential plant occupation of a soil patch influences litter decomposition is essential for carbon and nutrient management. Here, we discuss how winter cover crop (WCC) legacies influence decomposition drivers, and how decomposition is affected during the growing season following WCC residue incorporation.

\subsubsection{WCC litter quality and decomposition}

Litters with low C:N ratios usually decompose fast, as do litters with low lignin concentrations (Palm et al. 2001; Freschet, Aerts \& Cornelissen 2012b). We found that WCC decomposition rates related negatively with lignin, $\mathrm{C}$, and surprisingly also $\mathrm{N}$ concentrations. According to plant-economic spectrum theory (Cornwell et al. 2008), fastgrowing plants are expected to have high $\mathrm{N}$ concentrations and low levels of structural compounds, such as lignin. However, our legume litters showed high lignin as well as high $\mathrm{N}$ concentrations. Legumes have higher lignin concentrations compared to grasses (Cherney et al. 1988), grain and mustard cover crops (Ramirez-Garcia et al. 2015). The high legumes representation in our species pool contributed to the negative correlation between litter $\mathrm{N}$ concentration and decomposition rates.

We collected WCC litters as aboveground biomass in December, whereas in practice WCC residues include roots and are incorporated into the soil in February. Inevitably, the residue quality that actually entered the soil will vary from the presented litter quality but is expected to differ in a coordinated fashion across the WCC treatments (Freschet et al. 2010). Therefore, our litter quality should be interpreted as an approximation.

\subsubsection{Legacy effects on local abiotic and biotic conditions}

The history of main crops and especially WCCs created varying start conditions for the litter decomposition experiment. Changes in soil mineral $\mathrm{N}$ and potential $\mathrm{N}$ mineralisation result from $\mathrm{N}$ uptake and mineralisation during the WCC growing season and shortly after incorporation. Especially Raphanus productivity contributed to an elevated soil $\mathrm{N}$ pool (Barel et al. 2018) which may be attributed to high level of $\mathrm{N}$ scavenging, productivity and rooting depth (Thorup-Kristensen, Magid \& Jensen 2003). Preceding main crop induced little differences in abiotic conditions except in soil $\mathrm{pH}$, which was slightly higher in preceding Avena compared to Cichorium plots. We consider this slight difference as inconsequential. 
Plant legacies can also alter microbial biomass and community composition. Overall, our fungal biomass was lower compared to Hedlund (2002), whereas bacterial biomass in our soils was somewhat higher. Low fungal biomass could result from regular soil disturbance typical for agriculture (Stahl, Parkin \& Christensen 1999). Nevertheless, our microbial biomass (bacterial and fungal PLFA markers) and ergosterol concentrations supported our expectation to rank with WCC biomass input. Microbial biomass values were highest for Raphanus, Vicia and $R+V$, consistent with their aboveground biomass (Barel et al. 2018). Partial senescence of Vicia plants early in winter could have stimulated the microbial community differentially from other WCCs. Moreover, Avena residues likely have a higher $\mathrm{C}: \mathrm{N}$ ratio than Cichorium, which could stimulate saprotrophic-fungal biomass. Indeed, fungal PLFA concentrations and F:B ratio were higher in preceding Avena than in preceding Cichorium plots.

Additionally, we tested for rotation legacy effects on the microbial community composition by PLFA analysis. Community differences were mostly driven by PLFA 16:0, strongly associated with PCA axis 1 . This straight-chained PLFA, also known as palmitic acid, is a frequently occurring lipid of divers origin (Ruess \& Chamberlain 2010). Contrasting to our hypothesis, rotation history did not significantly influence microbial community composition. Instead, SOM and soil mineral $\mathrm{N}$ were significant predictors, indicating that changes in abiotic and biotic soil conditions go hand-in-hand. WCC treatments and to a lesser extend previous main crop treatments affected soil microbial biomass directly and could indirectly influence microbial community composition through legacy effects on abiotic soil properties. Although PLFA analysis is a well-established method for the quantification of broad functional microbial groups, it is less sensitive to changes in community composition compared to techniques for measuring taxonomic diversity (e.g. high-throughput sequencing). Therefore, small shifts in community composition could have been missed, which could signify long term changes (Chavarría et al. 2016; Brennan \& Acosta-Martinez 2017).

\subsubsection{WCC legacy effects on decomposition}

Home-field advantage (HFA) literature proposes that home-incubated litters decompose faster due to adaptation of the local soil community. Recalcitrant litters should benefit most from home-incubation, as decomposition of these litters require a more specialised decomposer community (Wallenstein et al. 2013). Conversely, our results suggest a stimulation of decomposition in plots with easily decomposable WCCs, as rates of fastdecomposing WCC litters tended to be enhanced when decomposing in their home-plot. This stimulation appeared to be non-specific as WCC legacies also influenced decomposition rates of newly added standard substrates of different qualities. Relative to fallow, Raphanus and Raphanus+Vicia legacies stimulated decomposition of standard 
substrates filter paper and rooibos tea, even more so than of the home-litters. In other words, the magnitude of legacy effects depends on the identity of the WCC leaving the legacy as well as the substrate quality. The stimulation of filter paper decomposition rather than home-litter decomposition suggests that WCC legacy effects on decomposition did not rely on specific adaptation of the local soil community to home litters and are the result of increased overall abundance and/or activity of the saprotrophic microbial community. In natural ecosystems, HFA varies in both strength and direction (Veen et al. 2015). For specialisation of the decomposer community to occur a clear 'litter quality' signal is required (Ayres et al. 2009; Freschet, Aerts \& Cornelissen 2012a; Veen et al. 2015). In agricultural systems temporal diversification through crop rotation likely increases the diversity of litters thereby promoting general activity of decomposers rather than selecting for specialised saprotrophic microbes (McDaniel et al. 2014; McDaniel et al. 2016).

The underlying mechanisms of WCC induced stimulation of decomposition were explored by regressing WCC litter characteristics, soil biotic and abiotic conditions to filter paper and rooibos tea decomposition. WCC residue biomass and inherent turn-over rate as well as microbial biomass and community composition could be main mechanisms through which (cover) crop legacies acts upon decomposition of organic substrates. Crop residue quality and microbial community could explain the observed preceding main crop effects on WCC and filter paper decomposition. Decomposition of cellulose in filter paper is primarily limited by $\mathrm{N}$ availability. Remaining low quality crop residues (e.g. preceding Avena) possibly immobilised N (Parton et al. 2007), thus restricting paper decomposition. Alternatively, WCC litters had much lower C:N ratios than cellulose and instead benefited from the higher microbial biomass in former Avena plots. Experimental manipulation of microbial biomass and nitrogen availability are recommended to provide a causal test of our findings.

Furthermore, the current main crops influenced decomposition of WCC litters, bamboo, green- and rooibos tea. Present plants can decrease decomposition by offering preferred resources (Saar et al. 2016), or by competing for nitrogen (Bek 1994). Additionally, effects of main crop presence on decomposition can be due to microclimatic differences (see Supplementary Information). Despite irrigation, current Avena plots had a lower soil moisture content than Cichorium plots during the second half of the experiment, probably reducing decomposition (Prescott 2010). The main crop influence on decomposition illustrates that success of soil fertility management with WCCs depends on the context of the whole rotation. How the dynamics of WCC litter decomposition and mineralisation synchronise with the nutrient demands of subsequent crops, and how WCC litter decomposition contributes to the build-up of soil organic matter over time are topics for further study. 


\subsubsection{Conclusions}

Carbon and nutrient cycling in agroecosystems differ from natural systems because of increased disturbances and high nutrient supply. Here, we show that the choice of WCC in crop rotation influences decomposition of both own and newly added organic residues. This effect is generated directly via the quantity and quality of WCC residues, as productive WCCs with labile litters can potentially form positive litter feedback loops through the general stimulation of the microbial community. Additionally, WCC that increase fungal biomass promote decomposition. Indirectly, WCC can mediated changes in SOM and soil mineral $\mathrm{N}$ which, in turn, influence the soil microbial community composition. Inclusion of WCC in rotation designs, offers scope for management of carbon and nutrient cycling in agricultural systems, through WCC litter feedbacks. Furthermore, assessment of temporal nutrient cycling dynamics during the growing season can benefit from information on crop residue quantity and quality as well as general decomposer activity.

\subsection{Acknowledgements}

We thank Henk Martens for PLFA-analysis, Dominika Piwcewicz, Elly Nijenhuis, Andreas Altinalmazis Kondylis, and Unifarm for practical support, Rob Broekman and Richard van Logtestijn for chemical analyses and Joost Keuskamp for constructive discussions, and two anonymous reviewers for their critical reflections. This work was supported by NWO-ALW VIDI to GBDD (grant no. 864.11003). The authors have no conflict of interest to declare. 


\section{Chapter 3 Supplementary Information}

\section{Additional methodological information}

Assessment of litter quality and abiotic soil properties

As reported in Barel et al. (2018), winter cover crop litter quality traits were determined on a ground subsample of dried biomass (Retsch MM 2000 ball grinder, Retsch Benelux VERDER NV, Aartselaar, Belgium). Plant carbon (C) and nitrogen (N) content were determined with a CHN analyser (LECO Corporation, St Joseph, Michigan, USA). Lignin concentration of WCC litter was measured according to (Poorter \& Villar 1997). A methanol chloroform extraction and subsequent hydrolysis in $3 \mathrm{M} \mathrm{HCl}$ was performed on ground litter material to remove all non-ligneous compounds. Litter lignin concentration is calculated based on the $\mathrm{CN}$ content of the dried residue.

Additional to soil $\mathrm{pH}$, percentage of soil organic matter (SOM) was determined as an abiotic soil property as loss on ignition ( 4 hours, $550^{\circ} \mathrm{C}$ ). Soil acidity was measured as $\mathrm{pH}-\mathrm{KCl}$ in a 1:5 (w/v) suspension of dry soil in $1 \mathrm{M} \mathrm{KCl}$. Soil mineral nitrogen $\left(\mathrm{NO}_{3}{ }^{-}+\mathrm{NH}_{4}{ }^{+}\right)$was measured after $\mathrm{KCl}(1 \mathrm{M})$ extraction on dried soil $\left(40^{\circ} \mathrm{C}\right)($ Keeney \& Nelson 1982). Potential $\mathrm{N}$ mineralisation comprised the $\mathrm{N}$ mineralised after three weeks of incubation of $10 \mathrm{~g}$ dry weight equivalent of fresh soil in plastic cups of $100 \mathrm{~mL}$ placed in a climate cabinet at $20^{\circ} \mathrm{C}$ and at $60 \%$ water holding capacity (water levels were adjusted regularly).

\section{Protocol Ergosterol extraction}

To determine the ergosterol concentration in the soil samples, one gram of fresh soil was mixed with $4 \mathrm{~mL}$ of $10 \% \mathrm{KOH}$ in methanol in $15 \mathrm{~mL}$ tubes (Greiner Bio-One, Frickenhausen, Germany). The samples were sonicated for $15 \mathrm{~min}$ at $47 \mathrm{kHz}$. Thereafter, the tubes were placed in a water bath for $90 \mathrm{~min}\left(70^{\circ} \mathrm{C}\right)$. One $\mathrm{mL}$ of Mili-Q water and $2 \mathrm{~mL}$ of $\mathrm{n}$-Hexane were added and mixed vigorously. Samples were centrifuged (4500 rpm, $10 \mathrm{~min}$ ) and $1 \mathrm{~mL}$ of the top phase transferred to small test tubes (VWR International, LLC, United States of America). Again, $1 \mathrm{~mL}$ of $\mathrm{n}$-Hexane was added to the Greiner tubes, centrifuged and topphase collected. Next, hexane was evaporated from the samples by placing the small test tubes in a water bath $\left(50^{\circ} \mathrm{C}\right)$ overnight. One $\mathrm{mL}$ of methanol was added and samples sonicated (4 min). After vortexing (30 sec), the solution was filtered (0.2 $\mu \mathrm{m}$ PTFE-syringe filter) and loaded for HPLC analysis. Ergosterol concentrations were corrected for soil moisture content. 
In order to control for possible soil temperature and moisture variation across the field experiment, data loggers were placed in the field. Daily average volumetric moisture content and soil temperature $(-6 \mathrm{~cm})$ were based on $15 \mathrm{~min}$ interval measurements with TMS-3 dataloggers (TOMST, Prague, Czech Republic), placed in former fallow plots during the litter incubation period. Twelve dataloggers were placed in all fallow plots in blocks 1 , 3 and 5, including both previous main crop treatments (Avena and Cichorium in S14) and current main crop treatments (Avena and Cichorium in S15). We were able to retrieve data from nine data loggers, three in current Avena and six in current Cichorium plots. Raw data were converted with the conversion tool (setting: sand $95 \%$, silt $4 \%$, clay $1 \%$ ) provided on the supplier's website. Variation in daily average soil volumetric moisture content and temperature over time was assessed with repeated-measures ANOVA, using R statistical software version 3.3.1 (R Core Team 2016) and package nlme (Pinheiro et al. 2016). We classified the duration of the experiment into two periods: before and after Cichorium planting.

\section{Additional results}

Soil moisture content and temperature

Volumetric moisture content varied with current crop and progression of the experiment ( $\mathrm{S} 15 \mathrm{~F}_{1,63}=1.29, \mathrm{P}=0.260$; Period: $\mathrm{F}_{1,63}=0.59, \mathrm{P}=0.447$; $\mathrm{S}_{15}$ Period $\mathrm{F}_{1,63}=115.31, \mathrm{P}<0.0001$ ). Before planting Cichorium, moisture content in Avena plots was somewhat higher than in Cichorium plots (Fig. S1a). After Cichorium had been planted, soil moisture was considerably lower in Avena plots than in Cichorium plots, despite regular irrigation. Mean daily temperature at $-6 \mathrm{~cm}$ depth was comparable for Avena and Cichorium cropping in the first half of the experiment. After planting Cichorium, soil temperature was higher in the Cichorium plots than Avena plots ( $\mathrm{S}_{15} \mathrm{~F}_{1,63}=26.60, \mathrm{P}<0.0001$; Period $\mathrm{F}_{1,63}=42.18, \mathrm{P}<0.0001$; $\mathrm{S}_{15}{ }^{*}$ Period $\mathrm{F}_{1,63}=40.40, \mathrm{P}<0.0001$; Fig.S1b). In other words, the choice of main crop affects soil microclimatic conditions. 

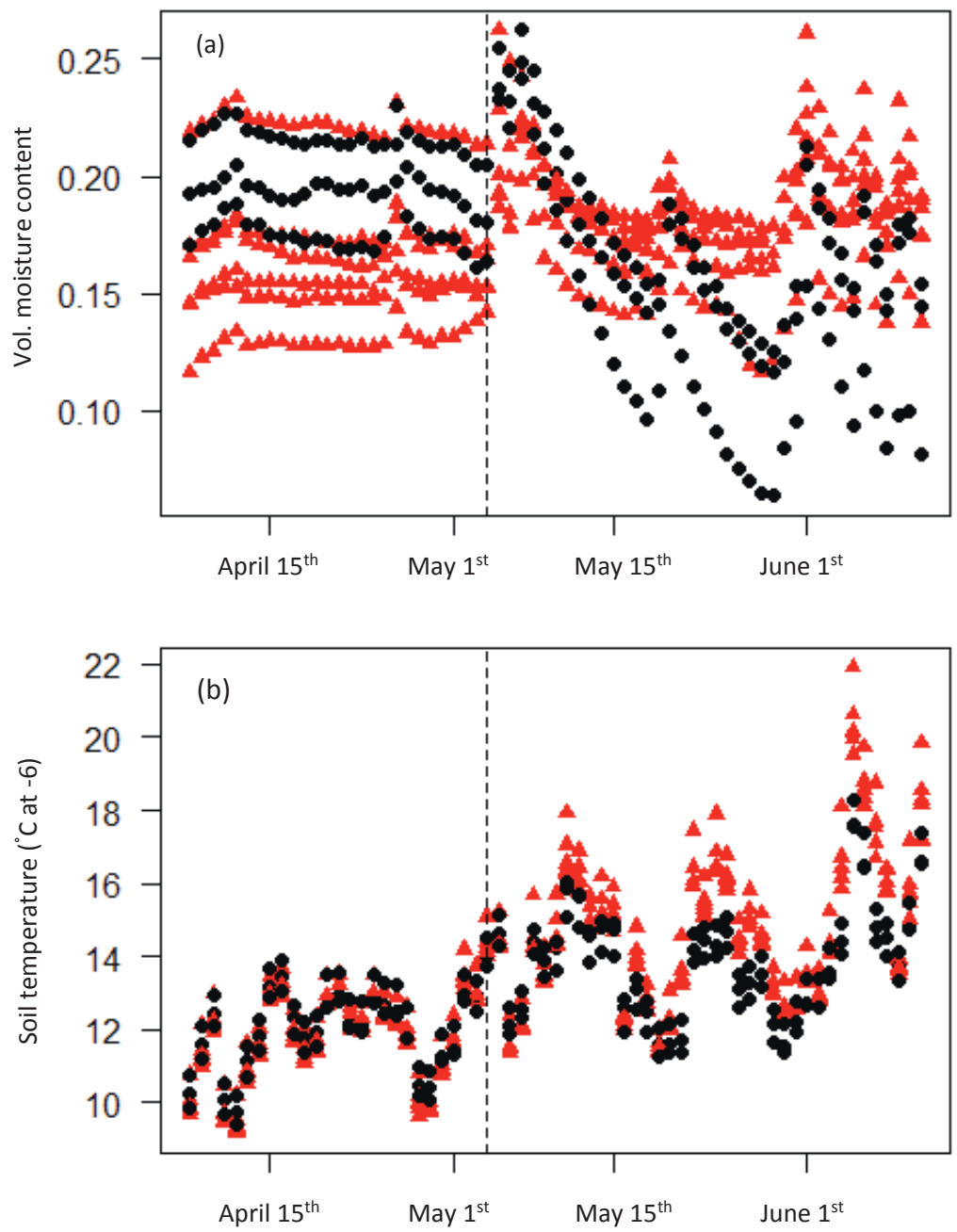

Date

Figure S 1 Volumetric moisture content(a) and soil temperature (b) in current Cichorium (red triangles) or current Avena (black circles) averaged per day per sensor $(n=9)$. Dashed line indicates planting date of Cichorium. 


\section{Winter cover crop litter traits}

T a b le S 1 Winter cover crop litter traits. Mean and standard error values are given by winter cover crop treatment (WCC) or previous main crop (S14). Statistics are given for final models per trait, all including W14 as main factor, block as random factor and a varIdent variance structure on W14. Different letters indicate significant differences $(\mathrm{P}<0.05)$ based on Tukey post-hoc. $\mathrm{N}=70$. Lolium + Trifolium $(\mathrm{L}+\mathrm{T})$ Raphanus+Vicia $(\mathrm{R}+\mathrm{V})$.

\begin{tabular}{|c|c|c|c|c|c|c|}
\hline \multirow[b]{2}{*}{ WCC } & \multicolumn{2}{|c|}{ Lignin $\left(\mathrm{mg} \mathrm{g}^{-1} \mathrm{dw}\right)$} & \multicolumn{2}{|c|}{ Nitrogen $\left(\mathrm{mg} \mathrm{g}^{-1} \mathrm{dw}\right)$} & \multicolumn{2}{|c|}{ Carbon $\left(\mathrm{mg} \mathrm{g}^{-1} \mathrm{dw}\right)$} \\
\hline & Mean & SE & Mean & SE & Mean & SE \\
\hline Lolium & $49.3^{\mathrm{b}}$ & 2.5 & $20.6^{\mathrm{d}}$ & 0.7 & $444.7^{a}$ & 1.9 \\
\hline Trifolium & $60.7^{\mathrm{ab}}$ & 6.9 & $40.0^{\mathrm{a}}$ & 0.9 & $440.0^{\mathrm{ab}}$ & 8.3 \\
\hline $\mathrm{L}+\mathrm{T}$ & $57.8^{\mathrm{ab}}$ & 9.6 & $26.3^{c}$ & 1.0 & $444.1^{\mathrm{ab}}$ & 4.7 \\
\hline Raphanus & $22.4^{\mathrm{c}}$ & 5.2 & $21.2^{\mathrm{d}}$ & 0.7 & $404.7^{\mathrm{d}}$ & 1.4 \\
\hline Vicia & $80.6^{\mathrm{a}}$ & 6.1 & $37.6^{\mathrm{ab}}$ & 1.2 & $453.6^{b}$ & 2.1 \\
\hline \multirow[t]{3}{*}{$\mathrm{R}+\mathrm{V}$} & $40.8^{\mathrm{bc}}$ & 4.6 & $32.9^{\mathrm{b}}$ & 2.1 & $415.7^{c}$ & 2.5 \\
\hline & $F_{5,62}$ & 11.69 & $\mathrm{~F}_{5,62}$ & 88.01 & $\mathrm{~F}_{5,62}$ & 107.60 \\
\hline & $\mathbf{P}$ & $<0.0001$ & $\mathbf{P}$ & $<0.0001$ & $\mathbf{P}$ & $<0.0001$ \\
\hline
\end{tabular}

T a b l e S 2 Correlations between winter cover crop traits. Pearsons $r$ given in lower triangle, with corresponding $\mathrm{P}$ values in italics in upper triangle.

\begin{tabular}{l|lll}
\hline \hline & Nitrogen & Carbon & Lignin \\
\hline Nitrogen & $\mathrm{x}$ & $\mathbf{0 . 0 0 3 3}$ & $\mathbf{0 . 0 0 0 8 6}$ \\
Carbon & 0.35 & $\mathrm{x}$ & $4.3 E-06$ \\
Lignin & 0.39 & 0.52 & $\mathrm{x}$ \\
\hline \hline
\end{tabular}


T a b l e S 3 Classification of phospholipid fatty acids (PLFA) and average amount found across all samples $(\mathrm{N}=137)$.

\begin{tabular}{|c|c|c|}
\hline & $\begin{array}{l}\text { PLFA content } \pm \text { SE } \\
(\mathrm{nmol} \mathrm{g-1} \mathrm{dw})\end{array}$ & Specification ${ }^{1}$ \\
\hline i14:0 & $0.248 \quad \pm 0.008$ & General $^{2}$ \\
\hline 14:0 & \pm 0.011 & General \\
\hline i15:0 & \pm 0.062 & Bacterial, Gram positive \\
\hline a15:0 & \pm 0.043 & Bacterial, Gram positive \\
\hline 15:0 & \pm 0.008 & Bacterial \\
\hline br16:0 & \pm 0.004 & General $^{2}$ \\
\hline i16:0 & \pm 0.022 & Bacterial, Gram positive \\
\hline $16: 1 \omega 9$ & \pm 0.017 & Bacterial \\
\hline $16: 1 \omega 7 \mathrm{c}$ & \pm 0.067 & Bacterial \\
\hline $16: 1 \omega 5$ & \pm 0.031 & General \\
\hline 16:0 & \pm 0.128 & General \\
\hline 10Me16:0 & \pm 0.032 & Sulphate reducing bacteria, Actinobacteria ${ }^{3}$ \\
\hline br17:0 & \pm 0.006 & General$^{2}$ \\
\hline i17:0 & \pm 0.004 & Bacterial, Gram positive \\
\hline a17:0 & \pm 0.006 & Bacterial, Gram positive \\
\hline cy17:0 & \pm 0.025 & Bacterial, Gram negative \\
\hline 17:0 & \pm 0.005 & Bacterial \\
\hline 10Me17:0 & \pm 0.002 & Sulphate reducing bacteria, Actinobacteria ${ }^{3}$ \\
\hline br18:0 & \pm 0.007 & General \\
\hline $18: 2 \omega 6$ & \pm 0.017 & Fungal, saprotrophic, ectomycorrhizal \\
\hline 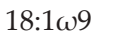 & \pm 0.043 & General \\
\hline $18: 1 \omega 7$ & \pm 0.062 & Bacterial, Gram negative ${ }^{4}$ \\
\hline 18:0 & \pm 0.023 & General \\
\hline 10Me18:0 & \pm 0.012 & Sulphate reducing bacteria, Actinobacteria ${ }^{3}$ \\
\hline су19:0 & \pm 0.032 & Bacterial, Gram negative \\
\hline 19:0 & \pm 0.006 & General \\
\hline 20:0 & \pm 0.008 & General \\
\hline
\end{tabular}

${ }^{1}$ Ruess and Chamberlain (2010), Frostegård and Bååth (1996); Hedlund (2002),

${ }^{2}$ Zelles (1999), ${ }^{3}$ Heijboer et al. (2016), ${ }^{4}$ Fanin, Hättenschwiler and Fromin (2014) 
Decomposition rates green tea and rooibos tea
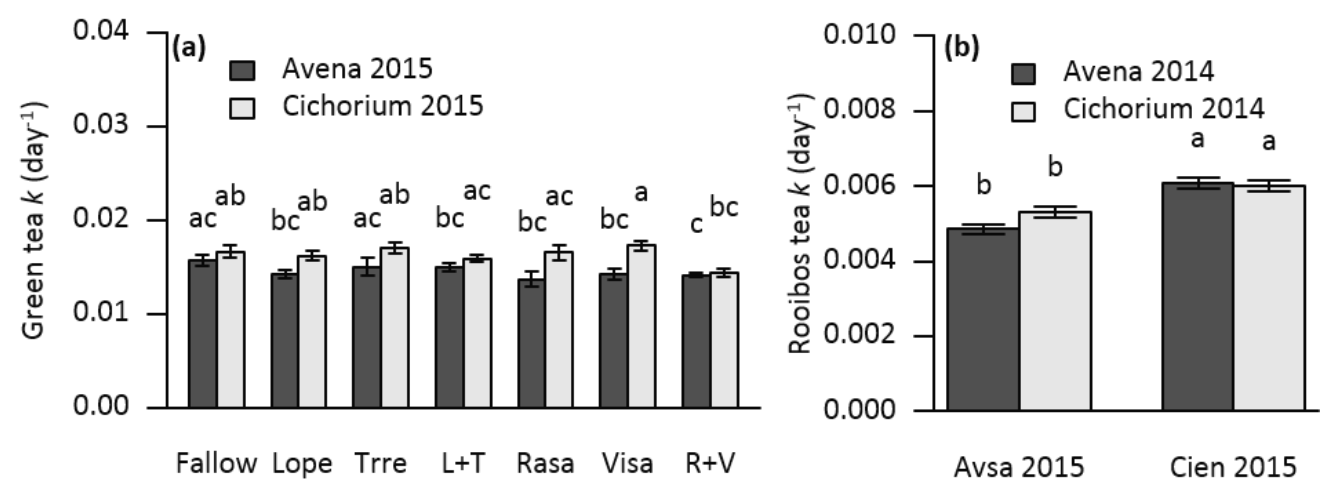

F i g u re S 2 Decomposition rates $(k) \pm S E$ of standard substrates green tea (a) and rooibos tea (b) for significant interaction terms presented in Table 5, in main manuscript. Green tea decomposition rates displayed as function of WCC treatments (see Fig.1 for abbreviations) and current main crops Avena (dark bars) and Cichorium (light). Rooibos decomposition rate in current main crop treatments Avena (left) and Cichorium (right) with a history of previous main crops Avena 2014 (dark) or Cichorium 2014 (light). Letters indicate $(\alpha \leq 0.05)$ difference based on Tukey post-hoc test. 


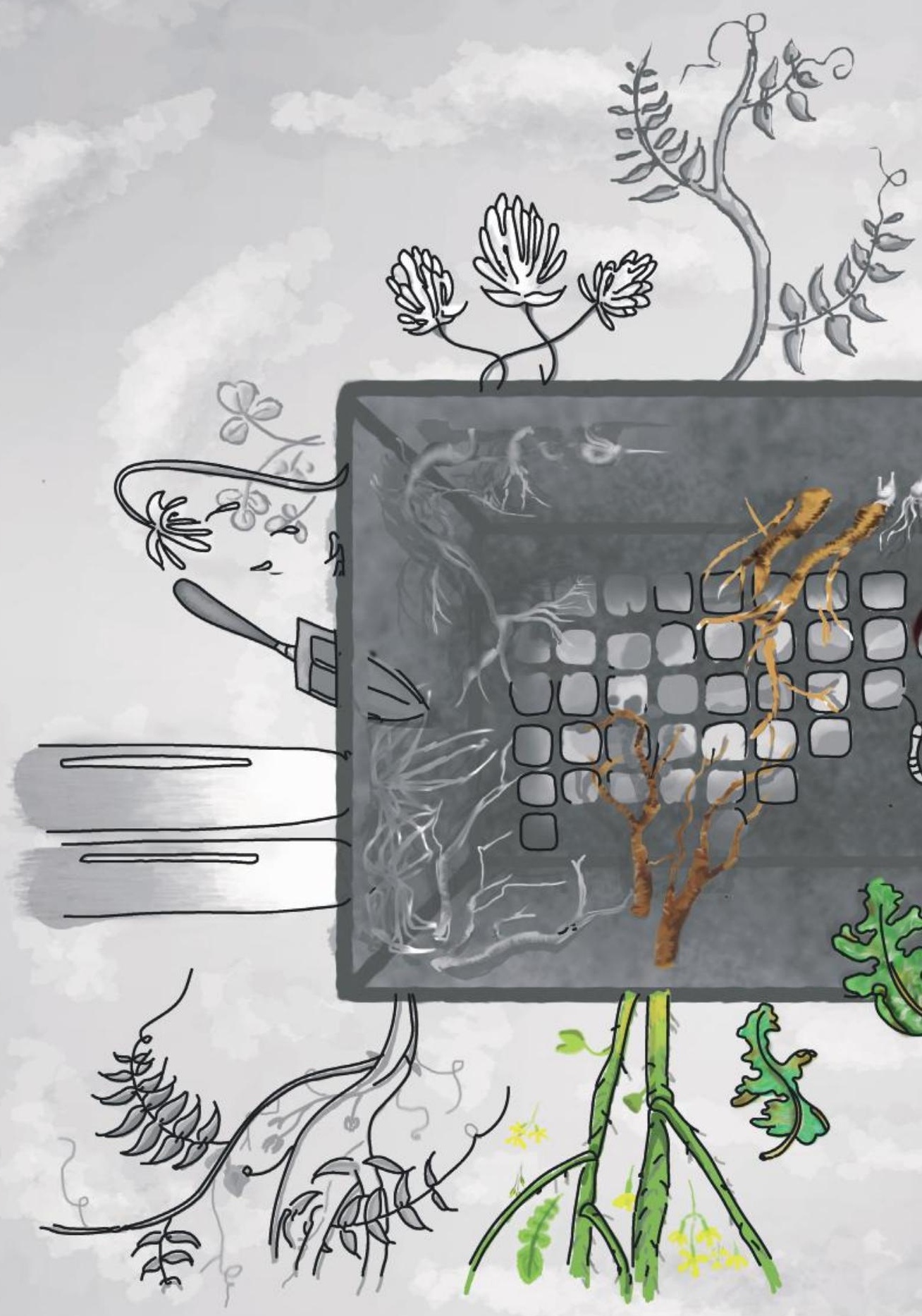




\subsection{Abstract}

Litter decomposition is a key process in carbon cycling and has been extensively studied for aboveground litter. However, root litter decomposition and the impact of living plants on litter decomposition rates remain largely unexplored. It can be expected that above- and belowground litter chemical traits and consequently their decomposition rate are coordinated, yet crop domestication may have weakened such coordination. Moreover, decomposition studies rarely quantify the influence of growing plants present in close vicinity of the decomposing litter, whereas priming literature demonstrated stimulating effects of plant presence on decomposition of soil organic matter. Here, trait coordination of crops and wild relatives is studied in relation to root and shoot decomposability. Also, the influence of plant presence on decomposition rates is tested.

For six pairs of crops and closely related natural grassland plants (two grasses, two legumes, two forbs) we tested i) whether chemical traits (N-, C- and lignin-concentration) and decomposition rates are coordinated between root and shoot in litters of crops and wild relatives and ii) whether plant presence stimulates litter decomposition rates. Root and shoot decomposability was measured by litterbag incubation in a greenhouse potexperiment in absence of a growing plant. Influence of plant presence was tested by incubating litterbags in presence of the same plant species as the litter species (own) or of two focal plants (a grass or forb) and compare decomposition rates with those in absence of a growing plant.

Except for litter lignin concentrations, chemical traits were coordinated in root and shoot litters, wherein crops had higher shoot $\mathrm{C}: \mathrm{N}$ ratios than wild relatives. Decomposability was likewise coordinated, with faster rates for shoots of crops than of wild relatives. Decomposition rate of shoots and roots correlated negatively with litter $\mathrm{C}$ and lignin, except for roots of crops which correlated negatively to litter $\mathrm{N}$.

Overall, plant presence suppressed litter decomposition, and this effect was strongest for root litters and in presence of a forb. Priming of crop root litter decomposition was positively related to litter $\mathrm{N}$ (suppression of decomposition rates were stronger for low $\mathrm{N}$ litter than for high N-litter). Priming effects on shoot and root litters of wild plants related negatively to litter decomposability (strongest reduction of decomposition rates in litters that easily decompose in plant absence). These priming effects can be understood in the light of microbial strategy types.

Not only do roots decompose slower than shoots but also the influence of plant presence is more negative than for decomposition of roots than for shoots. Therefore C-cycling by fresh litter decomposition might be slower than predicted based on shoots, especially in presence of a growing plant, with possible consequences for $\mathrm{N}$ mineralisation. These results are particularly relevant in agriculture systems where root biomass input is more important than shoot inputs. 


\subsection{Introduction}

Plant roots are a major contribution to C-cycling (Freschet et al. 2013; Jackson et al. 2017), but literature on root decomposition is scarce. Comparing root to shoot decomposition is highly relevant because significant coordination would make shoot decomposition a valuable proxy for root decomposition. However, root-shoot decomposition studies are often confounded by factors influencing the decomposition process, such as litter condition (comparing senesced leaves vs live roots), and incubation location (comparing surface incubation of leaves to buried incubation of roots) (Freschet et al. 2013). Even though there is a large body of literature suggesting that presence of growing plants can influence the breakdown of organic materials (Kuzyakov 2010; Huo, Luo \& Cheng 2017), plant influence on litter decomposition is rarely quantified. Testing whether root and shoot litters decompose predictably in presence of a growing plant fills an important knowledge gap in the understanding of $\mathrm{C}$ - and $\mathrm{N}$ cycling.

It is well-known that decomposition of plant litters is controlled by litter quality, along with abiotic and biotic environmental conditions (Swift, Heal \& Anderson 1978; Silver \& Miya 2001; Cornwell et al. 2008). Litter traits related to nutrient contents, such as nitrogen concentrations, are generally found to stimulate decomposition, while concentrations of structure-related compounds, such as $\mathrm{C}$ and lignin, relate negatively with decomposition rates (Vivanco \& Austin 2006; Cornwell et al. 2008; Zhang et al. 2008; Freschet, Aerts \& Cornelissen 2012b). Moreover, traits appear to be coordinated across organs of the same plant, e.g. plants with high N\%, C\% or lignin\% in leaves, also had high values in fine roots (Freschet et al. 2010). Even though literature on root traits is still scarce a relation between shoot and root traits can be expected as trait coordination among plant organs reflect a plant's nutrient-uptake strategy, also known as plant-economic spectrum (PES) ranging from nutrient conservative/slow-growing- to acquisitive/fast-growing plant types (Reich 2014). Indeed, pioneering studies showed that root decomposition appears to mirror shoot decomposition albeit they decompose at different rates (Vivanco \& Austin 2006; Birouste et al. 2012; Freschet, Aerts \& Cornelissen 2012b) with roots of grassland species decomposing 1.8 times slower than leaves (Freschet et al. 2013). When root decomposition did not reflect leaf decomposition also no trait coordination was found (Hobbie et al. 2010). Although these studies indicate that trait coordination underlies mirrored decomposition rates of root and shoots, these studies are confounded by factors such as differences in incubation location and litter preparation (as earlier mentioned), which stresses the need for a study testing trait coordination and decomposability of litters of similar condition in the same incubation environment.

Roots account up to $60 \%$ of primary productivity in grasslands (Jackson et al. 2017), and are estimated to represent 33\% of the average annual litter input (Freschet et al. 2013). In croplands, roots represent $10 \%$ of plant biomass production, of which $46 \% \mathrm{C}$ is retained in soil organic matter versus only $8 \%$ of aboveground $\mathrm{C}$ as most aboveground material is 
harvested while roots remain in soil (Jackson et al. 2017). Moreover, the use of cover crops in agriculture relies on decomposition of above- and belowground plant residues incorporated in soil to improve soil quality (Wagger, Cabrera \& Ranells 1998; ThorupKristensen, Magid \& Jensen 2003; Dias, Dukes \& Antunes 2014). Although chemical traits and decomposability of crop leaf litter is in line with PES theory, identifying crops as highly acquisitive plants with highly decomposable shoots (García-Palacios et al. 2013), it is unclear whether crop root traits and decomposability display similar responses to artificial selection. Domestication has selected for resource acquisitive plant traits (García-Palacios et al. 2013; Roucou et al. 2018), thus crops are expected to have higher litter $\mathrm{N}$ but lower litter $\mathrm{C}$ and lignin concentrations than their wild relatives. However, artificial selection in cropping systems also appears to have led to loss of coordination between above- and belowground traits (Milla et al. 2014; Roucou et al. 2018).

Another aspect often overlooked in litter decomposition studies is that of plant presence. Growing plants can alter decomposition rates of soil organic matter (SOM) (Kuzyakov 2010; Huo, Luo \& Cheng 2017), wherein stimulation of decomposition is referred to as positive priming, and suppression as negative priming (Bingeman, Varner \& Martin 1953). Positive priming can arise when plant rhizodeposits supply the decomposer community with a labile C-compounds, thus providing an energy-source to mine SOM for N. Mechanisms for negative priming are proposedly dependent on $\mathrm{N}$-availability. At low $\mathrm{N}$ availability, plants and decomposers might compete for $\mathrm{N}$, thus increasing decomposition, while at high $\mathrm{N}$ availability decomposers could prefer rhizodeposits as a C-source as there is no need to decompose organic matter for N (Dijkstra et al. 2013). Development of this theory is based on studies where priming effects of growing plants or fresh substrate additions are studied on decomposition of old SOM. Very few studies have focussed on the effect of plant presence on the decomposition of fresh plant litters, despite the relevance of exploring the extend of priming effects of plants on fresh litter decomposition for our understanding of $\mathrm{C}$ - and N-cycling.

Similar to priming effects on SOM, a growing plant provides the decomposers with rhizodeposits as a labile energy-source and can thereby stimulate litter decomposition. van der Krift et al. (2001a) reported increased decomposition and $\mathrm{N}$ mineralisation rates of grass root litters in presence of growing grasses. In another study monitoring of ${ }^{14} \mathrm{C}$-loss from labelled root litter confirmed positive priming effects of growing grasses on grass root decomposition rates (van der Krift, Kuikman \& Berendse 2002). Both studies found differences in priming effects between the different growing plant species and also between the litter species. Positive priming was also found for winter rye (Secale cereale), which stimulated ${ }^{14} \mathrm{C}$ mineralisation from rye straw (Cheng \& Coleman 1990). In contrast, mineralisation of ${ }^{14} \mathrm{C}$ from labelled straw was decreased in presence of a growing rape plant (Brassica napus), proposedly because of $\mathrm{N}$ competition between plant and decomposers (Bek 1994). Also, presence of white clover (Trifolium repens) had negative priming effects on nonlegume root litters, whereas the decomposition rate of the legume-root litters did not differ 
from unplanted controls (Saar et al. 2016). Additionally, the magnitude of the priming effect co-varied with the quality of the litter, with most negative priming effects for litter with low $\mathrm{N}$ - and P-concentrations (Saar et al. 2016). These studies suggest that priming effect on decomposing litter could vary with the present plant species, and with litter quality.

The objective of the current study is two-fold. Firstly, this research aims to assess how shoot and root litters of crops and wild relatives differ in chemical traits and decomposition rates. Secondly, this study examines the influence of growing plants on root and shoot litter decomposition and test the relationship with litter quality. Litters of six pairs of crops and closely related wild plants were incubated in absence and presence of growing plants to test the following hypotheses: 1) chemical traits of fresh litters of crops and wild relatives are coordinated between shoot and root, wherein crop litters have higher $\mathrm{N}$-concentrations, but lower C- and lignin concentrations than wild relatives; 2) decomposition rates of shoot and root litters incubated in the soil are coordinated, and correlate positively with litter Nand negatively with $\mathrm{C}$ - and lignin concentrations; 3) presence of a growing plant stimulates decomposition rates, with plant species identity having different overall priming effects and litter quality determining the magnitude of the priming effect. 


\subsection{Materials and methods}

\subsubsection{Litterbag preparation}

To prepare the plant litter six pairs of closely related crops and wild relatives (Table 4.1) were grown as individual plants in sandy soil under greenhouse conditions for ten weeks. In brief: seeds were surface sterilised with house hold bleach, and sown in autoclaved sand to germinate $\left(21: 19^{\circ} \mathrm{C}\right.$ day:night temperature, light regime of 16:8hrs L:D). After 2 weeks, seedlings were transplanted into $2 \mathrm{~L}$ pots $(18 \mathrm{~cm}$ height, $12 \mathrm{~cm}$ diameter) filled with sandy soil collected from a nearby agricultural field $\left(51^{\circ} 59^{\prime} 41.9^{\prime \prime} \mathrm{N}, 5^{\circ} 39^{\prime} 17.5^{\prime \prime} \mathrm{E}\right.$ (Barel et al. 2018)). The soil was sieved ( $8 \mathrm{~mm}$ diameter) and a part was sterilised by $\gamma$-radiation (Synergy Health Ede B.V., Ede, The Netherlands) and another part was kept as life soil to re-inoculate the sterilised soil with native soil microorganisms. The soil in which the plants for litter production were grown was a mix of 1:9 fresh soil (stored at $4^{\circ} \mathrm{C}$ ) and sterilised soil. This soil treatment was chosen as these plants served as control plants in an experiment in which plant-soil microbial community relations were studied. The soil used for the decomposition experiment was not sterilised (see below).

T a b l e 4.1 Overview of crops and closely related natural-grassland plant species used in the experiment assigned to one of six (near) congeneric plant pairs.

\begin{tabular}{|c|c|c|c|c|}
\hline \multirow{7}{*}{ 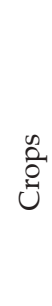 } & Pair & Family & Plant species & Common name \\
\hline & 1 & Poaceae & Avena sativa var. Dominik ${ }^{1}$ & Oat \\
\hline & 2 & Poaceae & Lolium perenne var. Mathilde ${ }^{1}$ & Perennial ryegrass \\
\hline & 3 & Fabaceae & Trifolium repens var. Alice ${ }^{1}$ & White clover \\
\hline & 4 & Fabaceae & Vicia sativa var. Ebena ${ }^{1}$ & Common vetch \\
\hline & 5 & Brassicaceae & Raphanus sativus var. Terranova ${ }^{2}$ & Fodder radish \\
\hline & 6 & Asteraceae & Cichorium endivia var. Nummer vijf2 ${ }^{3}$ & Endive \\
\hline \multirow{6}{*}{ 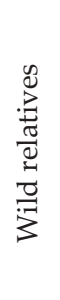 } & 1 & Poaceae & Arrhenatherum elatius 4 & False oat-grass \\
\hline & 2 & Poaceae & Festuca rubra ${ }^{4}$ & Red fescue \\
\hline & 3 & Fabaceae & Trifolium pratense 5 & (Wild) red clover \\
\hline & 4 & Fabaceae & Vicia cracca $^{4}$ & Tufted vetch \\
\hline & 5 & Brassicaceae & Raphanus raphanistrum ${ }^{5}$ & $\begin{array}{l}\text { Wild radish (jointed } \\
\text { charlock) }\end{array}$ \\
\hline & 6 & Asteraceae & Cichorium intybus ${ }^{5}$ & Common chicory \\
\hline
\end{tabular}

Sources of seeds: 1) AgriFirm Plant, Apeldoorn, NL, 2) J. Joordens' Zaadhandel B.V., Kessel, NL, 3) De Bolster, Epe, NL, 4) Emorsgate, Norfolk, UK, 5) Cruydt-Hoeck, Nijeberkoop, NL

Plants were grown for ten weeks under greenhouse conditions $\left(21: 16^{\circ} \mathrm{C}\right.$, ventilation cooled when $\left.>30^{\circ} \mathrm{C}, 16: 8 \mathrm{hrs} \mathrm{L}: \mathrm{D}\right)$ and soil moisture level of $60 \%$ maximum water holding capacity maintained by daily watering. To collect the above- and belowground plant litter shoots 
were cut at surface level, except for Raphanus plants which were cut at height of first cotyledons. Roots were rinsed to remove soil. Plant biomass was dried at $40^{\circ} \mathrm{C}$. The litter thus comprised freshly cut dried material rather than naturally senesced plant material as to standardise the litter collection, and because in many cropping systems the plant material that is returned to soil is not yet senesced. For each litter species four independent pools of litter were composed of two to five individual plants, such that paired shoot and root litters in this experiment originated from the same pool of plants. For shoot litter, flowers and seeds were omitted, as was the thick plant base of Raphanus species. For root litter only fine roots $(<2 \mathrm{~mm})$ were used. Litterbags were made of polyester fabric $(0.02 \mathrm{~mm}$ mesh size) sown into pockets of $5 \times 5 \mathrm{~cm}$. Each pocket was filled with $1 \mathrm{~g}$ dry litter cut to fragments of $1 \mathrm{~cm}$. For Avena sativa, Arrhenatherum elatius and Raphanus sp. $0.6 \mathrm{~g}$ of shoot and root litter was used, due to limited litter availability. The exact amount of dry litter in each bag was recorded. Litterbags were closed with three staples.

\subsubsection{Litter incubation and plant presence}

The decomposition experiment was executed under greenhouse conditions $\left(21: 16^{\circ} \mathrm{C}, 16: 8\right.$ hrs, L:D, March - May 2015 in Wageningen, The Netherlands), over the course of ten weeks. Fresh soil was collected at the aforementioned field in March 2015 and sieved ( $8 \mathrm{~mm}$ ). After filling the pots ( $2 \mathrm{~L}$ pots, $18 \mathrm{~cm}$ height, $12 \mathrm{~cm}$ diameter), the soil was brought to and maintained at $60 \%$ maximum water holding capacity by daily watering according to the required weight.

The effect of plant presence on litter decomposition was tested by incubating litters in pots with a present plant of the same species (own), or of two focal plants (grass or forb), or in absence of a plant (control). Focal plants for crop litters were Avena sativa (grass) and Cichorium endivia (forb). For wild litter species, Arrhenatherum elatius (grass) and Cichorium intybus (forb) were used. Note, Avena litters incubating in pots with growing Avena plants were considered as own-plant treatment as well as grass-focal plant. The experimental design thus included twelve no-plant, twelve own-plant, ten grass-focal plant and ten forbfocal plant treatments, and was replicated 4 times, resulting in 176 pots placed in the greenhouse in 4 randomised blocks. Before planting, seeds of all plant species were disinfected with household bleach (10\% solution 30 s), rinsed and sown in autoclaved sand. After two weeks, seedlings were transplanted, one individual per pot. Plants were grown for four more weeks until litterbags were inserted.

In each pot two litterbags were incubated, one with shoot and one with root litter. Litterbags were inserted vertically at $8 \mathrm{~cm}$ depth, both litterbags were placed at opposite sides between plant and pot wall. Litters were incubated for six weeks. At the end of the experiment, litterbags were collected and gently rinsed to remove adherent soil and roots. Litterbags were frozen at $-20^{\circ} \mathrm{C}$ and subsequently freeze dried (Alpha 1-4 LD Plus, Martin Christ 
Gefriertrocknungsanlagen GmbH, Osterode am Harz, Germany). Litterbags were opened, ingrown roots removed, and remaining litter dry weight determined.

\subsubsection{Litter traits measurements}

Litter nitrogen, carbon and lignin concentrations were measured to characterise the chemical quality of the litters. Analysis was done at the level of pools, thus for each litter species four observations were made resulting in $12 \times 4=48$ root and 48 shoot observations for each litter trait.

Dried litters were ground (MM2000 ball mill, Retsch Benelux VERDER NV, Aartselaar, Belgium). Ground material was analysed on a CHN analyser (LECO Corporation, St Joseph, Michigan, USA), to obtain litter $\mathrm{N}$ and C concentrations. Lignin concentrations were measured according to Poorter and Villar (1997), which is based on a methanol chloroform extraction followed by hydrolysis in $3 \mathrm{M} \mathrm{HCl}$, to remove all non-ligneous compounds (Freschet et al. 2010). The remaining residue, consisting of (hemi-)cellulose, proteins lignin and silicates, is dried for $48 \mathrm{hrs}$ at $70^{\circ} \mathrm{C}$, weighted and ground for $\mathrm{CN}$ analysis. Lignin concentration is calculated from the residue $\mathrm{C}$ and $\mathrm{N}$ concentrations. All litter N, C and lignin concentrations were corrected for ash-content. Ligninconcentrations of eight root samples (one V.sativa, three $R$. sativus, one A. sativa, three $L$. perenne samples) were found to be negative and were excluded from further data-analysis.

\subsubsection{Decomposition rate and priming calculations}

Litter decomposability and priming effects were based on litter decomposition rates. Decomposition rate $k\left(\right.$ day $\left.^{-1}\right)$ was calculated from fraction remaining mass ( $\left.f_{\text {rem }}\right)$ as a function of incubation duration ( $t$ (days)) (Olson 1963):

$f_{\text {rem }}=e^{-k t}$

Decomposability was defined as decomposition rate $k$ for litters decomposing in absence of a plant. Priming was quantified by taking the natural log of decomposition rate in presence of a plant $\left(k_{P_{\mathrm{i}}}\right)$ proportional to decomposition rate in absence of a plant $\left(k_{\mathrm{no}}\right)$ :

Priming $_{i}=\ln \left(k_{P_{i}} / k_{n o}\right)$

Positive priming implies faster decomposition in presence of a plant, negative priming entails slower decomposition in plant presence in comparison to decomposition in absence of a plant. 


\subsubsection{Statistical analysis}

All statistical analysis were performed in R, version 3.4.3 (R Core Team 2017), using the below-mentioned packages.

Coordination of trait values and decomposability among fresh shoot and root litters was tested with standardized major axis analysis (Warton et al. 2006), using smatr-package (Warton et al. 2012). Using the sma-function, the best line describing scatter of both $x$ (values for root litters) and y (values for shoot litters) variables was estimated and tested. Residuals of the model were inspected for normality with quantile plots. Litter C:N and decomposability were log-transformed. Differences between crops and wild relatives in slope, elevation, and shift of trait values along the same slope were tested for by standardised procedures (Warton et al. 2006). Correlations between litter decomposability and traits were tested as Spearman correlations, as were correlations among litter traits.

Influence of plant presence on litter decomposition was tested separately for crops and wild relatives, because crop litters decomposed in presence of crop plants, and wild litters in presence of wild plants. Linear mixed effects modelling was used to test whether primingeffects differed by litter species, litter type (root vs shoot) and identity of the present plant following the protocol by (Zuur, Ieno \& Elphick 2010), using the nlme-package (Pinheiro et al. 2016). Litter pool was included as random-factor. Appropriate variance structures were used to account for heteroscedasticity between strata. Optimisation of the full model ( plant ID * litter species * litter type) was done by backward-selection. Models were compared based on maximum likelihood ratio-tests. Residuals of the final model were tested for normality and homogeneity, with Kolmogorov-Smirnov test and Levene's test. Since litters from the same litter pool were used for incubation in the three plant-presence treatments, a conservative significance level was maintained: only terms with $\mathrm{P}<0.01$ were considered significant. Marginal $\mathrm{R}^{2}$ was calculated to inspect variance explained by the fixed-part of the models (Johnson 2014), using MuMIn-package (Barton 2017).

Next, the influence of litter properties instead of litter species was tested. First, litter properties (N, C, C:N, lignin and decomposability) were tested as explanatory variables in separate models, along with plant ID and litter type ( plant ID*litter property*litter type), according to the above protocol. Finally, full models selected by manually forward selecting significant litter properties from the single models, ranked by the variance explained. Again, a conservative significance level was maintained $(\alpha=0.01)$. 


\subsection{Results}

\subsubsection{Coordination litter traits for crops and wild relatives}

Chemical traits for root and shoot litter of crops and wild relatives displayed significant coordination, except for lignin concentrations (Fig. 4.1). Both N- and C-concentrations in root litters were positively related to concentrations in shoot litters. The curves crossed the 1:1 line (slopes $<1$ ); plant species with root litter with high $\mathrm{N}$ - and C-concentrations, had somewhat lower concentrations of $\mathrm{N}$ and $\mathrm{C}$ in their shoot litter and vice versa. Also, the standardised major axis for crop litter C-concentrations was shifted toward the lower end of the gradient $($ Wald $d f=1=8.32, \mathrm{P}=0.0039)$, compared to their wild relatives which had higher root and shoot litter C-concentrations. Crop shoot litter C:N ratio was found to be significantly higher than that of wild relative shoot litters (Wald $\mathrm{df}_{1=1}=5.46, \mathrm{P}=0.0194$ ). The estimate slope was $<1$ for similar for crops and wild relatives, thus the relationship between root and shoot C:N did not differ between crops and wild relatives. No significant relationship was found between root and shoot litter lignin concentrations.

Correlation between traits displayed that litter C:N ratios was determined by litter $\mathrm{N}$ concentration ( $r=-0.99$ or -1.00 , Table S1). Litter $\mathrm{C}$ and lignin almost always correlated positively ( $r=0.38$ to 0.76 ); in crop shoots, $\mathrm{N}$ - and $\mathrm{C}$ concentrations were positively correlated $(r=0.53)$.

\subsubsection{Decomposability of crop and wild relative litters}

Litter decomposability (i.e. decomposition in absence of a growing plant) of crops and wild relatives was coordinated significantly between roots and shoots (Fig. 4.2). At high shoot decomposability also root decomposability was high, with generally faster decomposition for shoot than root litters (above 1:1 line). Additionally, decomposability of shoot litter of crops was higher than of shoot litter of wild relatives, as standardised major axis analysis showed significant elevation of lines (Wald $\mathrm{df}_{1=1}=13.39, \mathrm{P}=0.0003$ ). Furthermore, the coordination of root and shoot decomposability was significant for wild relatives $(\mathrm{P}=0.0015)$, but only marginally significant $(\mathrm{P}=0.0718)$ for crops.

Correlations of root and shoot decomposability with litter traits were tested for both crops and wild relatives (Table 4.2). For both crops and wild relatives shoot decomposability was negatively related to litter $\mathrm{C}$ - and lignin-concentration. Root decomposability of crops correlated negatively with litter N-concentration, and positively with litter C:N. Root decomposability of wild relatives correlated negatively to litter C-concentration. 
(a) Nitrogen

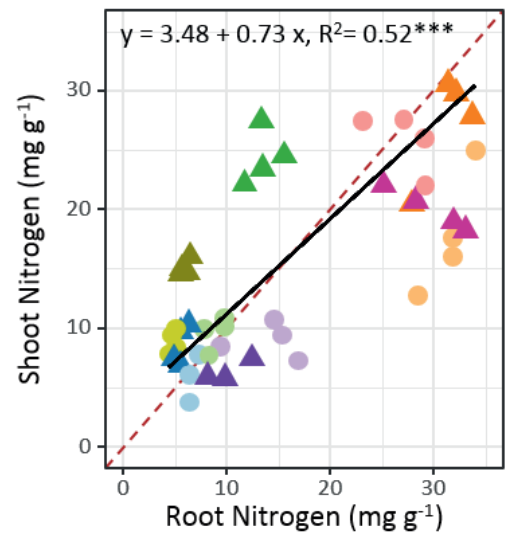

(c) $\mathrm{CN}$

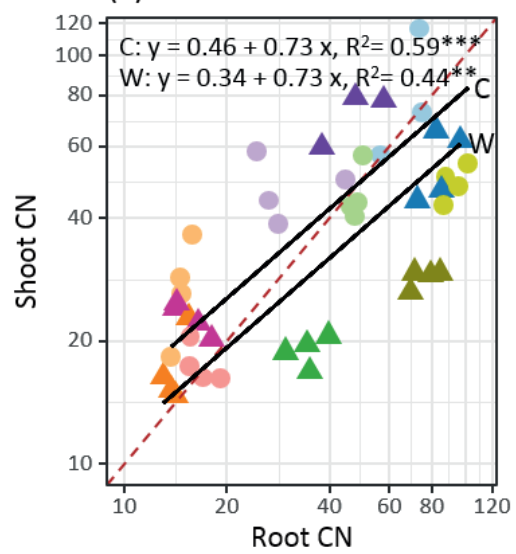

\section{(b) Carbon}

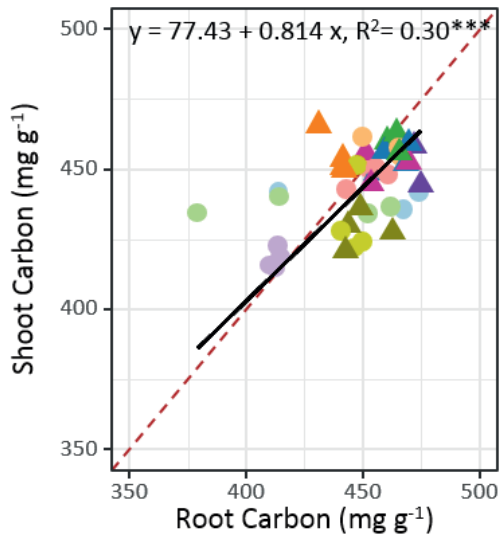

(d) Lignin

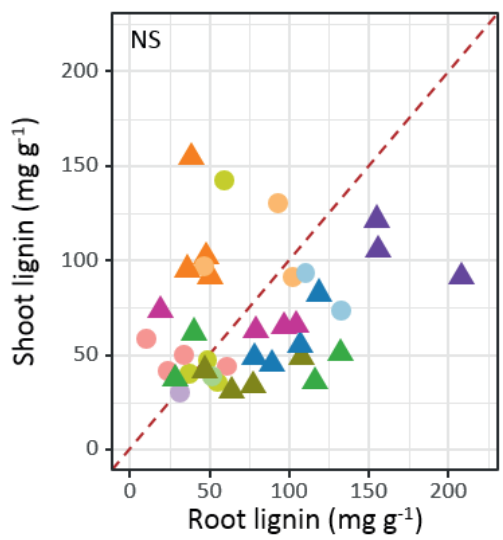

F i g u re 4.1 Standardize major axis regression between root and shoot litter traits nitrogen (a) and carbon concentration (b), C:N ratio (c), lignin concentration (d), for crop plants and wild relatives. Dashed red line indicates 1:1 line. ${ }^{* * *} \mathrm{P}<0.001,{ }^{* *} \mathrm{P}<0.01,{ }^{*} \mathrm{P}<0.05$. Note, axis in $\mathrm{c}$ are on log-scale.

\subsubsection{Influence plant presence on litter decomposition}

The effect of plant presence on litter decomposition rate in comparison to incubation in plant absence, or "priming effect", was tested separately for crops and wild relatives. Priming effect of crop presence on crop decomposition was influenced by the identity of the growing plant species $\left(\mathrm{F}_{2,120}=11.84, \mathrm{P}<0.0001\right)$ and by litter species $\left(\mathrm{F}_{5,120}=5.24, \mathrm{P}=0.0002\right)$. Moreover, priming effects were different for root and shoot litters (litter species*litter type: $\mathrm{F}_{5,120}=5.15, \mathrm{P}=0.0003$ ), although litter type (shoot or root) was not a significant main factor. Decomposition of shoot litters were not affected by the presence of own or grass-focal plant, 
but forb-presence resulted in negative priming effects. Particularly, decomposition of grass roots was negatively affected by plant presence.

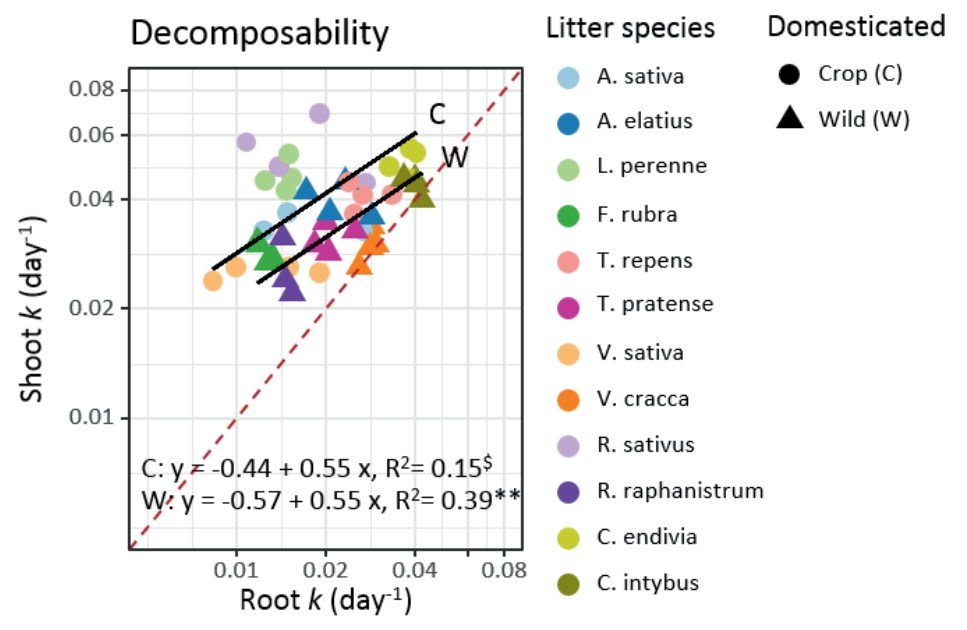

F i g u re 4.2 Standardize major axis regression between root and shoot litter decomposability, for crop plants and wild relatives. Dashed red line indicates 1:1 line. ${ }^{* *} \mathrm{P}<0.01, \$ \mathrm{P}<0.1$. Note, axes are on log-scale.

Table 4.2 Spearman correlation coefficients $(r)$ for crops and wild relatives, between shoot and root decomposability and their respective litter traits. ${ }^{* * *} \mathrm{P}<0.001,{ }^{* *} \mathrm{P}<0.01,{ }^{*} \mathrm{P}<0.05$

\begin{tabular}{|c|c|c|c|}
\hline \multicolumn{2}{|c|}{ Litter traits } & Shoot $k\left(\right.$ day $\left.^{-1}\right)$ & Root $k\left(\right.$ day $\left.^{-1}\right)$ \\
\hline \multirow{4}{*}{ 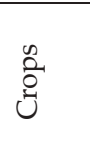 } & $\mathrm{N}$ & -0.27 & $-0.43^{*}$ \\
\hline & $\mathrm{C}$ & $-0.71^{* * *}$ & -0.06 \\
\hline & $\mathrm{C}: \mathrm{N}$ & 0.25 & $0.42^{*}$ \\
\hline & Lignin & $-0.60^{* *}$ & -0.33 \\
\hline \multirow{4}{*}{ 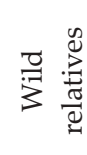 } & $\mathrm{N}$ & -0.27 & -0.15 \\
\hline & $\mathrm{C}$ & $-0.73^{* * *}$ & $-0.65^{* *}$ \\
\hline & C:N & 0.26 & 0.11 \\
\hline & Lignin & $-0.56^{* *}$ & -0.31 \\
\hline
\end{tabular}

Modelling the priming effect of crops as function of litter properties instead of litter species, litter $\mathrm{N}$ appeared to be a significant factor (Table 4.3), while litter decomposability or lignin concentrations were not. In addition to litter $\mathrm{N}$, litter $\mathrm{C}$ displayed a marginally significant effect $(\mathrm{P}<0.05)$ but was here regarded as non-significant $(\alpha=0.01)$. The priming effect on shoot litters was found unrelated to litter $\mathrm{N}$, but for root litters priming related positively to litter N (Fig. 4.3). 


\section{a) Crop shoots}

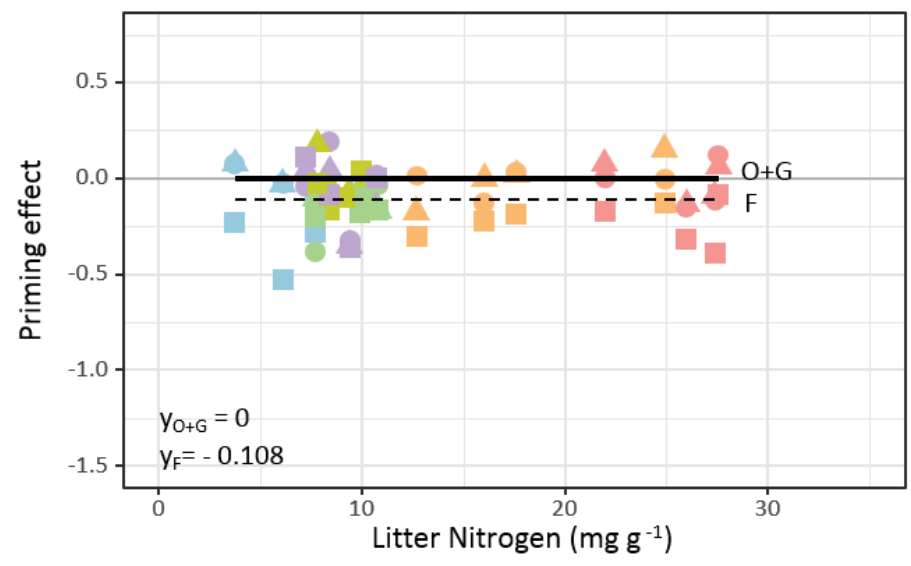

\section{Litter species}

A. sativa

L. perenne

T. repens

V. sativa

R. sativus

C. endivia

\section{Present plant ID}

- Own (O)

- Grass (G) - A. sativa

- Forb (F) - C. endivia

\section{b) Crops roots}

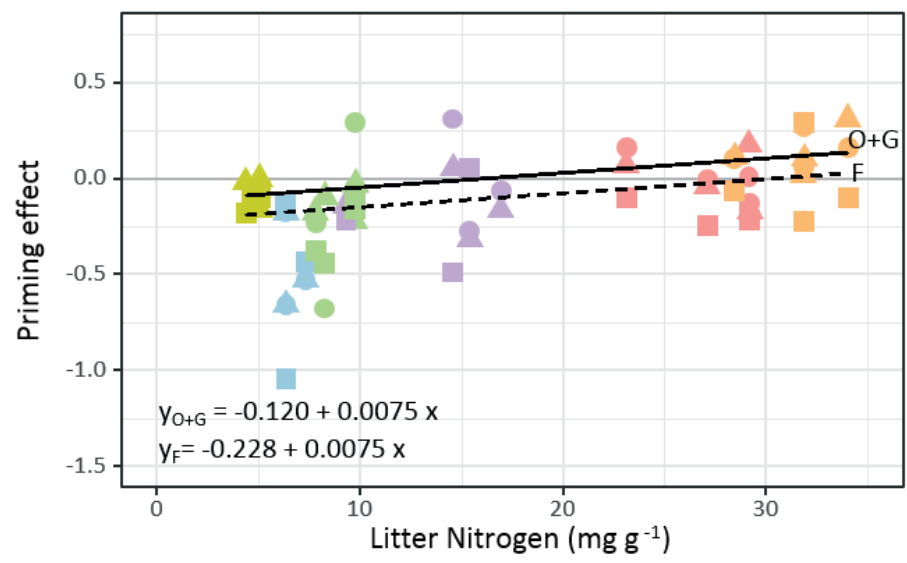

Figu re 4.3 Priming effect of presence of own-, grass- or forb-plants on shoot (a) or root (b) litters of crops in relation to litter $\mathrm{N}$-concentration, based on multiple-linear regression analysis.

Overall, priming effects of wild plants were negative, but differed only marginally between the different species of growing plants at a conservative significance level $\left(\mathrm{F}_{2,120}=4.53\right.$, $\mathrm{P}=0.0126, \alpha=0.01$ ). However, priming effects differed significantly between the litter species $\left(\mathrm{F}_{5,120}=9.09, \mathrm{P}<0.0001\right)$. Most negative priming was found for $A$. elatius litters and was neutral for $R$. raphanistrum to positive for F. rubra. No overall differences of litter type were observed, nor was the interaction between litter species and type significant. 
Ta b le 4.3 Results regression analysis modelling Priming effects by species of present plant (plant ID), litter properties (Litter N, Litter lignin, decomposability) and litter type (root or shoot). Bold values indicate significant terms $(\alpha=0.01)$.

\begin{tabular}{l|lll} 
& \multicolumn{3}{c}{ Crops $\left(\mathrm{R}^{2}\right.$ marginal $\left.=0.094\right)$} \\
& Df & $\mathrm{F}$ & $\mathrm{P}$ \\
\hline Plant ID & 2,128 & 11.20 & $<\mathbf{0 . 0 0 0 1}$ \\
Litter N & 1,128 & 8.82 & $\mathbf{0 . 0 0 3 6}$ \\
Litter type & 1,128 & 0.01 & 0.9388 \\
Litter & 1,128 & 7.93 & $\mathbf{0 . 0 0 5 6}$ \\
$\mathrm{N}^{*}$ type & & & \\
\hline \hline
\end{tabular}

\begin{tabular}{l|lll} 
& \multicolumn{3}{c}{ Wild relatives $\left(\mathrm{R}^{2}\right.$ marginal $\left.=0.301\right)$} \\
& Df & $\mathrm{F}$ & $\mathrm{P}$ \\
\hline Plant ID & 2,119 & 7.45 & $\mathbf{0 . 0 0 0 9}$ \\
Decomposability & 1,119 & 35.39 & $<\mathbf{0 . 0 0 0 1}$ \\
Litter lignin & 1,119 & 5.90 & 0.0167 \\
Litter type & 1,119 & 13.09 & $\mathbf{0 . 0 0 0 4}$
\end{tabular}

The optimal regression model explaining priming effects of wild plants included litter decomposability as a significant factor (Table 4.3), and litter lignin was marginally significant $(\mathrm{P}<0.05)$. Litter $\mathrm{C}$ nor litter $\mathrm{N}$ were significant factors. Litter decomposability negatively influenced priming of both shoot and root litter, but priming effects on root litters was more negative overall (Fig. 4.4). 
a) Wild shoots

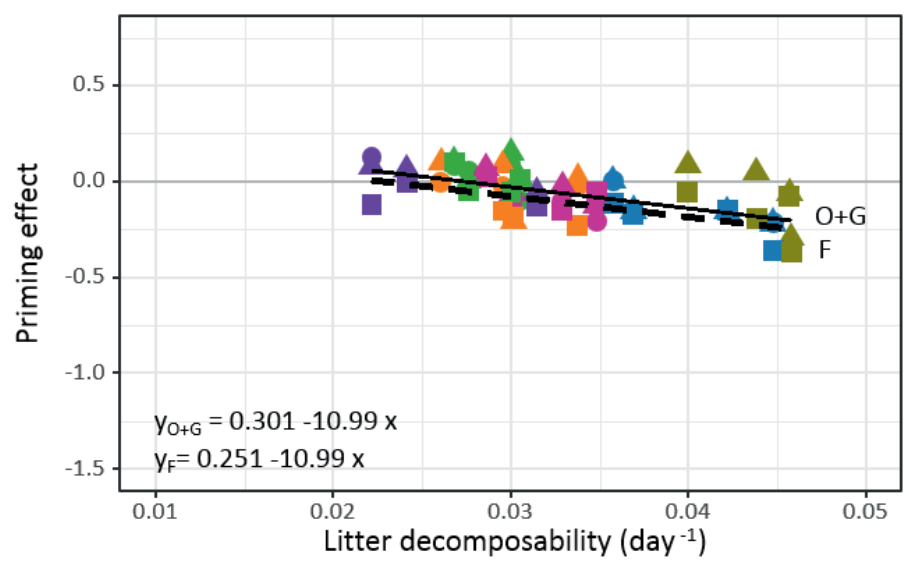

Litter species

- A. elatius

- F. rubra

- T. pratense

V. cracca

- R. raphanistrum

- C. intybus

b) Wild roots

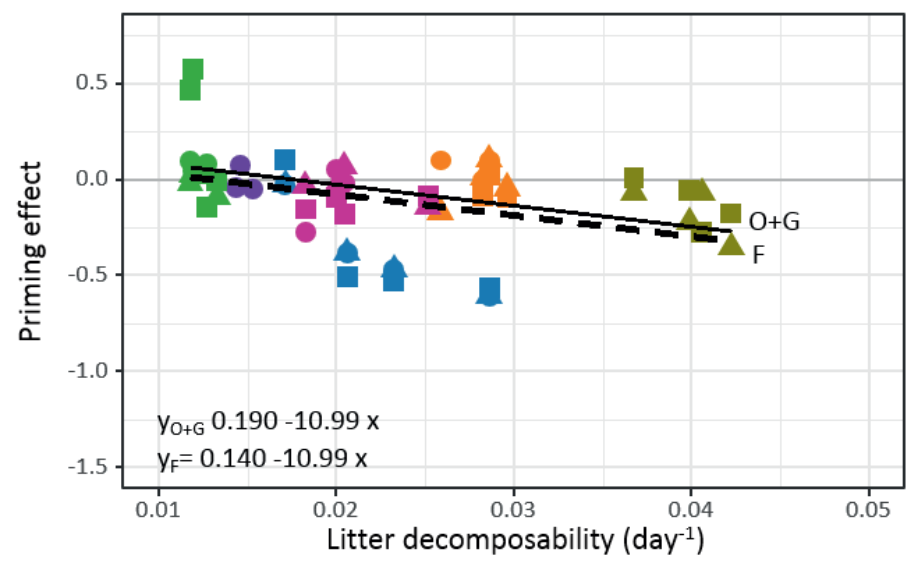

Figu re 4.4 Priming effect of presence of own-, grass- or forb-plants on shoot (a) or root (b) litters of wild plants in relation to litter decomposability, based on multiple-linear regression analysis. 


\subsection{Discussion}

Dead and live plant roots contribute to $\mathrm{C}$ and $\mathrm{N}$ cycling, particularly in arable systems. This research aimed to test shoot litter traits and decomposability as proxy for root traits and decomposability, by comparing coordination of traits and decomposition rates for litters of crops and wild relatives. Moreover, we quantified the influence of a growing plant on litter decomposition rates related to litter properties.

\subsubsection{Litter trait coordination for crops and wild relatives}

Fresh shoot and fine root $(<2 \mathrm{~mm})$ litters were expected to display comparable trait values. This trait coordination is a result of coordinated carbon and nutrient economics in aboveand belowground plant parts (Freschet et al. 2013; Reich 2014). In line with our hypothesis, litter $\mathrm{N}-, \mathrm{C}$ - concentration and $\mathrm{C}: \mathrm{N}$ ratio of crops and wild relatives were found to be coordinated between shoot and root. However, litter lignin-concentration was not. This result is contrary to results of Freschet et al. (2010), who found that traits related to structural investment, such as C- and lignin concentration, are stronger correlated across plant organs than nutritional-traits such as $\mathrm{N}$-concentration. Corresponding trait values between plant organs can differ between plant and ecosystem types, and regional scales, but within the boundaries of plant resource investment trade-offs (Freschet et al. 2010; Freschet et al. 2013). An alternative explanation might be found in the assumption on the function of fine roots. Fine roots (diameter $<2 \mathrm{~mm}$ ) in our study included several root orders, of which most have an absorptive function (orders 1-3) and some a transport function (order $4<$ ) (McCormack et al. 2015). The ratio of absorptive and transport roots within the fine-root fraction can vary between herbaceous and annual crop plants, as well as between forbs and grasses (McCormack et al. 2015), which could be a biological source of variation of ligninconcentrations found among our root litters.

Based on earlier findings by (García-Palacios et al. 2013), we expected that crops would represent an extension of the plant economic spectrum, with crop litters displaying higher $\mathrm{N}$-concentrations, but lower $\mathrm{C}$ - and lignin concentrations than wild relatives. In agreement with our hypothesis, crop litters showed a shift in SMA-fitted line for C-concentration, with lower concentrations for both root and shoot litters compared to their wild relatives. Surprisingly, crops had higher C:N ratios in shoot litter than the wild plants. This pattern seems to be driven by two wild plant species, F. rubra and C. intybus, which had high Nconcentrations and low C:N ratios in their shoot litters. The observed root C:N ratio for both species is in line with values found in earlier studies (Orwin et al. 2010; Saar et al. 2016) (see also Chapter 5), as is shoot C:N ratio for C. intybus (García-Palacios et al. 2013), and F. rubra (Orwin et al. 2010). A more extensive comparison of crop and related plant species comparison is needed to test if the difference in shoot C:N ratio between crop and wild 
plants is a general pattern or a consequence of selecting two wild plant species with deviating trait values.

\subsubsection{Litter decomposability of crops and wild relatives}

Litter decomposability, defined as litter decomposition rate in plant absence, was expected to be comparable for root and shoot litters as a consequence of coordination of chemical traits in root and shoot (Freschet et al. 2013). In line with our hypothesis, decomposability of root litters was slower but positively related to that of shoot litters. Moreover, for similar root decomposition rates shoot litters of crops decomposed faster than shoot litters of wild relatives. In previous work faster decomposition of crop leaf litters in comparison to wild ancestors was found to be driven by litter lignin concentrations which were lower for crops (García-Palacios et al. 2013), which is in line with our results. We found that shoot decomposability was negatively correlated with litter $\mathrm{C}$ - and lignin concentrations for litter of both crops and wild relatives. Also, root decomposability of wild plants was negatively correlated with litter C-concentrations. However, for crop root decomposability litter N correlated significantly, and surprisingly, negatively. This effect appears to be driven by the high root decomposability of $C$. endivia which had lowest root $\mathrm{N}$ concentrations, and relatively low root decomposability of $V$. sativa despite its high $\mathrm{N}$ concentrations. Perhaps the root $\mathrm{N}$ concentrations co-varied with unmeasured root litter traits underlying decomposability, such as high levels of easy decomposable C compounds in C. endivia or high root tissue density of $V$. sativa. Increased decomposition rates of shoot litters of crops and wild ancestors were found to coincide with increased mineral N availability (GarcíaPalacios et al. 2013), which puts forward the question whether this relationship is also present for root litters. Shoot decomposability could act as proxy for root decomposability for wild plants but not for crops, as the controlling mechanisms seem different for decomposition of crop root and shoot litter.

\subsubsection{Influence of growing plant on litter decomposition}

The vicinity of a growing plant root can alter microbial functioning. Most microorganisms are limited by $\mathrm{N}$ as their $\mathrm{C}: \mathrm{N}$ ratios are lower than the resources they utilize (Cleveland \& Liptzin 2007), however microbes also require enough available $C$ to function and multiply. Through rhizodeposition growing plants can facilitate microorganisms to mine for $\mathrm{N}$ in more recalcitrant organic matter by providing microorganisms with labile C-substrates. Thus, we expected that plant presence would stimulate the decomposition of root and shoot litters. However, we found negative priming effects of plant presence so that we need an alternative hypothesis. We verified that indeed the growing plant roots had made contact with the litter, as most litterbags contained in-grown roots from the present plant (these 
were removed to accurately measure the fraction litter remained after incubation) hence plant-litter interactions had occurred. It is known that litter decomposition rates can be slowed down by low soil moisture levels, which could have been lower in the presence than absence of a growing plant. However, this explanation is not likely as we minimised this influence by daily watering to the original soil moisture level. Alternative explanations may be found in the literature on negative priming effects.

Negative priming has been proposed to be the result of $\mathrm{N}$-competition between decomposing microorganisms and the present plant or to be the results of preferential substrate utilisation, and both mechanisms depend on mineral $\mathrm{N}$ availability (Cheng 1999; Dijkstra et al. 2013). We used the same soil throughout the experiment, thus variation in $\mathrm{N}$ availability between our treatments stems from either the incubated litter or the present plant. A potential role for differences in litter $\mathrm{N}$ for the magnitude of priming effects was explored by Saar et al. (2016). These authors found negative priming effects of legume plant presence on decomposition of non-legume root litters, in contrast to neutral to positive priming effects found on the more N-rich legume root litters. It was proposed that negative priming was the result of decomposing microorganisms that switch substrates and preferred the rhizodeposits over the non-legume root litters as the present legume alleviated any N-limitation, thus reducing the need of microorganisms to mine the litter for N. In our current experiment with grasses and non-legume forbs we found most negative priming effects in presence of forbs (C. endivia or C. intybus), which makes it unlikely that plant presence would have relieved any $\mathrm{N}$-limitation and rather increased $\mathrm{N}$-competition.

The magnitude of the priming effects was found to relate to the properties of the decomposing litter. Priming effects on shoot and root litters of wild plants was found be more negative with increasing litter decomposability (decomposition rate without growing plant). The reason for this may lie in the ecology of the decomposing organisms as it has been suggested that the direction and magnitude of priming effects can be explained by the life-history traits of the decomposer microorganisms (Fontaine, Mariotti \& Abbadie 2003; Dijkstra et al. 2013). Slow-growing microbial K-strategists decompose more recalcitrant substrates than r-microbial strategists (Blagodatskaya et al. 2007). Moreover, K-strategist can utilise rhizodeposits as a labile energy source to facilitate the decomposition of the more recalcitrant litter for $\mathrm{N}$, while $\mathrm{r}$-strategist are not able to access $\mathrm{N}$ in recalcitrant litters and will thus compete for $\mathrm{N}$ with the growing plant which reduces litter decomposition at low $\mathrm{N}$-availability (Fontaine, Mariotti \& Abbadie 2003). In absence of a growing plant, Kstrategist would decompose the more recalcitrant litters, and r-strategist would dominate the communities on labile litters. However, in presence of a growing plant the r-strategist dominated community would experience competition for $\mathrm{N}$, whereas a K-strategist community would mine the present litter for $\mathrm{N}$.

In our experiment we found a positive relationship between priming and root litter Nconcentration for crop root litters. Additionally, decomposability of crop roots was lower 
than of crop shoots and was negatively correlated with root litter $\mathrm{N}$ (Table 2). If the litter $\mathrm{N}$ is available to the decomposing K-strategists, this would reduce the competition for $\mathrm{N}$ with the growing plant and result in similar decomposition rate compared to litter incubation in plant absence. Conversely, in the N-poor litter competition of mineral $\mathrm{N}$ with the plants can slow down decomposition rates. A functional characterisation of the saprotrophic litter and rhizosphere community in presence and absence of a growing plant would enable testing of this hypothesis. Labelling studies with $\mathrm{N}$ and $\mathrm{C}$ isotopes are required to test litter $\mathrm{N}$ concentrations as a controlling factor in priming and establish if the observed suppression of decomposition rates is paralleled with reduced C-mineralisation from litter.

Across all litter species, we found the priming effect to depend on the identity of the present plant, which is in line with our expectation. Priming effects have been reported to differ between grass species present during litter decomposition (van der Krift et al. 2001a; van der Krift, Kuikman \& Berendse 2002). Plant species specific differences in rhizodeposition quantity and quality have been proposed as an underlying mechanism, as are differences in photosynthetic activity and in N-uptake from soil (Kuzyakov \& Cheng 2001; Huo, Luo \& Cheng 2017).

\subsubsection{Conclusion}

Decomposition of litters is dependent on its structural and nutritional quality. C-cycling estimates that are solely based on decomposition studies of aboveground plant parts will over estimate plant biomass turn-over as roots decompose slower. While shoots of wild plants can serve as a proxy for root decomposition, root decomposition of agricultural crops seems to be controlled differently than crop shoots. Moreover, presence of a growing plant can reduce litter decomposition rates, with most negative effects for easily decomposable litters as a possible consequence of microbial competition for $\mathrm{N}$ and different responses of microbial $\mathrm{r}$ - and K-strategists. These results can have important implications for $\mathrm{C}$ and $\mathrm{N}$ cycling from crop residues in agriculture as it could affect synchronisation of $\mathrm{N}$ mineralisation and crop requirement.

\subsection{Acknowledgements}

We thank Elly Nijenhuis, Hashmattulah Hotak and Henk Martens for practical support, Richard van Logtestijn and Rob Broekman for lignin-measurements. This work was financially supported by NWO-ALW VIDI to GBDD (grant no. 864.11003). 


\section{Appendix Chapter 4}

Table S1. Correlation matrices with spearman correlation coefficients $(r)$ between litter traits for crops and wild relatives and shoot and root. Significant correlation given in bold, marginally significant in italics ${ }^{* * *} \mathrm{P}<0.001,{ }^{* *} \mathrm{P}<0.01$,

${ }^{*} \mathrm{P}<0.05, \$ \mathrm{P}<0.1, \mathrm{NS} \mathrm{P}>0.1$

\begin{tabular}{|c|c|c|c|c|c|c|c|c|c|}
\hline \multirow{2}{*}{\multicolumn{2}{|c|}{ Litter traits }} & \multicolumn{4}{|c|}{ Shoot } & \multicolumn{4}{|c|}{ Root } \\
\hline & & $\mathrm{N}$ & $\mathrm{C}$ & $\mathrm{C}: \mathrm{N}$ & Lignin & $\mathrm{N}$ & $\mathrm{C}$ & C:N & Lignin \\
\hline \multirow{4}{*}{$\begin{array}{l}\stackrel{n}{0} \\
\text { 己े }\end{array}$} & $\mathrm{N}$ & - & * & $* * *$ & NS & - & NS & $* * *$ & NS \\
\hline & C & 0.53 & - & * & $* * *$ & 0.29 & - & NS & * \\
\hline & $\mathrm{C}: \mathrm{N}$ & -1.00 & -0.50 & - & NS & -1.00 & -0.26 & - & NS \\
\hline & Lignin & 0.03 & 0.76 & -0.00 & - & -0.21 & 0.58 & 0.23 & - \\
\hline \multirow{4}{*}{$\underset{⿱ 乛}{\overrightarrow{3}} \frac{\stackrel{D}{D}}{\stackrel{D}{D}}$} & $\mathrm{~N}$ & - & NS & $* * *$ & NS & - & NS & $* * *$ & $\$$ \\
\hline & C & 0.15 & - & NS & $\$$ & -0.34 & - & $\$$ & $* *$ \\
\hline & C:N & 1.00 & -0.14 & - & NS & -0.99 & 0.41 & - & $\$$ \\
\hline & Lignin & 0.01 & 0.38 & -0.02 & - & -0.36 & 0.67 & 0.40 & - \\
\hline
\end{tabular}




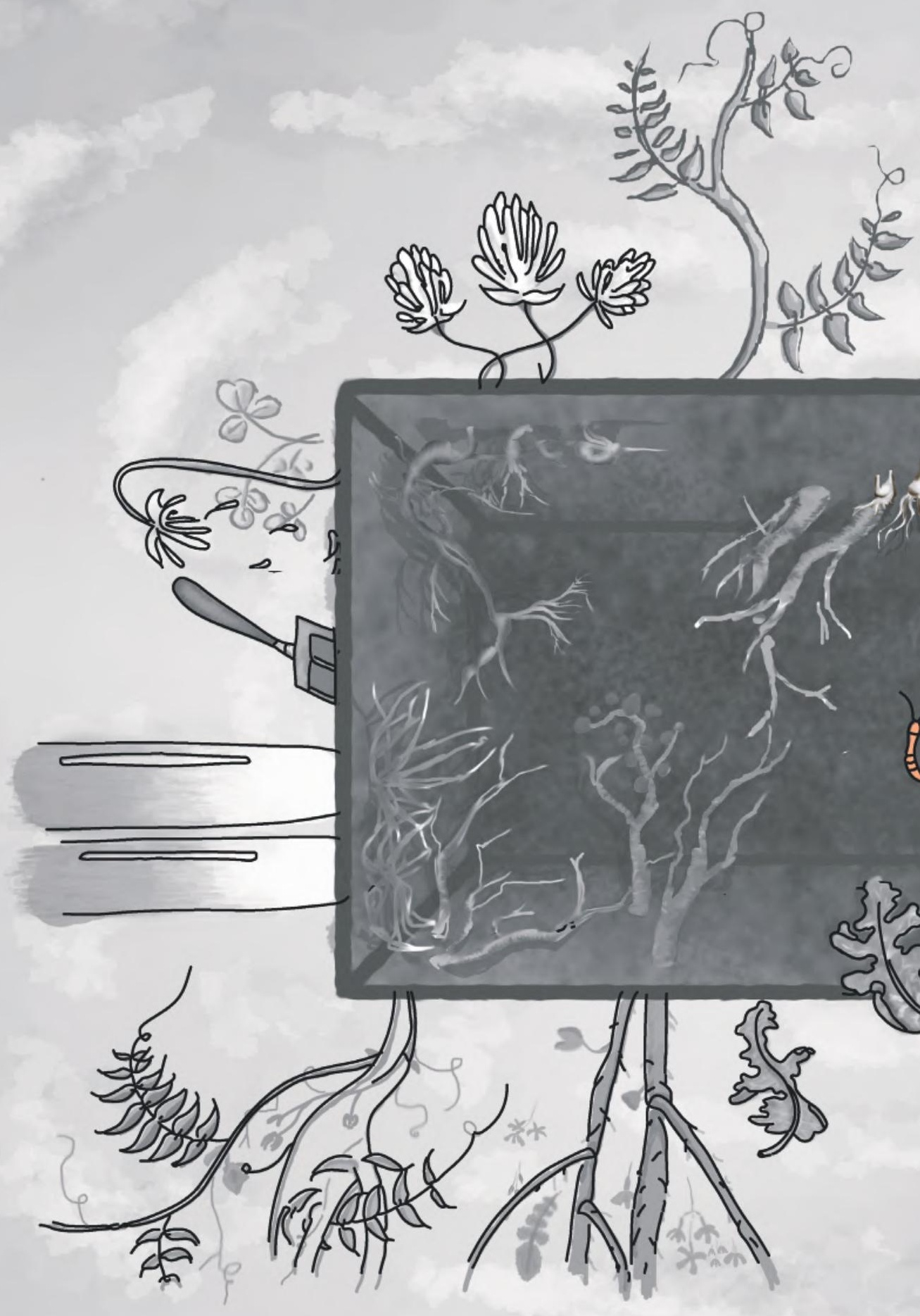




\subsection{Abstract}

The rhizosphere microbiome affects crop performance, therefore understanding how these microbiomes are assembled is of prime importance. The rhizosphere microbial assemblage is thought to be a plant-controlled sub-selection ("plant filter") of the microbial species pool in the surrounding bulk soil ("environmental filter"). How plant species differ in their influence on the rhizosphere microbiome in different soils has not been examined extensively. Plant-soil interactions are influenced by crop domestication through changes in plant traits, yet the effects of such artificial selection on the rhizosphere microbiome are largely unknown. We tested how domestication influenced rhizosphere microbiome assemblages and whether plant functional traits can explain the prokaryote and fungal community composition.

In a greenhouse, six pairs of crop species and their wild relatives of four different functional types belonging to four plant families (grasses, legumes and mycorrhizal and nonmycorrhizal forbs) were grown on four different soils; three agricultural and one restored grassland soil. After three months, rhizosphere soil was collected for $16 \mathrm{~S}$ and ITS amplicon sequencing and several morphological and physiological root traits were determined. We predicted that domestication would influence rhizosphere microbiome and plant functional traits, and that plant functional traits would explain rhizosphere community composition.

Both the prokaryote and fungal rhizosphere communities differed strongly with soil origin and to a lesser extent with plant species, confirming a larger role for environmental filtering than plant filtering. Across all soil-origin treatments, domestication did not influence microbial Shannon diversity, except for increased prokaryote diversity for domesticated Trifolium repens compared to wild $T$. pratense. When considering soil-origin treatments separately, rhizosphere microbiome differences between crops and wild plants were observed, especially in restored grassland soil. As expected, aboveground biomass and specific root length were generally higher in crops than their wild relatives. However, domestication effects on other architectural and physiological root traits varied between plant pairs. Plant functional traits explained a significant amount of variation between rhizosphere samples, but the explanatory power of traits varied between prokaryote and fungal communities and depended on soil origin.

Plants influence the rhizosphere microbiome in interaction with the environment, possibly due to plant plasticity or varying responses of the local microbial assemblages to the plant. Domestication affected the association of crops with their microbial communities, with possible consequences for plant functioning that require further research. Additionally, domestication has not affected root functional traits consistently, but varied with breeding objective. Plant functional traits could act as indicators of the rhizosphere microbiome, but their significance is soil dependent. Further research on the interaction between plant traits 
and soil conditions with respect to exudation patterns and rhizosphere microbiomes could improve our mechanistic understanding and inform both nature management and crop breeding for sustainable agricultural practice. 


\subsection{Introduction}

Soils host an enormous diversity of microbiota that exhibit key ecosystem functions (Wardle et al. 2004a; Wagg et al. 2014). The microbial community associated with plant roots can influence plant performance positively and negatively (Berendsen, Pieterse \& Bakker 2012), and thereby can mediate plant-soil feedback interactions and resulting vegetation dynamics (Bever 1994; van der Putten et al. 2013; Fitzpatrick et al. 2018). Rhizosphereassociated microbial communities are not mirror images of those in the bulk soil, but rather are plant-controlled subsets from this environmental species pool (Lundberg et al. 2012; Bulgarelli et al. 2013). It is unclear how plants shape the microbial assemblage in interaction with other environmental factors, while such insights are highly relevant for understanding rhizosphere ecology.

Variation in plant microbiome composition between different plants is thought to be the consequence of host selection as well as dispersal limitation, environmental constraints, microbe-microbe interactions and stochastic events (Lebeis 2014; Hacquard 2016). Physicochemical soil characteristics, microbial biogeography and soil management shape the local soil microbial assemblage to which a plant is exposed (Bulgarelli et al. 2013; Philippot et al. 2013). The plant characteristics act as a subsequent filter to the rhizosphere microbiome (Lundberg et al. 2012). This idea of strong selection of specific subsets of soil microbial assemblages has also been coined 'soil conditioning by plants' and is the central paradigm of plant-soil feedback research (Bever 1994; van der Putten et al. 2013). This type of research has been instrumental in explaining plant community dynamics, yet plant-soil feedback effects still remain hard to predict. Understanding how changes in the soil community are brought about by plants via their traits can unlock mechanistic comprehension of plant-soil feedback.

Insight in plant-microbe associations can be obtained by comparing rhizosphere microbiomes of various plants on different soils (Lebeis 2014). Similarities of microbiomes associated with different plant species growing in the same soil could indicate similarities in plant characteristics that drive the recruitment of specific taxa of microbes by the roots and rhizosphere. Alternatively, consistent recruitment of certain microbial taxa by one plant species growing at different locations could indicate tight plant-microbe interactions. However, to date it remains unclear how strong the plant selection of specific microbial communities is, as most studies included either only plant or only soil treatment and did not include both in a factorial design.

Comparing agro- and natural ecosystems was proposed as an additional tool in studying plant-soil interactions (Philippot et al. 2013; Mariotte et al. 2018). Agricultural and natural systems likely vary in drivers influencing rhizosphere microbiota (Philippot et al. 2013). This assumption is based on the fact that besides differences in soil management and nutrient availability, crops are generally selected for traits that enable growth on a range of 
different soils and environments with adequate management, whereas wild plants growing in native soils are more dependent on interactions with local soil microorganisms. As a consequence of domestication, crops could have a lower ability of establishing beneficial associations (Pérez-Jaramillo, Mendes \& Raaijmakers 2016). Although root-associated microbiomes of various crops have been studied, only few studies have focused on effects of domestication (Bulgarelli et al. 2015; Coleman-Derr et al. 2016; Leff et al. 2017; PerezJaramillo et al. 2017). These studies have found microbiome differences between modern cultivars, landraces and wild ancestors of several crops, raising the question whether consistent domestication effects occur when a broader selection of crops and their wild relatives is compared.

Soil microbial communities might be affected by domestication as a consequence of artificial selection of plant characteristics. For example, changes in plant chemistry affects soil microbial community functioning during decomposition of plant residues (GarcíaPalacios et al. 2013; Delgado-Baquerizo et al. 2016). Plant functional traits reflect the ecological strategy of plants to acquire and use nutrients and cope with disturbances (Wright et al. 2004; Violle et al. 2007). Domestication entails selection of plant characteristics, such as grain or fruit size, palatability and biomass allocation. However, as a side-effect of domestication, plant defence and resource acquisition traits have changed (Milla et al. 2014; Pérez-Jaramillo, Mendes \& Raaijmakers 2016; Milla \& Matesanz 2017). Domestication of wheat (Triticum turgidum ssp. durum) resulted in a shift towards the acquisitive end of the trait spectrum with decreased root-to-shoot ratio, but disrupted coordination of above- and belowground traits (Roucou et al. 2018). Currently, domestication studies on root traits are scarce, yet the few studies available indicate domestication effects are also apparent belowground. For example, modern barley (Hordeum vulgare) and wheat cultivars have higher specific root length (SRL) than wild ancestors (Grossman \& Rice 2012; Roucou et al. 2018). Since roots are the interface for interactions with the soil microbial community, differences in belowground plant functional traits are likely reflected in the rhizosphere microbiome. In a comparison of common bean (Phaseolus vulgaris) modern cultivars with a landrace and wild varieties, Perez-Jaramillo et al. (2017) found variation in the bacterial rhizosphere community to coincide with a change in root density and SRL. Also, a lower rhizosphere microbial richness was negatively correlated with plant growth in a study on common sunflower (Helianthus annuus) domestication (Leff et al. 2017). These last two examples illustrate that relating rhizosphere community composition to plant functional traits is a helpful approach to understand the shaping factors of rhizosphere microbiomes and the role of domestication therein.

In this study the influence of soil origin and plant species on rhizosphere microbiome is compared for six closely related plant pairs from arable and natural grasslands. We tested what effects domestication has on plant functional root traits related to resource acquisition, and how this affects prokaryote and fungal rhizosphere communities. We hypothesise (1) that soil origin has a stronger influence on rhizosphere microbiomes than plant species 
identity. We expected that (2) domestication influences plant rhizosphere microbial community composition and plant functional root traits. We predicted that domesticated plants (2a) have less diverse rhizosphere microbiomes of different composition than those of wild plants, and ( $2 b)$ display higher specific root length and fine-root mass fraction and lower C:N ratios than their wild relatives. Lastly, we hypothesise (3) that rhizosphere microbial community composition is associated with plant functional root traits. 


\subsection{Methods}

\subsubsection{Experimental design}

To compare cultivation system effects on the plant root microbiome, we set-up a greenhouse experiment (Wageningen, The Netherlands). The microbial rhizosphere community and functional plant traits were measured for six plant pairs, composed of one agricultural species and one closely related wild plant species from nutrient-rich grasslands (Table 5.1). To test plant conditioning of the rhizosphere community, plants were grown on four sandy soils of different origin. Similar to the conditioning phase of a plant-soil feedback experiment, the original microbial communities were diluted by mixing fresh soil with $\gamma$-radiated sterilised soil from the same origin (Bever 1994). In all, the experiment included six plant pairs, an unplanted control on four soils replicated eight times, resulting in $(12+1) \times 4 \times 8=416$ pots.

Ta b le 5.1 Overview of agricultural and natural grassland plant species used in the experiment assigned to one of six congeneric plant pairs.

\begin{tabular}{|c|c|c|c|}
\hline Pair & Plant family & Plant species & Supplier \\
\hline 1 & Poaceae & Avena sativa var. Dominik & AgriFirm Plant, Apeldoorn, NL \\
\hline 2 & Poaceae & Lolium perenne var. Mathilde & AgriFirm Plant, Apeldoorn, NL \\
\hline 3 & Fabaceae & Trifolium repens var. Alice & AgriFirm Plant, Apeldoorn, NL \\
\hline 4 & Fabaceae & Vicia sativa var. Ebena & Agrifirm Plant, Apeldoorn, NL \\
\hline 5 & Brassicaceae & Raphanus sativus var. Terranoca & $\begin{array}{l}\text { J. Joordens' Zaadhandel B.V., Kessel, } \\
\text { NL }\end{array}$ \\
\hline 6 & Asteraceae & Cichorium endivia var. Nummer vijf2 & De Bolster, Epe, NL \\
\hline 1 & Poaceae & Arrhenatherum elatius & Emorsgate, Norfolk, UK \\
\hline 2 & Poaceae & Festuca rubra & Emorsgate, Norfolk, UK \\
\hline 3 & Fabaceae & T. pratense & Cruydt-Hoeck, Nijeberkoop, NL \\
\hline 4 & Fabaceae & Vicia cracca & Emorsgate, Norfolk, UK \\
\hline 5 & Brassicaceae & Raphanus raphanistrum & Cruydt-Hoeck, Nijeberkoop, NL \\
\hline 6 & Asteraceae & Cichorium intybus & Cruydt-Hoeck, Nijeberkoop, NL \\
\hline
\end{tabular}




\subsubsection{Soils and Plants}

In May 2013, sandy soils were collected from four sites (all $<60 \mathrm{~km}$ from Wageningen): a restored grassland (long-term experimental site Clue: (van der Putten et al. 2000)), and three agricultural sites: Wageningen University experimental field site Nergena (Barel et al. 2018), Vredepeel fields under organic and conventional management (Korthals et al. 2014). Soils were sieved $(8 \mathrm{~mm})$. Fresh soil was kept at $4^{\circ} \mathrm{C}(<2$ months). The remaining soil was sterilised by $\gamma$-radiation (Synergy Health Ede B.V., Ede, The Netherlands). Fresh and sterilised soils were thoroughly mixed (15:85, dry weight equivalent ratio). Bulk soil samples were taken and analysed, to define start conditions on dried soil $\left(40^{\circ} \mathrm{C}\right)$ (see Supplementary Information Table S1). Pots were placed in the greenhouse in a randomised block design. Soil moisture content was kept at $60 \%$ maximum water holding capacity by daily watering all pots individually.

Agricultural plant species were selected as being (near-) native to The Netherlands, in order to reduce variation in plant-soil co-evolutionary history between pairs. Whenever possible, plants were selected as congeneric pairs, or otherwise closely related. Natural-grassland species were selected to occur in nutrient-rich grasslands, native to The Netherlands. Agricultural species were acquired from commercial seed companies as untreated material. Grassland species were obtained from seed companies who maintained or collected seed from natural populations (Table 5.1). Before sowing, Vicia seeds were scarified, and Raphanus raphanistrum seeds removed from their husks. Seeds were surface-sterilised in diluted household bleach (1:10). Seeds were germinated in autoclaved sand, under greenhouse conditions $\left(21: 19^{\circ} \mathrm{C}, 16: 8 \mathrm{hrs} \mathrm{L}: \mathrm{D}\right)$. Two-week old seedlings were transplanted into pots of test soil, one plant per pot. The plants were reared for 12 weeks $\left(21: 16^{\circ} \mathrm{C}, 16: 8\right.$ hrs L:D, greenhouse was ventilation-cooled above $30^{\circ} \mathrm{C}$ ).

\subsubsection{Data collection}

After 12 weeks, the experiment was terminated. Soil samples were collected for microbial community analysis and plant material was collected to determine functional traits. First, aboveground plant biomass was cut at soil surface level, for Raphanus species at height of first cotyledons. Next, rhizosphere soil was collected as soil close and adherent to the roots. Most plants had thoroughly rooted the pot to the extent that all soil adhered to the roots. Soil from unplanted control pots was also sampled to determine microbial communities in bulk soil. Soil samples were stored at $-70^{\circ} \mathrm{C}$. Finally, roots were gently rinsed with tap water to remove adherent soil. A representative subsample of fine roots $(<2 \mathrm{~mm})$ was stored in $50 \%$ alcohol. All other plant material was dried at $40^{\circ} \mathrm{C}$. 


\section{DNA extraction and amplicon sequencing}

Out of eight replicate soil samples, four individual replicates were pooled, creating two independent replicates per treatment. DNA was extracted from $250 \mathrm{mg}$ soil with the PowerSoil ${ }^{\circledR}$ DNA Isolation Kit (MoBio, Carlsbad, CA, USA) according to manufacturer's protocol. For prokaryotes (bacteria and archaea), 16S small-subunit ribosomal gene was amplified using the primer combination 515f/806r (Bates et al. 2011), whereof 806r contained specific sequencing tags. The PCR mix contained $0.5 \mu \mathrm{l}$ of each primer $(10 \mu \mathrm{M}), 1 \mu \mathrm{l}$ DNA, $10 \mu \mathrm{l} 5$ PRIME HotMasterMix 2,5X (5-PRIME) and 1.25 $\mu \mathrm{l} \mathrm{BSA}\left(4 \mathrm{mg} \mathrm{ml}^{-1}\right)$ in a total reaction volume of $25 \mu \mathrm{l}$. The PCR amplification of $16 \mathrm{~S}$ had an initial annealing temperature of $94^{\circ} \mathrm{C}$ (5 min), then 35 cycles with denaturation at $94^{\circ} \mathrm{C}(45 \mathrm{~s})$, annealing at $50^{\circ} \mathrm{C}(1 \mathrm{~min})$, extension at $72^{\circ} \mathrm{C}(90 \mathrm{~s})$ and final extension $72^{\circ} \mathrm{C}(10 \mathrm{~min})$.

For fungal community analysis, we amplified ITS2 of ribosomal encoding genes using the primer combination ITS4/ITS9 (Ihrmark et al. 2012). In this combination the ITS4 primer contains specific tags for sequencing. The amplification mixture contained $0.5 \mu \mathrm{l}$ of each primer $(10 \mu \mathrm{M}), 1 \mu \mathrm{l}$ DNA, $1 \mu \mathrm{l}$ dNTPs $(5 \mu \mathrm{M}), 0.15 \mu 1$ FastStart ${ }^{\mathrm{TM}}$ High Fidelity PCR System (ROCHE), $2.5 \mu \mathrm{l} 10 \times \mathrm{PCR}$ buffer with $\mathrm{MgCl}_{2}, 1 \mu \mathrm{l} 2.5 \mu \mathrm{M} \mathrm{MgCl}_{2}$ and $1.25 \mu \mathrm{lBSA}\left(4 \mathrm{mg} \mathrm{ml}^{-1}\right)$ in a total reaction volume of $25 \mu$. The PCR amplification of ITS had an initial annealing temperature of $94^{\circ} \mathrm{C}(5 \mathrm{~min})$, then 35 cycles with denaturation at $94^{\circ} \mathrm{C}(45 \mathrm{~s})$, annealing at $54^{\circ} \mathrm{C}(1 \mathrm{~min})$, extension at $72^{\circ} \mathrm{C}(90 \mathrm{~s})$ and final extension $72^{\circ} \mathrm{C}(10 \mathrm{~min})$.

For each sample a double PCR was done, and product presence and quality were verified with Gel-electrophoresis on $1.5 \%$ agarose gels. Successfully amplified PCR products of the two independent reactions per sample were pooled for PCR clean-up. PCR products were purified with Agencourt AMPure XP magnetic beads (Beckman Coulter), according to the manufacturer's protocol. Concentrations of the PCR products where analysed with the fragment analyser (Advanced Analytical) by using the (DNF-473) Standard Sensitivity NGS Fragment Analysis Kit (1 bp - 6,000 bp). After quantification of PCR products, equal molar ratios of each sample were pooled and sent for amplicon sequencing (Illumina MiSeq300, BGI Tech Solutions Co., Ltd., Hong Kong, China).

\section{Bioinformatics}

The raw Illumina 16S data were processed with Hydra, this pipeline is described in PerezJaramillo et al. (2017), a full description is given in the supplementary information. For ITS data the pipeline was adjusted by extracting ITS2 regions using ITSx 1.0.11 (BengtssonPalme et al. 2013) before clustering. Also, sequences were classified using the UNITE database version 7.2 (Kõljalg et al. 2013) provided by RDP. The resulting BIOM files were further filtered with custom scripts in R statistical software (R Core Team 2017) (v 3.4.0) using the Phyloseq package (McMurdie \& Holmes 2013) (1.20.0). For the $16 S$ dataset OTUs 
belonging to Bacteria and Archaea were extracted and chloroplast or mitochondrial sequences discarded. In the ITS dataset only OTUs identified as Fungi were selected. The resulting "full" datasets contained 102 16S samples, 103 ITS samples. The sequencing data were not rarefied, as this can result in high rates of false-positive results (McMurdie \& Holmes 2014). Instead we followed the recommendations by the aforementioned phyloseqpackage and used its available extensions.

\section{Prokaryote and fungal rhizosphere communities}

Relative abundances were calculated after removal of singletons. Also, samples with a reading depth $<4000$ reads for $16 S$ ( 4 samples) and $<550$ for ITS (4 samples) were excluded (Fig. S1). This trimmed dataset contained $9816 \mathrm{~S}$ samples and 99 ITS samples. Major phyla were identified as those containing OTUs with a relative abundance $>1 \%$. Shannon $\mathrm{H}^{\prime}$ index was used as a parameter of $\alpha$-diversity. Shannon $\mathrm{H}^{\prime}$ was calculated with the "estimate_richness" function from Phyloseq using the untrimmed data set including singletons, as recommended. Estimates of samples with low reading depth (Fig. S1) were excluded from further analysis. Microbial community composition ( $\beta$-diversity) was assessed by calculating Bray-Curtis distances of the "trimmed" data which were scaled to the smallest library size.

\section{Plant traits}

Above- and belowground plant biomass was based on dry weights of collected shoot and root material. Traits were measured on fine roots (diameter $<2 \mathrm{~mm}$ ), as these consist mostly of absorptive roots in herbaceous plants (McCormack et al. 2015) and interact most with the microbial soil community. The ratio standing fine-root $(<2 \mathrm{~mm})$ biomass to total plant biomass was included as fine-root mass fraction (FRMF) (Pérez-Harguindeguy et al. 2013). For specific root length (SRL), subsamples were stained ( $0.5 \mathrm{~g} \mathrm{~L}^{-1}$ neutral red for $\left.24 \mathrm{hrs}\right)$, rinsed, and scanned (Perfection V700/V750, EPSON America Inc, Long Beach, CA, USA) at $800 \mathrm{dpi}$, and the images were analysed with WINRHIZO (Regent Instruments Inc., Quebec City, QC, Canada) (Bouma, Nielsen \& Koutstaal 2000). SRL was quantified as the root length/biomass of root subsamples (Pérez-Harguindeguy et al. 2013).

For chemical analysis, fine roots for two replicates were pooled and ground (Retsch MM 2000 ball grinder, Retsch Benelux VERDER NV, Aartselaar, Belgium) to create four independent pooled replicates, because of material constraints. Fine-root carbon and nitrogen content $\left(\mathrm{mg} \mathrm{g}^{-1}\right)$ were analysed with a CHN analyser (LECO Corporation, St Joseph, Michigan, USA). On each pooled root sample, we measured $\mathrm{pH}$ by shaking $0.15 \mathrm{~mL}$ ground material into $1.2 \mathrm{~mL}$ demiwater in $2 \mathrm{~mL}$ Eppendorf tubes for an hour. After 
centrifuging for $1 \mathrm{~min}$ at $8000 \mathrm{rpm}$, the $\mathrm{pH}$ of the supernatant was measured (Cornelissen et al. 2006; Freschet et al. 2010).

\subsubsection{Data Analysis}

All data analyses were performed with R statistical software (R Core Team 2017) version 3.4.0 with the mentioned packages.

Overall differences in plant functional traits (aboveground, belowground biomass, FRMF, $\mathrm{SRL}$, root $\mathrm{C}, \mathrm{N}$ content and $\mathrm{pH}$ ) between the cultivation system (agricultural vs natural) were assessed per trait with linear mixed effects (lme) modelling according to Zuur et al. (2010) using nlme-package (Pinheiro et al. 2016), with cultivation system as fixed effect and plant pair nested in soil origin as random factor. Appropriate variance structures were applied to account for heterogeneity between strata. Final models were based on restricted maximum likelihood (REML). Normality and homogeneity of variance assumptions were verified with resp. Kolmogorov-Smirnov and Levene's test. Marginal $\mathrm{R}^{2}$ was calculated for the mixed-effects models (Johnson 2014) using package MuMIn (Barton 2017).

Cultivation system differences per trait were assessed in more detail by calculating the response ratio per plant pair, as the natural logarithm of trait value for the agricultural-pair member divided by the trait value for the wild-pair member. The differences in response ratio between plant pairs was tested with linear mixed-effects models for the separate traits, with pair as fixed effect, block as random factor and variance structures as needed. Significant cultivation system effects were tested by including a zero-baseline in the model and testing the respective contrasts.

Shannon diversity of $16 S$ and ITS communities were tested for differences between soil and plant treatments (including the unplanted control) according to the above-mentioned lme protocol, starting with an additive model. To assess domestication effects, response ratios were calculated (In diversitycrop/diversitywild) and tested as above. Differences in community composition were assessed by principal coordinate analysis (based on Bray-Curtis distances). The overall effects of Soil and Plant treatments (including unplanted control), were tested on the trimmed and normalised dataset with PERMANOVA ( Soil + Plant) (vegan package (Oksanen et al. 2016)) with 99999 permutations. Domestication effects were tested for the four soils separately ( Domesticated), excluding the unplanted control samples.

Constrained analysis of principal coordinates (CAP) was performed separately per soil origin, wherein all traits were used to constrain the analysis. Per soil treatment, significance of individual traits was tested by permutational multivariate analysis of variance (PERMANOVA). For a final model, traits were manually forward selected based on their variance explained and tested by PERMANOVA. 


\subsection{Results}

(a) Bacterial and Archaeal groups (16S)
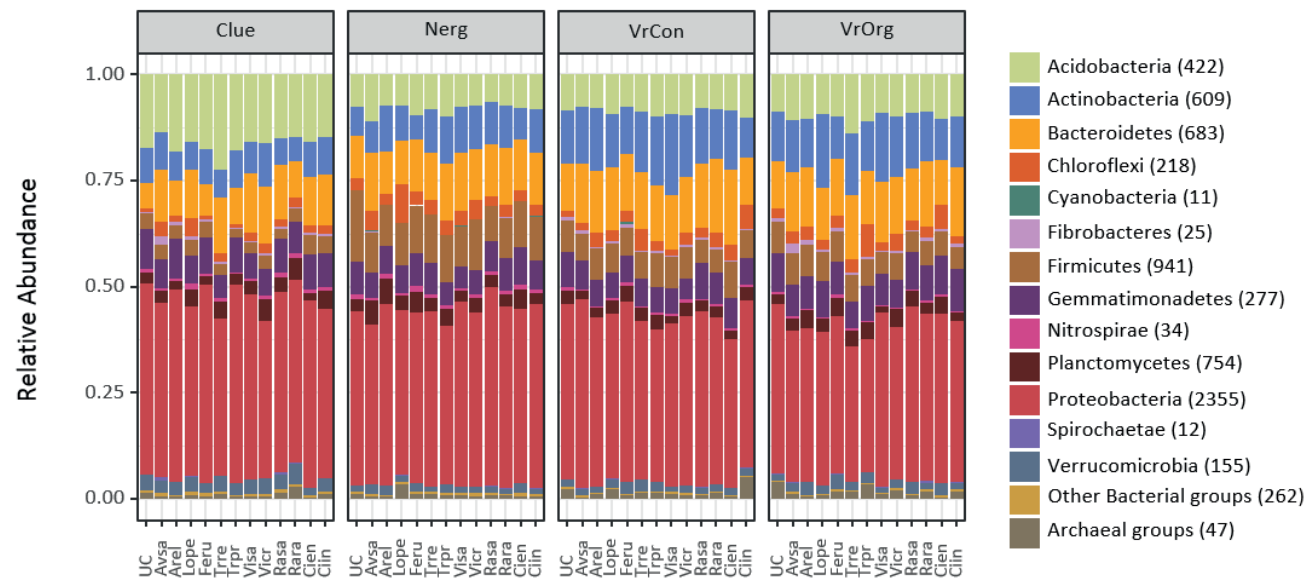

(b) Fungal groups (ITS)
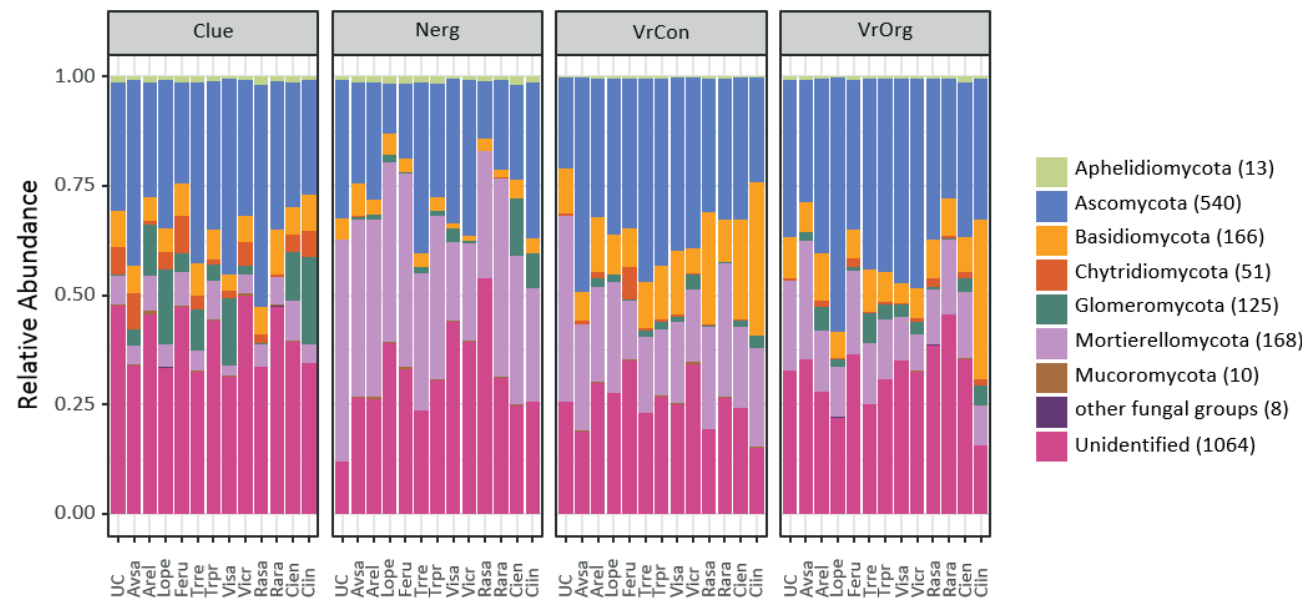

Figure 5.1 Relative composition of prokaryotic (a) and fungal communities (b) in unplanted control soil (UC) and plant rhizosphere samples per soil origin. Legend gives major taxonomic groups followed by number of observed OTUs between brackets. Plant abbreviated as A. sativa (Avsa), A. elatius (Arel), L. perenne (Lope), F. rubra (Feru), T. repens (Trre), T. pratense (Trpr), V. sativa (Visa), V. cracca (Vicr), R. sativus (Rasa), R. raphanistrum (Rara), C. endivia (Cien), C. intybus (Ciin). Soil treatments abbreviations: Clue (Clue), Nergena (Nerg), Vredepeel Conventional (VrCon), Vredepeel Organic (VrOrg).

\subsubsection{Relative abundance of prokaryote and fungal rhizosphere taxa}

In total 6805 different OTUs were found among the 16S samples, of which 47 Archaea OTUs (Fig. 5.1a). The phylum Proteobacteria was most abundant and had the highest number of OTUs. Other abundant phyla were Acidobacteria, Actinobacteria, and Bacteroidetes. Relative 
abundance of Bacteroidetes seemed to be higher in rhizosphere samples than in the unplanted control samples from fallow soil, although this was not statistically tested. Plants grown in three agricultural soils had a higher abundance of Firmicutes in their rhizospheres than plants grown in the restored grassland soil (Clue), with highest relative abundances for plants grown in Nergena soil. Acidobacteria were more prominent in the restored grassland than agricultural soils. Plants grown in both Vredepeel soils had higher relative abundances of Actinobacteria in their rhizosphere than plants grown in Nergena soil, whereas values were lowest for plants grown in Clue soil.

Among the ITS samples, 2145 different OTUs were found of which almost 50\% remained unidentified (Fig. 5.1b). From all identified OTUs Ascomycota were dominant in all samples. Basidiomycota and Glomeromycota were also common in most samples, however their relative abundances differed between soils. Relative abundances of Basidiomycota were lower in the rhizosphere of plants grown in Nergena agricultural soil. Furthermore, in the rhizosphere of plants grown in restored grassland soil (Clue) the relative abundance of Glomeromycota was higher than in rhizospheres of plants grown in the agricultural soils. Conversely, Mortierellomycota were less abundant in the rhizosphere of plants grown in the restored grassland soil. Moreover, unplanted-control samples had very low relative abundances of Glomeromycota compared to rhizosphere samples of all plants, except, as expected, for the non-mycorrhizal Raphanus species. This effect was most pronounced in samples from the restored grassland (Clue): relative abundances differed between agricultural and wild-plant rhizosphere samples, particularly for Glomeromycota, Ascomycota and unidentified OTUs.

\subsubsection{Soil and plant effects on prokaryote and fungal rhizosphere communities}

Shannon diversity of prokaryote rhizosphere assemblages differed between soil-origin $\left(\mathrm{F}_{3,82}=45.9, \mathrm{P}<0.0001\right)$. Diversity was highest for Nergena samples and lowest for Clue samples. Prokaryote diversity also displayed overall differences between the plant treatments $\left(\mathrm{F}_{12,82}=3.6, \mathrm{P}=0.0002\right)$, and was lowest for the unplanted-control samples and highest for rhizosphere samples of both Raphanus species, T. repens, A. sativa, C. intybus and $V$. cracca. Shannon diversity for fungi was significantly affected by both soil-origin $\left(\mathrm{F}_{3,83}=10.66, \mathrm{P}<0.0001\right)$ and plant treatments $\left(\mathrm{F}_{12,83}=3.42, \mathrm{P}=0.0004\right)$. Fungal diversity in Nergena and Clue soils was significantly lower than in Vredepeel Conventional and Organic soils. Rhizosphere samples from T. repens had the highest diversity, followed by $A$. elatius and T. pratense, whereas rhizosphere samples of $V$. cracca were least diverse. Fungal diversity of rhizosphere samples did not differ from the diversity in the unplanted-control samples, in any soil treatment.

The principle coordinate analysis (PCoA) of microbial communities displayed substantial composition differences (Fig. 5.2). For prokaryotes, the first PCoA axis explained $31.6 \%$ and 
the second axis $28.7 \%$ of variation in community composition (Fig 5.2a). Samples aggregated primarily by soil origin. Vredepeel Conventional and Organic 16S samples grouped together, although the two soil treatments only slightly overlapped. Clue and Nergena samples appeared as distinct groups in the 16S PCoA. PERMANOVA confirmed these observations. Soil origin explained $61.5 \%$ of variation among $16 \mathrm{~S}$ communities. Additionally, plant treatment was a significant factor explaining $9.8 \%$ of the variation (16S: Soil $\mathrm{F}_{3,82}=58.47, \mathrm{P}=0.00001, \mathrm{R}^{2}=0.6147$, Plant $\mathrm{F}_{12,82}=2.32, \mathrm{P}=0.00001, \mathrm{R}^{2}=0.0978$ ). Fungal community composition displayed similar patterns (Fig. 5.2b), with the first and second PCoA axis explaining $26.6 \%$, and $18.8 \%$ of the variation. Likewise, fungal rhizosphere assemblages were significantly influenced by soil and plant treatment (ITS: Soil F $\mathrm{F}_{3,83}=30.07$, $\mathrm{P}=0.0001, \mathrm{R}^{2}=0.454$; Plant $\mathrm{F}_{12,84}=2.12, \mathrm{P}=0.0001, \mathrm{R}^{2}=0.128$ ).

\subsubsection{Domestication effects on prokaryote and fungal rhizosphere communities}

The differences in Shannon diversity of the prokaryote rhizosphere communities were significant between crops and wild relatives, whereas there were no differences for Shannon diversity of the fungal rhizosphere communities (Table 5.2). For prokaryotes, we found a higher diversity in the rhizosphere of domesticated $T$. repens than in the rhizosphere of wild $T$. pratense, and $A$. sativa prokaryote communities tended to be more diverse compared to wild relative A. elatius ( $\left.\mathrm{t}_{1,44}=1.782, \mathrm{P}=0.0817\right)$.

Ta b l e 5.2 Mean effect size \pm standard error (SE) of domestication effect on Shannon diversity of rhizosphere communities per congeneric plant pair, calculated as Ln diversityagri/diversitywild. Positive values indicate higher diversity in crop vs wild plant rhizosphere samples. Given statistics tests differences between plant pairs with mixed effects modelling. Bold values indicate difference from zero, based on twosided t-test $\mathrm{P}<0.05$, italic values indicate marginal significance $\mathrm{P}<0.1$.

\begin{tabular}{l|ll|ll}
\hline \multirow{2}{*}{ Pair } & \multicolumn{2}{|c|}{ 16S diversity } & \multicolumn{2}{c}{ ITS diversity } \\
& Mean & SE & Mean & SE \\
\hline Avena/Arrhenatherum. & 0.018 & 0.010 & -0.075 & 0.046 \\
Lolium/Festuca & 0.007 & 0.009 & -0.128 & 0.106 \\
Trifolium & $\mathbf{0 . 0 2 2}$ & $\mathbf{0 . 0 0 8}$ & 0.017 & 0.028 \\
Vicia & -0.011 & 0.006 & 0.083 & 0.033 \\
Raphanus & 0.000 & 0.006 & 0.021 & 0.049 \\
Cichorium & -0.008 & 0.007 & 0.106 & 0.103 \\
\hline $\mathrm{df}$ & 5,37 & & 5,37 & \\
$\mathrm{~F}$ & 3.056 & & 0.793 & \\
$\mathrm{P}$ & 0.0208 & & 0.562 & \\
\hline \hline
\end{tabular}


(a) $16 \mathrm{~S}$

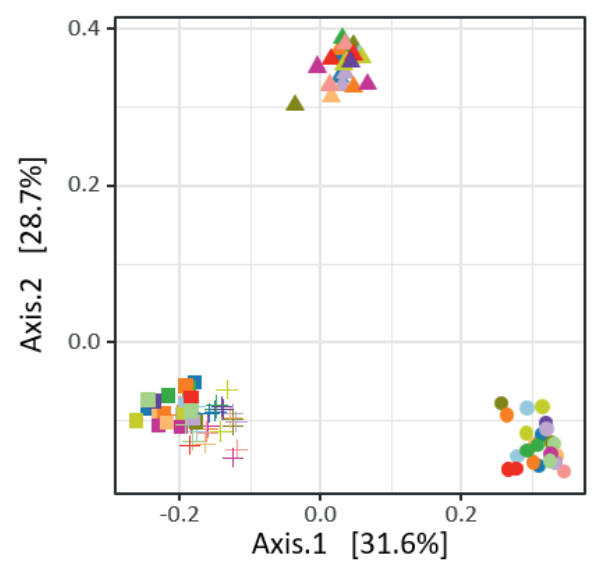

(b) ITS

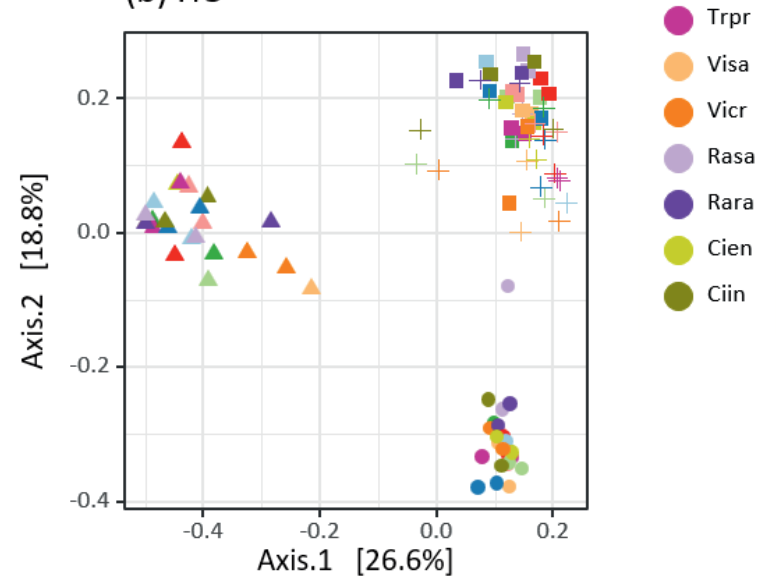

Figure 5.2 Principal coordinate analysis of prokaryotic (a) and fungal communities (b) in unplanted control soil (UC) and plant rhizosphere samples per soil origin. Dissimilarities based on Bray-Curtis distances of scaled data. 16S samples with $<4000$ and ITS samples $<550$ reads were excluded. See Fig 5.1 for abbreviations.

The effect of domestication on the rhizosphere community composition was tested per soil origin. Prokaryote communities in Clue and Vredepeel Organic soils were significantly different between domesticated and wild plants (Clue: $F 1,22=1.6181, P=0.02225, \mathrm{R}^{2}=0.06851$; Vredepeel Organic: F1,22=1.6164, $\left.\mathrm{P}=0.0105, \mathrm{R}^{2}=0.06844\right)$. Domestication was not a significant factor in the two other soils. Fungal communities differed between domesticated and wild plants in Clue soils ( $\left.F 1,22=1.644, \mathrm{P}=0.0296, \mathrm{R}^{2}=0.0695\right)$, and not in the other soils. 


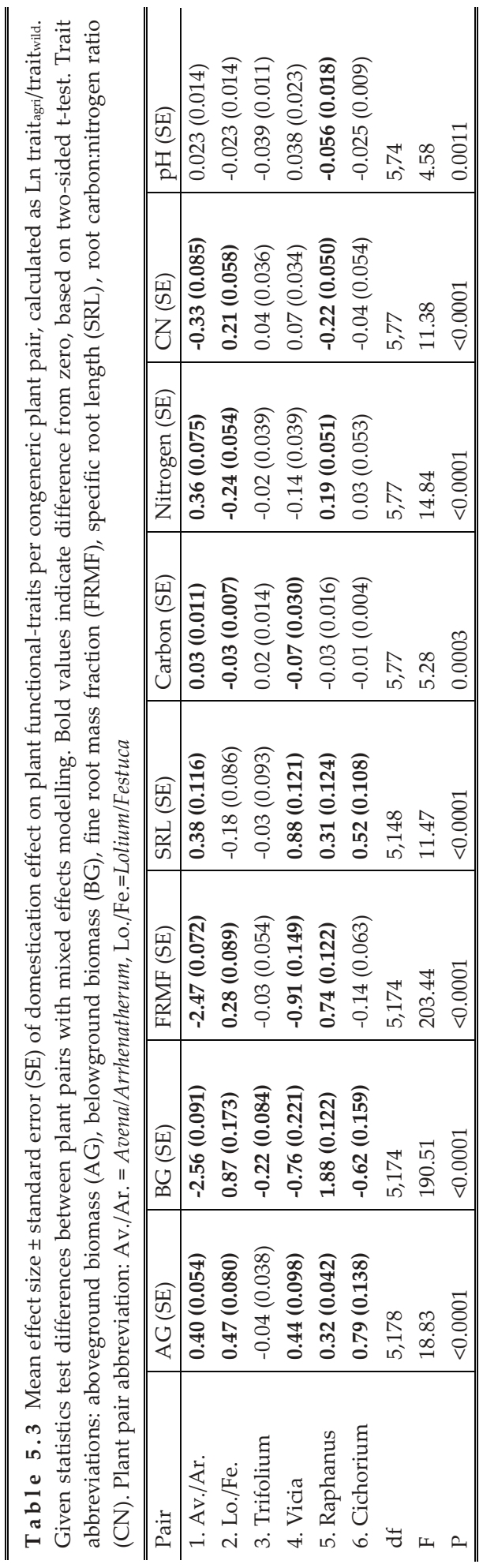




\subsubsection{Domestication effects on plant traits}

We tested domestication effects on plant traits by expressing the observed trait values of crops relative to the trait values of their wild relatives. The response ratios varied within and between plant traits (Table 5.3, for absolute values see Table S2). The aboveground biomass of the agricultural species was significantly higher for most plant pairs, except for Trifolium. Belowground biomass was larger for L. perenne and R. sativus than their wild counterpart, whereas in other pairs the wild relative had a larger belowground biomass than the crop. Similarly, FRMF was higher for agricultural species L. perenne and R. sativus, while agricultural species $A$. sativa and $V$. sativa had lower FRMF than their wild relatives. SRL was generally higher for agricultural than wild species. Root chemical traits displayed varying response ratios with both positive and negative values across pairs. Root $\mathrm{pH}$ did not vary significantly except for lower values for agricultural $R$. sativus than wild $R$. raphanistrum.

\subsubsection{Do plant functional-traits explain variation in rhizosphere microbiomes?}

Constrained analysis of principal coordinates (CAP) for prokaryote and fungal communities per soil origin indicated that plant functional traits explained a significant amount of variation in community composition (Fig. 5.3 \& 5.4). For prokaryote communities, the first canonical axis explained $10-14 \%$ of the variation and the second axis $8-10 \%$ (Fig. 5.3). The first axis was associated with root $\mathrm{N}$ concentration, aboveground biomass and SRL, whereas belowground biomass and FRMF associated mostly with the second axis. For all soils, the prokaryote communities of legume rhizospheres grouped apart from the other plant treatments, and the effect remained after removing taxa belonging to Rhizobium (Fig. S2). Moreover, Raphanus samples also appeared as distinct groups, whereas prokaryote communities of the grasses and Cichorium samples were more variable. In both Vredepeel soils, aboveground biomass appeared as a significant driving factor (Table 5.4, Fig. 5.3). For Clue and Nergena treatments prokaryote communities could be explained by root $\mathrm{N}$ concentrations.

For fungal communities the first canonical axis explained $10-18 \%$ of the variation, the second between $8-11 \%$. Fungal communities aggregated differently across soils. In most soils both Vicia plant treatments grouped apart, except in Clue soils. Raphanus samples also appeared as distinct clusters, except in Nergena soils. Cichorium-associated communities aggregated in Clue and Nergena soils. Also, the associations between fungal community composition and plant traits in the constrained ordination was variable across soils (Table 5.4, Fig. 5.4), as there were no consistent trait associations with ordination axes. Nevertheless, belowground biomass was a significant driver in all soils except Nergena, whereas root $\mathrm{N}$ or root $\mathrm{C}: \mathrm{N}$ ratio were traits that significantly affected the rhizosphere 
communities in all soils except Vredepeel Organic. Additionally, SRL was a relevant driver of the rhizosphere communities in Clue and Nergena soils.

(a) $16 \mathrm{~S}$ Clue

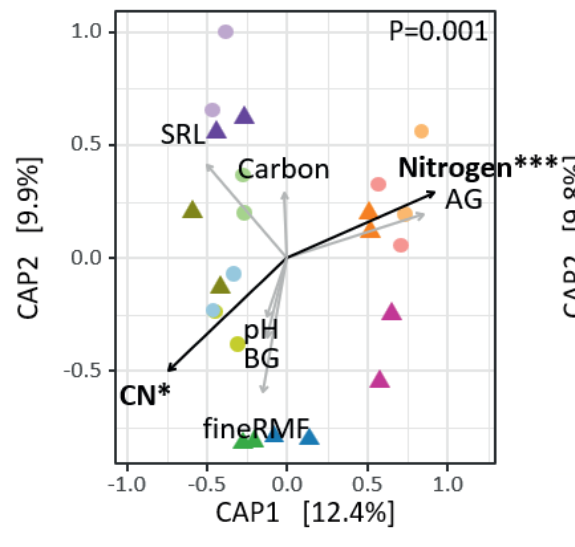

(c) $16 \mathrm{~S}$ VrOrganic

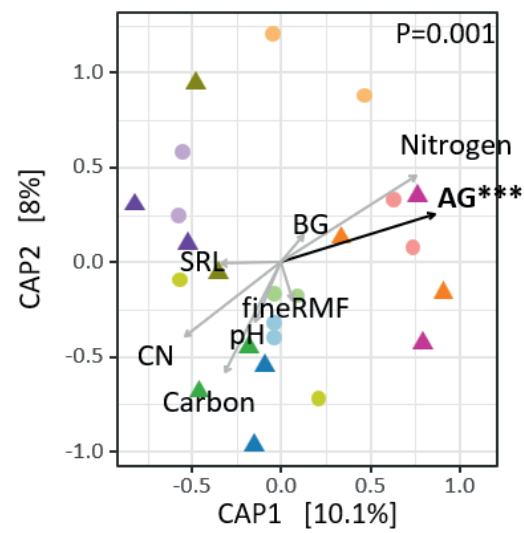

(b) 16S Nergena

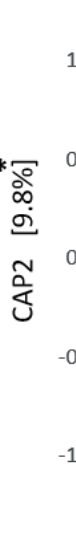

(d) $16 \mathrm{~S}$ VrConventional

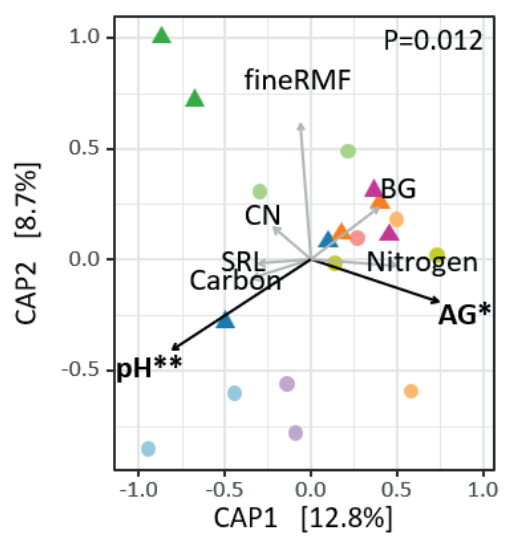

Domesticated

$\bigcirc A$

W

Plant

Avsa

- Arel

Lope

Feru

C Trre

Crpr

(1) Visa

Vicr

Rasa

Rara

Cien

Ciin

F i g u r e 5.3 Constrained PCoA of $16 \mathrm{~S}$ rhizosphere samples per soil origin (panels), by functional-traits: aboveground biomass (AG), belowground biomass (BG), fine root mass fraction (fineRMF), specific root length (SRL), root carbon:nitrogen ratio $(\mathrm{CN})$, root $\mathrm{pH}(\mathrm{pH})$. Colours indicate plant treatment (abbreviations Fig. 5.1), with circles for agricultural species (A) triangles for wild plant species (W). $\mathrm{P}<0.05$ expresses significant constrain by traits. Traits marked in bold were found significant in forward selected PERMANOVA (Table 4), ${ }^{*} \mathrm{P}<0.05,{ }^{* *}<0.01,{ }^{* * *}<0.001$. 
(a) ITS Clue

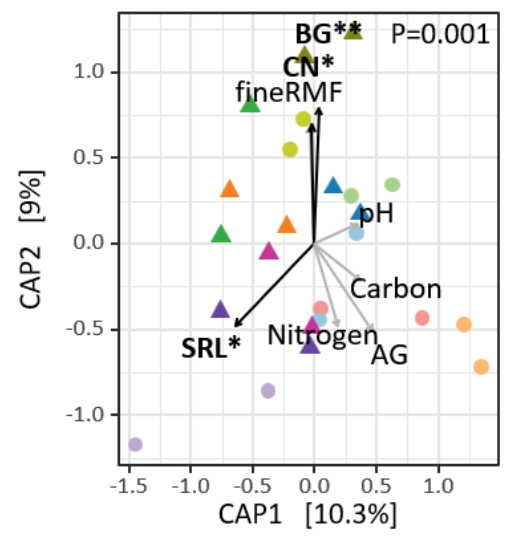

(c) ITS VrOrganic

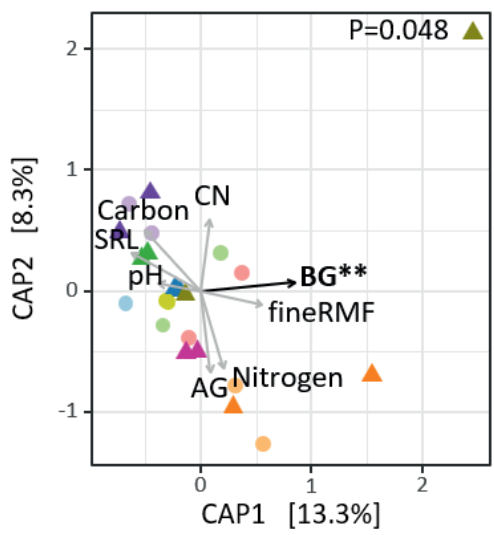

(b) ITS Nergena

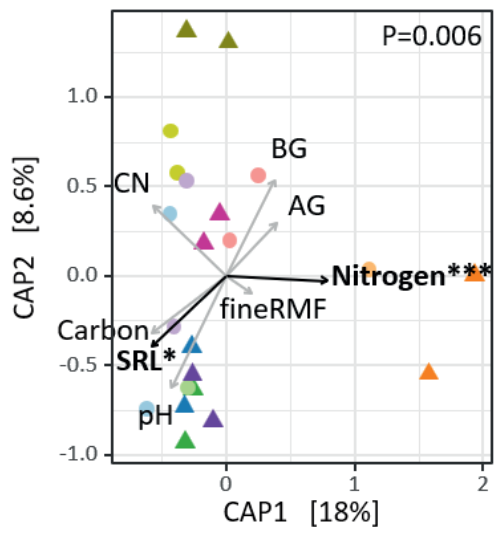

(d) ITS VrConventional

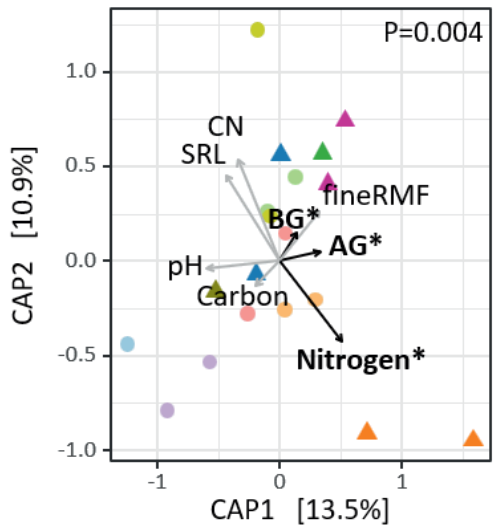

Domesticated

${ }^{\mathrm{A}}$

Plant

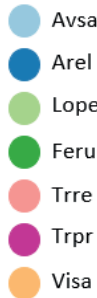

Vicr

Rasa

Rara

Cien

Ciin

Figu re 5.4 Constrained PCoA of ITS rhizosphere samples per soil origin (panels), by functional-traits (abbreviations see Fig. 5.3). Colours indicate plant treatment (abbreviations Fig. 5.1), with circles for agricultural species (A) triangles for wild plant species (W). $P<0.05$ expresses significant constrain by traits. Traits marked in bold were found significant in forward selected PERMANOVA (Table 5.4), ${ }^{*} \mathrm{P}<0.05,{ }^{* *}<0.01,{ }^{* * *}<0.001$. 
T a b l e 5.4 PERMANOVA results for prokaryotic (16S) and fungal (ITS) communities for rhizosphere samples per soil origin. Models composed of forward selected traits significant in single models, and according to variance explained. 99999 permutations. Traits abbreviations see Table 5.3 .

\begin{tabular}{|c|c|c|c|c|c|c|c|c|c|c|}
\hline & $16 S$ & & & & & ITS & & & & \\
\hline Soil & trait & $\mathrm{df}$ & F & $\mathrm{P}$ & $\mathrm{R}^{2}$ & trait & $\mathrm{df}$ & F & $\mathrm{P}$ & $\mathrm{R}^{2}$ \\
\hline \multirow[t]{3}{*}{ Clue } & Nitrogen & 1,21 & 2.93 & 0.00001 & 0.115 & BG & 1,19 & 1.99 & 0.0067 & 0.078 \\
\hline & $\mathrm{CN}$ & 1,21 & 1.49 & 0.04021 & 0.059 & SRL & 1,19 & 1.84 & 0.0175 & 0.072 \\
\hline & & & & & & $\mathrm{CN}$ & 1,19 & 1.60 & 0.0366 & 0.063 \\
\hline \multirow[t]{2}{*}{ Nergena } & Nitrogen & 1,19 & 2.55 & 0.0001 & 0.118 & Nitrogen & 1,19 & 2.98 & 0.0001 & 0.126 \\
\hline & & & & & & SRL & 1,19 & 1.71 & 0.031 & 0.072 \\
\hline VrOrg & AG & 1,22 & 2.14 & 0.00019 & 0.089 & BG & 1,21 & 2.51 & 0.0066 & 0.107 \\
\hline \multirow[t]{3}{*}{ VrCon } & $\mathrm{pH}$ & 1,16 & 2.02 & 0.00115 & 0.104 & BG & 1,18 & 1.726 & 0.0272 & 0.075 \\
\hline & AG & 1,16 & 1.45 & 0.04159 & 0.074 & AG & 1,18 & 1.736 & 0.0217 & 0.075 \\
\hline & & & & & & Nitrogen & 1,18 & 1.683 & 0.0373 & 0.073 \\
\hline
\end{tabular}




\subsection{Discussion}

Previous studies have indicated that soil-origin functions as a filter for the rhizosphere microbiome, as does plant identity (Berg \& Smalla 2009; Bulgarelli et al. 2013), but the effect of the two filters are rarely studied in concert. This study assessed how rhizosphere prokaryote and fungal community composition of six pairs of crop and closely related wild plants is influenced by plant species identity in the context of soil origin. We hypothesised that plant functional traits explain the influence of plant species on the rhizosphere microbiome. Since breeding of crops can result in trait variation (Milla et al. 2014; Milla \& Matesanz 2017; Roucou et al. 2018), we tested whether domesticated plants had a consistently different influence on their rhizosphere communities than do their closely related wild relatives. Our results suggest that plants filter local microbial soil communities in their rhizosphere in interaction with the soil environment, and variation in microbiomes are in part explained by plant functional traits. Here, the contribution of the results to the understanding of plant-soil interactions is discussed and implications for ecosystem functioning and management outlined.

\subsubsection{Influence of soil origin on microbial communities}

The influence of soil origin was evident, both in diversity and composition of rhizosphere microbiomes. For both prokaryote (16S) and fungal (ITS) markers, community composition strongly aggregated per soil origin, which is in line with our expectation that local soil conditions affect the microbial community composition (Berg \& Smalla 2009; Bulgarelli et al. 2013). Noteworthy is the higher similarity of microbial communities in the two Vredepeel soils (Vredepeel Organic and Conventional) to each other, than to communities from either of the other two sites (Clue and Nergena), indicating that although organic and conventional agricultural practice affect the microbial soil community differently (Gosling et al. 2006; Lupatini et al. 2017), dispersal limitation has a strong effect.

Other reported trends on effects of land use and soil properties are also reflected in our data. A recent meta-analysis showed that bacterial diversity in temperate agricultural soils is higher than in natural soils (Trivedi et al. 2016), which supports our observation of higher prokaryote diversity in samples of the three agricultural soils, compared to restored grassland samples (Clue). Acidobacteria are generally found at a lower $\mathrm{pH}$ (Lauber et al. 2009; Ramirez et al. 2017) and more nutrient-poor conditions (Fierer et al. 2011; Trivedi et al. 2016), and seemed more dominant in our restored grassland soil than the agricultural soils. Agricultural management practices, such as fertilisation, tillage and use of biocides can lead to low arbuscular mycorrhizal fungal (AMF) abundance in agricultural soils, although crop rotations and optimised organic fertilisation can stimulate AMF abundance and diversity (Gosling et al. 2006). Glomeromycota, to which AMF belong, were seemingly most abundant 
in restored grassland soil Clue samples. Additionally, relative abundances of fungal phylum Mortierellomycota appeared to differ between soil origin. Mortierellomycota were previously assigned to Zygomycota together with Mucoromycota (Spatafora et al. 2016). Although, Mortierellomycota were reported to occur in rhizosphere samples (Spatafora et al. 2016), it is unclear why their relative abundances vary by soil origin, most strikingly between agricultural soil Nergena and restored grassland soil (Clue).

The inclusion of four soils of different origin in our experiment, provides the context in which interactions between soil and plant filters on rhizosphere microbiomes can be tested. We do note that our experimental approach to study microbial community assembly by inoculating sterilised soil with live soil from the same site (Francioli et al. 2016) could have diluted the original soil community and selected for opportunistic species (Brinkman et al. 2010). The four soils included in this experiment provide insufficient replication to draw conclusions on microbial responses to soil properties or management. However, the effect of soil origin on microbiomes instead should be interpreted as such that differences in local microbial communities cannot be overcome by the selection of the plant.

\subsubsection{Plant species-specific influence on microbial rhizosphere communities}

Plant species-specific effects on rhizosphere microbiomes were observed. Plant identity provides a general filter, as the plant rhizosphere samples showed consistent differences across the four soil treatments. Prokaryote diversity was lowest for unplanted controls, and significantly elevated for a few plants (C. intybus, both Raphanus species, V. cracca, T. repens, A. sativa), which contrasts with the idea that the rhizosphere microbiome is a subsample of the microbial bulk soil community (Bulgarelli et al. 2013). Since plants fuel the soil food web (Wardle et al. 2004a), it is possible that the aforementioned plant species stimulated the rhizosphere microbiota and increased community evenness, thereby increasing prokaryote diversity. Moreover, this effect could have been amplified by the experimental dilution, and a different development of prokaryote communities in absence of a plant (fallow). Fungal diversity for rhizosphere samples did not differ from unplanted controls, but differences between plant species were observed. Inspection of the microbial community composition by constrained ordination showed grouping of prokaryote communities associated with legume plants (Trifolium and Vicia species), which is only partly due to their mutualism with $\mathrm{N}_{2}$-fixing Rhizobia bacteria. This effect was maintained after removal of Rhizobia and subsequent reanalysis by constrained ordination (Fig.S2), suggesting that the prokaryote community assembly as a whole was affected by legume-specific plant traits. Grouping of fungal communities was observed for rhizosphere samples of Raphanus species, possibly because Raphanus species are non-mycorrhizal (Harley \& Harley 1987), corresponding with the absence of Glomeromycota in the presented relative abundance of Raphanus associated fungal taxa. 


\subsubsection{Domestication effects on microbial rhizosphere communities}

Based on earlier findings (Bulgarelli et al. 2015; Coleman-Derr et al. 2016; Leff et al. 2017; Perez-Jaramillo et al. 2017) rhizosphere microbiomes of crops were expected to be less diverse, and of different composition compared to their wild relatives. Leff et al. (2017) proposed that rhizosphere microbial diversity negatively relates to plant growth rate as a consequence of promoting dominance of certain microbial taxa by exudation. Contrary to our hypothesis, prokaryote Shannon diversity in domesticated T. repens was significantly higher compared to wild T. pratense. A similar trend was observed for A. sativa. On the other hand, fungal diversity was not affected by domestication. Although T. repens and A. sativa had lower belowground biomass than their wild relatives, reduced root productivity is an unlikely explanation as other crops also displayed a reduction in root biomass without a corresponding diversity response. Rather, the observed domestication effect on prokaryote diversity seems to be a plant species-specific effect consistent across all soil treatments.

Domestication could affect interactions between plant and soil microbial community (Philippot et al. 2013; Pérez-Jaramillo, Mendes \& Raaijmakers 2016), thus different rhizosphere microbiomes of crops versus wild relatives are to be expected. Indeed, differences were found, but not for all soil treatments, implying that domestication effects depend on the soil environment. Domestication effects on rhizosphere microbiomes were found for plants grown on Clue soil, for both prokaryotes and fungi, and Vredepeel Organic soil, for prokaryotes only. Interactive effects could arise when crops and wild relatives differ in their ability to associate with beneficial microbes or cope with soil-borne pathogens, if these are present in the surrounding bulk soil. It has been proposed that some crops display reduced dependency on the symbiosis with mycorrhizal fungi or Rhizobia (Pérez-Jaramillo, Mendes \& Raaijmakers 2016; Martín-Robles et al. 2018), as a possible consequence of selection processes (Philippot et al. 2013). Compared to the three soils of agricultural origin, rhizosphere samples of plants grown on Clue soils had high relative abundances of Glomeromycota, but crops plants had relatively lower abundances of Glomeromycota than their wild relatives. These observations are in line with the proposed reduced ability of crops to associate with mycorrhizal fungi but need experimental confirmation by testing AMF roots-colonisation and efficiency of such symbiosis.

\subsubsection{Domestication effect on plant traits}

Domestication was expected to affect plant traits consistently across plant pairs, with higher SRL and FRMF and lower C:N ratios for crops compared to wild relatives. Although all plant pairs displayed trait differences between crop and wild relative, the direction and extent of the effects differed per pair and trait. One commonality was observed, though: crops had more aboveground biomass than their wild relatives, which was expected. Also, domestication effects observed in SRL were positive and in line with earlier findings 
(Grossman \& Rice 2012; Roucou et al. 2018). Variability of the domestication effect could be a consequence of different objectives for selection among our crops. Roucou et al. (2018) demonstrated that wheat, for which the objective of selection was the reproductive organ (grain kernels), displayed domestication side effects on architectural, physiological and morphological traits that support improved resource acquisition. Our selected crops comprise a grain (A. sativa), a leaf vegetable (C. endivia) and cover crops, selected for catching (L. perenne, R. sativus) or fixing (T. repens, V. sativa) nitrogen in the soil (ThorupKristensen, Magid \& Jensen 2003). Our catch crops L. perenne and R. sativa both displayed an increase in belowground biomass and FRMF compared to their wild relatives, whereas this effect was reversed in the other crops. These trait shifts indicate an increased biomass allocation to fine roots $(<2 \mathrm{~mm})$, and improved $\mathrm{N}$ uptake compared to their wild relatives (Bardgett, Mommer \& De Vries 2014). The variability of domestication effects between plant pairs suggests that effects of artificial selection cannot be generalised and are specific for the crop in question.

\subsubsection{Plant functional-traits explain rhizosphere microbiomes}

Since rhizosphere microorganisms primarily respond to resources provided by the plant or to plant chemicals that could suppress microbial functioning (Bulgarelli et al. 2013), functional plant traits could act as a proxy for other underlying mechanisms and possibly microbial community functioning (Cantarel et al. 2015; Legay et al. 2016). Plant functional traits, such as SRL, root $\mathrm{N}$ concentration and aboveground biomass explained microbial community composition in various studies (Legay et al. 2014; Legay et al. 2016; PerezJaramillo et al. 2017; Fitzpatrick et al. 2018), but not in Leff et al. (2017) and Leff et al. (2018). We identified root $\mathrm{N}$ concentration, $\mathrm{C}: \mathrm{N}$ ratio, and aboveground biomass as significant traits for both prokaryote and fungal communities. Root $\mathrm{pH}$ was additionally significant for prokaryote communities, SRL and belowground biomass for fungal communities. Root C concentration was not significant in any of the cases. Fitzpatrick et al. (2018) discussed that bacterial communities co-vary with plant productivity traits, such as SRL and aboveground biomass. SRL and root $\mathrm{N}$ concentration were found to reflect the root economic spectrum (Roumet et al. 2016). Co-variation of rhizosphere microbial community composition with these traits could indicate that plant-microbe interactions are related to plant carbon economics. Although quantity of exudates relates to plant productivity (van der Krift et al. 2001b; Jones, Hodge \& Kuzyakov 2004), insight how exudation patterns relate to plant functional traits and mechanistically explain plant-microbe interactions is lacking.

Interestingly, the observed plant selection effects on prokaryote and fungal rhizosphere communities depended on soil origin, suggesting predictors of rhizosphere microbiomes differ with environmental conditions. For example, root $\mathrm{N}$ and $\mathrm{C}: \mathrm{N}$ were significant drivers for prokaryote communities in Clue soils, but in Vredepeel Conventional root $\mathrm{pH}$ and 
aboveground biomass were significant. These interactions could be the result of plant plasticity as responses to different soil conditions result in different exudation patterns (Jones, Hodge \& Kuzyakov 2004). Alternatively, the predictive value of plant traits could vary because local microbial community differ in composition, implying that traits don't have a generalisable effect on microbial community assembly. Experimental manipulation of soil microbial community composition independent of abiotic soil conditions is recommended to disentangle these effects.

\subsubsection{Conclusions}

Plant species identity influences the microbial community assemblage in the rhizosphere. Irrespective of soil origin, legumes and non-mycorrhizal plants have rhizosphere prokaryote resp. fungal communities differing from grasses and forbs. Domestication of crops affects rhizosphere microbiomes depending on the bulk soil community. Crops differ in their ability to associate with natural soil communities, compared to closely related wild plants. Plant functional traits can only partly explain variation between microbial rhizosphere communities, although significance of the traits differed with soil origin and type of community studied (prokaryote versus fungal communities). Plant plasticity can be an explanation for these differential effects. Also, local soil communities can differ in their sensitivity to plant functional traits. Further research on this interaction between plant traits and soil conditions with respect to exudation patterns and rhizosphere microbiomes can improve our mechanistic understanding and inform both nature management and crop breeding for sustainable agricultural practice.

\subsection{Acknowledgements}

We thank our colleagues and students for practical help, Unifarm for facilitating the experiment, and Tamas Salanki \& Willeke van Tintelen for technical support. This work was supported by NWO-ALW VIDI to GBDD (grant no. 864.1003). The authors have no conflict of interest to declare. 


\section{Appendix Chapter 5}

Table S1 Chemical properties of soils used in the experiment: restored grassland soil Clue, conventionally managed agricultural soils Nergena (Nerg) and Vredepeel Conventional (VrCon), and organically managed agricultural soil Vredepeel Organic (VrOrg). Soil organic matter content $(\mathrm{SOM})$ determined by loss on ignition at $550^{\circ} \mathrm{C}$. $\mathrm{pH}, \mathrm{K}, \mathrm{NH}_{4}, \mathrm{NO}_{3}+\mathrm{NO}_{4}, \mathrm{~N}$ total $(\mathrm{Nts})$ and $\mathrm{PO}_{4}$ based on $0.01 \mathrm{M} \mathrm{CaCl}_{2}$ extraction, whereof $\mathrm{K}$ was determined by ICP-AES, $\mathrm{N}$ and P by SFA.

\begin{tabular}{l|lllllllll} 
& $\begin{array}{l}\mathrm{EC} \\
(\mathrm{uS} / \mathrm{cm})\end{array}$ & $\begin{array}{l}\mathrm{SOM} \\
(\%)\end{array}$ & $\mathrm{pH}$ & $\begin{array}{l}\mathrm{K} \\
(\mathrm{mg} / \mathrm{kg})\end{array}$ & $\begin{array}{l}\mathrm{N}-\mathrm{NH}_{4} \\
(\mathrm{mg} / \mathrm{kg})\end{array}$ & $\begin{array}{l}\mathrm{N}-\left(\mathrm{NO}_{3}+\mathrm{NO}_{2}\right) \\
(\mathrm{mg} / \mathrm{kg})\end{array}$ & $\begin{array}{l}\mathrm{Nts} \\
(\mathrm{mg} / \mathrm{kg})\end{array}$ & $\begin{array}{l}\mathrm{P}-\mathrm{PO} 4 \\
(\mathrm{mg} / \mathrm{kg})\end{array}$ & $\begin{array}{l}\mathrm{P}-\mathrm{O}) \mathrm{sen} \\
(\mathrm{mg} / \mathrm{kg})\end{array}$ \\
\hline Clue & 44.5 & 3.7 & 5.1 & 28.5 & 15.5 & 5.5 & 30.6 & 5.2 & 99.1 \\
VrCon & 124.5 & 4.3 & 5.4 & 159.5 & 7.9 & 30.8 & 46.6 & 4.2 & 97.9 \\
VrOrg & 79 & 4.1 & 5.3 & 55.5 & 8 & 22.6 & 37.7 & 2.3 & 87.6 \\
Nerg & 80 & 4.8 & 5.8 & 132.5 & 10.8 & 18.9 & 37.6 & 10.5 & 89
\end{tabular}

\section{Bioinformatics of sequencing data}

Handling of raw 16S sequencing data was similar to Perez-Jaramillo et al. (2017) (for description of the Hydra pipeline see: https://doi.org/10.5281/zenodo.597131). The RDP extension to PANDASeq (Masella et al. 2012) named Assembler (Cole et al. 2014) was used to merge paired-end reads with a minimum overlap of $150 \mathrm{bp}$ and at least a PHRED score of 25. Primer sequences were removed from the per sample FASTQ files using Flexbar version 2.5 (Dodt et al. 2012). Sequences are converted to FASTA format and concatenated into a single file. All reads are clustering into OTUs using the UPARSE strategy by dereplication, sorting by abundance with at least two sequences and clustering using the UCLUST smallmem algorithm (Edgar 2010). These steps were performed with VSEARCH version 1.0.10 (Rognes et al. 2016). Next, chimeric sequences were detected using the UCHIME algorithm (Edgar et al. 2011) implemented in VSEARCH. All reads before the dereplication step were mapped to OTUs using the usearch_global method implemented in VSEARCH to create an otutable and converted to BIOM-Format 1.3.1 (McDonald et al. 2012). Finally, taxonomic information for each OTU was added to the BIOM file by using the RDP Classifier version 2.10 (Cole et al. 2014). All steps where implemented in a workflow made with Snakemake (Köster \& Rahmann 2012).

The ITS sequences were analysed using the same pipeline as the $16 \mathrm{~S}$ with the following two adjustments. Firstly, ITS2 regions where extracted using ITSx 1.0.11 (Bengtsson-Palme et al. 2013) before clustering. Secondly, sequences were classified using the UNITE database (Kõljalg et al. 2013) provided by RDP. 


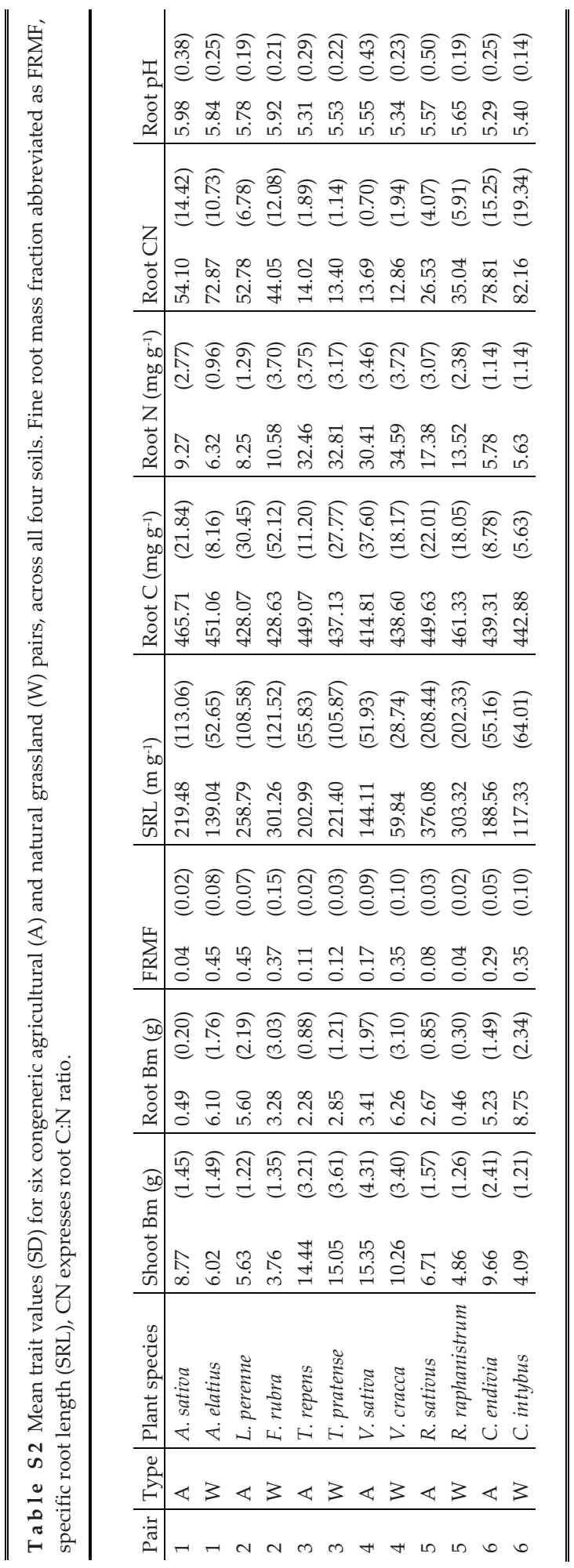


(a) 16S Shannon diversity

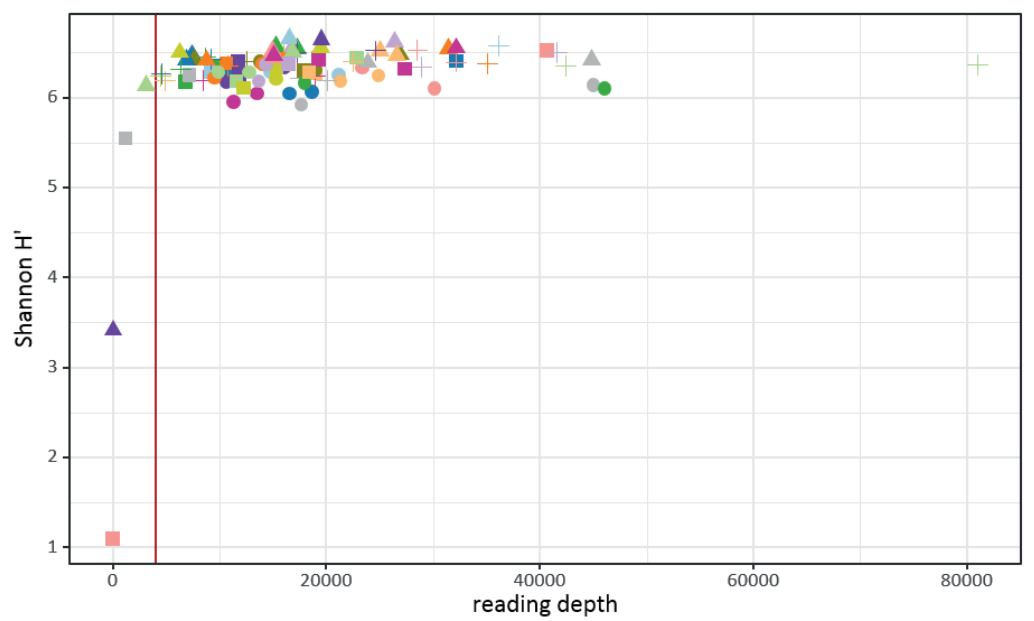

Soil

- Clue

A Nergena

- Vredepeel Conventional

+ Vredepeel Organic

Plant

- Unplanted control

A. sativa

- A. eliatus

L. perenne

- F. rubra

T. repens

- T. pratense

V. sativa

- V. cracca

R. sativus

(b) ITS Shannon diversity

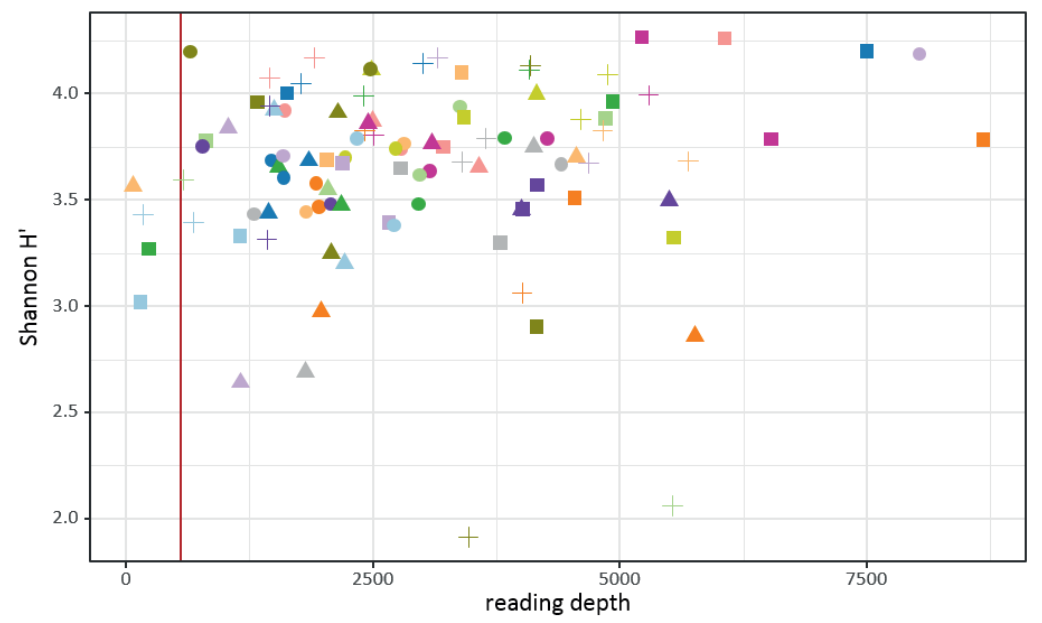

- R. raphanistrum

- C. endivia

- C. intybus

Figure S1 Reading depth plotted against estimated Shannon diversity. Red line indicates minimum reading depth for samples included in analysis and results (4000 in a, 550 in b). 
(a) $16 \mathrm{~S}$ Clue

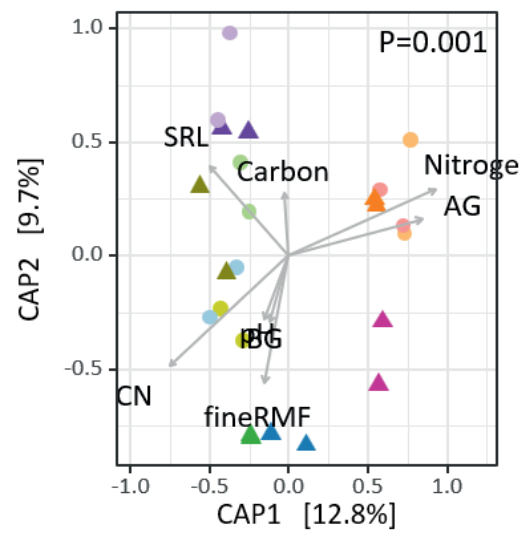

(c) $16 \mathrm{~S}$ VrOrganic

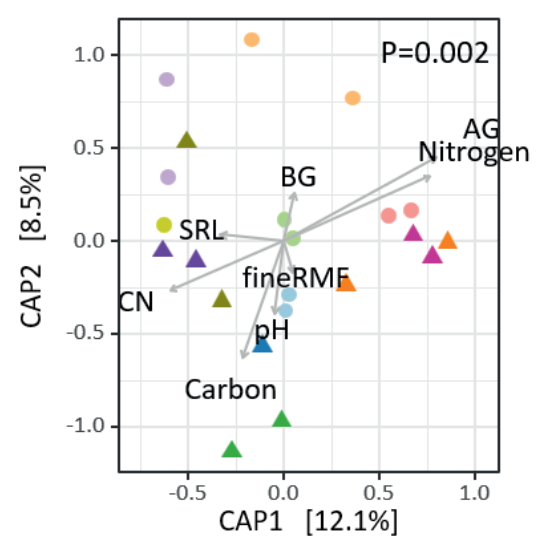

(b) $16 \mathrm{~S}$ Nergena

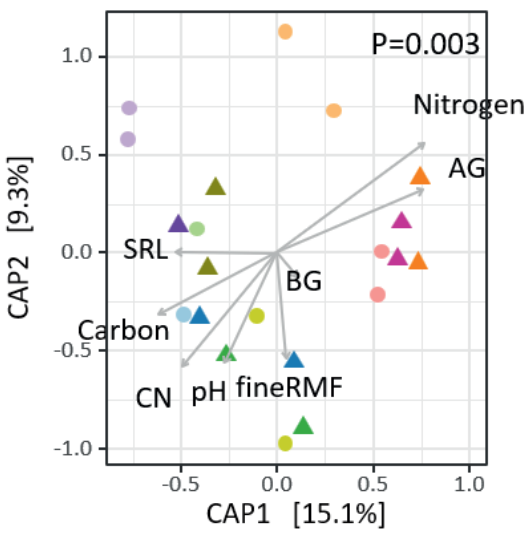

(d) $16 \mathrm{~S}$ VrConventional

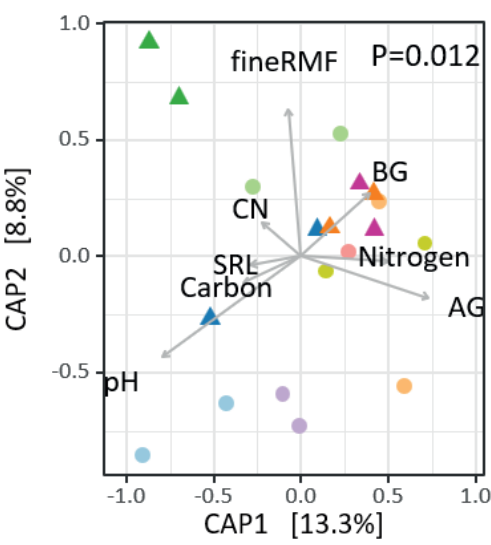

Domesticated

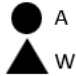

Plant

Avsa

Arel

Lope

Feru

Orre

Orpr

Visa

Vicr

Rasa

Rara

Cien

C Ciin

Figure S 2 Constrained PCoA of $16 \mathrm{~S}$ rhizosphere samples whereof taxa belonging to genus Rhizobium were removed from the data set. CAP was performed per soil origin (panels) by functional-traits: aboveground biomass (AG), belowground biomass (BG), fine root mass fraction (fineRMF), specific root length (SRL), root carbon:nitrogen ratio $(\mathrm{CN})$, root $\mathrm{pH}(\mathrm{pH})$. Colours indicate plant treatment: A. sativa (Avsa), A. elatius (Arel), L. perenne (Lope), F. rubra (Feru), T. repens (Trre), T. pratense (Trpr), V. sativa (Visa), V. cracca (Vicr), R. sativus (Rasa), R. raphanistrum (Rara), C. endivia (Cien), C. intybus (Ciin), with circles for agricultural species (A) triangles for wild plant species $(\mathrm{W}) . \mathrm{P}<0.05$ express significant constrain by traits. No forward selected PERMANOVA was performed on the traits. 


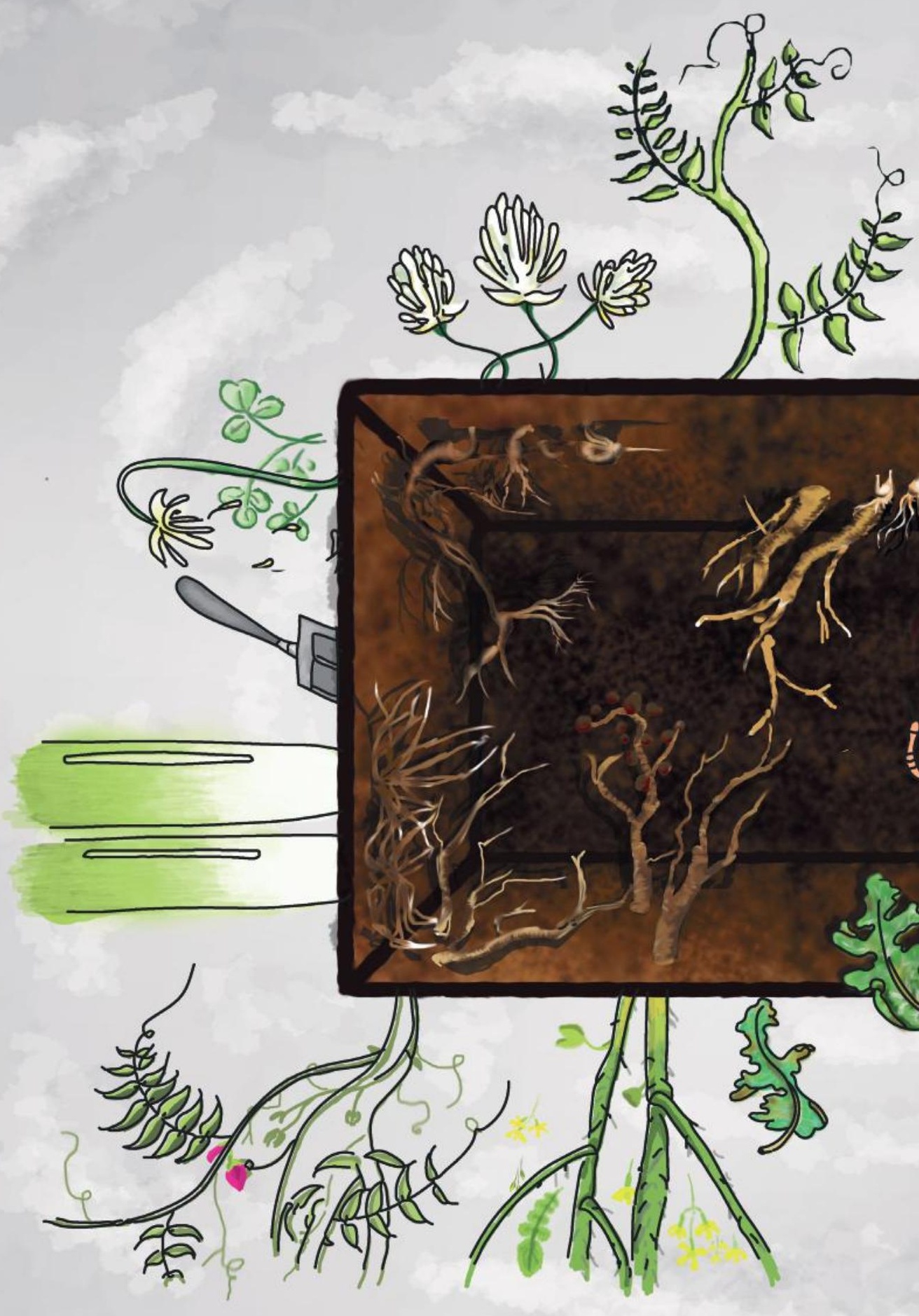




\section{Chapter 6}

General Discussion

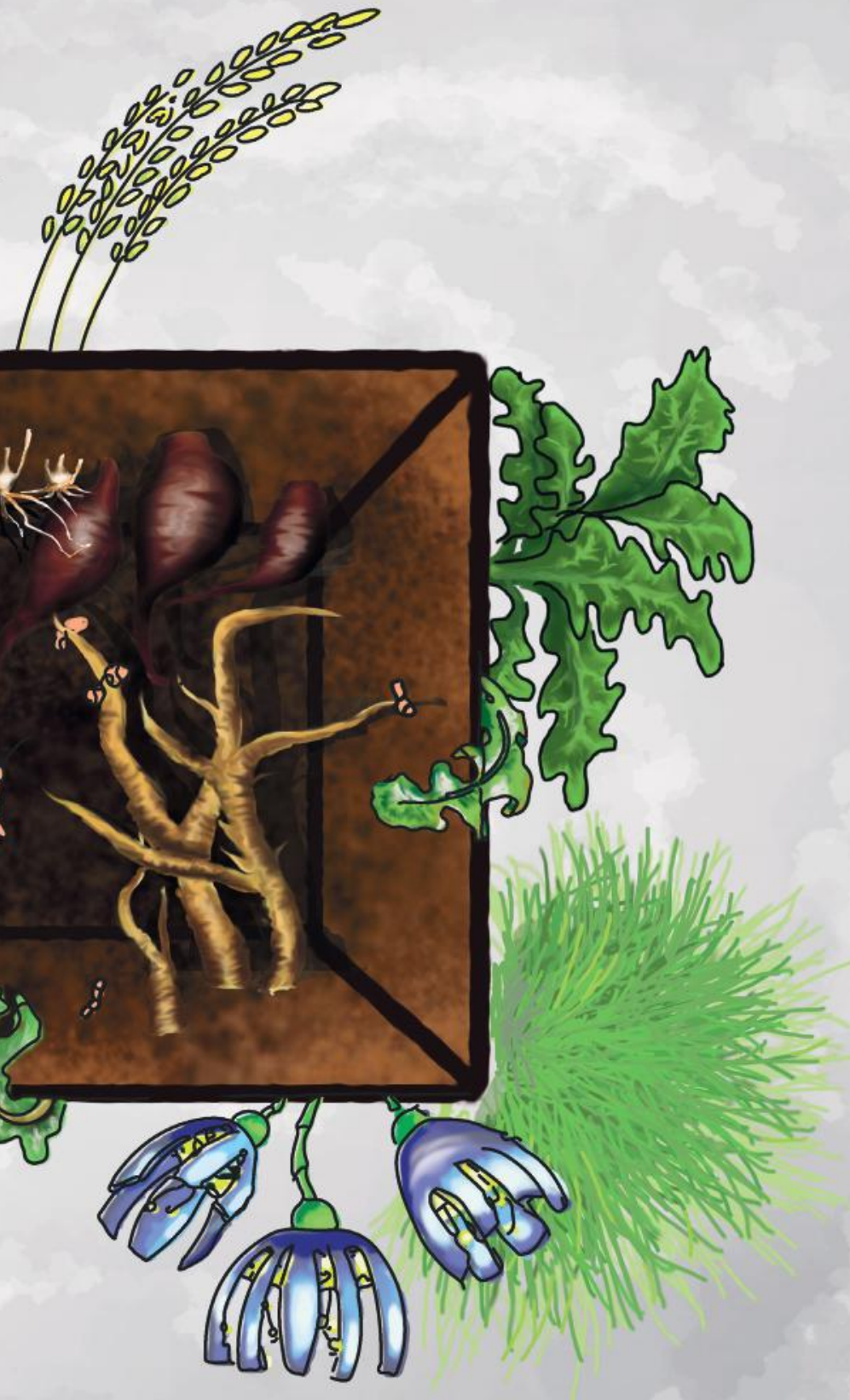


The versatile interactions of plants with their soil environment can have profound effects on ecosystem functioning (Wardle et al. 2004b). Growing plants can change physical, chemical and biological soil properties (Ehrenfeld, Ravit \& Elgersma 2005), and these changes can persist beyond the lifetime of the plant. Despite the scientific acknowledgement that plants influence soil community assembly and decomposition processes, it is unclear what plant properties control these interactions (van der Putten et al. 2016). Aboveground functional plant traits have been found to relate to ecosystem processes in natural and agro-ecosystems, such as nutrient cycling and primary productivity (Cornwell et al. 2008; de Bello et al. 2010; Faucon, Houben \& Lambers 2017). Because roots are an important interphase for plant-soil interactions throughout a plant's life and afterlife, they are the main mediators of soil legacy effects of plants. Therefore, it is expected that root traits can predict plant legacy effects better than shoot traits (Bardgett, Mommer \& De Vries 2014; Bardgett 2017). Moreover, anthropogenic influences in agroecosystems have led to selection pressures which differ from those in natural ecosystems (Mariotte et al. 2018). Given that the values of plant functional traits reflect the plant responses to environmental selection pressures and physiological trade-offs (Shipley et al. 2006; de Bello et al. 2010), different legacy effects can be expected between crops and wild plants (Milla et al. 2015; Pérez-Jaramillo, Mendes \& Raaijmakers 2016).

With this thesis I aim to improve the understanding of how plants shape their soil legacy by testing plant functional traits as predictors of microbial soil communities and litter decomposition. By pairwise comparison of agricultural and natural grassland plants across four plant families, controls of plant-soil interactions were studied in light of different selection pressures. The research presented in chapters 2-5 zoomed in on plant-soil interactions from field-scale towards the plant rhizosphere under controlled greenhouse conditions. In this chapter, I reflect on hypotheses and results presented in this thesis, starting at the fine-scaled plant-microbial interactions and zooming-out toward field-level. Finally, I consider the implications of the presented results for agro- and natural ecosystem functioning and give recommendations for further research.

\subsection{Pant legacy effects on the soil community}

The rhizosphere, the immediate vicinity of plant roots, is a hot-spot for micro-organisms (Buée et al. 2009; Raaijmakers et al. 2009). Rhizosphere microbial communities can harbour mutualists, which facilitate a plant's nutrient-uptake or provide disease suppression, or include potential plant pathogens, which can negatively impact plant growth. Since plant roots were demonstrated to associate with plant species specific microbiomes, understanding the controlling factors of rhizosphere microbial community assembly has become a prime research interest to improve soil and plant health and pave the way toward sustainable agricultural management practices (Schlaeppi \& Bulgarelli 2014; Bender, Wagg 
\& van der Heijden 2016; Toju et al. 2018). Additionally, a thorough understanding of rhizosphere ecology and plant-microbe interactions can aid ecosystem restoration (Wubs et al. 2016).

\subsubsection{Rhizosphere microbial community assembly}

Since roots are the interface of plant-microbial interactions in soil, I tested functional root traits as indicators of rhizosphere microbial community composition (chapter 5). I found that above- and belowground biomass and root traits cumulatively explained up to $23.9 \%$ and $26.6 \%$ of variation in respectively prokaryote and fungal rhizosphere assemblages (sum CAP 1+2, in figures 5.3 and 5.4), as measured by $16 \mathrm{~S}$ and ITS amplicon sequencing. Traits related to plant productivity (above- and belowground biomass) and nutrientuptake (root $\mathrm{N}$ concentration, root $\mathrm{C}: \mathrm{N}$ ratio, specific root length) are significant predictors of microbial rhizosphere assemblages. Other studies, likewise, found that variation in microbial community composition can be explained by plant functional traits (Cantarel et al. 2015; Perez-Jaramillo et al. 2017; Fitzpatrick et al. 2018). However, it remains to be tested how results obtained in individual plants grown in controlled conditions translate into effects in plant communities, as results on plant community level are contradictory. In both tropical forests (Barberán et al. 2015) and temperate grasslands (Leff et al. 2018) soil microbial community composition could be related to plant community composition, but not to plant traits. Which raises the questions: (1) what plant physiological characteristics underly plant species specific effects on soil microbial community composition, and (2) how do findings from controlled experiments studying microorganisms in the rhizosphere, translate to functional soil community composition relevant for plant productivity and ecosystem functioning at field scale?

Interestingly, the findings in chapter 5 indicate that plant control over the rhizosphere varies with soil conditions. I grew all plant species in four sandy soils with different land use history and found, for example, that root $\mathrm{N}$ was a significant indicator of prokaryote communities in rhizospheres of plants growing in Clue and Nergena soils, suggesting nutrient-uptake related mechanisms. In contrast, aboveground biomass related most strongly to the rhizosphere community composition of plants grown in the two Vredepeel soils, suggesting an underlying mechanism related to plant productivity (Table 5.4). Despite substantial differences in soil microbial communities between soil origins, plant species control the rhizosphere community composition (chapter 5). However, the action of the "plant-filter" is not independent from the soil conditions (Fig. 6.1), an aspect which has received relatively little attention in literature. Not only microbial communities differ between soils, also plant-trait values vary with environmental conditions (Lavorel \& Garnier 2002). Moreover, crops and wild ancestors show different phenotypic plasticity (Matesanz \& Milla 2018). Therefore, a plant's rhizosphere microbiome results from the 
interaction between the local pool of microbes and the plant traits as expressed in that soil. Unearthing the underlying mechanisms of plant species specific rhizosphere microbiomes across soil types will require researching exudation patterns in relation to plant functional traits and environmental controls and the associated changes in rhizosphere communities.

(a)
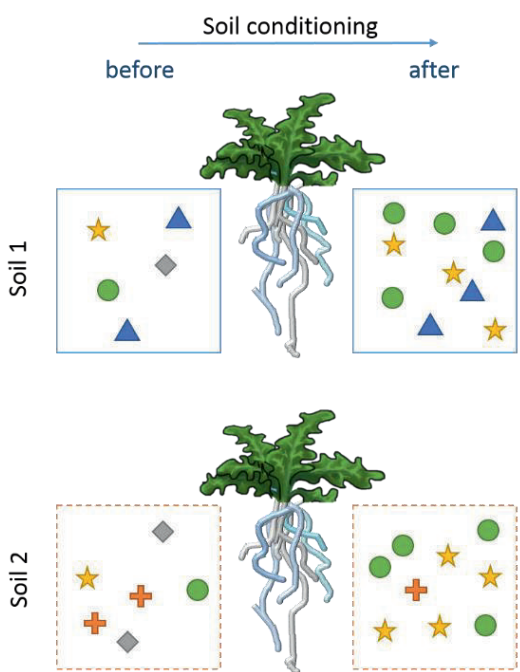

(b)
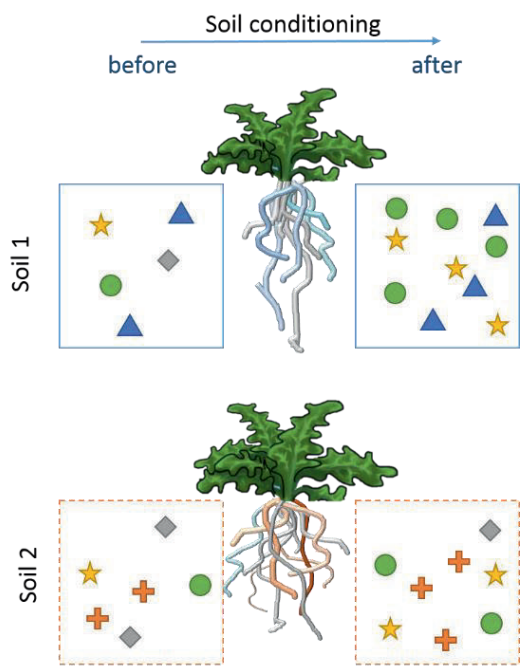

F i g u re 6.1 Conceptual diagram of a plant's influence on the soil community composition. Plants are thought to pose a similar selection filter (a) on microbial communities of soils 1 and 2 irrespective of local soil conditions. I propose (b) that the influence of a plant is context dependent as plants respond to local soil conditions, i.e. plant plasticity.

In this thesis, I tested plant legacy effects on soil microbial communities on field-scale in chapter 3. I showed that soil microbial community composition was not significantly affected by winter cover crop monocultures or mixtures previously occupying the soil and found only marginal effects of the preceding main crop. These result contrast with reported plant species specific influences in bulk soil microbial communities (Barberán et al. 2015; Leff et al. 2018), and the findings of chapter 5 . This discrepancy may in part be attributed to the use of different methods to study microbial community composition as the biological legacy effects in chapter 3 were measured by PLFA, which quantifies microbial biomass by fatty acid markers (Zelles et al. 1992; Zelles 1999; Frostegård, Tunlid \& Bååth 2011), whereas in chapter 5 I made use of amplicon-sequencing. The use of the rather coarse PLFA-method may have masked changes in microbial community measurable by the more sensitive amplicon sequencing technique. Also, in chapter 3 soil was sampled at 0-30 $\mathrm{cm}$ depth, whereas in chapter 5 soil was sampled from the rhizosphere of the plants. This difference in sampling can result in a dilution of plant effects as the plant control over microbiomes is strongest inside the roots (endosphere) and decreases towards the bulk soil (Lundberg et al. 2012; Bulgarelli et al. 2013). Moreover, a recent study demonstrated that soil biodiversity 
decreases with depth (Delgado-Baquerizo et al. 2017). Therefore, it is plausible that the measured plant legacy effect on the microbial community in the field is a diluted representation of the micro-organisms present in the upper soil layer. Overall, changes in bulk soil community by plants might take more time to build-up than the extend of the field experiment and require longer-term experiments to test this idea. An additional next step would be to identify which functions relate to taxonomic rhizosphere and bulk soil community composition, and how plants influence these functions. Functional gene microarrays (e.g. GeoChip (He et al. 2007)) could aid in such studies, for an example see Dignam et al. (2018).

\subsubsection{Plant legacy effects on other soil organisms}

Although the scope of chapters 3 and 5 was the microbial soil community, I recognise that soils host a whole suit of soil organisms that affect ecosystem functioning, for a review see Bardgett and van der Putten (2014). In chapter 2, I briefly reflected on the plant legacy effects on numbers of plant-parasitic nematodes. Plant-parasitic nematodes can cause considerable damage to crops (Singh, Hodda \& Ash 2013), and control succession of vegetation (van der Putten, van Dijk \& Troelstra 1988). Numbers of plant-parasitic nematodes increased with shoot biomass (chapter 2), but the shoot biomass in mixtures of $R$. sativus and $V$. sativa did not lead to a similar increase in plant-parasitic nematode abundances. Also increased nematode abundance did not affect subsequent plant productivity (chapter 2), implying that cover crop mediated increases of plant-parasitic nematodes do not automatically result in decreased crop yield. However, the size of the plant-feeding nematode population is not a sufficient measure to draw conclusions about the level of bio-control that could be provided by mixing plant species as opposed to monocultures. For a better understanding of legacy effects on the nematode community, it would be necessary to identify the nematode genera and feeding behaviour to assess potential risks and benefits to subsequent plant growth.

\subsection{Plant legacy effects on litter decomposition}

As primary producers, plants feed terrestrial food webs, both above- and belowground. Perhaps the most substantial influence of plants on ecosystem functioning is through recycling of the carbon and nutrients assimilated in plant biomass. Litter quality, soil biotic and abiotic properties are recognized as controlling factors of litter decomposition (Swift, Heal \& Anderson 1978; Bradford et al. 2016). The plant legacy effects via litter input may differ between natural and agricultural systems. In natural ecosystems most plant biomass returns to the soil directly as litter or indirectly as excrements of herbivores (Cebrian 1999). 
In agricultural systems, however, most aboveground plant material is harvested, and root biomass and root litter are often the main plant-derived inputs in soil. Alternatively to the use of main crops, the agricultural practice of cover crops entails incorporation of fresh above- and belowground biomass into the soil to improve soil quality (Thorup-Kristensen, Magid \& Jensen 2003; Dias, Dukes \& Antunes 2014; Poeplau \& Don 2015). In that practice, nutrients immobilised in above- and belowground plant tissues are returned to the soil, however without this biomass undergoing full senescence as in natural ecosystems. Notably, most studies of litter decomposition have focussed on aboveground plant litter (Freschet et al. 2013), whereas root litter can account for a substantial part of litter inputs in both natural and agricultural systems. Estimations of carbon- and nutrient-cycling can be improved by insights on plant-mediated controls of fresh litter decomposition in agriculture, and a standardised comparison on fresh root versus shoot litter decomposition of crops and wild relatives. Also, the influence of growing plants present during litter decomposition is rarely quantified, compared to effects on decomposition of old soil organic matter. Potentially living plants can have large effects on litter decomposition (Kuzyakov 2010; Dijkstra et al. 2013; Saar et al. 2016).

\subsubsection{Litter quality controls on decomposition}

Litter quality and microbial biomass are major drivers of litter decomposition rates (Cornwell et al. 2008; Bradford et al. 2016; Bradford et al. 2017; Djukic et al. 2018). My results in chapters 3 and 4 confirmed litter quality as a driver of decomposition rates, where litters with high carbon and lignin levels decomposed slower than litters with low carbon and lignin concentrations. However, in contrast to the expectations that nitrogen-rich litters decompose fast, I found that crop shoot litters with high nitrogen concentrations decomposed slower than nitrogen-poor litters (chapter 3). In line with these results, I found a negative correlation between root litter $\mathrm{N}$ concentration and decomposition rate in chapter 4 . These results are in contrast to the general idea that early litter decomposition is promoted by litter $\mathrm{N}$-concentration (Cornwell et al. 2008). A potential explanation for this discrepancy may be the large proportion of legumes in the total plant species pool in my experiments, as their high $\mathrm{N}$-concentrations coincided with high lignin-concentrations (chapter 3). Also in other research legumes were found to have higher lignin concentrations than grasses and forbs (Cherney et al. 1988; Ramirez-Garcia et al. 2015). Positive correlations of litter $\mathrm{N}$ to $\mathrm{C}$ - and lignin concentrations (chapter 3 and 4) could indicate different physiological trade-offs in legumes as opposed to non-legume species.

In agreement with my hypotheses, root litters decomposed slower than shoot litters. Also, decomposition rates, $\mathrm{C}$ and $\mathrm{N}$ concentration of cover crop shoot litters presented in chapter 3 , rank similarly in chapter 4 . The coordination of decomposability of root and shoot litters (chapter 4) implies that crops with high decomposable shoots would also have easily 
decomposing roots. These results can have implications for mineral $\mathrm{N}$-availability in soil as García-Palacios et al. (2013) found that high shoot decomposition leads to increased soil mineral N. My findings of stimulation of crop productivity by preceding winter cover crop biomass and nitrogen concentration is possibly the result of mineralisation (chapter 2). It would be very interesting to compare the mineralisation of $\mathrm{C}$ and $\mathrm{N}$ from decomposing root and shoot litters, because roots and shoots of the same $\mathrm{N}$ concentration can differ in the extend of $\mathrm{N}$ immobilisation during decomposition (Hobbie 2015).

\subsubsection{Interaction of plant litter and decomposers}

Microbial communities differ in their ability to decompose litters of variable quality (Strickland et al. 2009b; Austin et al. 2014). In natural ecosystems, repeated litter input can trigger microbial community adaptation to specialise in decomposing the dominant litter, or litter of comparably quality as the dominant litter (Veen et al. 2015). This specialisation of the decomposer community, known as home-field advantage, has rarely been tested in agro-ecosystems. Nevertheless, indications of home-field advantage (HFA) were found in potato-cultivation (Brolsma et al. 2015). Also, in production grasslands it was recently shown that local decomposer communities adapted to locally produced cattle-manure (Rashid et al. 2013; Rashid et al. 2017). In chapter 3, I tested whether winter cover crop cultivation leads to increased decomposition rates of winter cover crop litters in home-plots compared to decomposition in control plots. In line with HFA literature, I expected that litters of low quality (high C- and lignin concentration) and decomposability (decomposition rate in control plot) would benefit most from home-incubation. However, I found that litters of high decomposability decomposed at a higher rate in home-plots than control plots. The use of standardised substrates allowed me to disentangle the underlying mechanisms. The fast-growing winter cover crops (R. sativus, and mixture of R. sativus $+V$. sativa) appear to stimulate decomposition of their litters through increased fungal biomass.

Recent studies advocate reconsideration of the classic litter decomposition controls (Bradford et al. 2016; Bradford et al. 2017), proposing that micro-organisms are the first and foremost driving factor of decomposition. The results from my field experiment (chapter 3), suggest that fungal biomass and the supply of fresh organic matter are more important to decomposition than differences in soil nitrogen availability, soil organic matter or soil $\mathrm{pH}$. Also, reduction of soil moisture by evapotranspiration by a growing plant reduced decomposition irrespective of litter quality (chapter 3). In addition to microbial biomass, microbial communities can be functionally dissimilar but also communities of similar community composition may still function differently depending on the substrate provided (Strickland et al. 2009a; Strickland et al. 2009b). In other words, different litters are decomposed at different rates by the same microbial community but also the same litter can appear to be of different quality to different microbial communities because of variation 
of their inherent capacity (ability to produce enzymes necessary for litter decomposition) to break down this litter. This implies that responses of microbial biomass and functional composition to environmental change control carbon and nitrogen cycling. I propose that frequent inputs of fresh plant residue in large amount and of mixed quality can stimulate both biomass and functional ability of the decomposer community and can offer a sustainable means of managing nutrient-cycling in agriculture.

\subsubsection{Priming effects of growing plants, a living legacy?}

Whereas frequent resource supply to the microbial community can change its functional composition on the long term, on the short term additional resources can alter microbial activity. Activity of decomposers that break down soil organic matter can be facilitated by the presence of living roots, as rhizodeposits are a labile substrate and can fuel the Nmining from the more recalcitrant organic matter, e.g. positive priming (Kuzyakov 2010). In literature varying results are reported about the influence of a growing plant on the decomposition of plant litter. Both positive (Cheng \& Coleman 1990; van der Krift et al. 2001a; van der Krift, Kuikman \& Berendse 2002), and negative (Bek 1994; Saar et al. 2016) priming effects have been found. The magnitude of the priming effects can differ between litter species and species of plant present (van der Krift et al. 2001a; van der Krift, Kuikman \& Berendse 2002), and was found to depend on litter quality (Saar et al. 2016).

In chapter 4, I tested whether the presence of different plant species would stimulate litter decomposition differently and whether the priming effect depends on litter quality. Rhizodeposition can vary in quantity and quality depending on the plant species (van der Krift et al. 2001b; Jones, Hodge \& Kuzyakov 2004), which could explain observed differences of priming effect between plant species present (chapter 4). Contrary to my expectations, the overall effect of plant presence was negative (chapter 4). In Saar et al. (2016), white clover (Trifolium repens) reduced decomposition of non-legume roots but did not alter decomposition rates of roots of its own species or other legume species. Dijkstra et al. (2013) proposed that the direction (positive or negative) of the priming effect depends on the level of $\mathrm{N}$ competition that is experienced by the decomposing organisms. In my experiment, the source of variation in $\mathrm{N}$-competition was either caused by the plant species present or the characteristics of the litter, since the same soil was used throughout the experiment. At high mineral N-availability, such as in presence of a legume plant, the labile rhizodeposits is the preferred substrate to decomposers (Dijkstra et al. 2013; Saar et al. 2016). Under low mineral-N conditions, activity of micro-organisms is reduced by plant presence because of $\mathrm{N}$ competition, resulting in negative priming. Alternatively, micro-organisms escape $\mathrm{N}$ competition by utilising the labile $\mathrm{C}$ in the rhizodeposits to access $\mathrm{N}$ in the organic matter (Fontaine, Mariotti \& Abbadie 2003; Dijkstra et al. 2013). Because in my experiment 
most present plant species were non-legumes, and no fertilisation was applied, it is likely that plants and microbes were competing for mineral $\mathrm{N}$.

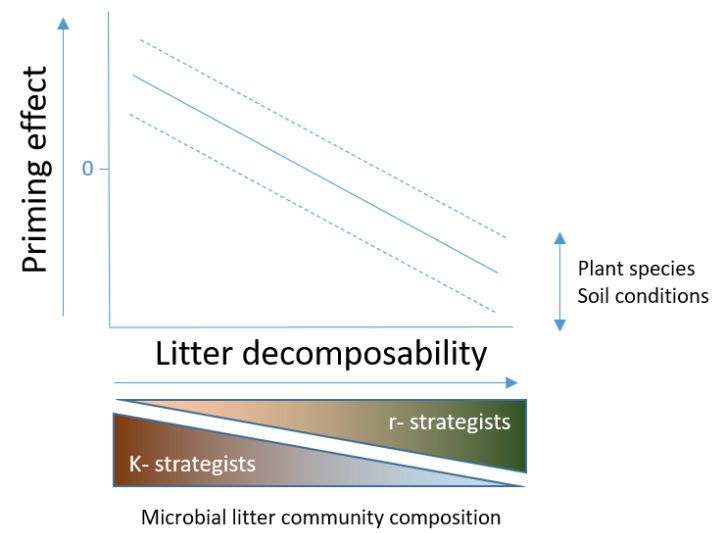

Figure 6.2 Conceptual model indicating underlying mechanism of priming effect and litter decomposability. Recalcitrant litters are expected to be decomposed by a microbial community dominated by K-strategists, labile litter by r-strategist dominated community. Plant presence facilitates decomposition by K-strategists, but competes for $\mathrm{N}$ with r-strategists, resulting in resp. positive or negative priming effects.

In chapter 4, I found that the magnitude of the priming effect depends on the quality of the litter. This relationship was different for crops and wild relatives. Priming effects on wild root and shoot litters were negatively related to litter decomposability (decomposition rate in absence of a growing plant). Priming effect on crop roots was positively related to litter $\mathrm{N}$, but this relationship was not significant for crop shoots. Additionally, decomposability of crop roots was negatively correlated to root litter N. I propose that the decomposability of litter reflects the functional composition of the decomposer community colonising the litter (Fig. 6.2). Easily decomposable litters will promote dominance of opportunistic rstrategists, whose activity is impaired in presence of a plant, i.e. resulting in negative priming. More recalcitrant litters will have decomposer communities dominated by slowgrowing K-strategist, whose activity is not affected or facilitated by plant presence, leading to more positive priming effects.

\subsection{Functionality of functional trait approach}

By relating ecosystem processes to functional plant traits, the interactions between plant and environment can be generalised beyond the plant species used in the experiment, and 
through consideration of variation between and within species (Lavorel \& Garnier 2002; Wright et al. 2004). A trait approach is a means of exploring interactions for which the exact mechanisms are still unknown, as trait-based relationships can indicate the type of underlying mechanism, e.g. being carbon or nitrogen related. In the experiments presented in this thesis, I used a trait approach to study plant legacy effects on soil microbial community composition, litter decomposition and feedbacks to subsequent plant growth. Plant functional traits reflect the physiological trade-offs for plants in cost-effective investment of available resources (Shipley et al. 2006; Reich 2014). I expected that plant specific legacy effects are related to interspecific variation in trait values along the plant economic spectrum (PES). A few of the presented results contradict with this expectation and warrant careful consideration.

In chapters 3 and 4, I presented a negative correlation between litter decomposability and litter $\mathrm{N}$-concentration. Also, litter $\mathrm{N}$ was negatively correlated with litter $\mathrm{C}$ and lignin concentrations in chapter 3 , and for crop root litters a negative correlation between litter $\mathrm{N}$ and $C$ was observed in chapter 4 , which could indicate different physiological trade-offs for legumes than for non-legumes. The legumes in the experimental species pool seem to drive these correlations, which are contradicting the PES-based prediction that fast decomposing litters have high $\mathrm{N}$ but low $\mathrm{C}$ and lignin concentrations. Also other studies found a high lignin concentration for legumes in comparison to forbs and grasses (Cherney et al. 1988; Orwin et al. 2010; García-Palacios et al. 2013; Ramirez-Garcia et al. 2015). McKey (1994) described that high $\mathrm{N}$ concentrations in legumes are a consequence of an $\mathrm{N}$ demanding lifestyle. Because both nodulating and non-nodulating legumes have N-rich tissues, the symbiosis with $\mathrm{N}$-fixing Rhizobia-bacteria appears to be a necessity to acquire sufficient N. Although high leaf-N generally allows for high photosynthetic capacity, nitrogen-fixing plants do not show a relationship between leaf $\mathrm{N}$ and photosynthesis, as non-N fixing plants do (Adams et al. 2016). Moreover, N-rich plant tissues are attractive to plant herbivores. In response to increased herbivory pressure, legumes are found to have high concentrations of N-rich defence chemicals in their leaves (McKey 1994), which could explain the negative relationship between shoot litter $\mathrm{N}$ concentration and decomposability found in chapter 3.

Moreover, PES theory was developed based on studies including large databases, and a wide range of trait values by inclusion of plants from all major biomes (Diaz et al. 2004; Wright et al. 2004; Reich 2014). Crop plants have a highly acquisitive growth strategy, as do their wild ancestors (García-Palacios et al. 2013; Milla et al. 2014). Closely related wild relatives used in chapters 4 and 5 occur in nutrient rich grasslands. In other words, the plant species pool I selected represents a small section of the PES and focussed at the 'fast' or 'acquisitive' side of the spectrum. Freschet et al. (2015) demonstrated that plant species occurring under the same conditions can have different strategies to maintain a balance in acquisition traits above- and belowground. The low C:N ratio observed for shoot of F. rubra and C. intybus in chapter 4 could be an example of co-occurring strategies. Moreover, 
indications of an economic spectrum for roots are much more recent and less widely tested than the leaf economic spectrum (Freschet et al. 2010; Reich 2014; Roumet et al. 2016), and is still under debate (Ma et al. 2018). While a functional trait approach is insightful when exploring underlying mechanisms and ecological implications of plant-soil interactions, I caution interpreting those results in terms of a root carbon-economy, particularly when the study covers a limited range in trait values.

\subsection{Lessons from agricultural \& natural ecosystems}

Plant-soil interactions have been studied in research fields of agro-ecology and natural plant ecology, largely independent from one another (Mariotte et al. 2018). In this thesis, I have compared the two systems by using pairs of crops and closely related wild plants. Selection pressures in agro- and natural ecosystems differ, with possible consequences for plant trait values and related interactions (Philippot et al. 2013; Milla et al. 2015; Mariotte et al. 2018). In chapters 4 and 5, I tested whether crops had consistently different trait values than wild plants. In line with earlier findings (Milla \& Matesanz 2017; Roucou et al. 2018), crops produced more aboveground biomass (chapter 5). However, other trait differences that were found did not have a consistent direction for all plant pairs included. In other words, I found that differences in trait values between crops and wild plants are not consistent, but are, more likely, a product of different domestication objectives. For example, catch cover crops L. perenne and R. sativus had increased fine-root mass fractions in comparison to their wild relatives, whereas this was decreased for crops in other pairs (chapter 5).

Additionally, associations of plants with soil organisms was proposed to be different for crops and wild plants (Philippot et al. 2013; Pérez-Jaramillo, Mendes \& Raaijmakers 2016). In chapter 5, I found this is indeed the case. Different associations with micro-organisms can have implications for soil health. It would be important to test whether the varying interactions of crops and wild plants with soil organisms have functional consequences, e.g. mutualistic interactions, development of disease suppression, or mineralisation of plant nutrients. Such functional consequences have already been found for the mutualistic interactions between crops and arbuscular mycorrhizal fungi (Martín-Robles et al. 2018). Furthermore, variation in controls of root decomposition between crops and wild plants that were found in chapter 4 can have important implications for nutrient cycling. Particularly because input of root biomass is more important for C-cycling in agriculture than in natural ecosystems (Freschet et al. 2013; Jackson et al. 2017).

Where plant ecology focusses on the implications of plant-soil interactions in terms of plant community dynamics, such generalisations are less relevant for agro-ecology. Cropping systems mostly include a single (monocultures) or a few crop species (mixtures, 
intercropping), which makes feedbacks between individual plant species highly relevant. Moreover, in agro-ecosystems there is ample scope to also study impacts of intra-specific trait variation and plant legacy effects as well (Philippot et al. 2013; Milla et al. 2015; Lammerts van Bueren \& Struik 2017). For example, Brassica crop and cultivars vary in levels of secondary metabolites and their ability to suppress plant parasitic nematodes (Fourie et al. 2016; Park et al. 2017). Therefore, I also recommend studies on plant-soil interactions in agro-ecosystems to include intraspecific plant trait variation in order to explore the full potential of optimizing crop traits to shape their soil legacies for sustainable management of agro-ecosystems. In natural plant ecology, understanding of plant legacy effects on ecosystem functioning can be improved by studying legacy effects of plant communities along a diversity gradient, to test to what extend diversity effects on plant legacies are sustaining the diversity effects observed in natural plant communities.

\subsection{Concluding remarks \& recommendations}

Analogous to the legacy that people pass on to their heirs, the inheritance of a plant can have a large impact on subsequent plants and their surroundings. I studied how plant growth strategies influence a plant's inheritance, and if this can be captured by plant functional traits. Functional traits are the manifestation of evolutionary and contemporal (plasticity) adaptation to stresses and disturbances in the plant's environment. By comparing closely related plants from agricultural cropping systems and natural grasslands, I studied whether differences in growth strategies of wild plants and crops influenced the effects of their legacies on soil functioning and subsequent plant growth. This thesis makes an important contribution to the scientific understanding of plant legacies. The comparison of crops to wild plants bridges a gap in our general understanding of plant-soil interactions. Where many other studies focussed on domestication of single crop species and intra-specific variation, I compared a range of crops and wild plants to unearth generalities and differences of plant-soil interactions between agro- and natural ecosystems.

My work did not only provide answers, the results from this thesis also raised new questions that require scientific attention in future work. Notably the interdependency between soil conditions and plant species influences on the soil community require a more extensive functional approach. Furthermore, the relative large importance of root biomass input in agricultural systems and the contrasting results on decomposition drivers for crop roots make a closer look at the decomposition processes in agriculture indispensable for our understanding of carbon storage and nutrient cycling. Both during their life and afterlife plants influence decomposition processes. The suppression of litter decomposition rates in the presence of growing plants has implications for $\mathrm{C}$ - and $\mathrm{N}$ cycling if this suppression is matched by decreased nutrient mineralisation from fresh litter and soil 
organic matter. Importantly, interactions between plants and decomposers could then affect nutrient synchronisation in agriculture and nutrient-mediated feedbacks in natural ecosystems. A functional trait approach can therefore be helpful in studying ecosystem processes. However, generalisations based on plant economic strategies and abovebelowground trait coordination for crop plants should be made with care as I found indications for a certain level of decoupling between shoot and root traits and decomposition in crops.

In conclusion, I found that a plant's inheritance can be predicted based on its functional traits: both the economic aspects (biomass and nutrient concentrations) of a plant's inheritance, as also the relationships with other organisms. Like the financial value and liquidity of the inheritance of a person, the legacy of a plant comprises the amount of resources and their quality, which stimulates the economy of the soil. Fresh resources are recycled to capitalise the nutrients and energy assimilated within, and the recycling speed is influenced by the quality of the resources and its liquidity in the eyes of the decomposers. In a field experiment, I demonstrated that stimulating the soil economy by high amount of resources of high quality can stimulate subsequent plant productivity. I also found that the presence of other growing plants influences the recycling of plant residues, thus the inheritor can influence the legacy of a predecessor. Crops generally produce aboveground biomass of a higher decomposability (liquidity) than closely related wild plants, but the economic value of crop roots differ from wild plant roots in ways that cannot be predicted based on plant economic strategies. Moreover, crops and wild plants seem to differ in the way they interact with soil micro-organisms, which could impact their own growth and the soil-plant interactions of their successors. Results from my field experiment suggest that crops, like wild plants, pass on potential detrimental relationships with soil-organisms. Particularly plants that are closely related to each other, are sensitive to these effects, like parents infecting their children with diseases. Moreover, effects of a plant's inheritance can extend beyond the upcoming growing season, like the legacy of grandparents influencing the prosperity of grandchildren. 


\section{Literature References}

Adams, M.A., Turnbull, T.L., Sprent, J.I. \& Buchmann, N. (2016) Legumes are different: Leaf nitrogen, photosynthesis, and water use efficiency. Proceedings of the National Academy of Sciences, 113, 4098-4103.

Austin, A.T., Vivanco, L., González-Arzac, A. \& Pérez, L.I.C. (2014) There's no place like home? An exploration of the mechanisms behind plant litter-decomposer affinity in terrestrial ecosystems. New Phytologist, 204, 307-314.

Ayres, E., Steltzer, H., Berg, S. \& Wall, D.H. (2009) Soil biota accelerate decomposition in high-elevation forests by specializing in the breakdown of litter produced by the plant species above them. Journal of Ecology, 97, 901-912.

Bååth, E. (2001) Estimation of fungal growth rates in soil using 14C-acetate incorporation into ergosterol. Soil Biology and Biochemistry, 33, 2011-2018.

Barberán, A., McGuire, K.L., Wolf, J.A., Jones, F.A., Wright, S.J., Turner, B.L., Essene, A., Hubbell, S.P., Faircloth, B.C. \& Fierer, N. (2015) Relating belowground microbial composition to the taxonomic, phylogenetic, and functional trait distributions of trees in a tropical forest. Ecology Letters, 18, 1397-1405.

Bardgett, R.D. (2017) Plant trait-based approaches for interrogating belowground function. Biology and Environment: Proceedings of the Royal Irish Academy, 117B, 1-13.

Bardgett, R.D., Mommer, L. \& De Vries, F.T. (2014) Going underground: root traits as drivers of ecosystem processes. Trends in Ecology \& Evolution, 29, 692-699.

Bardgett, R.D. \& van der Putten, W.H. (2014) Belowground biodiversity and ecosystem functioning. 515, 505-511.

Barel, J.M., Kuyper, T.W., de Boer, W., Douma, J.C. \& De Deyn, G.B. (2017) Data from: Legacy effects of diversity in space and time driven by winter cover crop biomass and nitrogen concentration. Dryad Digital Repository, doi:10.5061/dryad.sp5021b.

Barel, J.M., Kuyper, T.W., de Boer, W., Douma, J.C. \& De Deyn, G.B. (2018) Legacy effects of diversity in space and time driven by winter cover crop biomass and nitrogen concentration. Journal of Applied Ecology, 55, 299-310.

Bartelt-Ryser, J., Joshi, J., Schmid, B., Brandl, H. \& Balser, T. (2005) Soil feedbacks of plant diversity on soil microbial communities and subsequent plant growth. Perspectives in Plant Ecology, Evolution and Systematics, 7, 27-49.

Barton, K. (2017) Multi-Model Inference.

Bates, S.T., Berg-Lyons, D., Caporaso, J.G., Walters, W.A., Knight, R. \& Fierer, N. (2011) Examining the global distribution of dominant archaeal populations in soil. The Isme Journal, 5, 908-917.

Bek, S. (1994) Mineralization of 14C-labelled unripe straw in soil with and without rape (Brassica napus L.). Biology and Fertility of Soils, 17, 21-26.

Bender, S.F., Wagg, C. \& van der Heijden, M.G.A. (2016) An Underground Revolution: Biodiversity and Soil Ecological Engineering for Agricultural Sustainability. Trends in Ecology \& Evolution, 31, 440-452.

Bengtsson-Palme, J., Ryberg, M., Hartmann, M., Branco, S., Wang, Z., Godhe, A., De Wit, P., Sánchez-García, M., Ebersberger, I., de Sousa, F., Amend, A., Jumpponen, A., Unterseher, M., Kristiansson, E., Abarenkov, K., Bertrand, Y.J.K., Sanli, K., Eriksson, K.M., Vik, U., Veldre, V. \& Nilsson, R.H. (2013) Improved software detection and extraction of ITS1 and ITS2 from ribosomal ITS sequences of fungi 
and other eukaryotes for analysis of environmental sequencing data. Methods in Ecology and Evolution, 4, 914-919.

Berendsen, R.L., Pieterse, C.M.J. \& Bakker, P.A.H.M. (2012) The rhizosphere microbiome and plant health. Trends in Plant Science, 17, 478-486.

Berg, B. \& Meentemeyer, V. (2002) Litter quality in a north European transect versus carbon storage potential. Plant and Soil, 242, 83-92.

Berg, G. \& Smalla, K. (2009) Plant species and soil type cooperatively shape the structure and function of microbial communities in the rhizosphere. FEMS Microbiology Ecology, 68, 1-13.

Bever, J.D. (1994) Feedback between plants and their soil communities in an old field community. Ecology, 75, 1965-1977.

Bever, J.D., Westover, K.M. \& Antonovics, J. (1997) Incorporating the soil community into plant population dynamics: The utility of the feedback approach. Journal of Ecology, 85, 561-573.

Bingeman, C.W., Varner, J.E. \& Martin, W.P. (1953) The effect of the addition of organic materials on the decomposition of an organic soil. Soil Science Society Proceedings, $17,4$.

Birouste, M., Kazakou, E., Blanchard, A. \& Roumet, C. (2012) Plant traits and decomposition: Are the relationships for roots comparable to those for leaves? 109, 463-472.

Blagodatskaya, E.V., Blagodatsky, S.A., Anderson, T.H. \& Kuzyakov, Y. (2007) Priming effects in Chernozem induced by glucose and $\mathrm{N}$ in relation to microbial growth strategies. Applied Soil Ecology, 37, 95-105.

Bouma, T.J., Nielsen, K.L. \& Koutstaal, B. (2000) Sample preparation and scanning protocol for computerised analysis of root length and diameter. Plant and Soil, 218, 185-196.

Bradford, M.A., Berg, B., Maynard, D.S., Wieder, W.R. \& Wood, S.A. (2016) Understanding the dominant controls on litter decomposition. Journal of Ecology, 104, 229-238.

Bradford, M.A., Veen, G.F., Bonis, A., Bradford, E.M., Classen, A.T., Cornelissen, J.H.C., Crowther, T.W., De Long, J.R., Freschet, G.T., Kardol, P., Manrubia-Freixa, M., Maynard, D.S., Newman, G.S., Logtestijn, R.S.P., Viketoft, M., Wardle, D.A., Wieder, W.R., Wood, S.A. \& van der Putten, W.H. (2017) A test of the hierarchical model of litter decomposition. Nature Ecology E Evolution, 1, 1836-1845.

Brandsæter, L.O., Heggen, H., Riley, H., Stubhaug, E. \& Henriksen, T.M. (2008) Winter survival, biomass accumulation and $\mathrm{N}$ mineralization of winter annual and biennial legumes sown at various times of year in Northern Temperate Regions. European Journal of Agronomy, 28, 437-448.

Brennan, E.B. \& Acosta-Martinez, V. (2017) Cover cropping frequency is the main driver of soil microbial changes during six years of organic vegetable production. Soil Biology and Biochemistry, 109, 188-204.

Brinkman, P.E., Van der Putten, W.H., Bakker, E.-J. \& Verhoeven, K.J.F. (2010) Plant-soil feedback: experimental approaches, statistical analyses and ecological interpretations. Journal of Ecology, 98, 1063-1073.

Brolsma, K.M., Vonk, J.A., Hoffland, E., Mulder, C. \& de Goede, R.G.M. (2015) Effects of GM potato Modena on soil microbial activity and litter decomposition fall within 
the range of effects found for two conventional cultivars. Biology and Fertility of Soils, 51, 913-922.

Buée, M., de Boer, W., Martin, F., van Overbeek, L. \& Jurkevitch, E. (2009) The rhizosphere zoo: An overview of plant-associated communities of microorganisms, including phages, bacteria, archaea, and fungi, and of some of their structuring factors. Plant and Soil, 321, 189-212.

Bulgarelli, D., Garrido-Oter, R., Münch, Philipp C., Weiman, A., Dröge, J., Pan, Y., McHardy, Alice C. \& Schulze-Lefert, P. (2015) Structure and Function of the Bacterial Root Microbiota in Wild and Domesticated Barley. Cell Host $\mathcal{E}$ Microbe, 17, 392-403.

Bulgarelli, D., Schlaeppi, K., Spaepen, S., Themaat, E.V.L.v. \& Schulze-Lefert, P. (2013) Structure and Functions of the Bacterial Microbiota of Plants. Annual Review of Plant Biology, 64, 807-838.

Campiglia, E., Mancinelli, R., Di Felice, V. \& Radicetti, E. (2014) Long-term residual effects of the management of cover crop biomass on soil nitrogen and yield of endive (Cichorium endivia L.) and savoy cabbage (Brassica oleracea var. sabauda). Soil $\mathcal{E}$ Tillage Research, 139, 1-7.

Cantarel, A.A.M., Pommier, T., Desclos-Theveniau, M., Diquélou, S., Dumont, M., Grassein, F., Kastl, E.-M., Grigulis, K., Laîné, P., Lavorel, S., Lemauviel-Lavenant, S., Personeni, E., Schloter, M. \& Poly, F. (2015) Using plant traits to explain plantmicrobe relationships involved in nitrogen acquisition. Ecology, 96, 788-799.

Carter, M.R. (2002) Soil Quality for Sustainable Land Management. Agronomy Journal, 94, 38-47.

Cebrian, J. (1999) Patterns in the Fate of Production in Plant Communities. The American Naturalist, 154, 449-468.

Chavarría, D.N., Verdenelli, R.A., Serri, D.L., Restovich, S.B., Andriulo, A.E., Meriles, J.M. \& Vargas-Gil, S. (2016) Effect of cover crops on microbial community structure and related enzyme activities and macronutrient availability. European Journal of Soil Biology, 76, 74-82.

Chen, D., Pan, Q., Bai, Y., Hu, S., Huang, J., Wang, Q., Naeem, S., Elser, J.J., Wu, J. \& Han, $X$. (2016) Effects of plant functional group loss on soil biota and net ecosystem exchange: A plant removal experiment in the Mongolian grassland. Journal of Ecology, 104, 734-743.

Cheng, W. (1999) Rhizosphere feedbacks in elevated CO2. Tree Physiology, 19, 313-320.

Cheng, W. \& Coleman, D.C. (1990) Effect of living roots on soil organic matter decomposition. Soil Biology and Biochemistry, 22, 781-787.

Cherney, J.H., Johnson, K.D., Volenec, J.J. \& Anliker, K.S. (1988) Chemical composition of herbaceous grass and legume species grown for maximum biomass production. Biomass, 17, 215-238.

Cleveland, C.C. \& Liptzin, D. (2007) C:N:P stoichiometry in soil: is there a "Redfield ratio" for the microbial biomass? Biogeochemistry, 85, 235-252.

Cole, J.R., Wang, Q., Fish, J.A., Chai, B., McGarrell, D.M., Sun, Y., Brown, C.T., PorrasAlfaro, A., Kuske, C.R. \& Tiedje, J.M. (2014) Ribosomal Database Project: data and tools for high throughput rRNA analysis. Nucleic Acids Research, 42, D633-D642.

Coleman-Derr, D., Desgarennes, D., Fonseca-Garcia, C., Gross, S., Clingenpeel, S., Woyke, T., North, G., Visel, A., Partida-Martinez, L.P. \& Tringe, S.G.C. (2016) Plant 
compartment and biogeography affect microbiome composition in cultivated and native Agave species. New Phytologist, 209, 798-811.

Cong, W.F., van Ruijven, J., Mommer, L., De Deyn, G.B., Berendse, F. \& Hoffland, E. (2014) Plant species richness promotes soil carbon and nitrogen stocks in grasslands without legumes. Journal of Ecology, 102, 1163-1170.

Cornelissen, J.H.C., Quested, H.M., Van Logtestijn, R.S.P., Pérez-Harguindeguy, N., Gwynn-Jones, D., Díaz, S., Callaghan, T.V., Press, M.C. \& Aerts, R. (2006) Foliar $\mathrm{pH}$ as a new plant trait: Can it explain variation in foliar chemistry and carbon cycling processes among subarctic plant species and types? Oecologia, 147, 315-326.

Cornwell, W.K., Cornelissen, J.H.C., Amatangelo, K., Dorrepaal, E., Eviner, V.T., Godoy, O., Hobbie, S.E., Hoorens, B., Kurokawa, H., Pérez-Harguindeguy, N., Quested, H.M., Santiago, L.S., Wardle, D.A., Wright, I.J., Aerts, R., Allison, S.D., Van Bodegom, P., Brovkin, V., Chatain, A., Callaghan, T.V., Díaz, S., Garnier, E., Gurvich, D.E., Kazakou, E., Klein, J.A. et al. (2008) Plant species traits are the predominant control on litter decomposition rates within biomes worldwide. Ecology Letters, 11, 1065-1071.

Cortois, R., Schröder-Georgi, T., Weigelt, A., van der Putten, W.H. \& De Deyn, G.B. (2016) Plant-soil feedbacks: role of plant functional group and plant traits. Journal of Ecology, 104, 1608-1617.

Cortois, R., Veen, G.F., Duyts, H., Abbas, M., Strecker, T., Kostenko, O., Eisenhauer, N., Scheu, S., Gleixner, G., De Deyn, G.B. \& Putten, W.H.v.d. (2017) Possible mechanisms underlying abundance and diversity responses of nematode communities to plant diversity. Ecosphere, 8, e01719.

de Bello, F., Lavorel, S., Díaz, S., Harrington, R., Cornelissen, J.H.C., Bardgett, R.D., Berg, M.P., Cipriotti, P., Feld, C.K., Hering, D., da Silva, P.M., Potts, S.G., Sandin, L., Sousa, J.P., Storkey, J., Wardle, D.A. \& Harrison, P.A. (2010) Towards an assessment of multiple ecosystem processes and services via functional traits. Biodiversity and Conservation, 19, 2873-2893.

De Deyn, G.B., Cornelissen, J.H.C. \& Bardgett, R.D. (2008) Plant functional traits and soil carbon sequestration in contrasting biomes. Ecology Letters, 11, 516-531.

De Deyn, G.B., Quirk, H., Yi, Z., Oakley, S., Ostle, N.J. \& Bardgett, R.D. (2009) Vegetation composition promotes carbon and nitrogen storage in model grassland communities of contrasting soil fertility. Journal of Ecology, 97, 864-875.

de Ridder-Duine, A.S., Smant, W., van der Wal, A., van Veen, J.A. \& de Boer, W. (2006) Evaluation of a simple, non-alkaline extraction protocol to quantify soil ergosterol. Pedobiologia, 50, 293-300.

Delgado-Baquerizo, M., Powell, J.R., Hamonts, K., Reith, F., Mele, P., Brown, M.V., Dennis, P.G., Ferrari, B.C., Fitzgerald, A., Young, A., Singh, B.K. \& Bissett, A.C. (2017) Circular linkages between soil biodiversity, fertility and plant productivity are limited to topsoil at the continental scale. New Phytologist, 215, 1186-1196.

Delgado-Baquerizo, M., Reich, P.B., García-Palacios, P. \& Milla, R. (2016) Biogeographic bases for a shift in crop C: N: P stoichiometries during domestication. Ecology Letters, 19, 564-575.

Dias, T., Dukes, A. \& Antunes, P.M. (2014) Accounting for soil biotic effects on soil health and crop productivity in the design of crop rotations. Journal of the Science of Food and Agriculture, 95, 447-454. 
Diaz, S., Hodgson, J.G., Thompson, K., Cabido, M., Cornelissen, J.H.C., Jalili, A., Montserrat-Marti, G., Grime, J.P., Zarrinkamar, F., Asri, Y., Band, S.R., Basconcelo, S., Castro-Diez, P., Funes, G., Hamzehee, B., Khoshnevi, M., Perez-Harguindeguy, N., Perez-Rontome, M.C., Shirvany, F.A., Vendramini, F., Yazdani, S., AbbasAzimi, R., Bogaard, A., Boustani, S., Charles, M. et al. (2004) The plant traits that drive ecosystems: Evidence from three continents. Journal of Vegetation Science, 15, 295-304.

Dignam, B.E.A., O'Callaghan, M., Condron, L.M., Kowalchuk, G.A., Van Nostrand, J.D., Zhou, J. \& Wakelin, S.A. (2018) Effect of land use and soil organic matter quality on the structure and function of microbial communities in pastoral soils: Implications for disease suppression. PLoS ONE, 13, e 0196581.

Dijksma, S. (2014) Wijzigingen in invulling van de vergroening GLB, DGA-ELV/14119366. Den Haag, The Netherlands.

Dijkstra, F., Carrillo, Y., Pendall, E. \& Morgan, J. (2013) Rhizosphere priming: a nutrient perspective. Frontiers in Microbiology, 4.

Djukic, I., Kepfer-Rojas, S., Schmidt, I.K., Larsen, K.S., Beier, C., Berg, B., Verheyen, K., Caliman, A., Paquette, A., Gutiérrez-Girón, A., Humber, A., Valdecantos, A., Petraglia, A., Alexander, H., Augustaitis, A., Saillard, A., Fernández, A.C.R., Sousa, A.I., Lillebø, A.I., da Rocha Gripp, A., Francez, A.-J., Fischer, A., Bohner, A., Malyshev, A., Andrić, A. et al. (2018) Early stage litter decomposition across biomes. Science of The Total Environment, 628-629, 1369-1394.

Dodt, M., Roehr, J., Ahmed, R. \& Dieterich, C. (2012) FLEXBAR-Flexible Barcode and Adapter Processing for Next-Generation Sequencing Platforms. Biology, 1, 895.

Duval, M.E., Galantini, J.A., Capurro, J.E. \& Martinez, J.M. (2016) Winter cover crops in soybean monoculture: Effects on soil organic carbon and its fractions. Soil and Tillage Research, 161, 95-105.

Edgar, R.C. (2010) Search and clustering orders of magnitude faster than BLAST. Bioinformatics, 26, 2460-2461.

Edgar, R.C., Haas, B.J., Clemente, J.C., Quince, C. \& Knight, R. (2011) UCHIME [WWW Document]. URL http://www.drive5.com/uchime/ (accessed 6.20.11).

Ehrenfeld, J.G., Ravit, B. \& Elgersma, K. (2005) Feedback in the plant-soil system. Annual Review of Environment and Resources, 30, 75-115.

Fanin, N., Hättenschwiler, S. \& Fromin, N. (2014) Litter fingerprint on microbial biomass, activity, and community structure in the underlying soil. Plant and Soil, 379, 79-91.

FAO (2017) Volunatary guidelines for sustainable soil management. Food and Agriculture Organization of the United Nations, Rome, Italy.

Faucon, M.-P., Houben, D. \& Lambers, H. (2017) Plant Functional Traits: Soil and Ecosystem Services. Trends in Plant Science, 22, 385-394.

Fierer, N., Lauber, C.L., Ramirez, K.S., Zaneveld, J., Bradford, M.A. \& Knight, R. (2011) Comparative metagenomic, phylogenetic and physiological analyses of soil microbial communities across nitrogen gradients. The Isme Journal, 6, 1007.

Finney, D.M. \& Kaye, J.P. (2017) Functional diversity in cover crop polycultures increases multifunctionality of an agricultural system. Journal of Applied Ecology, 54, 509-517.

Finney, D.M., White, C.M. \& Kaye, J.P. (2016) Biomass Production and Carbon/Nitrogen Ratio Influence Ecosystem Services from Cover Crop Mixtures. Agronomy Journal, $108,39-52$. 
Fitzpatrick, C.R., Copeland, J., Wang, P.W., Guttman, D.S., Kotanen, P.M. \& Johnson, M.T.J. (2018) Assembly and ecological function of the root microbiome across angiosperm plant species. Proceedings of the National Academy of Sciences, 115, E1157-E1165.

Fontaine, S., Mariotti, A. \& Abbadie, L. (2003) The priming effect of organic matter: a question of microbial competition? Soil Biology and Biochemistry, 35, 837-843.

Fourie, H., Ahuja, P., Lammers, J. \& Daneel, M. (2016) Brassicacea-based management strategies as an alternative to combat nematode pests: A synopsis. Crop Protection, 80, 21-41.

Francioli, D., Schulz, E., Purahong, W., Buscot, F. \& Reitz, T. (2016) Reinoculation elucidates mechanisms of bacterial community assembly in soil and reveals undetected microbes. Biology and Fertility of Soils, 1-11.

Freschet, G.T., Aerts, R. \& Cornelissen, J.H.C. (2012a) Multiple mechanisms for trait effects on litter decomposition: Moving beyond home-field advantage with a new hypothesis. Journal of Ecology, 100, 619-630.

Freschet, G.T., Aerts, R. \& Cornelissen, J.H.C. (2012b) A plant economics spectrum of litter decomposability. Functional Ecology, 26, 56-65.

Freschet, G.T., Cornelissen, J.H.C., van Logtestijn, R.S.P. \& Aerts, R. (2010) Evidence of the 'plant economics spectrum' in a subarctic flora. Journal of Ecology, 98, 362-373.

Freschet, G.T., Cornwell, W.K., Wardle, D.A., Elumeeva, T.G., Liu, W., Jackson, B.G., Onipchenko, V.G., Soudzilovskaia, N.A., Tao, J. \& Cornelissen, J.H.C. (2013) Linking litter decomposition of above- and below-ground organs to plant-soil feedbacks worldwide. Journal of Ecology, 101, 943-952.

Freschet, G.T., Kichenin, E., Wardle, D.A. \& Bello, F. (2015) Explaining within-community variation in plant biomass allocation: a balance between organ biomass and morphology above vs below ground? Journal of Vegetation Science, 26, 431-440.

Frostegård, A. \& Bååth, E. (1996) The use of phospholipid fatty acid analysis to estimate bacterial and fungal biomass in soil. Biology and Fertility of Soils, 22, 59-65.

Frostegård, Å., Tunlid, A. \& Bååth, E. (2011) Use and misuse of PLFA measurements in soils. Soil Biology and Biochemistry, 43, 1621-1625.

García-Palacios, P., Milla, R., Delgado-Baquerizo, M., Martín-Robles, N., Álvaro-Sánchez, M. \& Wall, D.H. (2013) Side-effects of plant domestication: Ecosystem impacts of changes in litter quality. New Phytologist, 198, 504-513.

Gosling, P., Hodge, A., Goodlass, G. \& Bending, G.D. (2006) Arbuscular mycorrhizal fungi and organic farming. Agriculture, Ecosystems and Environment, 113, 17-35.

Grossman, J.D. \& Rice, K.J. (2012) Evolution of root plasticity responses to variation in soil nutrient distribution and concentration. Evolutionary Applications, 5, 850-857.

Hacquard, S.C. (2016) Disentangling the factors shaping microbiota composition across the plant holobiont. New Phytologist, 209, 454-457.

Harley, J.L. \& Harley, E.L. (1987) A Check-List of Mycorrhiza in the British Flora. The New Phytologist, 105, 1-102.

Harrington, R., Anton, C., Dawson, T., Bello, F., Feld, C., Haslett, J., Kluvánkova-Oravská, T., Kontogianni, A., Lavorel, S., Luck, G., Rounsevell, M.A., Samways, M., Settele, J., Skourtos, M., Spangenberg, J., Vandewalle, M., Zobel, M. \& Harrison, P. (2010) Ecosystem services and biodiversity conservation: concepts and a glossary. 19, 2773-2790. 
Hartmann, A., Rothballer, M. \& Schmid, M. (2008) Lorenz Hiltner, a pioneer in rhizosphere microbial ecology and soil bacteriology research. Plant and Soil, 312, 714.

Hartmann, A., Schmid, M., Tuinen, D. \& Berg, G. (2009) Plant-driven selection of microbes. Plant and Soil, 321, 235-257.

He, Z., Gentry, T.J., Schadt, C.W., Wu, L., Liebich, J., Chong, S.C., Huang, Z., Wu, W., Gu, B., Jardine, P., Criddle, C. \& Zhou, J. (2007) GeoChip: a comprehensive microarray for investigating biogeochemical, ecological and environmental processes. The Isme Journal, 1, 67.

Hedlund, K. (2002) Soil microbial community structure in relation to vegetation management on former agricultural land. Soil Biology and Biochemistry, 34, 12991307.

Heijboer, A., ten Berge, H.F.M., de Ruiter, P.C., Jørgensen, H.B., Kowalchuk, G.A. \& Bloem, J. (2016) Plant biomass, soil microbial community structure and nitrogen cycling under different organic amendment regimes; a ${ }^{15} \mathrm{~N}$ tracer-based approach. Applied Soil Ecology, 107, 251-260.

Hobbie, S.E. (2015) Plant species effects on nutrient cycling: revisiting litter feedbacks. Trends in Ecology and Evolution, 30, 357-363.

Hobbie, S.E., Oleksyn, J., Eissenstat, D.M. \& Reich, P.B. (2010) Fine root decomposition rates do not mirror those of leaf litter among temperate tree species. Oecologia, 162, 505-513.

Hodgson, J.G., Wilson, P.J., Hunt, R., Grime, J.P. \& Thompson, K. (1999) Allocating C-S-R plant functional types: A soft approach to a hard problem. Oikos, 85, 282-294.

Hu, S. \& van Bruggen, A.H.C. (1997) Microbial Dynamics Associated with Multiphasic Decomposition of 14C-Labeled Cellulose in Soil. Microbial Ecology, 33, 134-143.

Huo, C., Luo, Y. \& Cheng, W. (2017) Rhizosphere priming effect: A meta-analysis. Soil Biology and Biochemistry, 111, 78-84.

Ihrmark, K., Bödeker, I.T.M., Cruz-Martinez, K., Friberg, H., Kubartova, A., Schenck, J., Strid, Y., Stenlid, J., Brandström-Durling, M., Clemmensen, K.E. \& Lindahl, B.D. (2012) New primers to amplify the fungal ITS2 region - evaluation by 454sequencing of artificial and natural communities. FEMS Microbiology Ecology, 82, 666-677.

Iverson, A.L., Marín, L.E., Ennis, K.K., Gonthier, D.J., Connor-Barrie, B.T., Remfert, J.L., Cardinale, B.J. \& Perfecto, I. (2014) Do polycultures promote win-wins or tradeoffs in agricultural ecosystem services? A meta-analysis. Journal of Applied Ecology, 51, 1593-1602.

Jackson, R.B., Lajtha, K., Crow, S.E., Hugelius, G., Kramer, M.G. \& Piñeiro, G. (2017) The Ecology of Soil Carbon: Pools, Vulnerabilities, and Biotic and Abiotic Controls. Annual Review of Ecology, Evolution, and Systematics, 48, 419-445.

Johnson, P.C.D. (2014) Extension of Nakagawa \& Schielzeth's R2GLMM to random slopes models. Methods in Ecology and Evolution, 5, 944-946.

Jones, D.L. (1998) Organic acids in the rhizosphere - A critical review. Plant and Soil, 205, 25-44.

Jones, D.L., Hodge, A. \& Kuzyakov, Y. (2004) Plant and mycorrhizal regulation of rhizodeposition. New Phytologist, 163, 459-480.

Kardol, P., De Deyn, G.B., Laliberté, E., Mariotte, P. \& Hawkes, C.V. (2013) Biotic plantsoil feedbacks across temporal scales. Journal of Ecology, 101, 309-315. 
Kardol, P., Veen, G.F.C., Teste, F.P. \& Perring, M.P. (2015) Peeking into the black box: A trait-based approach to predicting plant-soil feedback. New Phytologist, 206, 1-4.

Keeney, D.R. \& Nelson, D.W. (1982) Nitrogen - Inorganic Forms. Methods of Soil Analysis. Part 2. Chemical and Microbiological Properties (ed. A.L. Page), pp. 643-698. American Society of Agronomy, Soil Science Society of America, Madison, WI.

Keiser, A.D., Strickland, M.S., Fierer, N. \& Bradford, M.A. (2011) The effect of resource history on the functioning of soil microbial communities is maintained across time. Biogeosciences, 8, 1477-1486.

Keuskamp, J.A., Dingemans, B.J.J., Lehtinen, T., Sarneel, J.M. \& Hefting, M.M. (2013) Tea Bag Index: A novel approach to collect uniform decomposition data across ecosystems. Methods in Ecology and Evolution, 4, 1070-1075.

Kõljalg, U., Nilsson, R.H., Abarenkov, K., Tedersoo, L., Taylor, A.F.S., Bahram, M., Bates, S.T., Bruns, T.D., Bengtsson-Palme, J., Callaghan, T.M., Douglas, B., Drenkhan, T., Eberhardt, U., Dueñas, M., Grebenc, T., Griffith, G.W., Hartmann, M., Kirk, P.M., Kohout, P., Larsson, E., Lindahl, B.D., Lücking, R., Martín, M.P., Matheny, P.B., Nguyen, N.H. et al. (2013) Towards a unified paradigm for sequence-based identification of fungi. Molecular Ecology, 22, 5271-5277.

Korkmaz, S., Goksuluk, D. \& Zararsiz, G. (2014) Multivariate Normality Tests. The R Journal, 6, 151-162.

Korthals, G.W., Thoden, T.C., van den Berg, W. \& Visser, J.H.M. (2014) Long-term effects of eight soil health treatments to control plant-parasitic nematodes and Verticillium dahliae in agro-ecosystems. Applied Soil Ecology, 76, 112-123.

Köster, J. \& Rahmann, S. (2012) Snakemake - a scalable bioinformatics workflow engine. Bioinformatics, 28, 2520-2522.

Kulmatiski, A., Beard, K.H., Stevens, J.R. \& Cobbold, S.M. (2008) Plant-soil feedbacks: a meta-analytical review. Ecology Letters, 11, 980-992.

Kuzyakov, Y. (2002) Review: Factors affecting rhizosphere priming effects. Journal of Plant Nutrition and Soil Science, 165, 382-396.

Kuzyakov, Y. (2010) Priming effects: Interactions between living and dead organic matter. Soil Biology and Biochemistry, 42, 1363-1371.

Kuzyakov, Y. \& Cheng, W. (2001) Photosynthesis controls of rhizosphere respiration and organic matter decomposition. Soil Biology and Biochemistry, 33, 1915-1925.

Lammerts van Bueren, E.T. \& Struik, P.C. (2017) Diverse concepts of breeding for nitrogen use efficiency. A review. Agronomy for Sustainable Development, 37, 50.

Lauber, C.L., Hamady, M., Knight, R. \& Fierer, N. (2009) Pyrosequencing-Based Assessment of Soil $\mathrm{pH}$ as a Predictor of Soil Bacterial Community Structure at the Continental Scale. Applied and Environmental Microbiology, 75, 5111-5120.

Lavorel, S. \& Garnier, E. (2002) Predicting changes in community composition and ecosystem functioning from plant traits: revisiting the Holy Grail. Functional Ecology, 16, 545-556.

Lavorel, S., McIntyre, S., Landsberg, J. \& Forbes, T.D.A. (1997) Plant functional classifications: From general groups to specific groups based on response to disturbance. Trends in Ecology and Evolution, 12, 474-478.

Lebeis, S.L. (2014) The potential for give and take in plant-microbiome relationships. Frontiers in Plant Science, 5.

Leff, J.W., Bardgett, R.D., Wilkinson, A., Jackson, B.G., Pritchard, W.J., De Long, J.R., Oakley, S., Mason, K.E., Ostle, N.J., Johnson, D., Baggs, E.M. \& Fierer, N. (2018) 
Predicting the structure of soil communities from plant community taxonomy, phylogeny, and traits. The Isme Journal.

Leff, J.W., Lynch, R.C., Kane, N.C. \& Fierer, N.C. (2017) Plant domestication and the assembly of bacterial and fungal communities associated with strains of the common sunflower, Helianthus annuus. New Phytologist, 214, 412-423.

Legay, N., Baxendale, C., Grigulis, K., Krainer, U., Kastl, E., Schloter, M., Bardgett, R.D., Arnoldi, C., Bahn, M., Dumont, M., Poly, F., Pommier, T., Clément, J.C. \& Lavorel, S. (2014) Contribution of above- and below-ground plant traits to the structure and function of grassland soil microbial communities. Annals of Botany, 114, 10111021.

Legay, N., Grassein, F., Binet, M.N., Arnoldi, C., Personeni, E., Perigon, S., Poly, F., Pommier, T., Puissant, J., Clément, J.C., Lavorel, S. \& Mouhamadou, B. (2016) Plant species identities and fertilization influence on arbuscular mycorrhizal fungal colonisation and soil bacterial activities. Applied Soil Ecology, 98, 132-139.

Loreau, M. \& Hector, A. (2001) Partitioning selection and complementarity in biodiversity experiments. Nature, 412, 72-76.

Lundberg, D.S., Lebeis, S.L., Paredes, S.H., Yourstone, S., Gehring, J., Malfatti, S., Tremblay, J., Engelbrektson, A., Kunin, V., Rio, T.G.d., Edgar, R.C., Eickhorst, T., Ley, R.E., Hugenholtz, P., Tringe, S.G. \& Dangl, J.L. (2012) Defining the core Arabidopsis thaliana root microbiome. 488, 86-90.

Lupatini, M., Korthals, G.W., de Hollander, M., Janssens, T.K.S. \& Kuramae, E.E. (2017) Soil Microbiome Is More Heterogeneous in Organic Than in Conventional Farming System. Frontiers in Microbiology, 7.

Ma, Z., Guo, D., Xu, X., Lu, M., Bardgett, R.D., Eissenstat, D.M., McCormack, M.L. \& Hedin, L.O. (2018) Evolutionary history resolves global organization of root functional traits. Nature, 555, 94.

Mariotte, P., Mehrabi, Z., Bezemer, T.M., De Deyn, G.B., Kulmatiski, A., Drigo, B., Veen, G.F., van der Heijden, M.G.A. \& Kardol, P. (2018) Plant-Soil Feedback: Bridging Natural and Agricultural Sciences. Trends in Ecology E Evolution, 33, 129-142.

Martín-Robles, N., Lehmann, A., Seco, E., Aroca, R., Rillig, M.C. \& Milla, R.C. (2018) Impacts of domestication on the arbuscular mycorrhizal symbiosis of 27 crop species. New Phytologist, 218, 322-334.

Martin, A.R. \& Isaac, M.E. (2015) Plant functional traits in agroecosystems: A blueprint for research. Journal of Applied Ecology, 52, 1425-1435.

Masella, A.P., Bartram, A.K., Truszkowski, J.M., Brown, D.G. \& Neufeld, J.D. (2012) PANDAseq: paired-end assembler for illumina sequences. BMC Bioinformatics, 13, 31.

Matesanz, S. \& Milla, R. (2018) Differential plasticity to water and nutrients between crops and their wild progenitors. Environmental and Experimental Botany, 145, 54-63.

McCormack, M.L., Dickie, I.A., Eissenstat, D.M., Fahey, T.J., Fernandez, C.W., Guo, D., Helmisaari, H.S., Hobbie, E.A., Iversen, C.M., Jackson, R.B., LeppälammiKujansuu, J., Norby, R.J., Phillips, R.P., Pregitzer, K.S., Pritchard, S.G., Rewald, B \& Zadworny, M. (2015) Redefining fine roots improves understanding of belowground contributions to terrestrial biosphere processes. New Phytologist, 207, $505-$ 518. 
McDaniel, M.D., Grandy, A.S., Tiemann, L.K. \& Weintraub, M.N. (2014) Crop rotation complexity regulates the decomposition of high and low quality residues. Soil Biology and Biochemistry, 78, 243-254.

McDaniel, M.D., Grandy, A.S., Tiemann, L.K. \& Weintraub, M.N. (2016) Eleven years of crop diversification alters decomposition dynamics of litter mixtures incubated with soil. Ecosphere, 7, e01426.

McDonald, D., Clemente, J.C., Kuczynski, J., Rideout, J.R., Stombaugh, J., Wendel, D., Wilke, A., Huse, S., Hufnagle, J., Meyer, F., Knight, R. \& Caporaso, J.G. (2012) The Biological Observation Matrix (BIOM) format or: how I learned to stop worrying and love the ome-ome. GigaScience, 1, 7.

McKey, D. (1994) Legumes and nitrogen: the evolutionary ecology of a nitrogen-demanding lifestyle. Royal Botanic Gardens, Kew.

McMurdie, P.J. \& Holmes, S. (2013) phyloseq: An R Package for Reproducible Interactive Analysis and Graphics of Microbiome Census Data. PLoS ONE, 8, e61217.

McMurdie, P.J. \& Holmes, S. (2014) Waste Not, Want Not: Why Rarefying Microbiome Data Is Inadmissible. PLOS Computational Biology, 10, e1003531.

Milla, R. \& Matesanz, S. (2017) Growing larger with domestication: a matter of physiology, morphology or allocation? Plant Biology, 19, 475-483.

Milla, R., Morente-López, J., Alonso-Rodrigo, J.M., Martín-Robles, N. \& Stuart Chapin, F. (2014) Shifts and disruptions in resource-use trait syndromes during the evolution of herbaceous crops. Proceedings of the Royal Society B: Biological Sciences, 281.

Milla, R., Osborne, C.P., Turcotte, M.M. \& Violle, C. (2015) Plant domestication through an ecological lens. Trends in Ecology \& Evolution, 30, 463-469.

Mitchell, C.E., Tilman, D. \& Groth, J.V. (2002) Effects of grassland plant species diversity, abundance, and composition on foliar fungal disease. Ecology, 83, 1713-1726.

Möller, K. \& Reents, H.J. (2009) Effects of various cover crops after peas on nitrate leaching and nitrogen supply to succeeding winter wheat or potato crops. Journal of Plant Nutrition and Soil Science, 172, 277-287.

Moretti, M., Dias, A.T.C., Bello, F.d., Altermatt, F., Chown, S.L., Azcárate, F.M., Bell, J.R., Fournier, B., Hedde, M., Hortal, J., Ibanez, S., Öckinger, E., Sousa, J.P., Ellers, J. \& Berg, M.P. (2017) Handbook of protocols for standardized measurement of terrestrial invertebrate functional traits. Functional Ecology, 31, 558-567.

Nesheim, L. \& Boller, B.C. (1991) Nitrogen fixation by white clover when competing with grasses at moderately low temperatures. Plant and Soil, 133, 47-56.

Nyfeler, D., Huguenin-Elie, O., Suter, M., Frossard, E., Connolly, J. \& Lüscher, A. (2009) Strong mixture effects among four species in fertilized agricultural grassland led to persistent and consistent transgressive overyielding. Journal of Applied Ecology, 46, 683-691.

Oksanen, J., Blanchet, F.G., Friendly, M., Kindt, R., Legendre, P., McGlinn, D., Minchin, P.R., O'Hara, R.B., Simpson, G.L., Solymos, P., Stevens, M.H.H., Szoecs, E. \& Wagner, H. (2016) vegan: Community Ecology Package.

Olson, J.S.C.F.p.d.A. (1963) Energy Storage and the Balance of Producers and Decomposers in Ecological Systems. Ecology, 44, 322-331.

Oostenbrink, M. (1960) Estimating nematode populations by some selected methods. Nematology, 85-102. 
Orwin, K.H., Buckland, S.M., Johnson, D., Turner, B.L., Smart, S., Oakley, S. \& Bardgett, R.D. (2010) Linkages of plant traits to soil properties and the functioning of temperate grassland. Journal of Ecology, 98, 1074-1083.

Palm, C.A., Giller, K.E., Mafongoya, P.L. \& Swift, M.J. (2001) Management of organic matter in the tropics: translating theory into practice. Nutrient Cycling in Agroecosystems, 61, 63-75.

Park, W., Kim, K.S., Jang, Y.S., Lee, K., Kim, S.J., Ahn, S.J., Hong, S.W. \& Lee, Y.H. (2017) Variation in glucosinolate contents of cruciferous plants. Records of Natural Products, 11, 185-192.

Parton, W., Silver, W.L., Burke, I.C., Grassens, L., Harmon, M.E., Currie, W.S., King, J.Y., Adair, E.C., Brandt, L.A., Hart, S.C. \& Fasth, B. (2007) Global-Scale Similarities in Nitrogen Release Patterns During Long-Term Decomposition. Science, 315, 361364.

Pérez-Harguindeguy, N., Díaz, S., Garnier, E., Lavorel, S., Poorter, H., Jaureguiberry, P., Bret-Harte, M.S., Cornwell, W.K., Craine, J.M., Gurvich, D.E., Urcelay, C., Veneklaas, E.J., Reich, P.B., Poorter, L., Wright, I.J., Ray, P., Enrico, L., Pausas, J.G., De Vos, A.C., Buchmann, N., Funes, G., Quétier, F., Hodgson, J.G., Thompson, K., Morgan, H.D. et al. (2013) New handbook for standardised measurement of plant functional traits worldwide. Australian Journal of Botany, 61, 167-234.

Perez-Jaramillo, J.E., Carrion, V.J., Bosse, M., Ferrao, L.F.V., de Hollander, M., Garcia, A.A.F., Ramirez, C.A., Mendes, R. \& Raaijmakers, J.M. (2017) Linking rhizosphere microbiome composition of wild and domesticated Phaseolus vulgaris to genotypic and root phenotypic traits. The Isme Journal.

Pérez-Jaramillo, J.E., Mendes, R. \& Raaijmakers, J.M. (2016) Impact of plant domestication on rhizosphere microbiome assembly and functions. Plant Molecular Biology, 90, 635-644.

Philippot, L., Raaijmakers, J.M., Lemanceau, P. \& van der Putten, W.H. (2013) Going back to the roots: the microbial ecology of the rhizosphere. 11, 789-799.

Pinheiro, J., Bates, D., DebRoy, S., Sarkar, D. \& R Core Team (2016) nlme: Linear and Nonlinear Mixed Effects Models.

Poeplau, C. \& Don, A. (2015) Carbon sequestration in agricultural soils via cultivation of cover crops - A meta-analysis. Agriculture, Ecosystems and Environment, 200, 33-41.

Poorter, H. \& Villar, R. (1997) The fate of acquired carbon in plants: chemical composition and construction cost. Plant Resource Allocation (eds F.A. Bazzaz \& J. Grace), pp. 39-72. Academic Press, San Diego, CA.

Prescott, C.E. (2010) Litter decomposition: what controls it and how can we alter it to sequester more carbon in forest soils? Biogeochemistry, 101, 133-149.

R Core Team (2015) R: A language and environment for statistical computing $R$ Foundation for Statistical Computing, Vienna, Austria.

R Core Team (2016) R: A language and environment for statistical computing. R Foundation for Statistical Computing, Vienna, Austria.

R Core Team (2017) R: A language and environment for statistical computing. R Foundation for Statistical Computing, Vienna, Austria.

Raaijmakers, J.M., Paulitz, T.C., Steinberg, C., Alabouvette, C. \& Moënne-Loccoz, Y. (2009) The rhizosphere: A playground and battlefield for soilborne pathogens and beneficial microorganisms. Plant and Soil, 321, 341-361. 
Ramirez-Garcia, J., Gabriel, J.L., Alonso-Ayuso, M. \& Quemada, M. (2015) Quantitative characterization of five cover crop species. The Journal of Agricultural Science, 153, 1174-1185.

Ramirez, K.S., Knight, C.G., de Hollander, M., Brearley, F.Q., Constantinides, B., Cotton, A., Creer, S., Crowther, T.W., Davison, J., Delgado-Baquerizo, M., Dorrepaal, E., Elliott, D.R., Fox, G., Griffiths, R.I., Hale, C., Hartman, K., Houlden, A., Jones, D.L., Krab, E.J., Maestre, F.T., McGuire, K.L., Monteux, S., Orr, C.H., van der Putten, W.H., Roberts, I.S. et al. (2017) Detecting macroecological patterns in bacterial communities across independent studies of global soils. Nature Microbiology.

Rashid, M.I., de Goede, R.G.M., Brussaard, L. \& Lantinga, E.A. (2013) Home field advantage of cattle manure decomposition affects the apparent nitrogen recovery in production grasslands. Soil Biology and Biochemistry, 57, 320-326.

Rashid, M.I., Lantinga, E.A., Brussaard, L. \& de Goede, R.G.M. (2017) The chemical convergence and decomposer control hypotheses explain solid cattle manure decomposition in production grasslands. Applied Soil Ecology, 113, 107-116.

Reich, P.B. (2014) The world-wide 'fast-slow' plant economics spectrum: a traits manifesto. Journal of Ecology, 102, 275-301.

Rognes, T., Flouri, T., Nichols, B., Quince, C. \& Mahé, F. (2016) VSEARCH: a versatile open source tool for metagenomics. PeerJ, 4, e2584.

Rosseel, Y. (2012) Lavaan: An R package for structural equation modeling. Journal of Statistical Software, 48, 1-36.

Roucou, A., Violle, C., Fort, F., Roumet, P., Ecarnot, M., Vile, D. \& Martin, A. (2018) Shifts in plant functional strategies over the course of wheat domestication. Journal of Applied Ecology, 55, 25-37.

Roumet, C., Birouste, M., Picon-Cochard, C., Ghestem, M., Osman, N., Vrignon-Brenas, S., Cao, K.f. \& Stokes, A. (2016) Root structure-function relationships in 74 species: evidence of a root economics spectrum related to carbon economy. New Phytologist, 210, 815-826.

Ruess, L. \& Chamberlain, P.M. (2010) The fat that matters: Soil food web analysis using fatty acids and their carbon stable isotope signature. Soil Biology and Biochemistry, 42, 1898-1910.

Saar, S., Semchenko, M., Barel, J.M. \& De Deyn, G.B. (2016) Legume presence reduces the decomposition rate of non-legume roots. Soil Biology and Biochemistry, 94, 88-93.

Scherer-Lorenzen, M. (2008) Functional diversity affects decomposition processes in experimental grasslands. Functional Ecology, 22, 547-555.

Schlaeppi, K. \& Bulgarelli, D. (2014) The Plant Microbiome at Work. Molecular PlantMicrobe Interactions, 28, 212-217.

Schmid, B., Hector, A., Saha, P. \& Loreau, M. (2008) Biodiversity effects and transgressive overyielding. Journal of Plant Ecology, 1, 95-102.

Schnitzer, S.A., Klironomos, J.N., HilleRisLambers, J., Kinkel, L.L., Reich, P.B., Xiao, K., Rillig, M.C., Sikes, B.A., Callaway, R.M., Mangan, S.A., Van Nes, E.H. \& Scheffer, M. (2011) Soil microbes drive the classic plant diversity-productivity pattern. Ecology, 92, 296-303.

Shipley, B. (2016) Cause and Correlation in Biology; A User's Guide to Path Analysis, Structural Equations and Causal Inference with $R$. Cambridge University Press, Cambridge. 
Shipley, B., Lechowicz, M.J., Wright, I. \& Reich, P.B. (2006) Fundamental trade-offs generating the worldwide leaf economics spectrum. Ecology, 87, 535-541.

Silver, W.L. \& Miya, R.K. (2001) Global patterns in root decomposition: comparisons of climate and litter quality effects. Oecologia, 129, 407-419.

Singh, S.K., Hodda, M. \& Ash, G.J. (2013) Plant-parasitic nematodes of potential phytosanitary importance, their main hosts and reported yield losses. EPPO Bulletin, 43, 334-374.

Snapp, S.S., Swinton, S.M., Labarta, R., Mutch, D., Black, J.R., Leep, R., Nyiraneza, J. \& O'Neil, K. (2005) Evaluating cover crops for benefits, costs and performance within cropping system niches. Agronomy Journal, 97, 322-332.

Soreng, R.J., Davis, J.I. \& Voionmaa, M.A. (2007) A phylogenetic analysis of Poaceae tribe Poeae sensu lato based on morphological characters and sequence data from three plastid-encoded genes: Evidence for reticulation, and a new classification for the tribe. Kew Bulletin, 62, 425-454.

Spatafora, J.W., Chang, Y., Benny, G.L., Lazarus, K., Smith, M.E., Berbee, M.L., Bonito, G., Corradi, N., Grigoriev, I., Gryganskyi, A., James, T.Y., O’Donnell, K., Roberson, R.W., Taylor, T.N., Uehling, J., Vilgalys, R., White, M.M. \& Stajich, J.E. (2016) A phylum-level phylogenetic classification of zygomycete fungi based on genomescale data. Mycologia, 108, 1028-1046.

Stahl, P.D., Parkin, T.B. \& Christensen, M. (1999) Fungal presence in paired cultivated and uncultivated soils in central Iowa, USA. Biology and Fertility of Soils, 29, 92-97.

Strickland, M.S., Lauber, C., Fierer, N. \& Bradford, M.A. (2009a) Testing the functional significance of microbial community composition. Ecology, 90, 441-451.

Strickland, M.S., Osburn, E., Lauber, C., Fierer, N. \& Bradford, M.A. (2009b) Litter quality is in the eye of the beholder: Initial decomposition rates as a function of inoculum characteristics. Functional Ecology, 23, 627-636.

Swift, M.J., Heal, O.W. \& Anderson, J. (1978) Decomposition in terrestrial ecosystems. Blackwell Scientific, Oxford [etc.] :.

Thoden, T., Korthals, G. \& Termorshuizen, A. (2011) Organic amendments and their influences on plant-parasitic and free-living nematodes: a promising method for nematode management? Nematology, 13, 133-153.

Thorup-Kristensen, K., Magid, J. \& Jensen, L.S. (2003) Catch crops and green manures as biological tools in nitrogen management in temperate zones. Advances in Agronomy, pp. 227-302.

Tiemann, L.K., Grandy, A.S., Atkinson, E.E., Marin-Spiotta, E. \& McDaniel, M.D. (2015) Crop rotational diversity enhances belowground communities and functions in an agroecosystem. Ecology Letters, 18, 761-771.

Tilman, D. (2001) Functional Diversity. Encyclopedia of Biodiversity (ed. A.L. Simon), pp. 109-120. Elsevier, New York.

Toju, H., Peay, K.G., Yamamichi, M., Narisawa, K., Hiruma, K., Naito, K., Fukuda, S., Ushio, M., Nakaoka, S., Onoda, Y., Yoshida, K., Schlaeppi, K., Bai, Y., Sugiura, R., Ichihashi, Y., Minamisawa, K. \& Kiers, E.T. (2018) Core microbiomes for sustainable agroecosystems. Nature Plants, 4, 247-257.

Tribouillois, H., Fort, F., Cruz, P., Charles, R., Flores, O., Garnier, E. \& Justes, E. (2015) A Functional Characterisation of a Wide Range of Cover Crop Species: Growth and Nitrogen Acquisition Rates, Leaf Traits and Ecological Strategies. PLoS ONE, 10, e0122156. 
Trivedi, P., Delgado-Baquerizo, M., Anderson, I.C. \& Singh, B.K. (2016) Response of Soil Properties and Microbial Communities to Agriculture: Implications for Primary Productivity and Soil Health Indicators. Frontiers in Plant Science, 7.

van der Krift, T.A.J., Gioacchini, P., Kuikman, P.J. \& Berendse, F. (2001a) Effects of high and low fertility plant species on dead root decomposition and nitrogen mineralisation. Soil Biology and Biochemistry, 33, 2115-2124.

van der Krift, T.A.J., Kuikman, P.J. \& Berendse, F. (2002) The effect of living plants on root decomposition of four grass species. Oikos, 96, 36-45.

van der Krift, T.A.J., Kuikman, P.J., Möller, F. \& Berendse, F. (2001b) Plant species and nutritional-mediated control over rhizodeposition and root decomposition. Plant and Soil, 228, 191-200.

van der Putten, W.H., Bardgett, R.D., Bever, J.D., Bezemer, T.M., Casper, B.B., Fukami, T., Kardol, P., Klironomos, J.N., Kulmatiski, A., Schweitzer, J.A., Suding, K.N., Van de Voorde, T.F.J. \& Wardle, D.A. (2013) Plant-soil feedbacks: The past, the present and future challenges. Journal of Ecology, 101, 265-276.

van der Putten, W.H., Bradford, M.A., Brinkman, P.E., van de Voorde, T.F.J. \& Veen, G.F. (2016) Where, when and how plant-soil feedback matters in a changing world. Functional Ecology, 30, 1109-1121.

van der Putten, W.H., Mortimer, S.R., Hedlund, K., van Dijk, C., Brown, V.K., Leps, J., Rodriguez-Barrueco, C., Roy, J., Len, T.A.D., Gormsen, D., Korthals, G.W., Lavorel, S., Santa-Regina, I. \& Smilauer, P. (2000) Plant species diversity as a driver of early succession in abandoned fields: a multi-site approach. Oecologia, 124, 91-99.

van der Putten, W.H., van Dijk, C. \& Troelstra, S.R. (1988) Biotic soil factors affecting the growth and development of Ammophila arenaria. Oecologia, 76, 313-320.

van der Wal, A., Geydan, T.D., Kuyper, T.W. \& De Boer, W. (2013) A thready affair: Linking Fungal diversity and community dynamics to terrestrial decomposition processes. FEMS Microbiology Reviews, 37, 477-494.

Vanzolini, J.I., Galantini, J.A., Martínez, J.M. \& Suñer, L. (2017) Changes in soil pH and phosphorus availability during decomposition of cover crop residues. Archives of Agronomy and Soil Science, 1-11.

Veen, G.F., Freschet, G.T., Ordonez, A. \& Wardle, D.A. (2015) Litter quality and environmental controls of home-field advantage effects on litter decomposition. Oikos, 124, 187-195.

Violle, C., Navas, M.L., Vile, D., Kazakou, E., Fortunel, C., Hummel, I. \& Garnier, E. (2007) Let the concept of trait be functional! Oikos, 116, 882-892.

Vivanco, L. \& Austin, A.T. (2006) Intrinsic effects of species on leaf litter and root decomposition: a comparison of temperate grasses from North and South America. Oecologia, 150, 97-107.

Wagg, C., Bender, S.F., Widmer, F. \& van der Heijden, M.G.A. (2014) Soil biodiversity and soil community composition determine ecosystem multifunctionality. Proceedings of the National Academy of Sciences, 111, 5266-5270.

Wagger, M.G., Cabrera, M.L. \& Ranells, N.N. (1998) Nitrogen and carbon cycling in relation to cover crop residue quality. Journal of Soil and Water Conservation, 53, 214-218.

Wallenstein, M.D., Haddix, M.L., Ayres, E., Steltzer, H., Magrini-Bair, K.A. \& Paul, E.A. (2013) Litter chemistry changes more rapidly when decomposed at home but 
converges during decomposition-transformation. Soil Biology and Biochemistry, 57, 311-319.

Wardle, D.A., Bardgett, R.D., Klironomos, J.N., Setälä, H., Van Der Putten, W.H. \& Wall, D.H. (2004a) Ecological linkages between aboveground and belowground biota. Science, 304, 1629-1633.

Wardle, D.A., Yeates, G.W., Williamson, W.M., Bonner, K.I. \& Barker, G.M. (2004b) Linking aboveground and belowground communities: The indirect influence of aphid species identity and diversity on a three trophic level soil food web. Oikos, 107, 283-294.

Warton, D.I., Duursma, R.A., Falster, D.S. \& Taskinen, S. (2012) smatr 3- an R package for estimation and inference about allometric lines. Methods in Ecology and Evolution, 3, 257-259.

Warton, D.I., Wright, I.J., Falster, D.S. \& Westoby, M. (2006) Bivariate line-fitting methods for allometry. Biological Reviews, 81, 259-291.

Wickings, K., Grandy, A.S., Reed, S.C. \& Cleveland, C.C. (2012) The origin of litter chemical complexity during decomposition. Ecology Letters, 15, 1180-1188.

Winterfeld, G., Döring, E. \& Röser, M. (2009) Chromosome evolution in wild oat grasses (Aveneae) revealed by molecular phylogeny. Genome, 52, 361-380.

Wood, S.A., Karp, D.S., DeClerck, F., Kremen, C., Naeem, S. \& Palm, C.A. (2015)

Functional traits in agriculture: Agrobiodiversity and ecosystem services. Trends in Ecology and Evolution, 30, 531-539.

Wright, I.J., Reich, P.B., Westoby, M., Ackerly, D.D., Baruch, Z., Bongers, F., CavenderBares, J., Chapin, T., Cornelissen, J.H.C., Diemer, M., Flexas, J., Garnier, E., Groom, P.K., Gulias, J., Hikosaka, K., Lamont, B.B., Lee, T., Lee, W., Lusk, C., Midgley, J.J., Navas, M.L., Niinemets, Ü., Oleksyn, J., Osada, H., Poorter, H. et al. (2004) The worldwide leaf economics spectrum. Nature, 428, 821-827.

Wubs, E.R.J., van der Putten, W.H., Bosch, M. \& Bezemer, T.M. (2016) Soil inoculation steers restoration of terrestrial ecosystems. Nature Plants, 2, 16107.

Yeates, G.W., Bongers, T., De Goede, R.G.M., Freckman, D.W. \& Georgieva, S.S. (1993) Feeding Habits in Soil Nematode Families and Genera-An Outline for Soil Ecologists. Journal of Nematology, 25, 315-331.

Zelles, L. (1999) Fatty acid patterns of phospholipids and lipopolysaccharides in the characterisation of microbial communities in soil: A review. Biology and Fertility of Soils, 29, 111-129.

Zelles, L., Bai, Q.Y., Beck, T. \& Beese, F. (1992) Signature fatty acids in phospholipids and lipopolysaccharides as indicators of microbial biomass and community structure in agricultural soils. Soil Biology and Biochemistry, 24, 317-323.

Zhang, D., Hui, D., Luo, Y. \& Zhou, G. (2008) Rates of litter decomposition in terrestrial ecosystems: global patterns and controlling factors. Journal of Plant Ecology, 1, 8593.

Zuur, A.F., Ieno, E.N. \& Elphick, C.S. (2010) A protocol for data exploration to avoid common statistical problems. Methods in Ecology and Evolution, 1, 3-14.

Zuur, A.F., Ieno, E.N., Walker, N.J., Saveliev, A.A. \& Smith, G.M. (2010) Mixed Effects Models and Extensions in Ecology with R. Springer-Verlag, New York. 


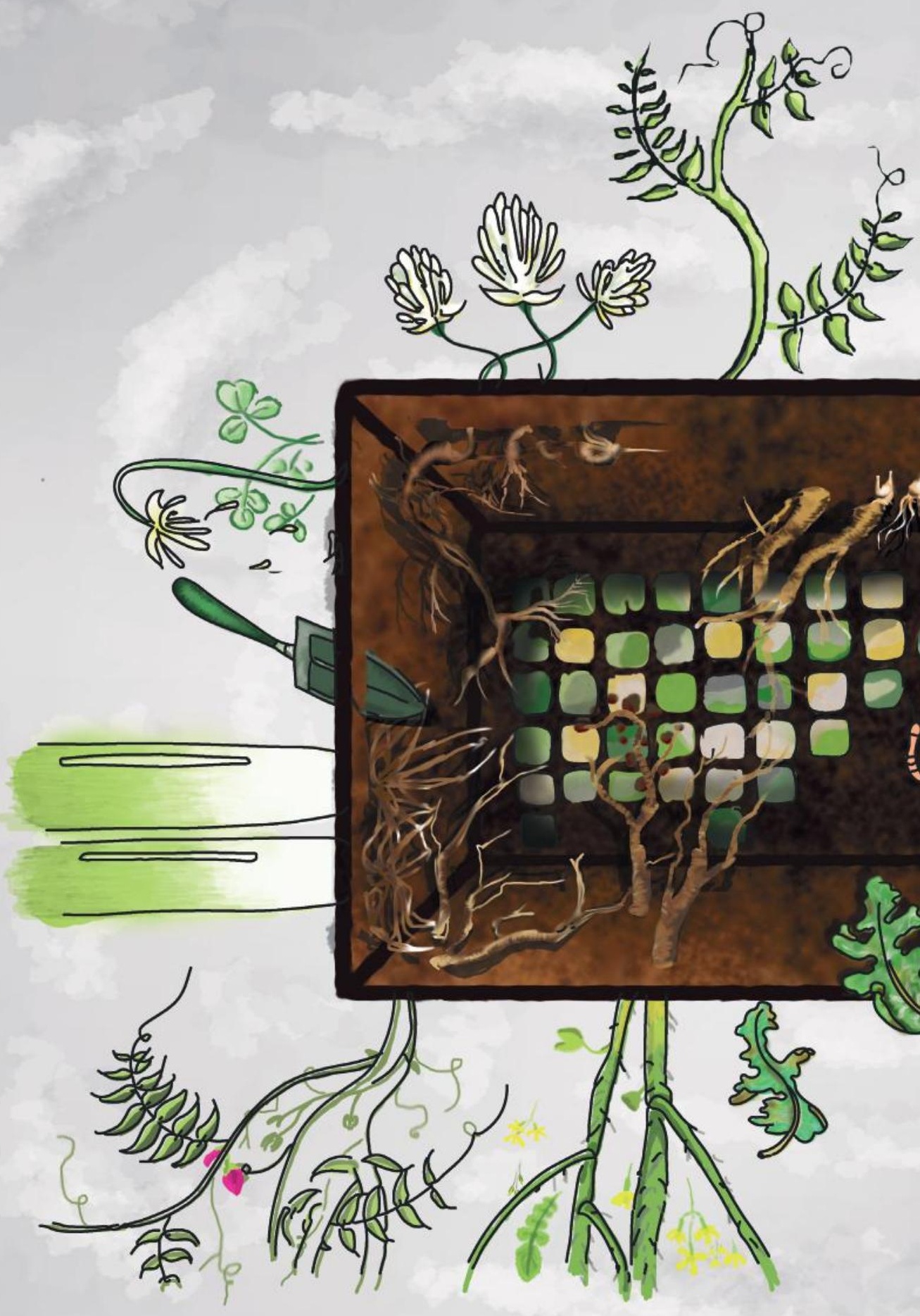




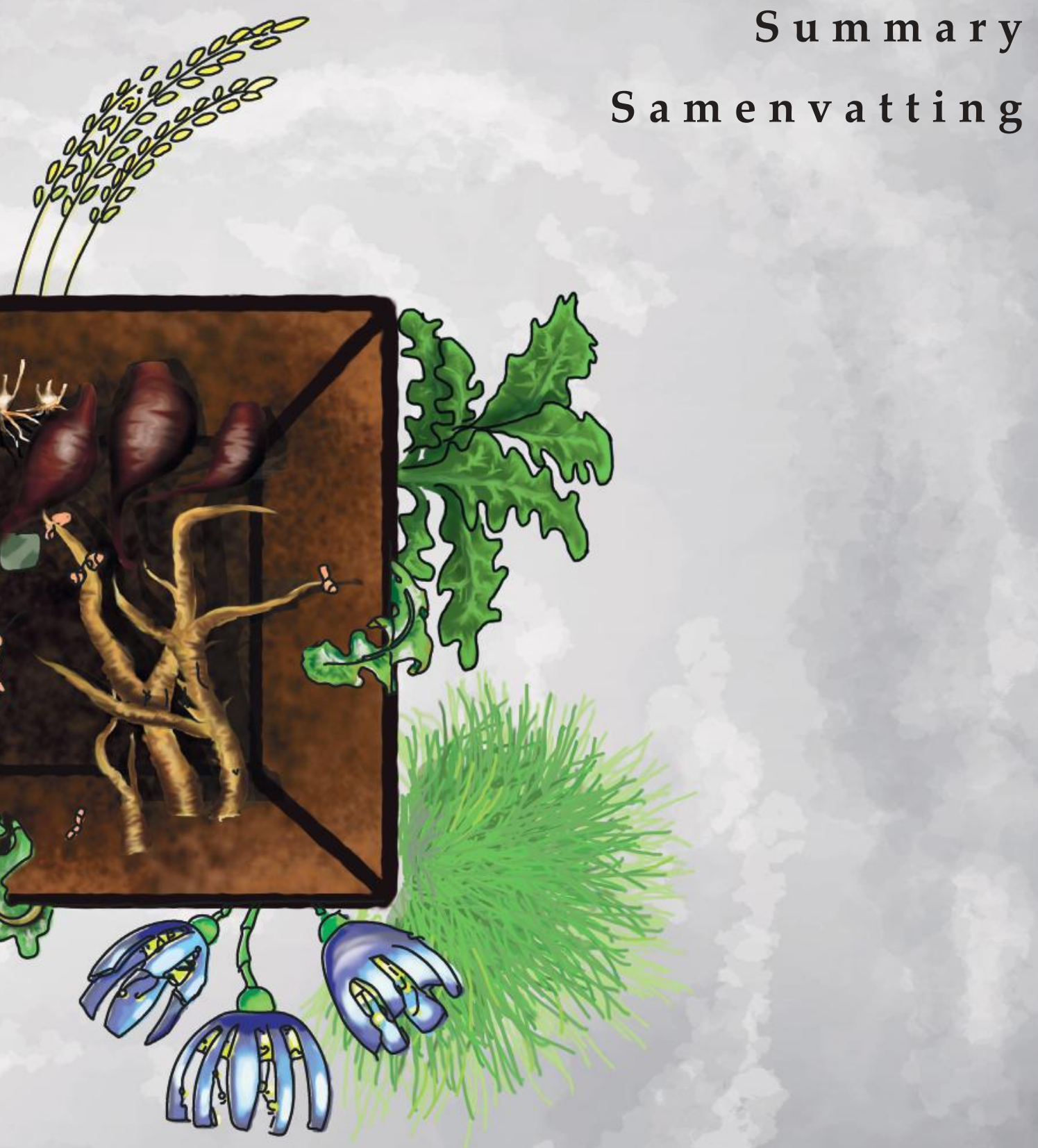




\section{Sum ary}

During their life and afterlife plants impact their soil environment. By rooting through the soil and uptake of nutrients, release of root-derived chemicals, and shedding their plant tissues, plants leave a legacy in the soil for subsequent plants to inherit. Plant legacies entail physical, chemical and biological changes of soil properties, which can influence growth of subsequent plants, (so called plant-soil feedback or plant legacy effects). Plant legacies can influence nutrient cycling carbon storage and soil health; they explain a wide array of ecological processes such as plant invasion, succession, plant diversity and productivity. Understanding how plants shape their legacies, therefore, is highly relevant for management of both agro- and natural ecosystems.

Plants, like all species, are subject to environmental conditions under which they grow. The strategy by which plants cope with selection forces is reflected in their characteristics, i.e. their functional traits. Because of physiological trade-offs as resources can only be invested once. Plants either invest in fast growth (through an acquisitive strategy) or in resource conservation and defence (conservative strategy). Based on their functional traits, plant species can be placed on this plant economics spectrum (PES), and their traits can help predict rates and direction of ecological processes.

Comparison between an agro- and natural ecosystems provides an interesting scope to test plant-soil interactions in the light of differential selection pressures. Agricultural plants rely on external inputs and have been selected for fast growth and high yield. Crops can be considered to represent an extension of the PES, showing faster growth, lower investment in structural compounds and higher nutrient uptake strategies than their wild ancestors. This difference has been shown, at least, aboveground. However, it is unclear what effects artificial selection has had on root traits of crops. In this thesis, six pairs of crops and their wild relatives were compared to test if artificial selection in agro-ecosystems has consistently influenced plant traits and soil legacies. A trait-based approach was adopted to test the driving factors of plant-soil legacies and test whether aboveground traits can be a proxy for belowground traits. I studied plant-soil legacies across scales, starting with legacy effects at field-scale and zooming in on underlying processes under controlled greenhouse conditions.

First, soil legacies of crops were studied in a field experiment. A 2-year crop rotation (including summer-winter-summer cropping) was set-up by growing two cash crops: oat (Avena sativa) and endive (Cichorium endivia), alternated with winter cover crops. Legacy effects of monocultures and mixtures of cover crops were monitored to test whether legacy effects can be improved by mixing plant species, and whether winter cover crops can override the soil legacies induced by previous main crops. I hypothesised that mixtures of cover crops would have a higher productivity and a higher shoot nitrogen (N) concentration in comparison to their monocultures. Mixtures of common vetch (Vicia sativa) 
and fodder radish (Raphanus sativus) indeed displayed positive diversity effects, as they were more productive aboveground than predicted based on productivity of the monocultures; this productivity increase did not come at the cost of altered shoot $\mathrm{N}$ concentrations. Although mixtures of English ryegrass (Lolium perenne) and white clover (Trifolium repens) showed an increase in root biomass, aboveground biomass was not significantly increased compared to the monoculture. Moreover, $\mathrm{N}$ concentrations of the shoots were lower than predicted. As a result, subsequent productivity of oat showed positive responses to the preceding cover crop mixture of vetch and radish, but negative responses to the ryegrass-clover mixture. These results indicate that beneficial soil legacy effects of plant mixtures can be more than the sum of parts, provided that plant species in the mixture complement each other given the environmental conditions (chapter 2).

Having established that diversity in space (cover crop mixture) has legacy effects on subsequent plant productivity, we additionally tested whether diversity in time (rotation) influenced plant-soil legacies. Effects of previously grown oats and endive (first summer) were observed on the productivity of the winter cover crop English ryegrass and productivity of subsequent oat (final summer). Both ryegrass and oat had lower biomass when grown on fields with a history of oat, compared to fields with an endive history. Also, legacy effects of winter cover crops on soil properties were influenced by cropping history. Soil organic matter content, availability of $\mathrm{N}$ and numbers of plant-parasitic nematodes were all lower after winter cover crops grown on previous oat-cultivated fields compared to former endive fields. The inheritance of initially grown oat and endive persisted for a year and was not erased by growing cover crops (chapter 2 ).

The plant-soil feedback (PSF) effects of winter cover crops on oat and endive productivity were likely mediated by changes in soil organic matter content, nutrient availability and abundance of plant-parasitic nematodes. Aboveground biomass (quantity) and Nconcentration (quality) of winter cover crops were tested as drivers of these PSF-pathways. Structural equation modelling was used to test which of these pathways significantly influenced productivity of subsequent oat and endive. The model showed that both winter cover crop quantity and quality stimulated oat and endive productivity. However, these feedback effects were not mediated via the measured changes in soil conditions, which may be due to the limitation of single point measurements of soil conditions. I propose that PSF is a dynamic process, and in situ nutrient cycling from cover crop residues during the subsequent growing season could be the unmeasured legacy effect underlying the PSF responses of oat and endive (chapter 2 and 3 ).

Litter decomposition is the starting point of nutrient cycling. Therefore, the legacy effects on decomposition were studied in more detail. The three main drivers of litter decomposition can all be influenced by a plant: abiotic conditions by nutrient and water uptake and release of chemical compounds from roots, biotic condition by plant-microbe interactions, and litter quality, which differs with plant species and growing conditions. In 
the same field experiment as described above, winter cover crop legacy effects on these three decomposition drivers were tested. By incubating all winter cover crop shoot litters in the same environment (without cover crop history) I found, as hypothesised, that litters with high C- and lignin concentration decomposed more slowly than litters with low Cand lignin concentrations. In contrast to the hypothesis, also high litter $\mathrm{N}$ concentration led to low decomposition rates, probably because legumes, with both high $\mathrm{N}$ and lignin concentrations, represented one third of the plant species pool and exerted a strong effect (chapter 3). Moreover, easily decomposable cover crop litters (radish, and radish + vetch mixtures) decomposed faster in their plot of origin (home-field) than in the control plots. By incubating the same standard substrates in all plots of the field experiment, I demonstrated that this home-field advantage was the combined result of incorporation of highly decomposable cover crop residues into the soil and the changes in fungal biomass induced by cover crop growth, but not via changes in abiotic conditions (SOM, N availability, soil $\mathrm{pH}$ ). In other words, cover crop legacies can stimulate the decomposition process, via the decomposability of their litters and via stimulation of the soil fungi (chapter $3)$.

Having confirmed that plants shape the decomposition process through the quality of their shoot litter, in the next experiment (chapter 4) I tested whether shoot traits and decomposability can act as a proxy for root traits and their decomposability. This comparison was done for the same six pairs of crops and closely related natural grassland species, in order to test the hypothesis that crops are more acquisitive plants along the PES gradient than their wild relatives. The results partially supported this hypothesis, as shoots of crops decomposed faster than those of their wild relatives. Crop litters also had lower $\mathrm{C}$ concentrations than wild litters. All litters, except roots of crops showed the predicted negative correlation between decomposition rate and $\mathrm{C}$ and lignin concentration. Crop root decomposability, however, showed a negative correlation to root litter $\mathrm{N}$ concentration. These results imply that shoot traits and decomposability of wild plants are indicative for trait values and decomposability of their roots of wild plants. Although crop shoots seem to represent an extension at the acquisitive-end of the PES, crop root decomposition seemed to be controlled differently. Further research recommendations include further characterisation of litter traits and relating decomposition rates to mineralisation rates (chapter 4).

The second objective of chapter 4 was to quantify the influence of a growing plant on litter decomposition. I hypothesised that plant presence would stimulate decomposition rates (positive priming), in which the magnitude of the effect differs between the plant species present and litter quality. However, we found negative priming effects. We show that presence of a forb suppressed decomposition rates more than presence of a grass or own plant species. Moreover, easily decomposable litters of wild plants displayed stronger negative priming effects than litters of low decomposability. Priming effects did not vary with crop shoot litter quality but were positively related to crop root litter $\mathrm{N}$ concentration. 
In chapter 4, I propose that the composition of the decomposer community mediates these priming effects. Decomposition of labile litters by opportunistic microbial r-strategists are likely hindered by competition for $\mathrm{N}$ invoked by plant presence (resulting in negative priming), whereas more slowly growing K-strategists, with the ability to decompose more recalcitrant litters, benefit from plant presence. Thereby K-strategist can use plants exudates as a labile energy source and facilitate litter decomposition for $\mathrm{N}$ mining (resulting in positive priming).

In contrast to the indirect plant legacy effect through litter decomposition and nutrient cycling, plant-microbe interactions can directly influence subsequent plant growth. The composition of microbial soil communities is pivotal for plant health as the comprise detrimental and beneficial micro-organisms. Understanding how plants shape these microbiomes (plant filter) holds great promise for sustainable soil management by engineering of rhizosphere microbial communities. Since roots are the interface for plantmicrobe interactions, I hypothesised that root traits explain the influence of a plant on its rhizosphere community composition (chapter 5). By growing the six crop-wild plant pairs in soils of four different origins, the influence of plants on prokaryotes and fungi in the rhizosphere was tested, relative to the influence of local soil conditions. As hypothesised, plant traits related to nutrient uptake (root $\mathrm{N}$ concentration, specific root length) and productivity (above- and belowground biomass) significantly explained variation between the rhizosphere microbial communities. However, the significance of these traits varied with soil origin, indicating that the plant filter is not a simple hierarchical influence additional to the soil filter, but is context dependent. Crops and wild relatives had consistently different prokaryote communities on two of the four soils, and different fungal communities in one soil (chapter 5), indicating that crop and wild relatives might differ in their ability to associate with soil microbes. Further research on interactions between plant traits and soil conditions with respect to root traits, including root exudation patterns, is needed before plant functional traits can be used to predict rhizosphere microbial community composition (chapter 5).

In chapter 6, I discuss the main findings of the four experimental chapters. Findings from controlled experiments in chapters 4 and 5 were reviewed with respect to possible implications of plant legacy effects on field scale. The dependency of plant filtering of the rhizosphere community on soil conditions brings forward the need to study trait plasticity and related exudation patterns in the rhizosphere along environmental gradients. Also, it is unclear how a plant's influence on rhizosphere communities translates to effects in the bulk soil in terms of microbial taxonomic composition and functioning. In other words, can keystone microbes be identified that have the potential to form interacting microbial networks relevant for nutrient cycling and disease suppression? Moreover, the indications for litter feedbacks (chapter 3 ) and negative priming effects due to plant presence (chapter 4), can have implications for nutrient cycling in both natural and agricultural systems. It would be particularly interesting to study the consequences of litter feedback and priming 
for synchronisation of nutrient availability and demand in arable systems with winter cover crops. Furthermore, the applicability of the trait approach is discussed with respect to ecological importance of plant functional groups. Taking agriculture as a model system and by comparing crops to closely related wild plant species, the effect of different selection pressures on plant-soil interactions can be studied. Domestication has had varying effects on plant traits, as the crops species included in this thesis have been subjected to different selection pressures due to differential breeding objectives. Differences in disturbances and inputs in agro- and natural ecosystems have consequences for the relevance of plant-soil interactions for ecosystem functioning. Plant legacies offer interesting avenues for sustainable management of agriculture. 


\section{Samenvatting}

\section{Een plantennalatenschap}

Gedurende hun leven, alsook daarna, laten planten een nalatenschap of erfenis achter in de grond waarin ze groeien. Door beworteling, opname van voedingsstoffen, stoffen die door de wortels worden uitgescheiden (wortelexudaten) en afbraak van plantenresten vormen planten een bodemerfenis. Deze nalatenschap omvat veranderingen in de bodem van fysische, chemische en biologische aard, welke de groei van opvolgende planten kan beïnvloeden (plant-bodem feedback of plant-bodemerfenis genaamd). Deze erfeniseffecten kunnen de kringlopen van voedingsstoffen en koolstof beïnvloeden, alsmede bodemgezondheid. Plant-bodemerfenissen verklaren veel ecologische processen waaronder natuurlijke successie, plantendiversiteit en productiviteit. Begrip van plantbodemerfenissen en de drijvende krachten erachter is dan ook bijzonder relevant voor duurzaam beheer van zowel landbouw als natuurlijke ecosystemen.

Planten, op hun beurt, worden beïnvloed door de groeiomstandigheden. De strategie waarmee planten reageren op omgevingsinvloeden wordt weerspiegeld in functionele planteigenschappen. Vanwege fysiologische beperkingen investeren planten energie en voedingsstoffen óf in snelle groei, simpele weefsels en groot vermogen tot opname van voedingsstoffen (acquisitieve strategie) óf in duurzame stevige weefsels en weerbaarheid (conservatieve strategie). Op basis van hun functionele eigenschappen kunnen planten worden ingedeeld langs een gradiënt van acquisitieve tot conservatieve plantentypen, ook bekend als het plant-economisch spectrum (PES). Bovendien kunnen functionele planteigenschappen ecologische processen helpen voorspellen.

Om plant-bodeminteracties te onderzoeken in het licht van verschillende in groeiomstandigheden, biedt de vergelijking tussen landbouw en natuurlijke ecosystemen een interessant perspectief. Landbouwplanten zijn geselecteerd op snelle groei en hoge opbrengst en zijn bovendien aangepast aan intensief beheer met externe aanvoer (bijvoorbeeld bemesting en bestrijdingsmiddelen). Gewassen worden daarom beschouwd als vertegenwoordigers van het acquisitieve deel van het PES, met snellere groei en nutriëntopname (hoger stikstofgehalte) en minder investering in stevigheidsweefsels (lager ligninegehalte) en afweer dan hun wilde voorouders. Althans, dit contrast is aangetoond voor bovengrondse planteigenschappen. Het is echter nog onduidelijk welk effect menselijke selectie heeft gehad op de functionele eigenschappen van wortels van gewassen. In dit proefschrift vergelijk ik zes paren van gewassen en nauw verwante wilde plantensoorten om te toetsen hoe gewassen en wilde planten verschillen in functionele eigenschappen en bodemnalatenschap. Het bestuderen van functionele planteigenschappen is gekozen als benadering om te onderzoeken wat de drijvende krachten zijn achter plant-bodemerfenissen en of bovengrondse planteigenschappen ook de ondergrondse planteigenschappen weerspiegelen. Ik onderzocht plantbodemerfenissen op verschillende schaalniveaus, beginnend met effecten op veldniveau 
om daarna de onderliggende processen in meer detail te bestuderen in gecontroleerde kasproeven.

\section{Erfenis van plantendiversiteit in ruimte en tijd}

Ten eerste testte ik de bodemerfenis van gewassen in een veldexperiment. Een tweejarige wisselteelt of gewasrotatie (zomer-winter-zomer) werd opgezet waarbij twee hoofdgewassen, te weten haver (Avena sativa) en andijvie (Cichorium endivia), werden afgewisseld met winterse groenbemesters. Door vier soorten groenbemesters in monocultuur en in mengsels te telen konden zowel de effecten van diversiteit in ruimte (mengsels) als in tijd (rotatie) worden getoetst, bijvoorbeeld: of een positieve nalatenschap kan worden versterkt door groenbemesters in mengsels te telen, of winterse groenbemesters de eventuele nalatenschap van het eerste hoofdgewas op het laatste hoofdgewas te niet kunnen doen.

Ik verwachtte dat mengsels van groenbemesters een hogere productiviteit en stikstofgehalte hebben in vergelijking met de monoculturen. Het mengsel van voederwikke (Vicia sativa) met bladrammenas (Raphanus sativus) vertoonde inderdaad een hogere bovengrondse productiviteit dan verwacht, wat niet ten koste ging van het stikstofgehalte in het plantenmateriaal. Het mengsel van Engels raaigras (Lolium perenne) met witte klaver (Trifolium repens) vertoonde weliswaar een hogere wortelbiomassa dan de monoculturen, maar dit gold niet voor de bovengrondse biomassa. Bovendien was het stikstofgehalte in de bovengrondse plantendelen van het gras-klavermengsel lager dan verwacht mocht worden op basis van de gehaltes in de raaigras- en klavermonoculturen. Daardoor was de productiviteit van haver op veldjes met een erfenis van wikkebladrammenas hoger dan op veldjes met een monocultuur-erfenis, maar werd de haveropbrengst negatief beïnvloed door de erfenis van het gras-klavermengsel. Deze resultaten geven aan dat de positieve bodemerfenis van plantenmengsels groter is dan de som der delen, mits de plantensoorten in het mengsel complementair zijn aan elkaar onder de gegeven omstandigheden (hoofdstuk 2).

In het veldexperiment werden ook verschillen in erfeniseffecten gevonden van de eerste hoofdgewassen haver en andijvie op de productiviteit van Engels raaigras, en op de productiviteit van haver als laatste hoofdgewas. Zowel het raaigras als de haver hadden een lagere opbrengst op velden met een bodemerfenis van haver, ten opzichte van velden met een erfenis van andijvie. Bovendien bleek de invloed die groenbemesters hebben op bodemeigenschappen afhankelijk van het voorgaande hoofdgewas. Gehalten van bodemorganische stof en minerale stikstof evenals aantallen plant-parasitaire aaltjes waren lager na groenbemesters die waren verbouwd op voormalige havervelden dan op voormalige andijvievelden. Met andere woorden: de erfenis van hoofdgewassen blijft langdurig meetbaar in de bodem en wordt niet uitgewist door tussentijds groenbemesters te telen (hoofdstuk 2). 
Verwacht werd dat het gehalte aan bodemorganische stof, beschikbaarheid van stikstof in de bodem en talrijkheid van plant-parasitaire aaltjes onderliggende mechanismen zijn waardoor plant-bodemerfenissen van winterse groenbemesters productiviteit van volgende hoofdgewassen beïnvloeden. Bovengrondse productiviteit en kwaliteit (stikstofgehalte) van groenbemesters werden getest als mogelijke drijvende krachten. Met behulp van een statistische analyse techniek, 'structural equation modelling', berekende ik welke van de bovengenoemde factoren de meeste invloed uitoefende op productiviteit van haver en andijvie. Het model toonde aan dat productiviteit en kwaliteit van groenbemesters zowel de productiviteit van haver als die van andijvie stimuleerden. Maar deze positieve terugkoppeling werd niet ondersteund door de gemeten bodemfactoren, waarschijnlijk doordat deze meting eenmalig was. Ik veronderstel dat plant-bodem feedback een dynamisch proces is, waarin de continue nutriëntenstromen veroorzaakt door geleidelijke afbraak van gewasresten en vrijkomen van voedingsstoffen de ongemeten erfeniseffecten behelzen, waardoor groei van haver en andijvie beïnvloed wordt (hoofdstuk 2 en 3).

\section{Erfenis via afbraak van gewasresten}

Bij de afbraak van plantenresten worden voedingstoffen die vastgelegd zijn in het plantenmateriaal vrijgemaakt, waardoor deze opnieuw beschikbaar kunnen komen voor plantengroei. De invloed van planten op het afbraakproces werd in meer detail bestudeerd in hoofdstuk 3 . Planten beïnvloeden de drie hoofdfactoren van het afbraakproces, namelijk: abiotische en biotische bodemeigenschappen en strooiselkwaliteit. Abiotische bodemeigenschappen worden beïnvloed door opname van voedingsstoffen en water en het uitscheiden van wortelexudaten. Ten tweede worden biologische bodemomstandigheden beïnvloed door interacties tussen de plant en het bodemleven. Tenslotte wordt de kwaliteit (en afbreekbaarheid) van de plantenresten bepaald door de plantensoort en groeiomstandigheden.

In het eerder genoemde veldexperiment werd de nalatenschap van groenbemesters op het afbraakproces getest. Door gewasresten van groenbemesters in een controleveld (zonder groenbemester-erfenis) te laten afbreken vond ik, zoals verwacht, dat gewasresten trager afbreken wanneer deze hoge koolstof- en ligninegehalten hebben. In tegenstelling tot mijn verwachting, leidde ook een hoog stikstofgehalte in gewasresten tot een tragere afbraak, waarschijnlijk doordat vlinderbloemige planten, met een hoog stikstof- en ligninegehalte, in twee derde van de behandelingen aanwezig waren. Daarnaast werd afbraak van gewasresten in het controleveld vergeleken met afbraak in het proefveld van herkomst. Makkelijk afbreekbaar plantenmateriaal (uit bladrammenasmonocultuur en wikke-bladrammenasmengsel) breekt sneller af in het eigen veld dan in het controleveld. Door vier standaard substraten (papier, bamboe, groene- en rooibosthee) in alle proefvelden af te laten breken, kon ik aantonen dat dit 'thuis-voordeel' een gecombineerd effect was van het inwerken van gewasresten en de verandering in schimmelbiomassa maar niet van verandering in abiotische 
bodemomstandigheden. Met andere woorden: de erfenis van groenbemesters kan het afbraakproces positief beïnvloeden via gewasresten en stimuleren van bodemschimmels (hoofdstuk 3).

\section{Levende planten remmen afbraak}

$\mathrm{Nu}$ is bevestigd dat planten het afbraakproces beïnvloeden door middel van de kwaliteit van hun bovengrondse plantendelen (scheut), testte ik, in een kasproef, of de functionele planteigenschappen van de scheut representatief zijn voor de functionele eigenschappen van de wortel (hoofdstuk 4). Deze boven-ondergrondse vergelijking van planteigenschappen werd gemaakt voor de zes plantenparen (gewas en een nauw verwante wilde plantensoort.) Daarmee toetste ik de hypothese dat gewassen meer acquisitieve eigenschappen hebben dan hun wilde verwanten. De resultaten ondersteunen deze hypothese ten dele. Scheuten van gewassen verteren sneller dan scheuten van wilde planten, ook hadden gewasresten lagere koolstofgehalten. Behalve gewaswortels vertoonden alle andere strooisels een negatief verband tussen afbraaksnelheid en koolstof- en ligninegehalte. Afbreekbaarheid van gewaswortels, daarentegen, was negatief gerelateerd aan stikstofgehalte. Deze resultaten impliceren dat bovengrondse eigenschappen en afbreekbaarheid bij wilde planten indicatief zijn voor die van hun wortels. Echter gaat deze vergelijking niet op voor gewassen. Hoewel gewasscheuten in het acquisitieve deel van het PES kunnen worden geplaatst, lijkt de afbreekbaarheid van gewaswortels op een andere manier te worden bepaald. Aanbevelingen voor toekomstig onderzoek omvatten dan ook verdere karakterisering van strooiseleigenschappen in relatie tot afbraak en het vrijkomen van voedingsstoffen (hoofdstuk 4).

De tweede doelstelling van hoofdstuk 4 was om te kwantificeren welke invloed levende planten uitoefenen op strooiselafbraak. Ik formuleerde de hypothese dat aanwezigheid van een groeiende plant de afbraaksnelheid van plantenresten stimuleert, waarbij de grootte van dit effect afhankelijk is van welke soort plant aanwezig is, en van strooiselkwaliteit. Ik vond echter remming van de afbraak in aanwezigheid van de levende plant. De aanwezigheid van een kruidachtige plant (hier cichorei en andijvie) vertraagde de afbraak meer dan de aanwezigheid van een gras of de eigen plantensoort. Daarbij vertoonde de makkelijk afbreekbare strooisels van wilde planten sterkere remming dan moeilijk afbreekbare strooisels. Deze effecten varieerden niet met de strooiselkwaliteit van gewasscheuten, maar de effecten van gewaswortels waren positief gerelateerd aan stikstofgehalte van de wortels. In hoofdstuk 4 stel ik voor dat de samenstelling van de microbiële gemeenschap deze effecten mede bepaalt. De afbraak van makkelijk afbreekbare plantenresten door opportunistische microben (r-strategen) wordt waarschijnlijk gehinderd door concurrentie om stikstof die ontstaat in aanwezigheid van een plant, wat resulteert in deze remming. Afbraak door 
gespecialiseerde microben (K-strategen) wordt daarentegen juist gefaciliteerd door stoffen die wortels van een aanwezige plant uitscheiden.

\section{Microbiële gemeenschap van plantenwortels}

Een plant onderhoudt nauwe contacten met microben die bovendien de groei van volgende planten op directe wijze beïnvloeden. De samenstelling van de microbiële bodemgemeenschap, die voor de plant voordelige (vrienden) en nadelige (vijanden) microben omvat, is essentieel voor plantgezondheid. Begrijpen hoe planten de microbiële bodemgemeenschap vormgeven (plant-filter) is veelbelovend voor duurzaam bodembeheer. Doordat interacties tussen microben en de plant zich veelal op en rond de wortels afspelen (in de rhizosfeer) verwachtte ik dat functionele worteleigenschappen de invloed van planten op de microbiële rhizosfeergemeenschap kunnen voorspellen (hoofdstuk 5).

Door de zes paren plantensoorten in de kas te laten groeien in bodems van vier verschillende locaties, kon de invloed van planten op bacteriën en schimmels door middel van DNA-technieken worden onderzocht. Zoals verwacht verklaarden planteigenschappen gerelateerd aan opname van voedingsstoffen en productiviteit verschillen in microbiële wortelgemeenschap. Maar het belang van de planteigenschappen verschilde tussen bodemherkomst. Dat betekent dat het plant-filter niet slechts van additieve invloed is bovenop de bodem(herkomst)-filter maar dat het plant-filter contextafhankelijk is (hier bodemherkomst). Daarnaast waren de bacteriegemeenschappen voor gewassen verschillend van die van wilde plantensoorten in twee van de vier bodems, terwijl schimmelgemeenschappen tussen gewas en wilde plantensoorten in één van de vier bodems verschilden (hoofdstuk 5). Deze verschillen geven aan dat gewassen en wilde planten waarschijnlijk verschillen in hun interacties met bodemmicroben. Ik adviseer nieuw onderzoek dat zich dient te richten op de wisselwerking tussen planteigenschappen en bodemomstandigheden, met name met betrekking tot worteleigenschappen en exudaten, alvorens planteigenschappen kunnen worden gebruikt om microbiële wortelgemeenschappen te voorspellen (hoofdstuk 5).

\section{Plant-bodemerfenissen in de bodemecologie}

In hoofdstuk 6, tenslotte, bespreek ik de belangrijkste bevindingen van de onderzoeken opgenomen in dit proefschrift. Implicaties van de bevindingen van de kasproeven gepresenteerd in hoofdstukken 4 \& 5 worden besproken in het kader van plantennalatenschap op veldniveau. Zo wijst de bodemafhankelijkheid van het plantfilter op de microbiële wortelgemeenschap op de noodzaak om plasticiteit en exudatiepatronen in de rhizosfeer te bestuderen ten aanzien van bodemomstandigheden. Bovendien is onduidelijk hoe de gemeten invloed van de plant op rhizosfeergemeenschappen zich vertaalt naar de gehele bodemgemeenschap in termen 
van soorten en functioneren van de microbiële gemeenschap. Daarnaast kunnen de aanwijzingen voor strooiselfeedback (hoofdstuk 3 ) en remming van afbraak in aanwezigheid van een plant (hoofdstuk 4) gevolgen hebben voor kringlopen in zowel landbouw- als ook in natuurlijke ecosystemen. Strooiselfeedback en de invloed van de levende plant op de afbraaksnelheid zijn bijvoorbeeld belangrijk voor het synchroniseren van het vrijkomen van voedingsstoffen uit afbrekende gewasresten met de behoefte van het volggewas. Tenslotte wordt de toepasbaarheid van een functionele planteigenschapaanpak bediscussieerd. Ook reflecteer ik op de vergelijking van gewassen met nauwverwante wilde plantensoorten. Verdeling heeft een wisselend effect gehad op planteigenschappen, aangezien de gewassen die in dit promotieonderzoek zijn opgenomen veredeld zijn voor verschillende doeleinden. Bovendien geven verschillen in verstoringen en externe toevoegingen tussen landbouw en natuurlijke ecosystemen de plant-bodeminteracties een verschillende betekenis voor het functioneren van natuurlijke of agro-ecosystemen. De vergelijking van natuurlijke en agro-ecosystemen vormt een waardevol uitgangspunt voor het ontwikkelen van duurzaam bodembeheer. 


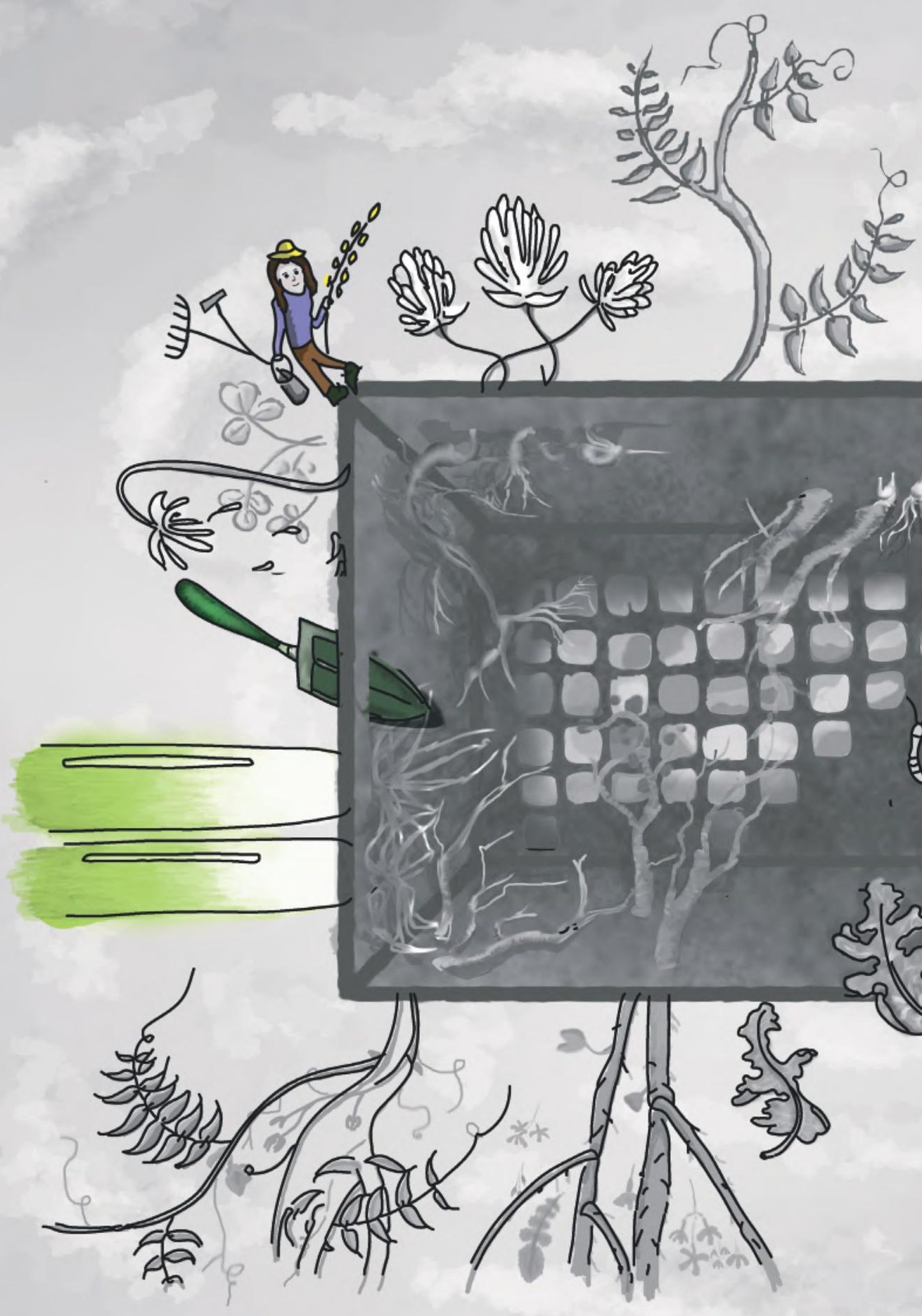




\section{Acknowledgement}

Just as it takes a village to raise a child, I have had guidance from great supervisors, an interactive chairgroup and support from friends and family to bring me to the happy !/?* end of my PhD trajectory. Because I am bound to forget mentioning someone, sorry for not listing you explicitly, and thank you too! Here, I take the opportunity to thank some people in particular while attempting to mention everyone anyway.

First and foremost, my supervisors. You allowed me to swim but avoided I would drift off too far. Gerlinde, ik zie ons nog staan op het dakterras van NIOO-KNAW tijdens een symposium eind 2012. Vol vuur legde je uit wat een tof project je zou starten met je pas toegekende Vidi-beurs en voor welke onderzoeksonderwerpen je een AIO zocht. Ja, de AIO zou gaan werken met plant-bodeminteracties waarvoor ik me zo interesseerde, en ook met functionele planteigenschappen en... landbouw. Ik durfde toen niet te zeggen dat ik landbouw niet zo interessant vond, want dat is toch geen echte natuur! Het werden spannende onderzoeksavonturen waarbij verschillende nieuwe samenwerkingen ons pad kruisten. Zo mondde, bijvoorbeeld, een wens voor een luchtfoto uit in een samenwerking en publicatie met Lammert Kooistra en collega's. Gedurende mijn PhD traject leerde ik dat landbouw ecologie juist nodig heeft, en kennis van natuurlijke en landbouw-systemen elkaar aanvullen. Gerlinde, je hebt me mijn eigen weg laten zoeken, en hoe frustrerend ik dat soms vond, ik ben je er erg dankbaar voor. Je uitnodiging, vorig jaar, om je naar de Ridderzaal te vergezellen voelde als een beloning voor mijn harde werken. Dank je wel! Thom, je ervaring en wijsheid zijn herhaaldelijk een eye-opener voor me geweest. Het was wonderlijk me halverwege m'n PhD te realiseren dat ik het een keer niet met je eens was. Je nam de tijd om me bekend te maken in decompositie modellen en met me mee te kijken waarom mijn vlinderbloemigen zich zo recalcitrant gedroegen. In gezamenlijk overleg was je een welkome wegwijzer wanneer we op een zijpad verdwaald dreigden te raken. Wietse, jij stond klaar om me advies te geven wanneer ik door alle bacteriën de bodem niet meer zag. In onze vergaderingen bracht je geduldig in herinnering even uit te leggen om welke proef of opzet het ook alweer ging. Je hield me een spiegel voor en ik kon leren welke punten voor de buitenwereld ingewikkeld of onduidelijk waren, terwijl het me in mijn hoofd zo helder leek. Ik kijk ernaar uit om onze discussies over rhizosfeer en bodemgemeenschappen voort te zetten.

My co-authors have enriched my views and facilitated the writing of papers beyond the extent of my PhD-project. Hans, wat een wonderlijk toeval dat we elkaar in dit project weer ontmoette. Als scholier leerde ik je kennen als fervent vogelaar en ecoloog tijdens een masterclass vogeltrek en die mooie Laplandreis. Zeven jaar later blijk je 'collaborator' te zijn in het Vidi-project van Gerlinde, waarvoor ik net was aangenomen. Dank je wel dat je de deur van je lab en kantoor in Amsterdam voor me openzette en uitgebreid de tijd nam om je bij te laten praten over mijn ideeën en resultaten. Ons eerste artikel is nu uit. Ik hoop dat we daar nog een mooi verhaal over wortel $\mathrm{pH}$ aan kunnen toevoegen. Gerard Korthals, ook jij was 'collaborator' en ik ben je heel dankbaar dat je deelgenoot hebt willen maken van je kennis over gewassen, groenbemesters en nematoden. Het was

* Please cross-out not applicable option 
heel fijn dat we op Vredepeel langs mochten komen en grond mochten verzamelen voor mijn proeven. Dat nematoden-artikel gaat er komen. Bob, samen met Wopke, Lia en Marjolein, heb je mij kennis laten maken met mixed-effects models en hoe statistische analyses uit te voeren in R. Dankzij de SEM-cursus en samenwerking die daaruit volgde heb ik het zelfvertrouwen gekregen in mijn analyse-vaardigheden. Het was fijn om met je te werken. Sirgi, Irene, Jara, Dominika, Somaye and Nieves you came to our group as visiting $\mathrm{PhD}$ candidates working with Gerlinde and some way or another we have collaborated, exchanged ideas, had discussions about science and life and you ladies have helped in maintaining and managing bits and pieces of my experiments. Sirgi, Irene, Dominika \& Somaye, I am really happy that the work we did together resulted/results in interesting publications.

Marije, a simple thank you doesn't "cover" it. You are not a co-author sensu stricto, perhaps co-creator is more appropriate. Your creativity has made my research come alive on the outer pages of this book. Dankjewel, hou van jou!

Science cannot do without technical support and good facilities. I have received lots of help and advice from the soil biology and chemistry labs. Henk, zonder jouw sjouw, zeef en pipeteer-skills was dit proefschrift er niet geweest. We leerden elkaar kennen op NIOO tijdens jouw stage en mijn afstudeeronderzoek, en ontmoeten elkaar daarna weer als collega's bij Gerlinde. Super tof dat jij mijn paranimf wilt zijn! Samen uit, samen thuis! Jaap, Willeke, Tamas en Wim, wat fijn dat ik op onbewaakte ogenblikken het lab op kon lopen (met of zonder studenten) voor advies, papieren zakken of instructies. En niet te vergeten: bedankt voor het tel, opschoon en weegwerk! Gerlinde Vink en André van Leeuwen, bedankt dat jullie mij en mijn studenten wegwijs hebt willen maken in de chemische protocollen en metingen. Mattias ik wil je ook graag hier noemen, want jouw bio-informatica ondersteuning was onmisbaar.

All experiments mentioned in this thesis were executed in the greenhouses and on the fields managed by Unifarm. André, Gerard, en John ik heb veel profijt gehad van jullie adviezen over belichting, beluchting beregening en praktische ervaring met potten, velden en machines. En niet te vergeten, bedankt voor jullie flexibiliteit wanneer zaden niet wilden kiemen of regen niet wilde vallen. Wat mooi dat de andijvie van het veldexperiment naar de voedselbank kon! Herman, Wim, Gerrit en Frans bedankt voor jullie gevraagd en ongevraagd advies en gezellig gesprekken. Om samen met jullie te mogen zaaien, planten en oogsten was een hele belevenis.

Without the help of lots of people I would probably still be watering plants, washing roots, sorting and measuring samples. Gerlinde, Henk, Wim, Sigrid, Sirgi, Janneke, Jara, Irene, Dominika, and all who spared an hour or morning to get their hands wet and eat my endive: THANK YOU!

In addition, I also want to thank my colleagues at Soil Quality for the discussions, reflections, laughs, insights, and funny stories we've shared. I am thankful to work in a group where the doors are always open if I have a question, and people are sharing their stories and experiences over coffee, cake-Wednesday-cake or SOQ-drinks. Rima, Laura, 
Guusje, Susan, Elise, Juan-Carlos, Meixiu, Carlos, Solomon, Diego, Mart, Walter, Pelin, Valentina, Tatiana, Karst, Angi, Joana, Mirjam, Hui, Qian, Jingmeng, Hannah, Anupol, Jeffrey, Yong, Xinxin, André, Giulia, Simon and my first roomies Bastiaan \& Kimo, middle roomies Carmen \& Peipei and current roommates Laura and Francesca, thank you for sharing your insights and feedback during office-chats, coffee, DisQ and PhDthesis rings, R-help whenever needed, laughs and frustrations over spontaneous drinks and food during lunch (not necessarily in that order or combination). Marnella, how do you keep track of all of us? Jij maakt regeldingen heel veel makkelijker! Colleagues from accross the street: Sigrid \& Roeland wat fijn om jullie af en toe gezien te hebben bij een team-Gerlinde activiteit, en met jullie ervaringen uit te wisselen. Sigrid, maken we nog eens een lunch wandeling? Joost als we elkaar tegenkomen is het altijd fijn met je praten, of het nu over theezakjes of over carrière gaat.

I also want to thank all the MSc and BSc thesis students that I (co-)supervised: Jingjue, Gregory, Gerard, Hashmat, Jos, Rianne, Isabella, Andreas, Chen, Paul. Your projects have contributed to the data presented in this thesis. I hope you have learned something during your time in our group, but I am sure I've learned from you!

Paula, Natalie, Lisette and Sigrid, thank you for sharing the organisation of the Plant-Soil Interaction discussion group with me. Always nice to have a good brainstorm over lunch, and see a plan come together. PPC-members, Claudius \& Lennart it was a valuable experience to be part of the PE\&RC PhD council. I got what I came for: getting a look insight WUR as an organisation, and bonus: learned a lot on PhD-programmes and challenges faced in practicing science. On top of that I got to meet some great people, from various departments: among others Mark, Masha, Amber, Paolo, Natalie, Claudio, Jasper and Chantal.

A friend of my parents once found a phrase saying: Janna's law, with a little music in your life you can deal with the whole world. In the past years, I have been enjoying singing and organising music, with great pleasure. Dankjewel Robert, AnnA, Nathan en andere NSK bestuurs- en commissie leden. Het was heel fijn om met jullie te mogen samenwerken. Dirigenten Kurt en Albert ik heb heel veel geleerd van jullie inzichten, zowel muzikaal als filosofisch. Mede-zangers van het NSK, Kamerkoor en Orpheus: genieten van muziek kan alleen met een fijne groep om je heen, dank jullie wel. Elysa, Jos, Joost, Sjoerd en Wouter, ik weet niet of ik jullie hier tussen zangers of samen met mijn andere vrienden moet noemen, jullie zijn allebei. Ik vind het heerlijk om muziek zo vriendschappelijk te kunnen delen. Canzone!

Jeltje \& Janneke, ik vind het heel bijzonder om met jullie een huis te delen, en daarna(ast) nog steeds vrienden te zijn. Jullie zijn misschien wel degene die het meeste van mijn frustraties en ergernissen hebben gezien. Ik vond en vind het erg fijn om samen in het zonnetje te eten, de dag te kunnen bespreken, lui op de bank te hangen. Jeltje, ik heb ervaren hoeveel energie het afronden van een proefschrift kost, en jij bereidde destijds ook je verhuizing naar Zweden voor! Petje af! Janneke, dank je wel voor al je geduld de laatste maanden en al je boodschappen die je deed, en maaltijden die je kookte zodat ik 
die achter m'n laptop kon opeten. Emily, wat heerlijk om met jou samen te schrijven. Wat kan jij ongelofelijk hard werken! Het is fijn om samen met jou Björn en Maja te wandelen en te praten over wat ons bezighoudt. Elysa, Jos, Joost, Sjoerd en Wouter, ik weet niet of ik jullie tussen zangers of hier samen met mijn andere vrienden moet noemen, jullie zijn allebei. Ik vind het heerlijk om muziek zo vriendschappelijk te kunnen delen. Canzone! Lieve Elysa, we ontmoetten elkaar tijdens een meeloopdag aan Wageningen University, biologie ging het worden. Voor mij wat eerder dan voor jou. En toen je eenmaal in Wageningen kwam wonen hebben we elkaar wekelijks gezien. Ik vind het heel waardevol dat we dat nog steeds doen. We hebben heel veel meegemaakt en gedeeld, en hoop dat we dat heel lang blijven doen. Ik vind het heel erg fijn dat je mijn paranimf wilt zijn!

Lieve Pap \& Mam, dit boekje draag ik aan jullie op. Zonder jullie was het er nooit gekomen. Jullie leerde me te ontdekken, doorzetten wanneer het moeilijk is en mijn hart te volgen.

Lieve Xander, Marije \& Marten: Wij gaan op berenjacht, we gaan een héle grote vangen! Wat een prachtige dag! Wij zijn niet bang!

Liefs Janna

Wageningen, juli 2018 


\section{About the Author}

Janna Marlinde Barel was born in Maastricht on the 1 September 1988. She grew up in Amersfoort and completed her secondary education in 2006 at 't Atrium. Her final school project (profielwerkstuk) on water pollution and purification was awarded in two national competitions organised by Aarde.nu and Vrije University Amsterdam. The rewards took her on two excursions to northern Scandinavia and were a crown to her secondary education and an ideal introduction to her studies. Her passion for nature and science brought her to Wageningen, where she studied biology. After her BSc, she continued to specialise in plant ecology and biotic interactions during her MSc biology. She

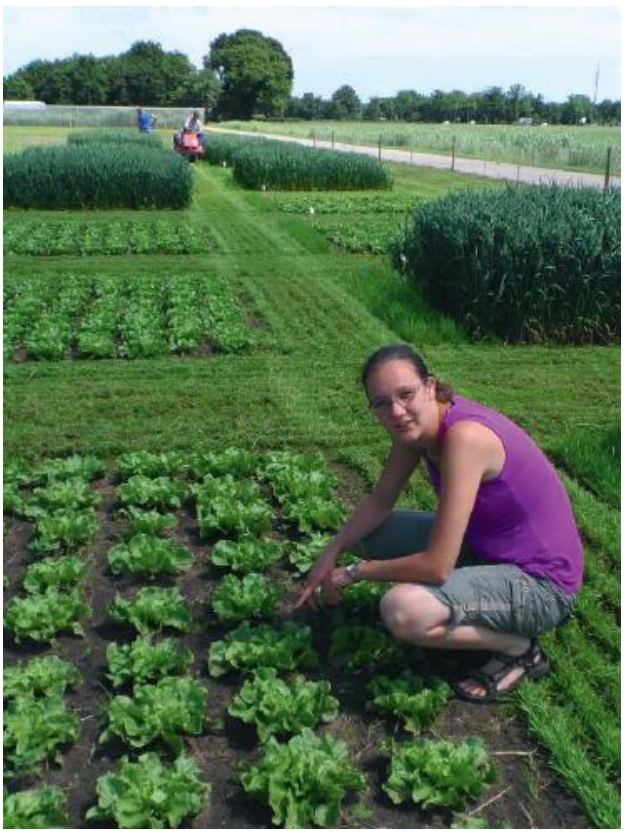
explored her academic (and cultural) interests during an Erasmus Exchange to the Swedish University of Agriculture Sciences (SLU) in Uppsala, Sweden (2010) and two MSc thesis projects: at NIOO-KNAW in Wageningen (2011) and Copenhagen University (2012) in Copenhagen, Denmark. By participating in the Research MSc program offered by PE\&RC graduate school, she further developed her research skills. During her studies and after her graduation in 2012, Janna instructed BSc students in cell biology and plant science as a student assistant, and taught high-school students about DNA in traveling practicals.

In 2013, Janna embarked on new research adventures in her PhD project with Gerlinde De Deyn, which offered the opportunity to pursue her fascination with plant-soil interactions. While opening the black-box of soil biology with her research, Janna tested her organisation skills by setting-up and coordinating a two-year field experiment, participating in the PE\&RC PhD council and co-organising discussion group Plant-Soil Interactions (PSI). She supervised several BSc and MSc thesis projects. She loves sharing her academic findings ideas at conferences and workshops, gave many poster and oral presentations and organised and convened a session during the Netherlands Annual Ecology Meeting. In October 2017, Janna got to present the importance of plant-soil interactions during the national evening of Science \& Society (Avond voor Wetenschap \& Maatschappij) in the Hall of Knights (Ridderzaal) in The Hague, as a junior scientist alongside her promotor. In addition, she reviewed literature on soil biology methods for Eurofins Agro. 
During her studies, Janna discovered her passion for choral singing. She committed herself to both the music and its organisation on local and national scale. Nowadays she participates in local choirs and is one of six friends singing in a cappella ensemble Canzone! (yes, the ! is part of the name and it is not the pizza). During her $\mathrm{PhD}$ she got infected with the gardening-virus, and now relives her childhood gardening dream in an allotment and home-garden after work as a post-doc for the Soil Biology and Biological Soil Quality Group.

\section{Publications}

Barel, J.M., Kuyper, T.W., de Boer, W., Douma, J.C. \& De Deyn, G.B. (2018) Legacy effects of diversity in space and time driven by winter cover crop biomass and nitrogen concentration. Journal of Applied Ecology, 55, 299-310.

Barel, J.M., Kuyper, T.W., Paul, J., De Boer, W., Cornelissen, J.H.C. \& De Deyn, G.B. (accepted) Winter cover crop legacy effects on litter decomposition act through litter quality and changes in microbial community. Journal of Applied Ecology.

Saar, S., Semchenko, M., Barel, J.M. \& De Deyn, G.B. (2016) Legume presence reduces the decomposition rate of non-legume roots. Soil Biology and Biochemistry, 94, 88-93.

Saar, S., Semchenko, M., Barel, J.M. \& De Deyn, G.B. (2018) Spatial heterogeneity in root litter and soil legacies differentially affect legume root traits. Plant and Soil, 428, 253264.

van der Meij, B., Kooistra, L., Suomalainen, J., Barel, J.M. \& De Deyn, G.B. (2017) Remote sensing of plant trait responses to field-based plant-soil feedback using UAV-based optical sensors. Biogeosciences, 14, 733-749.

\section{In preparation}

Barel, J.M., Kuyper, T.W., De Boer, W. \& De Deyn, G.B. (in preparation) Plant presence reduces root and shoot litter decomposition of crops and wild relatives: a traits perspective.

Barel, J.M., Martens, H., De Hollander, M., Kuyper, T.W., De Boer, W. \& De Deyn, G.B. (in preparation) Assessing the influence of soil origin and root traits on the rhizosphere microbiome of crops and their wild relatives.

García-González, I., Martínez-García, L.B., Barel, J.M., Martens, H., Snoek, L.B., Hontoria, C. \& De Deyn, G.B. (in preparation) Grasses as cover crop promote root fungi abundance and richness in subsequent crops.

Barel, J.M., Alvani, S., Korthals, G.W., De Goede, R. \& De Deyn, G.B. (in preparation) Impact of crop legacy and cover crop monocultures and mixtures on nematode communities. 


\section{Affiliation of co-authors}

Wietse de Boer

Johannes H. C. Cornelissen

Gerlinde B. De Deyn

Jacob C. Douma

Mattias de Hollander

Thomas W. Kuyper

Henk Martens

Jos Paul
Soil Biology and Biological Soil Quality,

Wageningen University \& Research

Microbial Ecology,

Netherlands Institute for Ecology (NIOO-KNAW)

Department of Ecological Science, Faculty of Science, Vrije Universiteit, Amsterdam

Soil Biology and Biological Soil Quality, Wageningen University \& Research

Centre for Crop Systems Analysis, Wageningen University \& Research

Laboratory of Entomology,

Wageningen University \& Research

Microbial Ecology,

Netherlands Institute of Ecology (NIOO-KNAW)

Soil Biology and Biological Soil Quality, Wageningen University \& Research

Soil Biology and Biological Soil Quality, Wageningen University \& Research

Soil Biology and Biological Soil Quality, Wageningen University \& Research 


\section{PE\&RC Training and}

\section{Education Statement}

With the training and education activities listed below the PhD candidate has complied with the requirements set by the C.T. de Wit Graduate School for Production Ecology and Resource Conservation (PE\&RC) which comprises of a minimum total of 32 ECTS (= 22 weeks of activities)

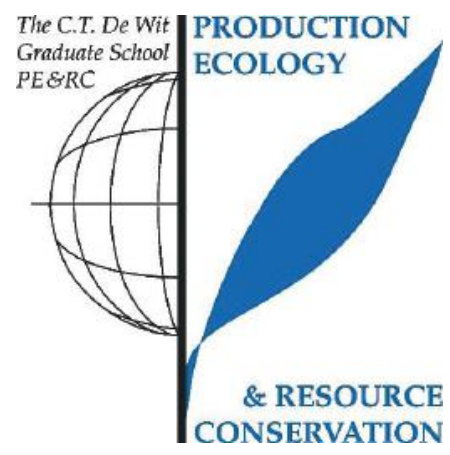

\section{Review of literature (4.5 ECTS)}

- Plant-soil feedback driven by plant traits - trade-offs of rhizosphere interactions

\section{Writing of project proposal (2.5 ECTS)}

- Exploiting positive plant-soil feedbacks through understanding root traits and trade-offs

\section{Post-graduate courses (8.6 ECTS)}

- New frontiers in microbial ecology: RSEE and PE\&RC (2013)

- The use of biological traits in ecology: IMAR, Coimbra (2013)

- Introduction to R: PE\&RC and Sense (2013)

- Multivariate analysis of ecological data using Canoco: PE\&RC (2014)

- Structural equation modelling: PE\&RC (2015)

- Soil ecology - planetary boundaries: PE\&RC (2016)

\section{Laboratory training and working visits (2 ECTS)}

- Plant traits: Lignin protocol, Vrije Universiteit, Amsterdam, NL (2013)

\section{Invited review of (unpublished) journal manuscript (2 ECTS)}

- Ecosystems: decomposition and drought (2015)

- New Phytologist: root associated fungal community (2017)

\section{Deficiency, refresh, brush-up courses (6 ECTS)}

- Ecological modelling and data-analysis in R; CSA-WUR (2015)

\section{Competence strengthening / skills courses (4.7 ECTS)}

- PhD Competence assessment: WGS (2013) 
- Jena writing workshop: Jena Consortium (2015)

- Brain training: WGS (2015)

- Entrepreneurship in- and outside science: WGS (2015)

- Last stretch of PhD programme: WGS (2016)

- PhD Career coaching: ESG $(2016,2017)$

PE\&RC Annual meetings, seminars and the PE\&RC weekend (2.4 ECTS)

- $\quad$ PE\&RC Weekend (2013, 2016)

- PE\&RC Day (participant 2014, organiser 2015)

Discussion groups / local seminars / other scientific meetings (6.8 ECTS)

- Discussions in soil quality $(2013,2017)$

- Ecological theory and application (2014-2016)

- Decomposition masterclass: NIOO-KNAW (2015)

- Plant-soil interactions (organiser and participant 2016-2017)

- Frontiers in ecology symposium \& masterclass (2017)

\section{International symposia, workshops and conferences (22.1 ECTS)}

- Intecol: London, UK (2013)

- Vegetation-soil interaction symposium: poster presentation, Wageningen, NL (2014)

- NERN - Netherlands Annual Ecology Meeting, Lunteren, NL (poster presentation 2014 \&2015, convener 2016, poster \& oral presentation 2018)

- Rhizosphere 4: poster presentation, Maastricht, NL (2015)

- GSBI Conference: poster presentation, Dijon, F (2015)

- Current themes in ecology: Lunteren, NL (2015)

- Plant-soil-microbe interactions for crop and pest management workshop: Wageningen, NL (2016)

- British ecological society annual meeting; oral presentation, Liverpool, UK (2016), and poster presentation, Ghent, B (2017)

- Wageningen soil conference: oral presentation, Wageningen, NL (2017)

- K(C)lever cover cropping workshop; oral presentation: Kleve, D (2017)

Lecturing / Supervision of practicals / tutorials (1.2 ECTS)

- $\quad$ Ecology I (2015)

\section{Supervision of 6 MSc students (16.8 ECTS)}

- Plant litter decomposition

- Plant-soil feedback

- Plant-functional traits 
The research described in this thesis was financially supported by NWO-ALW VIDI (grant nr 864.11.003) to Prof Dr G.B. De Deyn.

Financial support from Wageningen University for printing this thesis is gratefully acknowledged.

\section{Cover and bookmark}

designed by Marije Y. Barel I MyBesign

created by Marije Y. Barel and Janna M. Barel

\section{Printed by}

DigiForce I ProefschriftMaken on FSC certified paper 



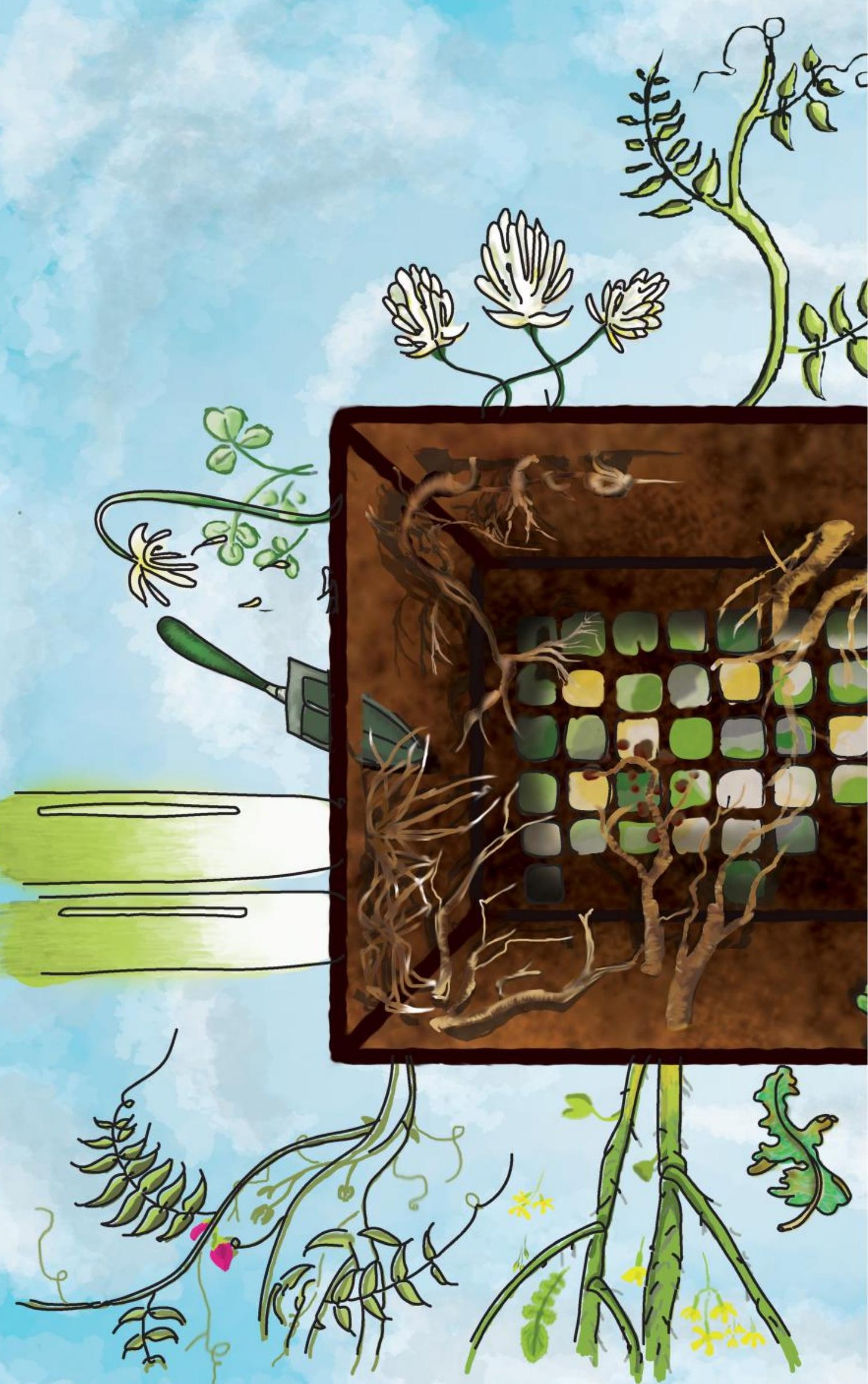




\section{Propositions}

1. A nitrogen-demanding lifestyle spoils the plant economic spectrum. (this thesis)

2. Agro-ecology and natural plant ecology differ in the scale at which results are generalised.

(this thesis)

3. Single-mindedness is an essential transferable skill.

4. Choral singing reduces society's medical expenses.

5. Gardening should be mandatory in school curricula.

6. Writing a good scientific article takes time, writing a bad scientific article takes too much time.

Propositions belonging to the thesis, entitled:

A plant's inheritance:

soil legacy effects of crops and wild relatives in relation to plant functional traits

Janna Marlinde Barel

Wageningen, 30 August 2018 